\title{
IntechOpen
}

\section{Recent Advances in Grain Crops Research}

Edited by Faroog Shah, Zafar Khan, Amjad Iqbal, Metin Turan and Murat Olgun 



\title{
Recent Advances in Grain Crops Research
}

\author{
Edited by Farooq Shah, Zafar Khan, \\ Amjad Iqbal, Metin Turan and Murat Olgun
}



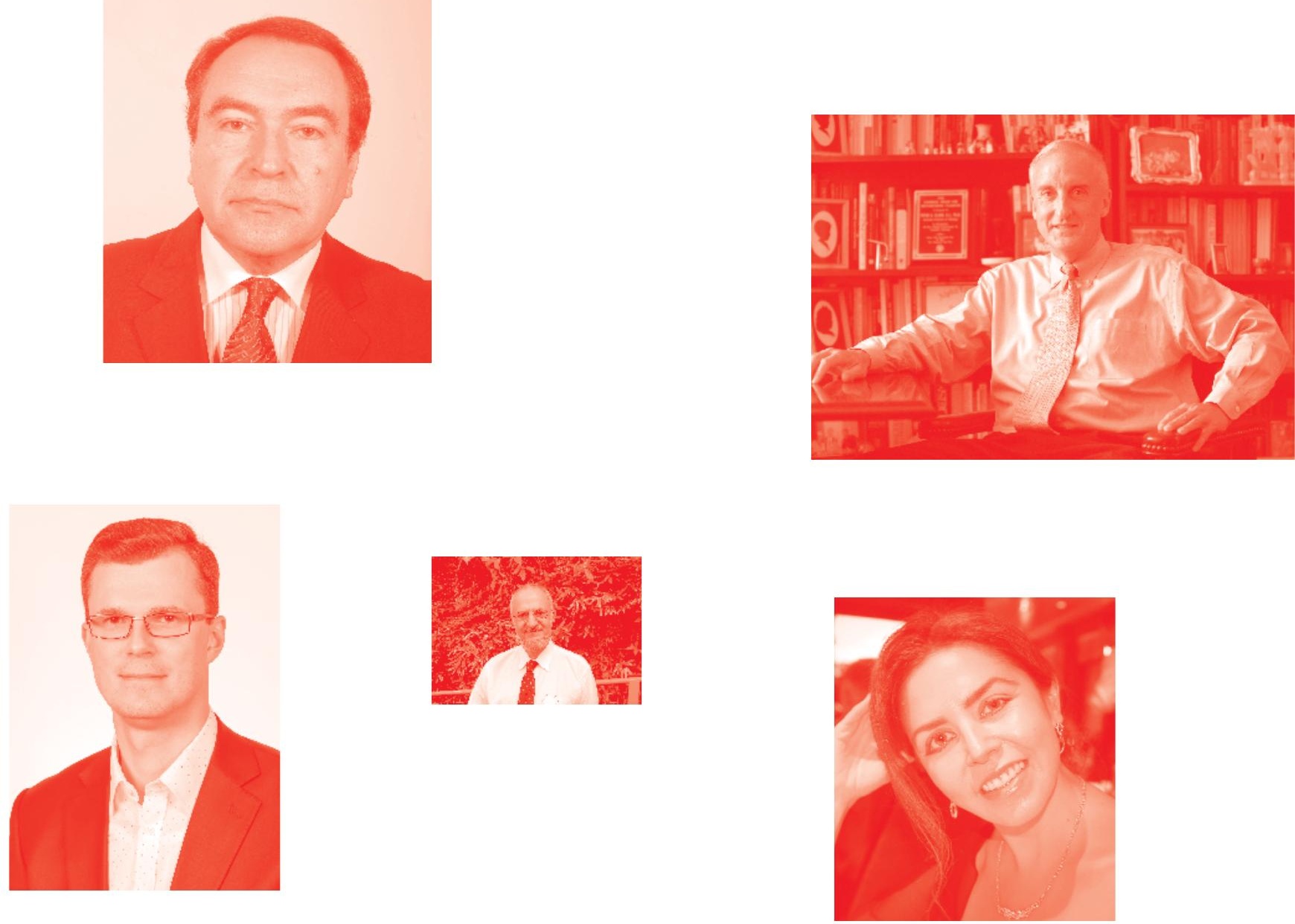

Supporting open minds since 2005
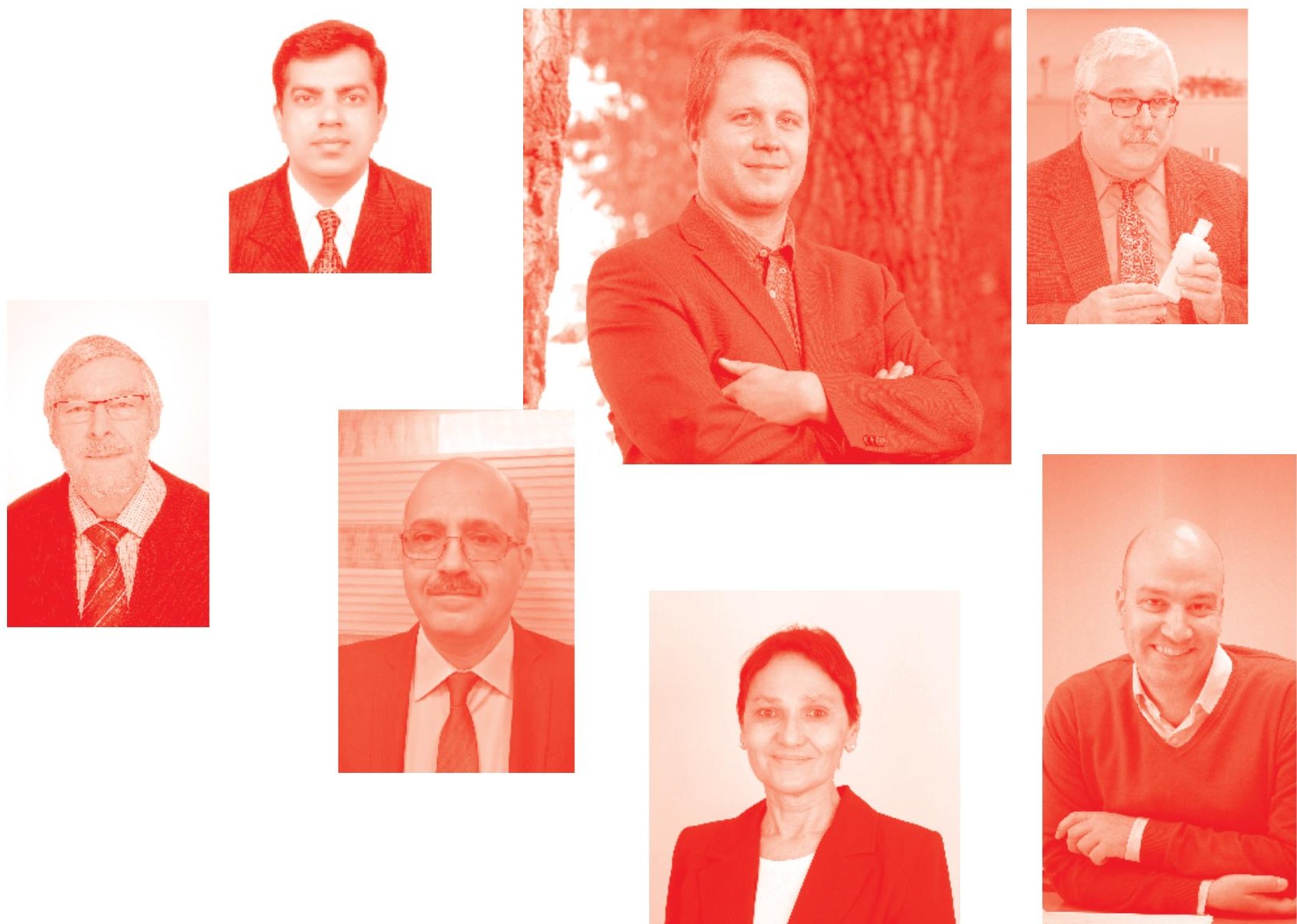
Recent Advances in Grain Crops Research

http : //dx . doi. org/10.5772/intechopen. 78117

Edited by Farooq Shah, Zafar Khan, Amjad Iqbal, Metin Turan and Murat Olgun

\section{Contributors}

Nina Terletskaya, Meruyert Kurmanbayeva, Ulzhan Erezhetova, Xue-Feng Ma, Frank Maulana, Joshua D. Anderson, Twain J. Butler, Sendhil Ramadas, T. M. Kiran Kumar, Gyanendra Pratap Singh, Usman Babar, Iqrar Ahmad Rana, Usama Arshad, Rana Muhammad Atif, Muhammad Tehseen Azhar, Abdulaziz Abdullah Alsahli, Ibrahim A. Alaraidh, Aysha Kiran, Gyuhwa Chung, Adil Hussain, Byung-Wook Yun, Qari Muhammad Imran, Omena Ojuederie, Jacob Popoola, Conrad Omonhinmin, Adegoke Adegbite, Neerja Sharma, Renu Khanna, Farooq Shah, Amjad Iqbal, Zafar Khan

( ) The Editor(s) and the Author(s) 2020

The rights of the editor(s) and the author(s) have been asserted in accordance with the Copyright, Designs and Patents Act 1988. All rights to the book as a whole are reserved by INTECHOPEN LIMITED. The book as a whole (compilation) cannot be reproduced, distributed or used for commercial or non-commercial purposes without INTECHOPEN LIMITED's written permission. Enquiries concerning the use of the book should be directed to INTECHOPEN LIMITED rights and permissions department (permissions@intechopen.com).

Violations are liable to prosecution under the governing Copyright Law .

\section{(cc) BY}

Individual chapters of this publication are distributed under the terms of the Creative Commons Attribution 3.๑ Unported License which permits commercial use, distribution and reproduction of the individual chapters, provided the original author(s) and source publication are appropriately acknowledged. If so indicated, certain images may not be included under the Creative Commons license. In such cases users will need to obtain permission from the license holder to reproduce the material. More details and guidelines concerning content reuse and adaptation can be found at http : //www . intechopen . com/copyright-policy . html .

\section{Notice}

Statements and opinions expressed in the chapters are these of the individual contributors and not necessarily those of the editors or publisher. No responsibility is accepted for the accuracy of information contained in the published chapters. The publisher assumes no responsibility for any damage or injury to persons or property arising out of the use of any materials, instructions, methods or ideas contained in the book.

First published in London, United Kingdom, 2020 by IntechOpen IntechOpen is the global imprint of INTECHOPEN LIMITED, registered in England and Wales, registration number: 11086078 , 7th floor, 10 Lower Thames Street, London,

EC3R 6AF, United Kingdom

Printed in Croatia

British Library Cataloguing-in-Publication Data

A catalogue record for this book is available from the British Library

Additional hard and PDF copies can be obtained from orders@intechopen.com

Recent Advances in Grain Crops Research

Edited by Farooq Shah, Zafar Khan, Amjad Iqbal, Metin Turan and Murat Olgun

p. cm.

Print ISBN 978-1-78985-449-7

Online ISBN 978-1-78985-450-3

eBook (PDF) ISBN 978-1-78985-643-9 


\section{We are IntechOpen, \\ the world's leading publisher of Open Access books}

\section{Built by scientists, for scientists}

\section{$4,600+$}

Open access books available

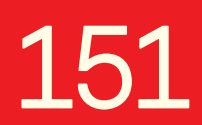

Countries delivered to

\section{$120,000+$}

International authors and editors

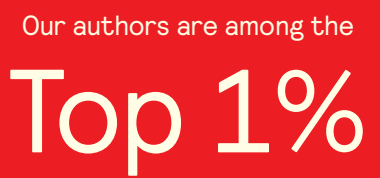

most cited scientists

Contributors from top 500 universities
$135 \mathrm{M}+$

Downloads
$12.2 \%$

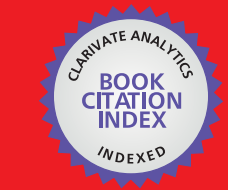

WEB OF SCIENCE ${ }^{\text {M }}$

Selection of our books indexed in the Book Citation Index in Web of Science ${ }^{\mathrm{TM}}$ Core Collection (BKCI)

\section{Interested in publishing with us? \\ Contact book.department@intechopen.com}

Numbers displayed above are based on latest data collected.

For more information visit www.intechopen.com 



\section{Meet the editors}

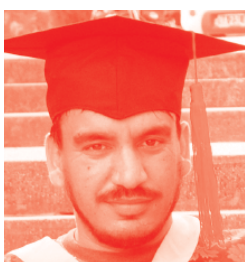

Dr. Farooq Shah is a Pakistani scientist who is working as an Associate Professor at the Department of Agronomy, Abdul Wali Khan University Mardan, Pakistan. His research interests mainly include crop responses to various abiotic stresses, particularly heat stress. He received his $\mathrm{PhD}$ degree from Huazhong Agricultural University, Wuhan, China, with specialization in Crop Cultivation and Farming Systems. He has more than 80 research articles to his credit, which are published in highly reputed journals. He is the editorial board member and reviewer of many peer-reviewed SCI journals. He has participated in several international training and faculty exchange programs in several countries. Dr. Shah is a member of the National Curriculum Revision Committee constituted by the Higher Education Commission of Pakistan for Agronomy and several other international professional societies. Presently, he is doing his post-doctorate studies at the Northwest Agriculture \& Forest University Yangling, Shaanxi, China.

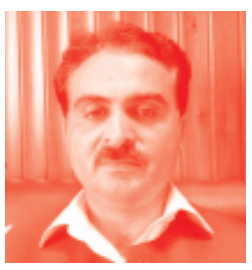

Dr. Zafar Hayat Khan is an agronomist and is currently working as Chairman of the Department of Agronomy, Abdul Wali Khan University Mardan, Pakistan. After completion of his $\mathrm{PhD}$ from the University of Agriculture Peshawar in 2011, he joined Abdul Wali Khan University Mardan as an Assistant Professor. He has been involved in teaching, research, and administrative activities in the university. He is a member of the National Curriculum Revision Committee on Agronomy in Pakistan. He co-edited a book titled "Rice Crop: Current Developments" in 2018. He has published many research articles on different crops in peer-reviewed and reputed journals. His prime focus is on research related to best agronomic practices and modern technologies in the wake of a changing climate and food security. He has been actively involved in organizing national and international seminars, workshops, and conferences.

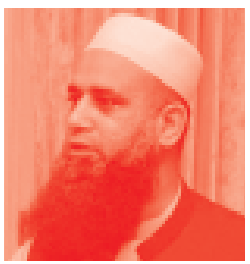

Dr. Amjad Iqbal is currently working as Associate Professor in the Department of Food Sciences, Abdul Wali Khan University Mardan, Pakistan. He received his $\mathrm{PhD}$ degree from The University of Edinburgh, United Kingdom in Biological Sciences. Dr. Iqbal has published 100 research articles in highly reputed journals such as Frontiers in Plant Science, Annals of Botany, Journal of Experimental Botany, Food Chemistry, PlosONE, and Food and Nutrition Research, etc. He has also reviewed many articles for SCI journals and is a member of the editorial boards of several journals. Dr. Iqbal has his PostDocs from UK and China and has served a year as a Talented Young Scientist in Chinese Academy of Tropical Agricultural Sciences, Wenchang, Hainan-P.R.China. 


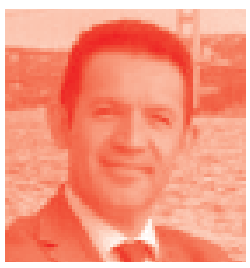

Dr. Metin Turan was born in Turkey in 1972. He obtained his $\mathrm{PhD}$ degree in 2002 from the Soil Science and Plant Nutrition Department, at Atatürk University, Turkey. He is currently working as a Professor in the Genetics and Bioengineering Department at the Yeditepe University, Turkey. He has published more than a hundred papers in reputed journals. Dr. Turan is a scientific member of many organizations and has chaired many conferences in Turkey and other European countries.

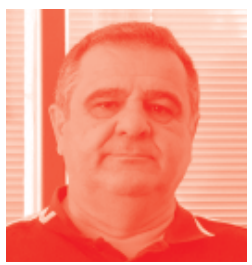

Dr. Murat Olgun was born in Turkey in 1961. He obtained his $\mathrm{PhD}$ degree in 2002 from the Field Crops Department, at Ataturk University, Turkey. He is currently working as a professor at Field Crops Department, Eskisehir Osmangazi University, Turkey. He has more than a hundred papers published in various journals. Dr. Olgun has held many international workshops and conferences in Turkey and other countries. 


\section{Contents}

Preface

Chapter 1

Introductory Chapter: Recent Advances in Grain Crops Research

by Adil Hussain, Amjad Iqbal, Zafar Hayat Khan and Farooq Shah

Chapter 2

CRISPR/Cas9-Mediated Gene Editing in Grain Crops

by Adil Hussain, Qari Muhammad Imran and Byung-Wook Yun

Chapter 3

Wheat in the Era of Genomics and Transgenics

by Usman Babar, Usama Arshad, Muhammad Tehseen Azhar,

Rana Muhammad Atif, Abdulaziz Abdullah Alsahli, Ibrahim A. Alaraidh, Aysha Kiran, Iqrar Ahmad Rana and Gyuhwa Chung

Chapter 4

Morphophysiological and Photosynthetic Reactions of Wheat

(T. aestivum L.) and Its Wild Congeners to Drought Condition In Vivo and In Vitro

by Nina Terletskaya, Meruert Kurmanbayeva and Ulzhan Erezhetova

Chapter 5

Improving Dual-Purpose Winter Wheat in the Southern Great Plains of the United States

by Frank Maulana, Joshua D. Anderson, Twain J. Butler and Xue-Feng Ma

Chapter 6

Wheat Production in India: Trends and Prospects

by Sendhil Ramadas, T.M. Kiran Kumar and Gyanendra Pratap Singh

Chapter 7

Rice Grain Quality: Current Developments and Future Prospects

by Neerja Sharma and Renu Khanna

Chapter 8

Neglected and Underutilized Legume Crops: Improvement and Future Prospects

by Jacob Popoola, Omena Ojuederie, Conrad Omonhinmin and Adegoke Adegbite 



\section{Preface}

Global food security is highly dependent on grain crops, which produce edible dry seeds that serve as a good source of protein, carbohydrates, and vitamins. Being the most critical component of a human diet, it is not astonishing that over $50 \%$ of world daily caloric intake is derived directly from grains. These crops are grown in greater quantities worldwide than any other crop and have undoubtedly played a key role in shaping human civilization.

Current crop production systems are under unprecedented pressure, not only due to the galloping world population but also because of changes in the climate. The frequent occurrence of extreme weather events such as drought and extreme temperatures are some of the key hindrances that threaten the sustainability of agricultural systems.

Recent developments in agriculture have only been possible due to the innovations and advancements in the field of biotechnology. Efforts are under way for development of molecular markers, mapping of genes, sequencing of marker genes, and their utilization through marker-assisted selection. Clustered, regularly interspaced short palindromic repeats (CRISPRs) and the CRISPR-associated 9 (Cas9) nucleases are some of the remarkable breakthroughs that are shaping the future's agriculture.

Ensuring proper water availability is pivotal for crop production. Scientists are focusing on developing drought resistant varieties of grain crops through conventional breeding methods as well as through the use of molecular biology and biotechnology.

Quality characteristics of grains are major determinants of market price, which includes milling, physical appearance, cooking, sensory, palatability, and nutritional value. A better understanding of the factors that regulate these quality characteristics will be useful for developing new breeding strategies.

Intensive production systems involving major grain crops all over the world have contributed to soil deterioration. One promissory approach is to emphasize soil sustainability through neglected and underutilized grain legumes (MNUGLs) to withstand the effects of abiotic stresses, climate change, and to boost nutritional security.

This book has been co-edited by editors from Pakistan and Turkey, and as a joint venture; we proudly dedicate this effort to the everlasting friendship between two brotherly nations: Pakistan and Turkey. 
Zafar Khan and Amjad Iqbal Abdul Wali Khan University, Pakistan

Metin Turan Yeditepe University, Turkey

Murat Olgun Eskişehir Osmangazi University, Turkey 


\title{
Introductory Chapter: Recent Advances in Grain Crops Research
}

\author{
Adil Hussain, Amjad Iqbal, Zafar Hayat Khan \\ and Farooq Shah
}

\section{Introduction}

Grain crops produce small, hard, dry seeds that may or may not have an attached hull used for human and/or animal consumption. Grain crops are mainly of two different types, i.e., cereals and legumes. Grain crops are energy sources containing carbohydrates, proteins, and fats. Besides being the energy providing macromolecules, grain crops also contain health-supporting compounds, including dietary fibers, antioxidants, vitamins, and minerals [1]. The relatively higher durability of grain crops due to their low moisture content upon maturity has made them wellsuited to industrial agriculture as compared to other fleshy fruits and vegetables that have very low shelf life due to higher moisture content. It is these attributes of easy storage, measurements, and transportation that may well be the reasons for selection and domestication of the grain crops by our earliest ancestors. It is now widely accepted that the development of grain agriculture is one of the most important factors in permanent settlements of human ancestors and their divisions into different social classes in history [2]. Earliest evidence of plant domestication comes from the middle east where rye grains with domesticated traits have been recovered [3], whereas the first evidence of cereal crop domestication comes from 9000 BCE. Later on, continued domestication and the resultant shift from a huntergatherer society to a settled agricultural society continued for thousands of years mainly consisting of grain crops. However, this domestication was primarily based on intermittent trial and error driven by a crude knowledge of selection and choice. Later, the selection and use of grain crops research were based on more scientific knowledge.

Among the grain crops, cereal grains occupied the central position concerning production, consumption, and health benefits. Cereal crops belong to the grass family, which is also known as Poaceae. The whole cereal grain consists of bran, endosperm, and the germ. Bran is the outermost layer having higher amounts of ๑-3 fatty acids, fibers, macro and micro minerals, and vitamins. The endosperm mainly contains starch, where the germ consists of water and fat soluble vitamins, magnesium, and phosphorous. It is believed that the consumption of cereal grains has been co-started with human civilization that became the major part of human diet with the passage of time. Among the cereal grains, wheat, maize, rice, millet, buckwheat, and sorghum are used as a staple food by the people from different localities of the developed and under-developed world. It is assumed that about half of the daily caloric requirement is fulfilled through the consumption of cereal grains. A diet rich in cereals can in fact provide us with starches, soluble and insoluble fibers, digestible carbohydrates, essential fatty acids, appreciable amounts of 
proteins, higher amounts of folate, iron, magnesium, copper, phosphorus, zinc, and phytochemicals. The phytochemicals with antioxidant properties can lower the blood cholesterol levels and thus help in controlling heart diseases. In short, the whole cereal grain consists of a whole range of primary and secondary metabolites that not only provides energy, but also health supporting substances [4]. The phytochemicals or secondary metabolites of whole cereal grains are also known to be associated with significant health benefits. The phytochemicals that are rich in cereal grains include phenolics, lignans, phytic acid, phytosterols, saponin, squalene, tocotrienols, phytosterol, and oryzanol. Some of these phytochemicals can act as antioxidants and lower the blood cholesterol level, thus preventing the cardiovascular diseases and reduces the risk of cancer. On the other hand, industrial revolution led to the milling of the cereal grains that intensively involve the removal of the bran and germ. Albeit milling has improved the sensory attributes of the finished product, but the milled products lack important health beneficiary components, such as dietary fibers, phenolics, minerals, and vitamins [4]. Carbohydrates are the main class of primary metabolites that attribute the health benefits of cereal grains. It is known for the years that insoluble polysaccharides/ fibers can relax constipation, whereas the soluble polysaccharides/mixed-link $\beta$-glucans can regulate the blood cholesterol level. The soluble and non-soluble polysaccharides that are present naturally in cereal grains have positive health implications in humans. These polysaccharides have the ability to hold water, give bulk to the stool, and can be broken down into short chain fatty acids. Such activities may help to resist the degenerative diseases, i.e., coronary heart diseases and cancer [5].

Another important group of grain crops include legumes that belong to the Leguminosae, which is also named as Fabaceae. Legumes are recognized as pulses after decortication or dehulling of seeds. Legumes are grown on a large area worldwide. The important grain legumes include chickpea, cowpea, lentil, green peas, etc. Pulses are cultivated in tropical and temperate regions around the globe, mainly in the South-East Asia. Food legumes are considered to be healthy plant-based food and are a good source of vitamins (B-complex), minerals (macro and microminerals), and dietary fiber [6]. Chickpea seed has high protein and carbohydrate with small amounts of fiber, oil, vitamins, and minerals. The digestibility of pulses proteins varies from $70-80 \%$. Pulses have a hypocholesteremic effect, and the seeds are eaten fresh as green vegetables or boiled with condiments. The flour of some pulses, such as chickpea is used in food preparation as a dressing for vegetables (e.g., bringle and potato) and meat (e.g., fish and chicken). The flour of chickpea is utilized for making bread with pepper and salt.

Pulses are good sources of protein that add to the nutritional importance of cereal-based diets. Pulse proteins are abundant in amino acid, arginine and lysine, but they have lower amounts of cysteine and methionine, which are known as sulfur containing amino acids. The other limiting essential amino acids include the cyclic amino acid tryptophan, valine, and threonine. From the nutritional standpoint, it is necessary to provide the body with an appropriate amount of essential amino acids. To meet the human dietary needs the four most important essential amino acids of protein should be present in the ratio of: four parts of lysine, three parts of methionine, two parts of threonine, and one part of tryptophan. If any one of these amino acids is so low as to affect the above ratio, it becomes the limiting factor in determining the nutritive value of the protein. The content of the proteins in pulses is almost double as compared to the cereals. Moreover, pulses taken with cereals in diet can fulfill the basic requirements for protein and thus enhance the nutritional importance of cereal-based diets [7]. 
Pulses are known to be good sources of macro and macro-minerals, mainly calcium $(\mathrm{Ca})$, magnesium $(\mathrm{Mg})$, potassium $(\mathrm{K})$, phosphorus $(\mathrm{P})$, zinc $(\mathrm{Zn})$, and iron $(\mathrm{Fe})$. These minerals are important for the body because of their role in physiological as well as biochemical processes of the cells and tissues. $\mathrm{Mg}$ is an integral part of metabolic enzymes, $\mathrm{K}$ helps in the regulation of energy and metabolism, $\mathrm{P}$ gives strength to the bone and is involved in the formation of high-energy compounds, i.e., AMP, ADP, and ATP. Likewise, $\mathrm{Zn}$ also acts as a cofactor of certain enzymes, and $\mathrm{Fe}$ is a part of hemoglobin and myoglobin. The ionized minerals can help in blood coagulation and keep the membrane permeability intact. Besides, sodium $(\mathrm{Na})$ and $\mathrm{K}$ are vital for the regulation of an acid-base balance and osmotic pressure of the cells. Legumes also contain antinutrients, i.e., phytate, which is rich in P. Phytic acid (Inositol hexaphosphoric acid) is abundant in legumes that can inhibit the absorption of $\mathrm{Zn}$ and other essential elements by the small intestine of humans and monogastric animals, thus making it unavailable to the body. Phytic acid forms complexes with the metal ions $\left(\mathrm{Cu}^{+2}, \mathrm{Ca}^{+2}, \mathrm{Zn}^{+2}\right.$, and $\left.\mathrm{Fe}^{+3}\right)$, thus excreting them out of the body. The excretion of such essential elements may lead to various deficiency diseases. Phytate may also limit the absorption of vitamins and proteins, which can decrease the nutritional value of the legumes [8].

Furthermore, several grain crops are also required as a source of animal feed. Recent interest in wheat research is supported by the directives following the meeting of the G20 ministries of agriculture, of the wheat initiative [9] to profess the coordination of international research on wheat to fulfill global wheat production demand. Global population is predicted to increase up to over 9 billion by 2050 [10], which means that the demand will increase by $60 \%$ as compared to that in 2010 . In order to meet this end, global wheat production must increase by $1.6 \%$ annually, compared to the current $1 \%$ global increase per year (2001-2010) - reviewed by Giraldo et al. [11]. Other initiatives such as the International Barley Hub [12] started to support the increasing demand of grain crops. In this chapter, we discuss the recent advances made in grain crops research, related to few important traits.

Seed shattering is a character that has probably played one of the most important roles in domestication of grain crops. Grain crop varieties or cultivars with less auto-shattering of the seeds, siliques, seed pods, and spikelets have been more desirable with regards to farming [13]. Evolutionary studies show that the loss of seeds shattering was a character independently acquired by monocots and dicots via "convergent phenotypic evolution" producing low dehiscent and/or indehiscent crop species. At tissue level, seed or seed pod shattering level is governed by histological modifications that involve the development of an abscission layer at the point where the seeds or spikelets/pods are attached with the plant [14-17]. Pourkheirandish et al. [18] demonstrated that a lower thickness of both primary and secondary cell walls of the abscission or separation layer results in higher seeds shattering in barley. Because of the importance that seed shattering carries in the adoption of grain crops for food and feed, it has been studied in detail in various grain crops at genetic level. A plethora of genes have been shown to regulate seed shattering in rice [19-22], barley [18], and legume crops such as soybean [23, 24], cow pea [25], common beans [26, 27], and medicago [28]. These genes encode various proteins such as the Shatterproof protein, NAC, Myc, and bHLH transcription factors, ALCATRAZ and the BEL-1-type homeobox SH5. Careful selection of crop varieties and cultivars by the farmers and scientific research have settled the seed shattering issue and most of the grain crop cultivars grown these days are indehiscent.

Other important aspects of research on grain crops include factors responsible for quantity and quality of the produce. Such factors have been studied by scientists throughout the world and in almost all grain crops. Most of these studies describe 
both negative or positive effects of different interventions and treatments. Research targeted toward the understanding of genetic basis of crop improvement is often conducted under restricted or unfavorable environmental conditions. Such projects include research on uptake and use efficiency of various macro and micro nutrients $[29,30]$. Chen et al. [31] identified at least 10 genes related to nitrogen metabolism in different cultivars of barley. Most interestingly, these included the 2nd isoform of nitrate reductase enzyme (HvNIA2), which is responsible for catalyzing the 1st reaction in nitrate assimilation, i.e., the conversion of nitrate to nitrite and is also involved in the production of nitric oxide (NO) in plants [32]. Other genes induced under low nitrogen stress included those encoding enzymes such as the chloroplastic glutamine synthetase (HvGS2), ferredoxin dependent glutamate synthase (HvGLU2), and asparagine synthetase (HvASN1). Interestingly, the expression of these genes was found to be strictly regulated by nitrogen stress and in a tissue specific manner [31].

The elucidation of the genetic role played by the members of the plant nitrate transporters (NRT) or peptide transporters (PTR) is also of particular importance in the transportation of various nutrients from the soil to plants and ultimately crop production. Lin et al. [33] in the year 2000 cloned and functionally characterized NRT1 from rice. The NRT is constitutively expressed in the epidermis and root hairs of the roots. The importance of this gene in nitrate transport can be determined by the fact that even slight variations in the sequence of this gene results in nitrate-use divergence in different rice subspecies [34]. This is associated with the higher nitrate-absorption activity of Indica rice as compared to Japonica rice. As the Japonica rice plants expressing the Indica NRT1.1B allele showed significantly higher grain yield and nitrogen-use efficiency compared to Japonica plants that did not express the Indica allele [34]. The role of plant NRT and their functional applications has been reviewed by Fan et al. [35]. Plant NRT/PTR gene family has been renamed as NPF family [36] and contains a large number of genes that can be subdivided into at about 10 sub-families. The family has 93 known genes in rice [37]. NPF members not only transport nitrate but a wide range of other substrates including peptides [38], phytohormones such as auxin [39], abscisic acid [40], Jasmonates [41], and Gibberellins [42] further indicating the importance of these genes in plant physiology and crop production. Several members of the family have remained a focus of different scientific studies, especially in rice, describing significant increase in the overall yield, early maturity and the composition of soil microbiota [43-45] and should be a topic of future research in grain crops.

After decades of research in different living organisms, it has now become clear that practical utilization of recent advances in modern biotechnology is inevitable. Plant science has probably benefited the most from biotechnological advancements in terms of modifications at genome and proteome levels. With the advent of different gene editing techniques such as the CRISPR/Cas technology, any type of genetic modification has become easy and quick. A simple search on the web of science using "CRISPR rice" as keywords turns up 96 different research papers published from 2013 to 2020. Similarly, a search for "CRISPR wheat" shows up 25 research papers between 2017 and 2019, whereas searching for "CRISPR maize" shows up 17 research papers. This indicates the rapid adoption of newly developed techniques by plant scientists for genetic modifications in these plants. The use CRISPR/ Cas technology for genetic modifications in grain crops has been described in the chapter by Hussain et al. [46] available as online first (https://www.intechopen.com/ online-first/crispr-cas9-mediated-gene-editing-in-grain-crops). In this scenario, the availability of genome sequences and other genetic resources of grain crops such as rice (Rice Genome Annotation Project http://rice.plantbiology.msu.edu/), wheat (International Wheat Genome Sequencing Consortium https://www.wheatgenome. 
org/), maize (Maize Genetics and Genomics Database https://www.maizegdb. org/), soybean (Integrating Genetics and Genomics to Advance Soybean Research: SoyBase https://www.soybase.org/), and other legumes (Legume Information system https://www.legumeinfo.org/) has further facilitated scientific research on grain crops at the cell or genome level. Further scientometric, informetric, and bibliometric studies are required to establish a detailed account for the impact of recent advances in grain crops research.

\section{Author details}

Adil Hussain, Amjad Iqbal, Zafar Hayat Khan and Farooq Shah* Department of Agriculture, Abdul Wali Khan University Mardan, Khyber Pakhtunkhwa, Pakistan

*Address all correspondence to: farooqshah@awkum.edu.pk

\section{IntechOpen}

(C) 2020 The Author(s). Licensee IntechOpen. This chapter is distributed under the terms of the Creative Commons Attribution License (http://creativecommons.org/licenses/ by/3.0), which permits unrestricted use, distribution, and reproduction in any medium, provided the original work is properly cited. (cc) BY 


\section{References}

[1] Belobrajdic DP, AR B. The potential role of phytochemicals in wholegrain cereals for the prevention of type-2 diabetes. Nutrition Journal. 2013;12(1):62

[2] Wessel TJA, Values H. The agricultural foundations of civilization. Agriculture Human Values. 1984;1(2):9-12

[3] Hillman G, Hedges R, Moore A, Colledge S, Pettitt P. New evidence of Lateglacial cereal cultivation at Abu Hureyra on the Euphrates. The Holocene. 2001;11(4):383-393

[4] Sarwar MH, Sarwar MF, Sarwar M, Qadri NA, Moghal S. The importance of cereals (Poaceae: Gramineae) nutrition in human health: A review. Journal of Cereals. 2013;4(3):32-35

[5] Kumar V, Sinha AK, Makkar HP, De Boeck G, Becker K. Dietary roles of non-starch polysaccharides in human nutrition: A review. Critical Reviews in Food Science. 2012;52(10):899-935

[6] Jukanti AK, Gaur PM, Gowda C, Chibbar RN. Nutritional quality and health benefits of chickpea (Cicer arietinum L.): A review. British Journal of Nutrition. 2012;108(S1):S11-S26

[7] Iqbal A, Khalil IA, Ateeq N, MS K. Nutritional quality of important food legumes. Food Chemistry. 2006;97(2):331-335

[8] Nkhata SG, Ayua E, Kamau EH, Shingiro JB. Fermentation and germination improve nutritional value of cereals and legumes through activation of endogenous enzymes. Food Science. 2018;6(8):2446-2458

[9] Wheat, Initiative. Available from: https://wwwwheatinitiativeorg/ [Accessed: November 2019]
[10] United Nations Department of Economics and Social Affairs. Population Division. Available from: https://www.un.org/en/development/ desa/population/index.asp [Accessed: November 2019]

[11] Giraldo P, Benavente E, Manzano-Agugliaro F, Gimenez EJA. Worldwide research trends on wheat and barley: A bibliometric comparative analysis. Agronomy. 2019;9(7):352

[12] International Barley Hub. Available from: http://www.barleyhub.org/ [Accessed: November 2019]

[13] Di Vittori V, Gioia T, Rodriguez M, Bellucci E, Bitocchi E, Nanni L, et al. Convergent evolution of the seed shattering trait. Genes (Basel). 2019;10(1):1-16

[14] Liljegren SJ, Ditta GS, Eshed Y, Savidge B, Bowman JL, Yanofsky MF. SHATTERPROOF MADS-box genes control seed dispersal in Arabidopsis. Nature. 2000;404(6779):766-770

[15] Rajani S, Sundaresan V. The Arabidopsis myc/bHLH gene ALCATRAZ enables cell separation in fruit dehiscence. Current Biology. 2001;11(24):1914-1922

[16] Mitsuda N, Ohme-Takagi M. NAC transcription factors NST1 and NST3 regulate pod shattering in a partially redundant manner by promoting secondary wall formation after the establishment of tissue identity. The Plant Journal. 2008;56(5):768-778

[17] Mitsuda N, Iwase A, Yamamoto H, Yoshida M, Seki M, Shinozaki K, et al. NAC transcription factors, NST1 and NST3, are key regulators of the formation of secondary walls in woody tissues of Arabidopsis. Plant Cell. 2007;19(1):270-280 
[18] Pourkheirandish M, Hensel G, Kilian B, Senthil N, Chen G, Sameri M, et al. Evolution of the grain dispersal system in barley. Cell. 2015;162(3): 527-539

[19] Konishi S, Izawa T, Lin SY, Ebana K, Fukuta Y, Sasaki T, et al. An SNP caused loss of seed shattering during rice domestication. Science. 2006;312(5778):1392-1396

[20] Li C, Zhou A, Sang T. Rice domestication by reducing shattering. Science. 2006;311(5769):1936-1939

[21] Zhou Y, Lu D, Li C, Luo J, Zhu BF, $\mathrm{Zhu}$ J, et al. Genetic control of seed shattering in rice by the APETALA2 transcription factor shattering abortion. Plant Cell. 2012;24(3):1034-1048

[22] Yoon J, Cho LH, Kim SL, Choi H, Koh HJ, An G. The BEL1-type homeobox gene SH5 induces seed shattering by enhancing abscissionzone development and inhibiting lignin biosynthesis. The Plant Journal. 2014 Sep;79(5):717-728

[23] Funatsuki H, Suzuki M, Hirose A, Inaba $\mathrm{H}$, Yamada T, Hajika M, et al. Molecular basis of a shattering resistance boosting global dissemination of soybean. Proceedings of the National Academy of Sciences of the United States of America. 2014;111(50):17797-17802

[24] Dong Y, Yang X, Liu J, Wang B-H, Liu B-L, Wang Y-Z. Pod shattering resistance associated with domestication is mediated by a NAC gene in soybean. Nature Communications. 2014;5(1):3352

[25] Suanum W, Somta P, Kongjaimun A, Yimram T, Kaga A, Tomooka N, et al. Co-localization of QTLs for pod fiber content and pod shattering in F2 and backcross populations between yardlong bean and wild cowpea. Molecular Breeding. 2016;36(6):80
[26] Koinange EMK, Singh SP, Gepts P. Genetic control of the domestication syndrome in common bean. Crop Science. 1996;36:1037-1045

[27] Rau D, Murgia ML, Rodriguez M, Bitocchi E, Bellucci E, Fois D, et al. Genomic dissection of pod shattering in common bean: Mutations at non-orthologous loci at the basis of convergent phenotypic evolution under domestication of leguminous species. The Plant Journal. 2019;97(4):693-714

[28] Fourquin C, del Cerro C, Victoria FC, Vialette-Guiraud A, de Oliveira AC, Ferrándiz C. A change in SHATTERPROOF protein lies at the origin of a fruit morphological novelty and a new strategy for seed dispersal in Medicago genus. Plant Physiology. 2013;162(2):907-917

[29] Cormier F, Foulkes J, Hirel B, Gouache D, Moënne-LoccozY, Le Gouis J. Breeding for increased nitrogen-use efficiency: A review for wheat (T. aestivum L.). Plant Breeding. 2016;135(3):255-278

[30] Hu B, Wang W, Ou S, Tang J, Li H, Che R, et al. Variation in NRT1.1B contributes to nitrate-use divergence between rice subspecies. Nature Genetics. 2015 Jul;47(7):834-838

[31] Chen Z, Liu C, Wang Y, He T, $\mathrm{Gao} \mathrm{R}, \mathrm{Xu} \mathrm{H}$, et al. Expression analysis of nitrogen metabolism-related genes reveals differences in adaptation to lownitrogen stress between two different barley cultivars at seedling stage. International Journal of Genomics. 2018;2018:1-10

[32] Astier J, Gross I, Durner J. Nitric oxide production in plants: An update. Journal of Experimental Botany. 2018;69(14):3401-3411

[33] Lin CM, Koh S, Stacey G, Yu SM, Lin TY, Tsay YF. Cloning and functional characterization of a constitutively 
expressed nitrate transporter gene, OsNRT1, from rice. Plant Physiology. 2000;122(2):379-388

[34] Hu B, Wei W, Ou S, Tang J, Hua I, Che R, et al. Nature Genetics. 2015;47:834-838

[35] Fan X, Naz M, Fan X, Xuan W, Miller AJ, Xu G. Plant nitrate transporters: From gene function to application. Journal of Experimental Botany. 2017;68(10):2463-2475

[36] Leran S, Varala K, Boyer JC, Chiurazzi M, Crawford N, DanielVedele F, et al. A unified nomenclature of NITRATE TRANSPORTER 1/ PEPTIDE TRANSPORTER family members in plants. Trends in Plant Science. 2014;19(1):5-9

[37] von Wittgenstein NJ, Le CH, Hawkins BJ, Ehlting J. Evolutionary classification of ammonium, nitrate, and peptide transporters in land plants. BMC Evolutionary Biology. 2014;14:11

[38] Komarova NY, Thor K, Gubler A, Meier S, Dietrich D, Weichert A, et al. AtPTR1 and AtPTR5 transport dipeptides in planta. Plant Physiology. 2008;148(2):856-869

[39] Krouk G, Lacombe B, Bielach A, Perrine-Walker F, Malinska K, Mounier E, et al. Nitrate-regulated auxin transport by NRT1.1 defines a mechanism for nutrient sensing in plants. Developmental Cell. 2010;18(6):927-937

[40] Kanno Y, Hanada A, Chiba Y, Ichikawa T, Nakazawa M, Matsui M, et al. Identification of an abscisic acid transporter by functional screening using the receptor complex as a sensor. Proceedings of the National Academy of Sciences of the United States of America. 2012;109(24):9653-9658

[41] Chiba Y, Shimizu T, Miyakawa S, Kanno Y, Koshiba T, Kamiya Y, et al.
Identification of Arabidopsis thaliana NRT1/PTR FAMILY (NPF) proteins capable of transporting plant hormones. Journal of Plant Research. 2015;128(4):679-686

[42] David LC, Berquin P, KannoY, Seo M, Daniel-Vedele F, Ferrario-Mery S. N availability modulates the role of NPF3.1, a gibberellin transporter, in GA-mediated phenotypes in Arabidopsis. Planta. 2016 Dec;244(6):1315-1328

[43] Zhao M, Geng X, Bi W, Xu Q, Sun J, Huang Y, et al. Recombination between DEP1 and NRT1.1B under japonica and indica genetic backgrounds to improve grain yield in rice. Euphytica. 2017;213(12):265

[44] Wang W, Hu B, Yuan D, Liu Y, Che R, Hu Y, et al. Expression of the nitrate transporter gene OsNRT1.1A/ OsNPF6.3 confers high yield and early maturation in Rice. The Plant Cell. 2018;30(3):638-651

[45] Zhang J, Liu YX, Zhang N, Hu B, Jin T, Xu H, et al. NRT1.1B is associated with root microbiota composition and nitrogen use in field-grown rice. Nature Biotechnology. 2019;37(6):676-684

[46] Hussain A, Imran QM, Yun B-W. CRISPR/Cas9-Mediated Gene Editing in Grain Crops. Recent Advances in Grain Crops Research: IntechOpen; 2019 


\title{
CRISPR/Cas9-Mediated Gene Editing in Grain Crops
}

\author{
Adil Hussain, Qari Muhammad Imran and Byung-Wook Yun
}

\begin{abstract}
The development of reliable and efficient techniques for making precise targeted changes in the genome of living organisms has been a long-standing objective of researchers throughout the world. In plants, different methods, each with several different variations, have been developed for this purpose, though many of them are hampered either by providing only temporary modification of gene function or unpredictable off-target results. The recent discovery of clustered regularly interspaced short palindromic repeats (CRISPRs) and the CRISPR-associated 9 (Cas9) nucleases started a new era in genome editing. Basically, the CRISPR/Cas system is a natural immune response of prokaryotes to resist foreign genetic elements entering via plasmids and phages. Through this naturally occurring gene editing system, bacteria create DNA segments known as CRISPR arrays that allow them to "remember" foreign genetic material for protection against it and other similar sequences in the future. This system has now been adopted by researchers in laboratory to create a short guide RNA that binds to specific target sequences of DNA in eukaryotic genome, and the Cas9 enzyme cuts the DNA at the targeted location. Once cut, the cell's endogenous DNA repair machinery is used to add, delete, or replace pieces of genetic material. Though CRISPR/Cas9 technology has been recently developed, it has started to be regularly used for gene editing in plants as well as animals to good success. It has been proved as an efficient transgene-free technique. A simple search on PubMed (NCBI) shows that among all plants, 80 different studies published since 2013 involved CRISPR/Cas9-mediated genome editing in rice. Of these, 20,13 , and 24 papers have been published in 2019, 2018, and 2017, respectively. Furthermore, 20 different studies published since 2014 utilized CRISPR/Cas 9 system for gene editing in wheat, where five of these studies were published in 2019 and seven were published in 2018. Genomes of other grain crops edited through this technique include maize, sorghum, barley, etc. This indicates the high utility of this technique for gene editing in grain crops. Here we emphasize on CRISPR/Cas9mediated gene editing in rice, wheat, and maize.
\end{abstract}

Keywords: gene editing, cereal crops, CRISPR/Cas9, rice, wheat, maize

\section{Introduction}

Perhaps one of the most important differences that can define humans apart from others in the animal kingdom is the ability to make choices among good, better, and best. The ability to reason, argue, research, and adopt what is (or at least what he thinks is) best for him. Plants, being the primary producers on this planet, have always been the most important resource of life for the human omnivores. We 
have always chosen, selected, and adopted plant species that produced either more or good; and hence, driving plant domestication to this day. Initially, this domestication was only based upon observations, personal, physical likes and dislikes. Later, it was based on more complex characteristics that tempted the crossing of different plants with desirable characters to make a new variety or cultivar carrying multiple desirable characters. Such classical or conventional breeding methods included selection and hybridization. Afterward, using DNA-level information, scientists used these methods to tag a large number of quantitative trait loci (QTLs) via marker-assisted breeding or selection for combining different traits in a single variety.

With further developments in genetic engineering, genome modification studies were performed in plants [1]. This was specifically aided by the discovery of nuclease enzyme, the utilization of different bacterial plasmids for cloning of target genes in bacteria as well as target plants and by the development of plasmid vectors carrying antibiotic resistance genes, a variety of constitutive, inducible as well as tissue-specific promoters, and different reporter genes that made the cloning and transformation easier. The discovery of the Zinc finger nucleases (ZFNs), transcription activator-like effector nucleases (TALENs), and more recently that of the clustered regularly interspaced short palindromic repeats (CRISPRs) in genomes has further aided the genome editing techniques in different plant species.

\subsection{Genome editing in nature}

Genome editing involves molecular tools that lead to targeted modification of specific DNA sequences inside the genome. These are usually based on the production of double strand brakes (DSBs) at the specific DNA sites that trigger DNA repair of the cell. In plant cells, this generally happens through the process of nonhomologous end-joining commonly abbreviated as NHEJ. However, this process is error-prone, thus exploited by scientists to target genes for possible modification. Sometimes, plants repair the DSBs through homologous recombination which is error-free. Hence, it could be used by scientists to precisely edit DNA or insert DNA sequences in a given genome.

Genetic modification or genome editing is already in practice in cells of living organisms and is one of the most magnificent specters of nature. Natural DNA repair mechanisms, losing and acquiring of genetic material in bacteria, transmission of bacteriophages through bacterial transduction, and genetic modification of plant genome by Ti plasmid during infection by Agrobacterium tumefaciens are some of the examples of genetic modifications from nature. DSBs have also been shown to be induced naturally by different factors such as various reactive oxygen species (ROS), radiation, and others. Intricate and complex interconnected cellular networks drive post-transcriptional RNA modifications and post-translational protein modifications to accommodate a literally unlimited number of functions from a limited set of genes.

In the last few decades by unraveling the details of mechanisms underlying natural genome editing, scientists have shown that such editing can also be induced by synthetic nucleases and more recently by the CRIPR system adopted from bacterial defense system which is one of the most promising gene editing technologies introduced in 2012.

\subsection{The CRISPR/Cas system}

Among the different types of defense systems found in prokaryotes and eukaryotes, a unique molecular system known as the CRISPR/Cas not only provides 
protection against genetic attack, but also keeps a record or genetic memory of such attacks for future safety. This technique has been employed in several different studies by scientists from around the world for targeted genetic modifications in a plethora of living organisms, but perhaps most ambitiously by the Chinese scientists who not only used the technique for gene editing an armada of plant and animal species but also humans (https://www.nature.com/articles/d41586-01900673-1), which raises certain ethical concerns about the practical application and subsequent implications of such studies.

A key factor for sustainable agriculture is improvement of crops via genetic engineering. It is true that DNA-free editing techniques are now desirable for molecular breeding in crops for which CRISPR/Cas may offer a better option for more complex and controlled genetic rearrangements. CRISPR arrays are characterized by a series of 20- to 50-bp genomic loci, which are unique spacers separated by direct repeats that usually have similar length to preceding AT-rich fragments [2]. CRISPR loci were discovered about two decades ago in Escherichia coli following viral infection as part of the immune system through which the bacteria keep a genetic memory of the viral genome fragments in order to defend against future infections if any other foreign DNA sequences match the unique spacer sequences in the memory (also known as protospacers) [2,3]. Briefly speaking about the chief attributes of the mechanism of action, CRISPR-based defense system can be divided into three distinct events: adaptation, biogenesis of CRISPR-RNAs, and interference. Upon the introduction of a foreign DNA, the machinery selects protospacers that are inserted into the CRISPR locus following which CRISPR-RNAs (CrRNAs) are synthesized through a series of events, each with a corresponding spacer. Then, the Cas proteins interact with CrRNAs to initiate interference and consequent degradation of the foreign DNA by endonucleases [4]. It is now clear that CRISPR/Cas9 action is based on the participation of Cas9 protein and single guide RNA (sgRNA) [5].

Though CRISPR/Cas9 technology is relatively recent, it has started to be regularly used for gene editing in plants as well as animals to good success. It has been proved to be an efficient transgene-free technique. A simple search on PubMed (NCBI) shows that among all plants, 80 different studies published since 2013 involved CRISPR/Cas9-mediated genome editing in rice. Of these, 20, 13, and 24 papers have been published in 2019, 2018, and 2017, respectively. Furthermore, 20 different studies published since 2014 utilized CRISPR/Cas9 system for gene editing in wheat, where five of these studies were published in 2019 and seven were published in 2018. Genomes of other grain crops edited through this technique include maize, sorghum, barley etc. This indicates the high utility of this technique for gene editing in grain crops. Evidence that CRISPR/Cas9 system can be used for gene editing came around $2013[6,7]$ and the next paper showing the use of this technique for gene editing in rice and wheat was published in 2014 [8]. Furthermore, other studies published from 2013 to 2015 showed the use of this technique for gene editing in an array of organisms such as yeast, zebrafish, fruit flies, mosquitoes, nematodes, mice, monkeys, and human embryos, and several plant species, indicating sufficiently fast and easy application of this technique in this crop.

\subsection{CRISPR/Cas9 for crop improvement in rice, wheat, and maize}

The importance of agriculture for human survival cannot be questioned. As mentioned earlier, plants are the only primary producers on planet earth providing food, fiber, and other raw material generating the bulk of energy required for the growth of human population. However, plants/crops are facing several challenges and now their own survival may well be at stake. In this context, classical breeding 
methods may not be suitable for increasing per unit area production relatively quickly. Hence, the rational use of biotechnological tools is of paramount importance. Editing crop genomes is a promising technique to cope with agricultural challenges. Development of these methodologies is useful for genetic improvement of crops [9]. In 2013, the pioneering works published by Lit et al. using Arabidopsis [10], Nekrasov et al. using tobacco [11], and Shan et al. using rice and wheat [12] demonstrated the suitability of the CRISPR/Cas9 system for crop genetic improvement. Since then, a plethora of research on crop genome editing via CRISPR/ Cas9 has been published. Crops targeted for genetic editing via this system include soybean [13-15], tomato [16-19], potato [20], cucumber [21], maize [22, 23], the oil-seed plant camellia sativa [24], grapes and apple [25], Brassica oleracea and barley [26], watermelon [27], sweet orange [28], Populus tomentosa [29], and others to various ends.

The maize ARGOS8 variants generated via CRISPR/Cas9 showed significantly improved yield under drought stress conditions [30].

Rice, given its worldwide relevance for food, has been one of the most studied crops in terms of CRISPR/Cas9 application [31-36]. These include genetic modification for increased disease resistance [37], and herbicide resistance [38]. At present, more than 80 different research papers have been published using CRISPRbased genetic editing in rice and more than 15 papers involving wheat. These studies involve applicative use of CRISPR in rice. Li et al. [39] developed photo- and thermo-sensitive male sterile rice lines using this technique to exploit heterosis and speed up breeding [40]. Rice cultivars carrying high genetic resistance to the rice blast disease have been recently developed by Wang et al. [37]. Li et al. [41] at the South China Normal University, China, targeted four yield-related genes Gn1a, DEP1, GS3, and IPA1 in the rice genome for modification via CRISPR/Cas9 for the improvement of different agronomic traits such as grain number and size, panicle structure indicating the application of this technique for improvement of agronomic traits in rice. Furthermore, the much required herbicide resistance in rice has also been genetically enhanced through CRISPR/Cas9-mediated gene editing [38]. More interestingly, the use of Cpf1 which is an endonuclease (alternative to Cas9) has been successfully used for targeted gene editing in rice and as a transcriptional regulator [42, 43]. More recently, a research group from University of Arkansas, USA, developed a soybean heat shock-inducible promoter CRISPR/Cas9 system for heritable mutations in rice. They transformed the HS-CRISPR/Cas9 vectors in rice and found only a low rate of target mutations before induction by heat shock compared to an increased rate of target mutations after heat shock treatment indicating that CRISPR/Cas9 is a controlled and efficient platform for gene editing in rice. This work is available online as Pre-print at BioRxiv [44]. Xu et al. in 2016 [45] mutated three rice genes GW2, GW5, and TGW6 to increase seed size by up to $30 \%$ in the triple mutant lines.

Both durum and bread wheat have also been the subject of successful CRISPR/ Cas9-mediated genetic modification for powdery mildew resistance and other objectives [42, 46-48]. However, in wheat, regeneration of plants from CRISPRedited protoplasts has been difficult [12]. In addition, the complexity of wheat genome together with time-consuming tissue culture techniques has made it difficult for scientists to undergo ambitious genome editing projects via CRISPR/Cas9 in this important cereal. Researchers at the Chinese Academy of Science obtained the first CRISPR/Cas9-edited wheat plants [48] by editing three homoeoalleles of a hexaploid bread wheat cultivar to confer heritable resistance against powdery mildew of wheat. Later, the same research group obtained transgene-free genomeedited wheat plants using transient expression of CRISPR/Cas9 DNA or RNA [46]. In 2018, Wang et al. [49] knocked out all the wheat homologs of the rice TaGW2 
(a gene that negatively regulates seed size) in order to significantly increase wheat kernel size. Transgene-free low-gluten wheat has been developed by Sánchez-León et al. via CRISPR/Cas9-mediated genetic engineering [50]. This indicates that CRISPR/Cas9 can be successfully applied to engineer cereal crops for higher yields.

In their book chapter, Chilcoat et al. [51] discuss the use of CRISPR/Cas9 for crop improvement in maize and soybean and have discussed the molecular details of gene editing projects via CRISPR/Cas9 such as those involving $W X 1, A L S$, and ARGOS8 genes in maize. Different studies report successful modification of maize genome using CRISPR/Cas technology $[22,23,30,52]$ for editing traits such as

\begin{tabular}{|c|c|c|c|}
\hline S. no. & Plant/fungus & Gene/locus & Citation \\
\hline 1 & Rice blast fungus (Pyricularia oryzae) & RNAP II & [57] \\
\hline 2 & \multirow[t]{15}{*}{ Rice (Oryza sativa) } & TMS5 & [58] \\
\hline 3 & & MPK1 and MPK6 & [59] \\
\hline 4 & & HAK1 & {$[60]$} \\
\hline 5 & & $C D K A 1, C D K A 2$ and $C D K B 1$ & [32] \\
\hline 6 & & IAA23 & [61] \\
\hline 7 & & EPSPS & [62] \\
\hline 8 & & GN1A, DEP1, GS3 and IPA1 & {$[41]$} \\
\hline 9 & & GBSSI & [63] \\
\hline 10 & & $O s A P L 2$ and $O s A P S 2 b$ & {$[64]$} \\
\hline 11 & & TOS17 & [65] \\
\hline 12 & & $S B E I$ and $S B E I I b$ & {$[66]$} \\
\hline 13 & & $C A L D 5 H 1$ & [67] \\
\hline 14 & & NRAMP5 & {$[68]$} \\
\hline 15 & & ERF922 & [37] \\
\hline 16 & & EPFL9 & [69] \\
\hline 17 & \multirow[t]{5}{*}{ Wheat (Triticum aestivum) } & $D R E B 2$ and $E R F 3$ & {$[70]$} \\
\hline 18 & & $L O X 2$ and $U B I L 1$ & [71] \\
\hline 19 & & MS1 & {$[72]$} \\
\hline 20 & & $\alpha$-GLIADINS & {$[50]$} \\
\hline 21 & & MS45 & {$[73]$} \\
\hline 22 & \multirow[t]{5}{*}{ Maize (Zea mays) } & $A G O 18 A$ and $A G O 18 B$ & {$[22]$} \\
\hline 23 & & MS8 & [49] \\
\hline 24 & & $D M C 1$ & [74] \\
\hline 25 & & $Z B 7$ & [75] \\
\hline 26 & & ARGOS8 & {$[76]$} \\
\hline 27 & \multirow[t]{3}{*}{ Barley (Hordeum vulgare) } & CKX1, CKX3 & {$[77]$} \\
\hline 28 & & PAPHY & [78] \\
\hline 29 & & ENGASE & [79] \\
\hline 30 & Sorghum (Sorghum bicolor) & $C A D$ and $P D S$ & {$[80]$} \\
\hline
\end{tabular}

Table 1.

List of studies involving CRISPR/Cas9-mediated gene editing in grain crops. 
lignin biosynthesis, sterility, and herbicide resistance, secondary metabolism, RNA metabolism, drought tolerance, and agronomic traits [51]. Male sterility in maize provides a useful tool to harness hybrid vigor. Therefore, generation of male sterile mutant lines is considered to be of paramount importance in the hybrid seed production industry. Chen et al. in 2018 [49] used CRISPR/Cas9 to target the MS8 gene of maize and obtained transgene-free $m s 8$ male sterile plants in the F2 generation that could be used for crossing with other elite lines for hybrid seed production. Zhu et al. in 1999 [53] manipulated maize genes AHAs108 and AHA109 encoding acetohydroxyacid synthase enzyme using chimeric RNA/DNA oligonucleotides. Similar studies were performed for targeting various genes in cereal crops such as maize, rice, wheat, and barley [54-56].

Table 1 summarizes the list of important studies involving CRISPR/Cas9mediated gene editing in grain crops.

\section{Conflict of interest}

The authors declare no conflict of interest.

\section{Author details}

Adil Hussain ${ }^{1 *}$, Qari Muhammad Imran ${ }^{2}$ and Byung-Wook Yun ${ }^{2 *}$

1 Department of Agriculture, Abdul Wali Khan University, Mardan, Khyber Pakhtunkhwa, Pakistan

2 School of Applied Biosciences, College of Agriculture and Life Sciences, Kyungpook National University, Republic of Korea

*Address all correspondence to: adilhussain@awkum.edu.pk and bwyun@knu.ac.kr

IntechOpen

(C) 2019 The Author(s). Licensee IntechOpen. This chapter is distributed under the terms of the Creative Commons Attribution License (http://creativecommons.org/licenses/ by/3.0), which permits unrestricted use, distribution, and reproduction in any medium, provided the original work is properly cited. (cc) BY 


\section{References}

[1] Puchta H, Fauser F. Gene targeting in plants: 25 years later. The International Journal of Developmental Biology. 2013;57(6-8):629-637

[2] Kunin V, Sorek R, Hugenholtz P. Evolutionary conservation of sequence and secondary structures in CRISPR repeats. Genome Biology. 2007;8(4):R61

[3] Belhaj K, Chaparro-Garcia A, Kamoun S, Patron NJ, Nekrasov V. Editing plant genomes with CRISPR/ Cas9. Current Opinion in Biotechnology. 2015;32:76-84

[4] Wright AV, Nuñez JK, Doudna JA. Biology and applications of CRISPR systems: Harnessing nature's toolbox for genome engineering. Cell. 2016;164(1-2):29-44

[5] Liu X, Wu S, Xu J, Sui C, Wei J. Application of CRISPR/Cas9 in plant biology. Acta Pharmaceutica Sinica B. 2017;7(3):292-302

[6] Mali P, Yang L, Esvelt KM, Aach J, Guell M, DiCarlo JE, et al. RNA-guided human genome engineering via Cas9. Science (New York, N.Y.). 2013;339(6121):823-826

[7] Cong L, Ran FA, Cox D, Lin S, Barretto R, Habib N, et al. Multiplex genome engineering using CRISPR/Cas systems. Science. 2013;339(6121):819-823

[8] Shan Q, Wang Y, Li J, Gao C. Genome editing in rice and wheat using the CRISPR/Cas system. Nature Protocols. 2014;9(10):2395-2410

[9] Huang S, Weigel D, Beachy RN, Li J. A proposed regulatory framework for genome-edited crops. Nature Genetics. 2016;48(2):109

[10] Li J-F, Norville JE, Aach J, McCormack M, Zhang D,
Bush J, et al. Multiplex and homologous recombination-mediated genome editing in Arabidopsis and Nicotiana benthamiana using guide RNA and Cas9. Nature Biotechnology. 2013;31(8):688

[11] Nekrasov V, Staskawicz B, Weigel D, Jones JD, Kamoun S. Targeted mutagenesis in the model plant Nicotiana benthamiana using Cas9 RNA-guided endonuclease. Nature Biotechnology. 2013;31(8):691

[12] Shan Q, Wang Y, Li J, Zhang Y, Chen $\mathrm{K}$, Liang Z, et al. Targeted genome modification of crop plants using a CRISPR-Cas system. Nature Biotechnology. 2013;31(8):686

[13] Sun X, Hu Z, Chen R, Jiang Q, Song $\mathrm{G}$, Zhang $\mathrm{H}$, et al. Targeted mutagenesis in soybean using the CRISPR-Cas9 system. Scientific Reports. 2015;5:10342

[14] Jacobs TB, LaFayette PR, Schmitz RJ, Parrott WA. Targeted genome modifications in soybean with CRISPR/Cas9. BMC Biotechnology. 2015;15(1):16

[15] Cai Y, Chen L, Liu X, Sun S, Wu C, Jiang B, et al. CRISPR/Cas9-mediated genome editing in soybean hairy roots. PLoS One. 2015;10(8):e0136064

[16] Brooks C, Nekrasov V, Lippman ZB, Van Eck J. Efficient gene editing in tomato in the first generation using the clustered regularly interspaced short palindromic repeats/CRISPRassociated9 system. Plant Physiology. 2014;166(3):1292-1297

[17] Pan C, Ye L, Qin L, Liu X, He Y, Wang J, et al. CRISPR/Cas9-mediated efficient and heritable targeted mutagenesis in tomato plants in the first and later generations. Scientific Reports. 2016;6:24765 
[18] Ito Y, Nishizawa-Yokoi A, Endo M, Mikami M, Toki S. CRISPR/Cas9mediated mutagenesis of the RIN locus that regulates tomato fruit ripening. Biochemical and Biophysical Research Communications. 2015;467(1):76-82

[19] Ueta R, Abe C, Watanabe T, Sugano SS, Ishihara R, Ezura H, et al. Rapid breeding of parthenocarpic tomato plants using CRISPR/Cas9. Scientific Reports. 2017;7(1):507

[20] Wang S, Zhang S, Wang W, Xiong X, Meng F, Cui X. Efficient targeted mutagenesis in potato by the CRISPR/Cas9 system. Plant Cell Reports. 2015;34(9):1473-1476

[21] Chandrasekaran J, Brumin M, Wolf D, Leibman D, Klap C, Pearlsman M, et al. Development of broad virus resistance in non-transgenic cucumber using CRISPR/Cas9 technology. Molecular Plant Pathology. 2016;17(7):1140-1153

[22] Char SN, Neelakandan AK, Nahampun H, Frame B, Main M, Spalding MH, et al. An Agrobacteriumdelivered CRISPR/Cas9 system for high-frequency targeted mutagenesis in maize. Plant Biotechnology Journal. 2017;15(2):257-268

[23] Svitashev S, Schwartz C, Lenderts B, Young JK, Cigan AM. Genome editing in maize directed by CRISPR-Cas9 ribonucleoprotein complexes. Nature Communications. 2016;7:13274

[24] Morineau C, Bellec Y, Tellier F, Gissot L, Kelemen Z, Nogué F, et al. Selective gene dosage by CRISPR-Cas9 genome editing in hexaploid Camelina sativa. Plant Biotechnology Journal. 2017;15(6):729-739

[25] Malnoy M, Viola R, Jung M-H, Koo O-J, Kim S, Kim J-S, et al. DNAfree genetically edited grapevine and apple protoplast using CRISPR/Cas9 ribonucleoproteins. Frontiers in Plant Science. 2016;7:1904

[26] Lawrenson T, Shorinola O, Stacey N, Li C, Østergaard L, Patron N, et al. Induction of targeted, heritable mutations in barley and Brassica oleracea using RNA-guided Cas9 nuclease. Genome Biology. 2015;16(1):258

[27] Tian S, Jiang L, Gao Q, Zhang J, Zong $\mathrm{M}$, Zhang $\mathrm{H}$, et al. Efficient CRISPR/Cas9-based gene knockout in watermelon. Plant Cell Reports. 2017;36(3):399-406

[28] Jia H, Wang N. Targeted genome editing of sweet orange using Cas9/ sgRNA. PLoS One. 2014;9(4):e93806

[29] Fan D, Liu T, Li C, Jiao B, Li S, Hou Y, et al. Efficient CRISPR/Cas9mediated targeted mutagenesis in Populus in the first generation. Scientific Reports. 2015;5:12217

[30] Shi J, Gao H, Wang H, Lafitte HR, Archibald RL, Yang M, et al. ARGOS 8 variants generated by CRISPR-Cas 9 improve maize grain yield under field drought stress conditions. Plant Biotechnology Journal. 2017;15(2):207-216

[31] Zhou H, Liu B, Weeks DP, Spalding MH, Yang B. Large chromosomal deletions and heritable small genetic changes induced by CRISPR/Cas9 in rice. Nucleic Acids Research. 2014;42(17):10903-10914

[32] Endo M, Mikami M, Toki S. Multigene knockout utilizing off-target mutations of the CRISPR/Cas9 system in rice. Plant and Cell Physiology. 2015;56(1):41-47

[33] Xu R-F, Li H, Qin R-Y, Li J, Qiu $\mathrm{C}-\mathrm{H}$, Yang Y-C, et al. Generation of inheritable and "transgene clean" targeted genome-modified rice in later generations using the CRISPR/Cas9 system. Scientific Reports. 2015;5:11491 
[34] Lu Y, Zhu J-K. Precise editing of a target base in the rice genome using a modified CRISPR/Cas9 system. Molecular Plant. 2017;10(3):523-525

[35] Jiang W, Zhou H, Bi H, Fromm M, Yang B, Weeks DP. Demonstration of CRISPR/Cas9/sgRNA-mediated targeted gene modification in Arabidopsis, tobacco, sorghum and rice. Nucleic Acids Research. 2013;41(20):e188

[36] Xie K, Yang Y. RNA-guided genome editing in plants using a CRISPR-Cas system. Molecular Plant. 2013;6(6):1975-1983

[37] Wang F, Wang C, Liu P, Lei C, Hao W, Gao Y, et al. Enhanced rice blast resistance by CRISPR/Cas9-targeted mutagenesis of the ERF transcription factor gene OsERF922. PLoS One. 2016;11(4):e0154027

[38] Sun Y, Zhang X, Wu C, He Y, Ma Y, $\mathrm{Hou} \mathrm{H}$, et al. Engineering herbicideresistant rice plants through CRISPR/ Cas9-mediated homologous recombination of acetolactate synthase. Molecular Plant. 2016;9(4):628-631

[39] Li Q, Zhang D, Chen M, Liang W, Wei J, Qi Y, et al. Development of japonica photo-sensitive genic male sterile rice lines by editing carbon starved anther using CRISPR/Cas9. Journal of Genetics and Genomics $=\mathrm{Yi}$ chuan xue bao. 2016;43(6):415

[40] Zhou H, He M, Li J, Chen L, Huang Z, Zheng S, et al. Development of commercial thermo-sensitive genic male sterile rice accelerates hybrid rice breeding using the CRISPR/ Cas9-mediated TMS5 editing system. Scientific Reports. 2016;6:37395

[41] Li M, Li X, Zhou Z, Wu P, Fang M, Pan X, et al. Reassessment of the four yield-related genes Gn1a, DEP1, GS3, and IPA1 in rice using a CRISPR/Cas9 system. Frontiers in Plant Science. 2016;7:377
[42] Gil-Humanes J, Wang Y, Liang Z, Shan Q, Ozuna CV, Sánchez-León S, et al. High-efficiency gene targeting in hexaploid wheat using DNA replicons and CRISPR/Cas9. The Plant Journal. 2017;89(6):1251-1262

[43] Xu R, Qin R, Li H, Li D, Li L, Wei $\mathrm{P}$, et al. Generation of targeted mutant rice using a CRISPR-Cpf1 system. Plant Biotechnology Journal. 2017;15(6):713-717

[44] Nandy S, Pathak B, Zhao S, Srivastava V. Heat-shock-inducible CRISPR/Cas9 system generates heritable mutations in rice. Plant Direct. 2019;3:1-14. DOI: 10.1002/ pld3.145

[45] Xu R, Yang Y, Qin R, Li H, Qiu C, $\mathrm{Li} \mathrm{L}$, et al. Rapid improvement of grain weight via highly efficient CRISPR/Cas9mediated multiplex genome editing in rice. Journal of Genetics and Genomics = Yi chuan xue bao. 2016;43(8):529

[46] Zhang Y, Liang Z, Zong Y, Wang Y, Liu J, Chen K, et al. Efficient and transgene-free genome editing in wheat through transient expression of CRISPR/Cas9 DNA or RNA. Nature Communications. 2016;7:12617

[47] Liang Z, Chen K, Li T, Zhang Y, Wang Y, Zhao Q, et al. Efficient DNAfree genome editing of bread wheat using CRISPR/Cas9 ribonucleoprotein complexes. Nature Communications. 2017;8:14261

[48] Wang Y, Cheng X, Shan Q, Zhang Y, Liu J, Gao C, et al. Simultaneous editing of three homoeoalleles in hexaploid bread wheat confers heritable resistance to powdery mildew. Nature Biotechnology. 2014;32(9):947

[49] Chen R, Xu Q, Liu Y, Zhang J, Ren D, Wang G, et al. Generation of transgene-free maize male sterile lines using the CRISPR/Cas9 system. Frontiers in Plant Science. 2018;9:1180 
[50] Sánchez-León S, Gil-Humanes J, Ozuna CV, Giménez MJ, Sousa C, Voytas DF, et al. Low-gluten, nontransgenic wheat engineered with CRISPR/Cas9. Plant Biotechnology Journal. 2018;16(4):902-910

[51] Chilcoat D, Liu Z-B, Sander J. Chapter two-Use of CRISPR/Cas9 for crop improvement in maize and soybean. In: Weeks D, Yang B, editors. Progress in Molecular Biology and Translational Science. Vol. 149. USA: Academic Press; 26 Jun 2017. pp. 27-46. ISBN: 9780128117439

[52] Svitashev S, Young JK, Schwartz C, Gao H, Falco SC, Cigan AM. Targeted mutagenesis, precise gene editing, and site-specific gene insertion in maize using Cas9 and guide RNA. Plant Physiology. 2015;169(2):931-945

[53] Zhu T, Peterson DJ, Tagliani L, Clair GS, Baszczynski CL,

Bowen B. Targeted manipulation of maize genes in vivo using chimeric RNA/DNA oligonucleotides.

Proceedings of the National Academy of Sciencesof the United States of America. 1999;96(15):8768-8773

[54] Terada R, Urawa H, Inagaki Y, Tsugane K, Iida S. Efficient gene targeting by homologous recombination in rice. Nature Biotechnology.

2002;20(10):1030

[55] Gao H, Smith J, Yang M, Jones S, Djukanovic V, Nicholson MG, et al. Heritable targeted mutagenesis in maize using a designed endonuclease. The Plant Journal. 2010;61(1):176-187

[56] Mrizova K, Holaskova E, Öz MT, Jiskrova E, Frebort I, Galuszka P. Transgenic barley: A prospective tool for biotechnology and agriculture. Biotechnology Advances. 2014;32(1):137-157

[57] Arazoe T, Miyoshi K, Yamato T, Ogawa T, Ohsato S, Arie T, et al. Tailormade CRISPR/Cas system for highly efficient targeted gene replacement in the rice blast fungus. Biotechnology and Bioengineering. 2015;112:2543-2549

[58] Barman HN, Sheng Z, Fiaz S, Zhong M, Wu Y, Cai Y, et al. Generation of a new thermo-sensitive genic male sterile rice line by targeted mutagenesis of TMS5 gene through CRISPR/Cas9 system. BMC Plant Biology. 2019;19:109

[59] Minkenberg B, Xie K, Yang Y. Discovery of rice essential genes by characterizing a CRISPR-edited mutation of closely related rice MAP kinase genes. The Plant Journal. 2017;89:636-648

[60] Nieves-Cordones M, Mohamed S, Tanoi K, Kobayashi NI, Takagi K, Vernet A, et al. Production of low-Cs(+) rice plants by inactivation of the $\mathrm{K}(+)$ transporter OsHAK1 with the CRISPR-Cas system. The Plant Journal. 2017;92:43-56

[61] Jiang M, Hu H, Kai J, Traw MB, Yang S, Zhang X. Different knockout genotypes of OsIAA23 in rice using CRISPR/Cas9 generating different phenotypes. Plant Molecular Biology. 2019;100:467-479

[62] Li J, Meng X, Zong Y, Chen K, Zhang H, Liu J, et al. Gene replacements and insertions in rice by intron targeting using CRISPR-Cas9. Nature Plants. 2016;2:16139

[63] Perez L, Soto E, Farre G, Juanos J, Villorbina G, Bassie L, et al. CRISPR/ Cas9 mutations in the rice Waxy/ GBSSI gene induce allele-specific and zygosity-dependent feedback effects on endosperm starch biosynthesis. Plant Cell Reports. 2019;38:417-433

[64] Perez L, Soto E, Villorbina G, Bassie L, Medina V, Munoz P, et al. CRISPR/Cas9-induced monoallelic mutations in the cytosolic AGPase large subunit gene APL2 induce the ectopic expression of APL2 and the 
corresponding small subunit gene APS2b in rice leaves. Transgenic Research. 2018;27:423-439

[65] Saika H, Mori A, Endo M, Toki S. Targeted deletion of rice retrotransposon Tos17 via CRISPR/Cas9. Plant Cell Reports. 2019;38:455-458

[66] Sun Y, Jiao G, Liu Z, Zhang X, Li J, Guo X, et al. Generation of highamylose rice through CRISPR/Cas9mediated targeted mutagenesis of starch branching enzymes. Frontiers in Plant Science. 2017;8:298

[67] Takeda Y, Suzuki S, Tobimatsu Y, Osakabe K, Osakabe Y, Ragamustari SK, et al. Lignin characterization of rice CONIFERALDEHYDE 5-HYDROXYLASE loss-of-function mutants generated with the CRISPR/ Cas9 system. The Plant Journal. 2019;97:543-554

[68] Tang L, Mao B, Li Y, Lv Q, Zhang L, Chen C, et al. Knockout of OsNramp5 using the CRISPR/Cas9 system produces low $\mathrm{Cd}$-accumulating indica rice without compromising yield. Scientific Reports. 2017;7:14438

[69] Yin X, Anand A, Quick P, Bandyopadhyay A. Editing a stomatal developmental gene in rice with CRISPR/Cpf1. Methods in Molecular Biology. 1917;2019:257-268

[70] Kim D, Alptekin B, Budak H. CRISPR/Cas9 genome editing in wheat. Functional and Integrative Genomics. 2018;18:31-41

[71] Bhowmik P, Ellison E, Polley B, Bollina V, Kulkarni M, Ghanbarnia K, et al. Targeted mutagenesis in wheat microspores using CRISPR/Cas9. Scientific Reports. 2018;8:6502

[72] Okada A, Arndell T, Borisjuk N, Sharma N, Watson-Haigh NS, Tucker EJ, et al. CRISPR/Cas9-mediated knockout of Ms1 enables the rapid generation of male-sterile hexaploid wheat lines for use in hybrid seed production. Plant Biotechnology Journal. 2019. DOI: 10.1111/pbi.13106

[73] Singh M, Kumar M, Albertsen MC, Young JK, Cigan AM. Concurrent modifications in the three homeologs of Ms45 gene with CRISPR-Cas9 lead to rapid generation of male sterile bread wheat (Triticum aestivum L.). Plant Molecular Biology. 2018;97:371-383

[74] Feng C, Su H, Bai H, Wang R, Liu Y, Guo X, et al. High-efficiency genome editing using a dmc1 promotercontrolled CRISPR/Cas9 system in maize. Plant Biotechnology Journal. 2018;16:1848-1857

[75] Feng C, Yuan J, Wang R, Liu Y, Birchler JA, Han F. Efficient targeted genome modification in maize using CRISPR/Cas9 system. Journal of Genetics and Genomics. 2016;43:37-43

[76] Shi J, Gao H, Wang H, Lafitte HR, Archibald RL, Yang M, et al. ARGOS8 variants generated by CRISPR-Cas9 improve maize grain yield under field drought stress conditions. Plant Biotechnology Journal. 2017;15:207-216

[77] Gasparis S, Kala M, Przyborowski M, Lyznik LA, Orczyk W, Nadolska-Orczyk A. A simple and efficient CRISPR/Cas9 platform for induction of single and multiple, heritable mutations in barley (Hordeum vulgare L.). Plant Methods. 2018;14:111

[78] Holme IB, Wendt T, Gil-Humanes J, Deleuran LC, Starker CG, Voytas DF, et al. Evaluation of the mature grain phytase candidate HvPAPhy_a gene in barley (Hordeum vulgare L.) using CRISPR/Cas9 and TALENs. Plant Molecular Biology. 2017;95:111-121

[79] Kapusi E, Corcuera-Gomez M, Melnik S, Stoger E. Heritable genomic fragment deletions and small indels in the putative ENGase gene induced by 
CRISPR/Cas9 in barley. Frontiers in Plant Science. 2017;8:540

[80] Liu G, Li J, Godwin ID. Genome editing by CRISPR/Cas9 in sorghum through biolistic bombardment. Methods in Molecular Biology. 1931;2019:169-183 


\title{
Wheat in the Era of Genomics and Transgenics
}

\author{
Usman Babar, Usama Arshad, Muhammad Tehseen Azhar, \\ Rana Muhammad Atif, Abdulaziz Abdullah Alsahli, \\ Ibrahim A. Alaraidh, Aysha Kiran, Iqrar Ahmad Rana \\ and Gyuhwa Chung
}

\begin{abstract}
Wheat, as one of the most important cereal crops in the world and second major caloric source in the world after rice, is the major staple food in South Asia and many other countries of the world. Prior to onset of "Green Revolution," South Asian countries were facing the threat of severe famine. Green Revolution wheat genotypes brought out these countries from the crisis they were facing and has helped them to sustain their productions for more than half a century. With the emergence of molecular biology and biotechnology, another window of opportunity is opened to sustain wheat yields by using modern techniques of genes identification and utilization. Through this chapter, we have tried to gather information that was generated for wheat improvement in last 3 decades. These afforest included the development of molecular markers, mapping of genes, sequencing of markers genes, and their utilization through marker-assisted selection. The other part recorded various efforts to genetically transform wheat for traits improvements and/or to study their molecular control.
\end{abstract}

Keywords: wheat, marker-assisted selection (MAS), transformation, gene mapping, rust resistance

\section{Introduction}

Wheat (Triticum aestivum) belonging to Triticeae tribe of Poaceae family exhibits the most complex allohexaploid genome of approximately $17 \mathrm{~Gb}$. Moreover, wheat is the second largest crop of the world after rice, but it has higher nutrition value than rice and is consumed by more than 2.5 billion people across the world. It is cultivated over a land of 215 million hectares worldwide every year, which is more than that of any other crop of commercial significance. Growing on a diverse range of environments and responding variably to temperate, tropical, and subtropical climates during spring and winter seasons, wheat is the most crucial as well as dominant staple food of Asia and North Africa. It is highly susceptible to abiotic stresses such as higher temperatures and depression in its yield could be resulted which is not permissible for a major food crop. Green revolution based upon a single objective to improve the yields of major cereal crops resulted in major yield shift for wheat during the previous century $[1,2]$. Global export value of wheat is around 50 billion US\$ [3-5]. 
DNA, a biomolecule, is coiled in form of double-stranded helix which carries all the essential genetic information in specific codes/sequences for the proper functioning of an organism. Modern era of genomics and transgenics emerged after the identification of DNA structure in 1958 and discovery of restriction endonucleases later. By thorough analysis of complexity in wheat genome, it is believed that probability of transgenic events to occur is most likely within wheat as it is far greater than that of other monocots as it exhibits higher gene copies [6]. Information generated through DNA and genome sequencing lead to genetic improvement of the organisms by comparing the available genomics data as well as determining the undiscovered perspectives. Functional genomics have unlocked the roadmap of transgenesis by providing necessitated annotated information of genes naturally present in different organisms. By following up previous genomics studies done through molecular and morphological markers, researchers have taken a step toward exploring complex wheat genome and developing detailed physical and genetic maps of hexaploid genome of wheat $[7,8]$. The functional and structural genomics of wheat is being stored in databases such as GenBank, TIGR, etc. [9]. The manipulation in genome comes next to exploration, and various alterations have been made by the implementation of conventional as well as advanced biotechnological approaches for the genome editing and genetic engineering [10].

Increasing wheat yield and nutritive quality are the major focus of studies going on currently in the world. It has been estimated that by 2050, the demand of wheat is going to increase up to $60 \%$. Conventional cross breeding cannot fulfill this demand rapidly, only the genomics aided breeding and genetic engineering of wheat genotypes with genes from related and unrelated sources can speed up breeding and bring required genetic gains to feed rapid growing world population. Though genetic manipulations are of utmost importance yet biosafety is a great concern before commercializing products carrying genetic manipulations. This review focuses on the status of wheat crop since the very beginning of green evolution and the cascades of advancements that have been made upon progress in science and technology with the passage of time. How have these advancements been utilized by now and are going to be used in near future for increasing wheat yields and quality in order to provide growing populations a healthy food?

\section{Global statistics of wheat:}

Wheat crop have experienced rises and declines in its yield eventually over the years. Figures 1 and 2 shows the graphical representation of global wheat production among last 6 decades (1961-2018). Before the onset of green revolution in 1960 s, many wheat consuming countries were on the brink of famine due to insufficient yield. The issue had even worsened in South Asia, where wheat has been the major staple food and the area is thickly populated [13]. Norman Borlaug presented the idea of developing short-statured wheat genotypes by selective cross breeding techniques, which proved beneficial, and as a result dwarf varieties of wheat became rust free and the yield enhanced multiple times. Green revolution indeed sorted out the issue of crop yield, but many challenges remained consistent $[2,14]$. With the emergence of green revolution, older wheat genotypes were almost eliminated and the diverse gene pools got weaker, as the sources of many essential genes were lost; in other words, the evolutionary process was shaken to a great extent. The older genotypes were taller, and relatively more vulnerable to rusts than the semidwarf green revolution varieties. Later on, the work over acquiring resistance by implementing DNA manipulative technologies was evidenced [15], which involve different native genetic markers and transgenes from other organisms.

Graphs, given above, showed that during the last 6 decades, production of wheat worldwide has exceeded 3.3 folds, i.e., from 222.1 metric tons to 755.9 metric tons. By 2050, it needs to be enhanced further over $60 \%$ for fulfilling the 
Harvested Area and Yield Statistics (1961-2018)

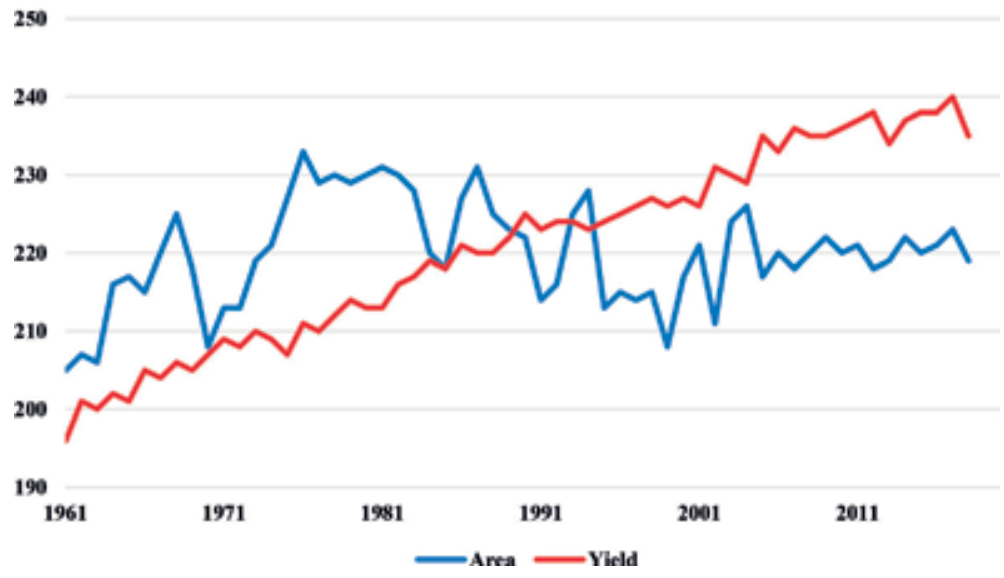

Figure 1.

Trend of wheat production worldwide (1961-2018) (Source: [11, 12]).

Global Wheat Production Statistics (1961-2018)

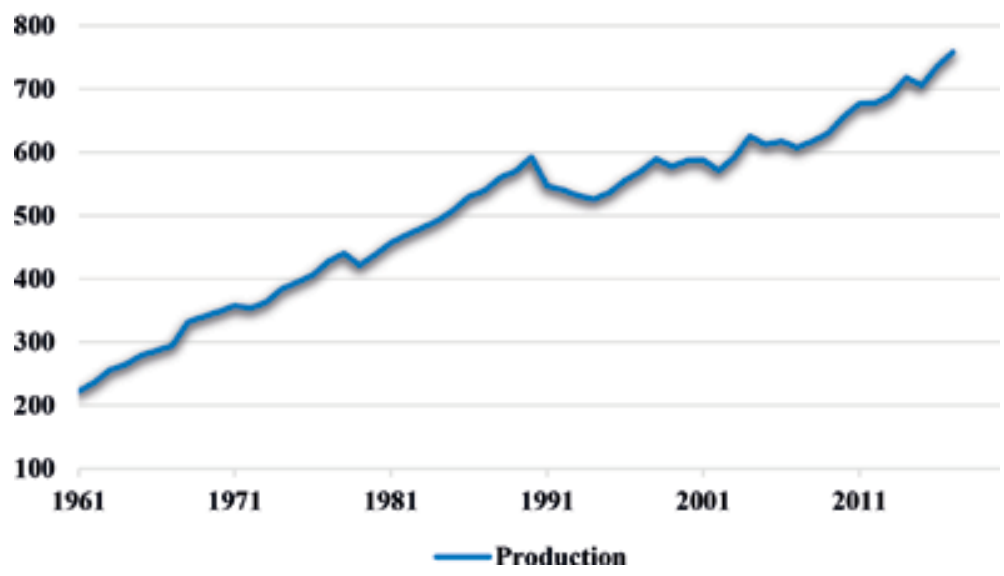

Figure 2.

Trend of area harvested and yield obtained from wheat worldwide (1961-2018).

consumers demand [16]. The global production of wheat has increased by $3.38 \%$ on average every year in each decade after 1970. A phase of declined production has been recorded after consecutive rise of production. This could be a result of several conditions combined, which involve exposure to insect/rust attack, harsh environmental conditions, and poor land management practices. After green revolution, the exponential growth in global wheat production can be clearly seen till the next decade of 1970s. First declined phase was experienced in late 1970s, prior to the beginning of genomic era. Following the genomic era from early 1980s, the wheat production started to grow exponentially once again for another decade. The major drop in production can be seen at the start of 1990s, which has been recovering ever since. The decade with the most variable production is 2000-2010. While, the decades of highest wheat productions is 1980s and the most recent one.

The major producers of wheat are China (134 mt), India (98 mt), Russia (85 mt), US (47 mt), France (36 mt), Australia (31 mt), Canada (29 mt), Pakistan (26.6 mt), Ukraine $(26.2 \mathrm{mt})$, and Germany $(24 \mathrm{mt})$. They produce approximately $70 \%$ of total wheat of the world [17]. 


\section{Challenges in wheat production before and after genomics Era}

Wheat grain quality and yield have always remained the foremost preference of research interest for getting the genetically improved crop with enhanced yield and better grain quality. Initially, the task was performed by implementing various artificial breeding techniques, which took longer than usual, and still the results obtained were not as efficient as anticipated [18]. The genomic era started in early 1980s with the discovery of recombinant DNA technology, a breakthrough in biotechnology [14]. With the passage of time, advancements in these technologies have eased up genome-wide analyses among different organisms by using Bioinformatics databases and tools. Similar struggle was done for the sake of wheat improvement, which have been highly susceptible to numerous stresses such as insects, rusts, and climate change, since the very beginning and gradually shifted toward molecular breeding [19]; while, the most serious challenge is to fulfill the demand with continuously increasing consumption. In past, marker-assisted breeding had been used extensively for getting the desired manipulative task done; but with the amendments in biosafety and bioethics, most of the research has been directed toward marker-free technology. Genomics era involved the advanced molecular breeding and genetic modification techniques for the wheat improvement, which was done by conventional plant breeding techniques under green revolution, prior to genomics era which no longer seems effective lately $[20,21]$. A lot of work has been done over acquiring resistance against these stress factors, and researchers have also succeeded in developing such characters/traits within the wheat by utilizing a broad range of genetic engineering and genome editing technologies. Though genetically modified wheat presents high potential for trait improvement, only one GM event has been commercialized, which is MON-71800 or roundup ready wheat developed by Monsanto in 2004 for inducing glyphosate herbicide tolerance through CP4 Epsps gene transformation [22].

The challenges are commonly reported from developing countries; most probably, the ones with hot and dry climatic conditions, i.e., African and Asian regions. Besides, some of these challenges are also encountered in developed countries such as America, Canada, and Australia [23,24], as the climate change is hitting almost everywhere on globe.

DNA technologies opened a gateway for the detection and induction of genetic mutations, but the inaccuracy of developed procedures as well as off-target outcomes have shown certain complications which might affect some other gene, apart from the targeted one. Besides, rise of bioethics and biosafety issues led to the failure of established DNA technology regarding the genetic manipulation of living organisms, as it was believed that these practices are meant to be contaminating and playing with nature which of course showed adverse effects in some of the cases. Later on, with the establishment of bioethics and biosafety act, the approach of transgenesis for genetic improvement of crops has been granted to be used globally as long as the biosecurity of product is ensured [25]. The recent advancements of genome editing and targeted or site-directed mutagenesis are very advantageous and destined to provide most promising results for the development of sustainable agriculture.

\section{Complexity of wheat genome}

Wheat exhibits one of the enormous and complex genomes with diverse ploidy levels among 23 different species. Out of which, 6 species cultivated across the globe are most common, i.e., Bread wheat (T. aestivum), Durum (T. durum), Emmer 


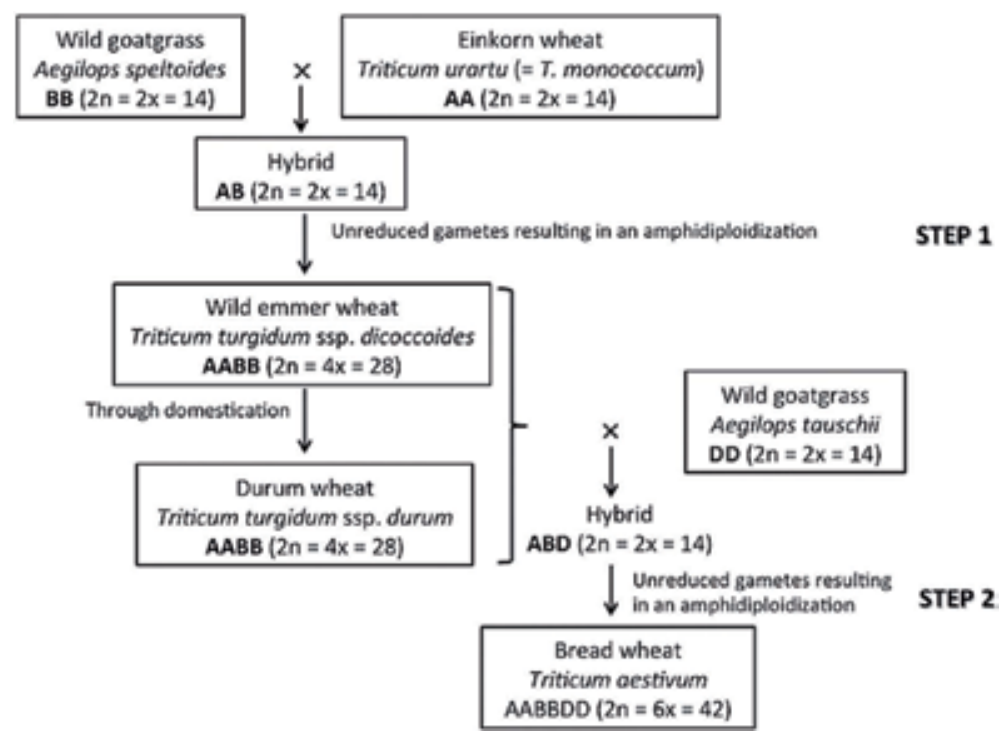

Figure 3.

The complexity and evolution in wheat genome: the tetraploid wheat (T. turgidum spp. Dicoccoides) was developed by amphidiploidization between T. urartu and A. speltoides (diploids) (step 1), which later on hybridized into the allohexaploid wheat (T. aestivum) by amphiploidization of T. turgidum spp. Dicoccoides, T. turgidum spp. Durum (tetraploids) and A. tauschii (diploid) together (step 2) [28].

(T. dicoccon), Einkorn (T. monococcum), Khorasan (T. turgidum or T. turanicum), and Speltoid (T. speltoid). As known, Einkorn is diploid; Durum, Emmer, and Khorasan are tetraploid; while Bread wheat and Durum are hexaploid. All the species other than T. aestivum and T. durum are ancient ancestors as they are cultivated at limited locations [26, 27] (Figure 3).

Wheat consisting of three genomes (AABBDD) exhibits genome size of approximately $17 \mathrm{~Gb}$ with $164,000-334,000$ genes, $85 \%$ of which lies within $<10 \%$ of all its chromosomes, i.e., 7. Wheat contains six copies of each gene as per its ploidy level and most of its traits are polygenic including the yield causing difficulty in inducing modifications in its genome. It has been reported that there are greater possibilities of developing these changes with extensive planning and targeting each copy of the gene separately [5, 29-31].

\section{Recent advances of genomics era in wheat improvement}

By the emergence of the genomic technologies, the steps toward improvement of wheat crop were taken to get sustainable production. For this core purpose, the posed challenges needed to be sorted out, which were done by using molecular breeding or marker-assisted breeding technologies [21]. Various members of aphid-resistant $D n$ gene family ( $D n 1, D n 2, D n 4$, and $D n 5)$ within wheat were found to be responsible for exhibiting some resistance against these insects by screening via RAPD and SCAR molecular markers [32]. $R$ genes and $A P R$ genes were reported to be used for rust resistance either by screening and enhancing their expression through SNPs or by transforming wheat through suitable technique for gene delivery into plant genome [33-35]. Inbred lines in wheat having drought tolerance were evaluated by using microsatellite markers to get an idea of the responsible gene(s) present naturally within wheat genome [36]. 


\section{Physical mapping of wheat genome}

The International Wheat Genome Sequencing Consortium (IWGSC) database exhibits entire physical map of 21 chromosomes of bread wheat (T. aestivum) with High Information Content Fingerprinting (HCIF) and whole-genome profiling (WGS) in form of BAC libraries. Whereas, the physical contigs contain all the mapped information regarding markers, positions, and deletion bins of BAC clones. Different software programs, such as linear topological contig (LTC) and fingerprinted contig (FPC), are available within the database that are required for maintenance and update of data on physical map [37-39].

\section{Genetic mapping of wheat genome}

Molecular markers for genome mapping, such as amplified fragment length polymorphism (AFLP), expressed sequence tags (EST), quantitative traits Locus (QTLs), restricted fragment length polymorphism (RFLP), random amplification of polymorphic DNA (RAPD), sequence of characterized amplified region (SCAR), single nucleotide polymorphism (SNP), simple sequence repeats (SSR), and sequence tagged sites (STS) along with the sequence-based mapping technologies, can be used as the efficacious tools for functional genomics of wheat. These phenomena help in getting comprehensive understanding of the genes responsible for certain traits and their phylogenetic analysis, which can thereby help in improvement of some closely related genotype through marker-assisted breeding [40-43]. Table 1 shows some of the studies done in wheat to assess different populations and genotypes using molecular markers.

\begin{tabular}{|c|c|c|c|}
\hline Molecular markers & Population & Mapped loci & References \\
\hline \multirow[t]{2}{*}{ AFLP } & RILs (Wangshuibai × Alondra's) & 250 & {$[44]$} \\
\hline & T. aestivum $($ Chinese Spring $\times$ T. spelta $)$ & 24 & {$[45]$} \\
\hline EST & T. aestivum & 22 & {$[46]$} \\
\hline \multirow[t]{2}{*}{ QTL } & RILs (Arina $\times$ Forno) $F_{5: 7}$ & 8 & {$[47]$} \\
\hline & F2 (BC5 and BC9) T. tauschii & 2 & {$[48]$} \\
\hline \multirow[t]{2}{*}{ RFLP } & T. aestivum & 245 & [49] \\
\hline & Triticum aestivum L. em Thell. & 82 & {$[50]$} \\
\hline \multirow[t]{2}{*}{ RAPD } & Yangmai 5 & 180 & {$[51]$} \\
\hline & T. aestivum & 71 & {$[52]$} \\
\hline \multirow[t]{2}{*}{ SCAR } & T. aestivum F2 & 43 & {$[53]$} \\
\hline & T. aestivum & 23 & {$[41]$} \\
\hline \multirow[t]{2}{*}{ SNP } & T. aestivum $($ Chinese Spring $\times$ Renan $)$ & $3.3 \times 10^{6}$ & {$[43]$} \\
\hline & RILs (Ning7840 $\times$ Clark and Heyne $\times$ Lakin) & 3541 & {$[42]$} \\
\hline \multirow[t]{2}{*}{ SSR } & RILs (Ning7840 $\times$ Clark and Heyne $\times$ Lakin) & 145 & {$[42]$} \\
\hline & DHs (Kitamoe $\times$ Munstertaler) & 464 & {$[54]$} \\
\hline \multirow[t]{2}{*}{ STS } & DHs (AC Karma × 87E03-S2B1) & 165 & {$[55]$} \\
\hline & RILs $($ Dream $\times$ Lynx $)$ & 283 & {$[56]$} \\
\hline
\end{tabular}

RILS, recombinant inbred lines; DHs, doubled haploids; BC, back-crossed; F, filial generation.

Table 1.

Molecular markers for wheat genome mapping. 


\section{Sequencing technologies and wheat}

The genome sequences play a crucial role in comprehensive understanding of phenotypic traits, their molecular basis, and alterations in them. The comparative genomics studies for enhancement of wheat have been constraint by its less genomic conservation. The wheat genome sequencing has become the utmost priority for the sake of crop improvement in order to know the genetic basis of traits controlled by a complex genome. The enormous complexity in genome and its size have caused several limitations of efforts in sequencing studies. Currently, several drafts of wheat genome have been sequenced on the basis of chromosomes of either of its genomes with the help of advancements in next-generation sequencing technologies $[57,58]$.

The entire genome including cDNA of T. aestivum cv. Chinese Spring (CS42) was sequenced by the application of random shotgun next-generation sequencing that involved Illumina HiSeq 2000, Genome Analyzer IIx, and Roche 454 pyrosequencing technology. The sequenced data were then compared with the previously identified genome sequences of Aegilops, A. Tauschii, A. speltoides, and T. monoccum. This could identify 124,000 genes distributed into A, B, and D genomes [7, 8, 59]. The diploid species of wheat, T. urartu and $A$. tauschii were also sequenced and reported to be having 34,879 and 43,150 genes, respectively [60, 61]. Indeed, the information obtained from all these efforts have caused a lot of ease in localizing the identical genes in hexaploid species, while the information regarding their evolution remained undiscovered for a while [57]. In 2014, IWGSC started to work over the whole-genome sequencing of wheat cv. Chinese Spring (Hexaploid) and started de novo assembly of each of the chromosomes except 3B, which was done independently by Choulet and his coworkers [8, 62].

\section{Sequence-based mapping}

The advancements in new sequencing technologies of genomic era have offered various cost-efficient approaches to carry out the genetic mapping of complex genomes with high resolution. The case of wheat genome sequencing, due to its polyloidy causes hurdles in spite of all the known promising applications of these technologies [63]. In a study, DH wheat variety was mapped by application of whole-genome shotgun NGS and the consistent outcomes were obtained from variant mapping and compared with the ones obtained from 9000 SNP iSelect assay of wheat. Significant resemblance was found among these results. As per findings, a reference map of entire wheat genome was developed, which consisted of 118 SSRs, 1351 diversity array technology, 2740 genes linked SNPs by wheat iSelect assay, and 416,856 genetic markers. By the detailed analysis, it was revealed that these markers reside within the range of 40-100 kb from their neighbor gene, hereby enhancing the possibility of genome mapping for gene identification. The given information is quite beneficial for the thorough study of wheat genome by linking both of its genetic and physical maps [63, 64].

\section{Mapped traits in wheat}

By the implementation of forward genetics approaches in molecular markers, such as QTLs, a large number of studies have been conducted based upon the genome mapping of wheat in order to identify response of plant against biotic and abiotic stresses. It is reported that while performing QTL study, environmental interactions always remain a significant factor $[65,66]$. A short list of conducted studies for various traits in wheat regarding QTL or gene tagging is given in Table 2. 


\begin{tabular}{|c|c|c|c|c|}
\hline Trait & Gene/QTLs & Chromosome & Population & References \\
\hline \multicolumn{5}{|l|}{ Abiotic stress tolerance } \\
\hline Aluminum tolerance & ALMT1 & $4 \mathrm{D}$ & DH & {$[67]$} \\
\hline Boron toxicity tolerance & Bo1 & $7 \mathrm{BL}$ & DH & {$[68]$} \\
\hline Drought tolerance & DREB1 & $3 \mathrm{~A}$ & Barakatli-95 & [69] \\
\hline Frost tolerance & QTL & $5 \mathrm{~B}$ & RSI & {$[70]$} \\
\hline Photoperiod insensitive & Ppd-B1 & 2BS & RILs & {$[71]$} \\
\hline Salinity tolerance & $Q T L$ & $3 \mathrm{~A}, 3 \mathrm{~B}, 4,6 \mathrm{DL}$ & RILs & {$[72]$} \\
\hline \multirow[t]{4}{*}{ Russian wheat aphid resistance } & $D n 1, D n 2, D n 5$ & 7DS & $\mathrm{F} 2$ & [73] \\
\hline & $D n 4, D n 6$ & $1 \mathrm{D}, 7 \mathrm{D}$ & $\mathrm{F} 2$ & {$[74]$} \\
\hline & $D n 7$ & 1B & $\mathrm{F} 2$ & {$[75]$} \\
\hline & $D n 8, D n 9, D n x$ & 7DS, 1DL & $\mathrm{F} 2$ & [73] \\
\hline \multirow[t]{3}{*}{ Stem rust resistance } & $\operatorname{Sr} 2$ & 3BS & F3 & {$[76]$} \\
\hline & Sr22 & $7 \mathrm{~A}$ & $\mathrm{~F} 2$ & {$[77]$} \\
\hline & Sr38 & $2 \mathrm{AS}$ & NILs & [78] \\
\hline \multirow[t]{16}{*}{ Leaf rust resistance } & $\operatorname{Lr} 1$ & $5 \mathrm{DL}$ & F2 & [79] \\
\hline & Lr3 & $6 \mathrm{BL}$ & F2 & {$[80]$} \\
\hline & $\operatorname{Lr} 9$ & $6 \mathrm{BL}$ & NILs & {$[81]$} \\
\hline & $\operatorname{Lr} 10$ & $1 \mathrm{AS}$ & F2 & {$[82]$} \\
\hline & Lr19 & $7 \mathrm{D}$ & F2 & {$[83]$} \\
\hline & $\operatorname{Lr} 20$ & 7AL & F2 & {$[84]$} \\
\hline & $L r 21$ & 1DS & F2 & {$[85]$} \\
\hline & $L r 22 a$ & 2DS & F2 & {$[86]$} \\
\hline & $\operatorname{Lr} 24$ & $3 \mathrm{DL}$ & $\mathrm{F} 2$ & [87] \\
\hline & $\operatorname{Lr34}$ & $7 \mathrm{D}$ & RILs & {$[88]$} \\
\hline & $\operatorname{Lr} 35$ & $2 \mathrm{~B}$ & F2 & [89] \\
\hline & Lr37 & $2 \mathrm{AS}$ & NILs & {$[78]$} \\
\hline & $\operatorname{Lr} 40$ & 1DS & F2 & {$[85]$} \\
\hline & Lr47 & $7 \mathrm{~A}$ & BC1F2 & {$[90]$} \\
\hline & $\operatorname{Lr} 52$ & $5 \mathrm{~B}$ & F2 & {$[91]$} \\
\hline & $\operatorname{LrTr}$ & 4BS & F2 & [92] \\
\hline \multirow[t]{4}{*}{ Fusarium head blight resistance } & Fhb2 & $6 \mathrm{BS}$ & RILs & [93] \\
\hline & QTL & $1 \mathrm{~B}, 3 \mathrm{~B}, 5 \mathrm{~A}$ & RILs & [94] \\
\hline & QTL & $2 \mathrm{~B}$ & RILs & [95] \\
\hline & QTL & $4 A, 5 B, 6 D$ & RILs & [96] \\
\hline
\end{tabular}

Table 2.

Studies for various traits conducted in wheat regarding using QTL and gene tagging.

\section{Comparative genomics with Arabidopsis}

The genome-wide analyses in wheat (Triticum aestivum) and Arabidopsis thaliana have been performed for their comparative genomics studies. For this purpose, the ESTs as well as BLAST have been compared to evaluate the identity and similarity 
index within certain genes of their genome sequences taken from Arabidopsis and endosperm clones of wheat (Accession Numbers: BQ605537-609969, GenBank). As the wheat genome is approximately 126 folds greater than that of the Arabidopsis $[97,98]$. The error rate regarding unresolved nucleotides was recorded to be less than $2 \%$ during comparison of almost every 500 base pairs. The data of Arabidopsis were recruited from the TIGR databases of nucleotide and protein, and ESTs were clustered by PHRAP program. ESTs of wheat (4433) were clustered by self-BLAST as well into the contigs. The result of multiple sequence alignment represented relatively lower percentage of the sequences with low complexity of ESTs constituents; hence, higher score of alignments was produced on average. The number of clustered ESTs (Contigs) reported were 789, while that of unclustered ESTs was 1348 . Therefore, the number of unique sequences obtained was 2137 , which were proceeded for further genomic analyses and comparison with genome of Arabidopsis that revealed the grouping of these wheat ESTs with 1130 unique genes of Arabidopsis dispersed randomly within its genome upon different chromosomes which resembles in approximately $75 \%$ in their functions to wheat ESTs $[99,100]$.

\section{Comparative genomics with other grasses}

The most common members belonging to Poaceae, the grass family, include Avena sativa, Hordeum vulgare, Oryza sativa, and Zea mays. The wheat genome is 1.5 folds larger than Oat, 3 folds than Barley, 6.8 folds than maize, and 39 folds than rice. Triticeae is a tribe of this particular family consisting of over 15 genus as well as 300 species including barley and wheat. Number and size of the genes present within members of grass family are most likely to be same [101, 102]. Apart from genome size, the genes present within all these species are closely related to each other, and hence it clarifies the fact that rice, maize, and wheat have diverged over 50 million years ago and belong to a common ancestor [103]. The conservation of gene order is evident among these organisms, while the evolution is responsible for extent. The percentage of conserved markers among wheat, barley, and oat is $94 \%$, while that of maize and rice is $62 \%$. The greater resemblances have been observed among the members of Triticeae than that of the Poaceae family, while performing their comparative genomics studies [104-107]. The gene containing proportion among all the species of Poaceae seems to be similar, while the estimations upon presence of this particular's fraction within their genomes have been made, i.e., wheat $(7 \%)$, barley $(12 \%)$, maize $(17 \%)$, and rice $(24 \%)[5,108,109]$.

\section{Transgenics for wheat improvement}

Transgenics refer to genetically engineered (GE) or genetically modified (GM) organisms carrying some exogenous segment of DNA that is responsible for encoding some protein. The function, expression, and interaction of particular protein in metabolism of plant system other than its native one under variable conditions can be evaluated at molecular level, in vitro, as well as in vivo by using transgenic approaches [132]. According to ISAAA [22], only one GM wheat event got wheat approved for commercialization, and that for herbicide tolerance. CP4 Epsps gene was taken from a bacterial source which created resistance against glyphosate herbicide. The inserted genes might perform differently and affect some other trait negatively. In such cases, multiple factors are involved and all of them are of crucial significance, which have to be taken care of simultaneously in order to discover the exact cause of encountering issue [133]. 


\section{Transgenics for improvement of agronomic characters}

Attempts to transform wheat were started in mid-1980s, and first successful wheat transformation was reported in 1991 by Vasil and colleagues using biolistic transformation. Wheat protoplasts were transformed with chloramphenicol acetyltransferase (CAT) gene from a bacterium in order to get the gene expression by application of electroporation transformation technique [134]. PEG-mediated genetic transformation of T. monococcum protoplasts was performed for introducing Tn5-aminoglycoside phosphotransferase type II (NPTII) gene into wheat genome as a selectable marker [135]. Wheat, at its early boot stage with a few spikes, was transformed in planta by Agrobacterium-mediated floral-dip transformation which involved the pollen tube pathway for the insertion of $h g h$ and NPTII transgenes as selectable markers. The inheritance pattern of this transformation was also evaluated into further two generations, i.e., T1 and T2 [136]. First transgene-free mutants of

\begin{tabular}{|c|c|c|c|c|c|}
\hline $\begin{array}{l}\text { Transformation } \\
\text { technique }\end{array}$ & Vector & Gene & Trait & $\begin{array}{l}\text { Transformation } \\
\text { efficiency }\end{array}$ & References \\
\hline $\begin{array}{l}\text { Agrobacterium- } \\
\text { mediated (Callus) }\end{array}$ & pROK2 & CptI & $\begin{array}{l}\text { Insect } \\
\text { resistance }\end{array}$ & N/A & [110] \\
\hline $\begin{array}{l}\text { Agrobacterium- } \\
\text { mediated (Seed) }\end{array}$ & pWUbi & TaMATE1B & $\begin{array}{c}\text { Heavy metals } \\
\text { tolerance }\end{array}$ & N/A & [111] \\
\hline \multirow{2}{*}{$\begin{array}{l}\text { Agrobacterium- } \\
\text { mediated (in } \\
\text { planta) }\end{array}$} & $\begin{array}{l}\text { pVecNeo } \\
\text { pWBvec8 }\end{array}$ & $\operatorname{Lr67}$ & $\begin{array}{l}\text { Disease } \\
\text { resistance }\end{array}$ & N/A & [112] \\
\hline & pBI121 & $\operatorname{Csp} A$ & $\begin{array}{l}\text { Drought } \\
\text { tolerance }\end{array}$ & N/A & [113] \\
\hline \multirow{10}{*}{$\begin{array}{l}\text { Agrobacterium- } \\
\text { mediated } \\
\text { (embryo) }\end{array}$} & pCMV35S & AtNTX1 & Salt tolerance & $5.7-7.5 \%$ & [114] \\
\hline & $\begin{array}{l}\text { pGH215 } \\
\text { pVS1 }\end{array}$ & $\begin{array}{l}\text { Gfp } \\
H p t\end{array}$ & $\begin{array}{c}\text { Visual } \\
\text { selection } \\
\text { Antibiotic } \\
\text { resistance }\end{array}$ & $2-10 \%$ & [115] \\
\hline & $\begin{array}{l}\text { pZP201 } \\
\text { pPTN290 }\end{array}$ & $\begin{array}{l}\text { Gus } \\
\text { Bar }\end{array}$ & $\begin{array}{l}\text { Visual } \\
\text { selection } \\
\text { Herbicide } \\
\text { tolerance }\end{array}$ & $2.7-37.7 \%$ & [116] \\
\hline & pB1101 & $\begin{array}{l}\text { Act1 } \\
\text { Bar }\end{array}$ & $\begin{array}{c}\text { Quality } \\
\text { improvement } \\
\text { Herbicide } \\
\text { tolerance }\end{array}$ & $1.28 \%$ & [117] \\
\hline & pGA482 & Gus & $\begin{array}{l}\text { Selectable } \\
\text { marker }\end{array}$ & $27 \%$ & [118] \\
\hline & pIG121Hm & Gus & $\begin{array}{l}\text { Selectable } \\
\text { marker }\end{array}$ & $52-56 \%$ & [119] \\
\hline & $\begin{array}{l}\text { pCAMBIA3301 } \\
\text { p35SSGUSINT }\end{array}$ & Bar & $\begin{array}{l}\text { Herbicide } \\
\text { selection }\end{array}$ & $0.84-1.16 \%$ & [120] \\
\hline & pWVec8 & Bar & $\begin{array}{l}\text { Herbicide } \\
\text { tolerance }\end{array}$ & $1.5-51 \%$ & [121] \\
\hline & $\begin{array}{l}\text { pCAMBIA } \\
\text { pGreen }\end{array}$ & $\begin{array}{c}\text { Bar } \\
\text { NptII }\end{array}$ & $\begin{array}{l}\text { Selectable } \\
\text { markers }\end{array}$ & $1.4-1.8 \%$ & [122] \\
\hline & $\begin{array}{l}\text { pLC41Hm } \\
\text { pLC41bar }\end{array}$ & $\begin{array}{l}\text { Bar } \\
\text { Hpt }\end{array}$ & $\begin{array}{l}\text { Herbicide } \\
\text { tolerance } \\
\text { Antibiotic } \\
\text { resistance }\end{array}$ & $40 \%$ & {$[30,31]$} \\
\hline
\end{tabular}




\begin{tabular}{|c|c|c|c|c|c|}
\hline $\begin{array}{l}\text { Transformation } \\
\text { technique }\end{array}$ & Vector & Gene & Trait & $\begin{array}{c}\text { Transformation } \\
\text { efficiency }\end{array}$ & References \\
\hline \multirow[t]{6}{*}{$\begin{array}{l}\text { Biolistics- } \\
\text { mediated }\end{array}$} & $\begin{array}{l}\text { pVst-HarChit } \\
\text { pVst-Harcho }\end{array}$ & HarChitHarCho & $\begin{array}{l}\text { Disease } \\
\text { resistance }\end{array}$ & $0.17-0.26 \%$ & {$[123]$} \\
\hline & pLNU-SG & $\begin{array}{c}\text { TaGSL3 } \\
\text { TaGSL8 } \\
\text { TaGSL10 }\end{array}$ & $\begin{array}{l}\text { Disease } \\
\text { resistance }\end{array}$ & Less than $1 \%$ & [124] \\
\hline & $\begin{array}{l}\text { pAHC20 } \\
\text { pAHC17 }\end{array}$ & $\begin{array}{c}\text { SSI-IV } \\
\text { GBSS }\end{array}$ & $\begin{array}{l}\text { Heat tolerance } \\
\text { Yield } \\
\text { improvement }\end{array}$ & N/A & {$[125]$} \\
\hline & pAHC25 & $H M V-G S 1 D x 5$ & $\begin{array}{c}\text { Quality } \\
\text { improvement }\end{array}$ & $0.4 \%$ & {$[126]$} \\
\hline & pUba & $s G f p$ & $\begin{array}{c}\text { Visual } \\
\text { selection }\end{array}$ & $0.8 \%$ & {$[127]$} \\
\hline & pHAC20 & $G f p$ & $\begin{array}{c}\text { Visual } \\
\text { selection }\end{array}$ & $5-10 \%$ & {$[125]$} \\
\hline $\begin{array}{l}\text { CRISPR/ } \\
\text { Cas-mediated }\end{array}$ & $\mathrm{P} 6 \mathrm{U}$ & Lr34 & $\begin{array}{c}\text { Disease } \\
\text { resistance }\end{array}$ & N/A & {$[128]$} \\
\hline $\begin{array}{l}\text { CRISPR/ } \\
\text { Cas-mediated }\end{array}$ & $\begin{array}{l}\text { pA9mRFP } \\
\text { pU6sg }\end{array}$ & GW2 & $\begin{array}{l}\text { Improved } \\
\text { grain quality }\end{array}$ & $20 \%$ & [129] \\
\hline $\begin{array}{l}\text { CRISPR/ } \\
\text { Cas-mediated }\end{array}$ & pB1121 & $\begin{array}{l}\text { Inox } \\
\text { Pds }\end{array}$ & $\begin{array}{c}\text { Quality } \\
\text { improvement }\end{array}$ & $8-12 \%$ & [130] \\
\hline PEG-mediated & pAHC25 & $\begin{array}{l}\text { Gus } \\
\text { Hpt }\end{array}$ & $\begin{array}{c}\text { Visual } \\
\text { selection } \\
\text { Antibiotic } \\
\text { resistance }\end{array}$ & $1-5 \%$ & [131] \\
\hline
\end{tabular}

Table 3.

Transformation events targeted for improving agronomic traits.

wheat were reported to be generated by application of CRISPR/Cas9 system by editing the genome at directed site, while the transgene-based transformation through CRISPR/Cas faces certain hurdles due to complexity in wheat genome $[137,138]$.

Several transgenic technologies have been developed so far for the sake of improvement of major agronomic characters (Table 3) leading to increased grain yield and quality in wheat. These traits include genes for biotic and abiotic stress tolerance, including herbicide tolerance, drought tolerance, salt tolerance, disease resistance, etc. By the genetic transformation of wheat genome, numerous low-molecular-weight glutenin subunits (LMW-GS) and high-molecular weight glutenin subunits (HMW-GS) could be added to wheat genome, which plays a vital role in improvement of wheat grain quality [139-141]. Wheat cv. Bobwhite was transformed with $1 \mathrm{Ax} 1 \mathrm{HMW}-\mathrm{GS}$ subunit through biolistics-mediated transformation of immature zygotic embryos. As a result of which, 71\% improvement in gluten contents was observed in transformed grains [142].

\section{Technologies for developing marker-free transgenic wheat}

Selectable markers, as a crucial component of transformation procedures, have played significant role in enhancing the transformation efficiency. Various hazards in these particular genes upon environment and health have been feared, which need to be addressed by developing marker-free transgenics. Different strategies, such as co-transformation, site-specific recombination, and transposon-mediated 
elimination, tend to be proved advantageous in the removal of selectable markers from plant systems [143-145]. Besides, customized marker-free vectors, known as pCLEAN vectors, for the transformation have been designed for delivering multiple transgenes specifically without adding any superfluous DNA sequences within plant genome [146]. The enhanced transformation efficiency has also been reported by the use of pCLEAN vectors for gene delivery [147]. Researchers have started to use the plant-derived genes for selection purpose as well while performing genetic transformation in wheat, i.e., AlSAP, drought and salinity-tolerant gene from Aeluropus littoralis; ALS, herbicide-tolerant gene from Oryza sativa; and AtMYB12, visible selection gene from Arabidopsis thaliana [148-150].

\section{Transgenic wheat and its commercial acceptability}

The level of acceptance of GM wheat is similar to that of other commercial transgenic crops, i.e., tomato, maize, rice, cotton, etc. European countries are reluctant to grow GMOs, while American and less developed countries are in favor. In countries like Pakistan, where wheat has been the traditional staple food, there is always a fear of famine on wheat crop failures. The governments in such countries are ready to adopt technologies ensuring yield sustainability of staple. Even due to the opposition of public, market, governments, farmers, and trade organizations to transgenic crops, the stakeholders cannot switch from them until any competitive alternative attracts the attention $[151,152]$. The goals in wheat transgenics include biotic and abiotic stress tolerance, nutritive quality of grain, and herbicide tolerance, as described in Table 3. The core purpose of transgenic wheat development is to overcome global issues by providing best possible as well as permanent solutions, such as enhanced crop yield, improved grain quality, drought tolerance, and insect and rust resistance. It is reported that insertion of a gene responsible for particular trait causes variable improvements ranging from 20 to $40 \%$ and even higher in some cases, but still not complete eradication of issues under study. This illustrates the significance and efficacy of this technology. It is estimated that world population will be doubled by 2050, and transgenic crops will cover up to $70 \%$ of the cultivation land $[153,154]$. Transgenic contamination in wild-type and organic wheat varieties is the most emerging issue that has been aroused for opposing transgenic wheat, but the acceptability of transgenic wheat does not seem to be a major issue in near future as the approved event of herbicide-tolerant wheat is being commercialized since 2004, and no other approaches have been reported so far that could deal with meeting up demand and production hurdles single handedly [22, 155].

Apart from global significance, wheat is last among all the major cereal crops that have been transformed depending upon various parameters, such as dependency of genotype upon exogenous DNA delivered by Agrobacterium and recalcitrance in tissue culturing $[156,157]$. The companies of agribusiness, like Bayer Crop Science, have announced the alliance of Commonwealth Scientific and Industrial Organization (CSIRO); Monsanto have indicated their interest in GM wheat and planned to commercialize it sooner, while Syngenta have formed the alliance with CIMMYT for working over wheat improvement regarding its stress tolerance and quality [158].

\section{Future prospects}

Wheat, as a staple food, is the most significant and demanding crop all over the world and the remarkable enhancement in its production needs to be done, which is only possible by the commercial application of transgenic wheat and smart use 
of genomics for bringing desirable gene combinations in commercial varieties, at least in developing countries. The companies of agribusiness have been working on it really hard to get transgenic wheat commercialized in spite of all the challenges being faced and working over sorting out the challenges by developing the markerfree transgenic approaches [159]. The advancements in current era of genomics and transgenics have played a crucial role in the maintenance of agriculture, health, and environment in the world, even though several hazards regarding them could be possible. A transgenic revolution similar to that of 1960s is now required in order to develop all the high yielding varieties for the sustainable production by implementing the most recent and efficient technologies for genetic manipulation.

\section{Author details}

Usman Babar ${ }^{1}$, Usama Arshad ${ }^{1}$, Muhammad Tehseen Azhar ${ }^{2}$, Rana Muhammad Atif ${ }^{2}$, Abdulaziz Abdullah Alsahli ${ }^{3}$, Ibrahim A. Alaraidh $^{3}$, Aysha Kiran ${ }^{4}$, Iqrar Ahmad Rana ${ }^{1 *}$ and Gyuhwa Chung ${ }^{5}$

1 Centre of Advanced Studies in Agriculture and Food Security/Center of Agricultural Biochemistry and Biotechnology, University of Agriculture, Faisalabad, Pakistan

2 Department of Plant Breeding and Genetics, University of Agriculture, Faisalabad, Pakistan

3 Department of Botany and Microbiology, King Saud University Science College, Riyadh, Saudi Arabia

4 Department of Botany, University of Agriculture, Faisalabad, Pakistan

5 Department of Biotechnology, Chonnam National University, Jeonnam, South Korea

*Address all correspondence to: iqrar_rana@uaf.edu.pk

\section{IntechOpen}

(C) 2019 The Author(s). Licensee IntechOpen. This chapter is distributed under the terms of the Creative Commons Attribution License (http://creativecommons.org/licenses/ by/3.0), which permits unrestricted use, distribution, and reproduction in any medium, provided the original work is properly cited. (cc) BY 


\section{References}

[1] Awika JM. Major cereal grains production and use around the world. In: Advances in Cereal Science: Implications to Food Processing and Health Promotion. American Chemical Society (ACS), ACS Symposium series. Vol. 1089. 2011. pp. 1-13. ISBN: 9780841226364

[2] Hays J. Green Revolution, GM Crops and Improving Agriculture in Developing World. 2012. http:// factsanddetails.com/world/cat57/ sub383/item2127.html

[3] CGIAR. Consultative Group of International Agricultural Research. Wheat in the World. 2018. Available from: www.wheat.org

[4] FAO. Food and Agriculture Organization. Wheat-The Largest Primary Commodity. 2014. Available fom: www.fao.org

[5] Sandhu D, Champoux JA, Bondareva SN, Gill KS. Identification and physical localization of useful genes and markers to a major gene-rich region on wheat group $1 \mathrm{~S}$ chromosomes. Genetics. 2001;157(4):1735-1747

[6] Bourke PM, Voorrips RE, Visser RG, Maliepaard C. Tools for genetic studies in experimental populations of polyploids. Frontiers in Plant Science. 2018;9:513

[7] Brenchley R, Spannagl M, Pfeifer M, Barker GL, D'Amore R, Allen AM, et al. Analysis of the bread wheat genome using whole-genome shotgun sequencing. Nature. 2012;491(7426):705

[8] IWGSC. A chromosome-based draft sequence of the hexaploid bread wheat (Triticum aestivum) genome. Science. 2014;345(6194):1251788
[9] Mehboob-ur-Rahman TS, Mahmoodur-Rahman MAI, Zafar Y. Bioinformatics: A way forward to explore "plant omics". In: Bioinformatics-Updated Features and Applications. Croatia: Intech; 2016. p. 203. ISBN: 978-953-51-2546-4. http:// dx.doi.org/10.5772/61421

[10] Ceasar SA, Rajan V, Prykhozhij SV, Berman JN, Ignacimuthu S. Insert, remove orreplace: A highly advanced genome editing system using CRISPR/ Cas9. Biochimica et Biophysica Acta (BBA)-Molecular Cell Research. 2016;1863(9):2333-2344

[11] FAOSTAT. Food and Agriculture Organization Statistics. 2016. Available fom: www.fao.org

[12] Statistica: The Statistics Portal. 2018. Available from: www.statistica. com

[13] Ito S. World Wheat Statistics and Graphics. 2018. Available from: www. worldfood.apionet.or.jp

[14] Folger T. The Next Green Revolution. 2014. Available fom: www. nationalgeographic.com/foodfeatures/ green-revolution/

[15] Smale M. The green revolution and wheat genetic diversity: Some unfounded assumptions. World Development. 1997;25(8):1257-1269

[16] Smith R. Eight Major Factors that have Changed Agriculture in the Last 50 Years. 2016. Available from: www.farmprogress.com/equipment/ eight-major-factors-have-changedagriculture-last-50-years

[17] FAOSTAT. Food and Agriculture Organization Statistics. 2018. Available from: www.fao.org 
[18] Guzman C, Peña RJ, Singh R, Autrique E, Dreisigacker S, Crossa J, et al. Wheat quality improvement at CIMMYT and the use of genomic selection on it. Applied \& Translational Genomics. 2016;11:3-8

[19] Araya A, Kisekka I, Girma A, Hadgu K, Tegebu F, Kassa A, et al. The challenges and opportunities for wheat production under future climate in Northern Ethiopia. The Journal of Agricultural Science. 2017;155(3):379-393

[20] Breseghello F, Coelho ASG. Traditional and modern plant breeding methods with examples in rice (Oryza sativa L.). Journal of Agricultural and Food Chemistry. 2013;61(35):8277-8286

[21] Vagndorf N, Kristensen PS, Andersen JR, Jahoor A, Orabi J. Markerassisted breeding in wheat. In: Next Generation Plant Breeding. London, UK: IntechOpen; 2018

[22] ISAAA. International Service for Acquisition of Agri-Biotech Applications. GM Approval Database. 2018

[23] Chatrath R, Mishra B, Ferrara GO, Singh S, Joshi A. Challenges to wheat production in South Asia. Euphytica. 2007;157(3):447-456

[24] Pretorius Z, Pakendorf K, Marais G, Prins R, Komen J. Challenges for sustainable cereal rust control in South Africa. Australian Journal of Agricultural Research. 2007;58(6):593-601

[25] Khan S, Ullah MW, Siddique R, Nabi G, Manan S, Yousaf M, et al. Role of recombinant DNA technology to improve life. International Journal of Genomics. 2016;2016:2405954

[26] Belderok B, Mesdag J, Donner DA, Mesdag H. Bread-making Quality of Wheat: A Century of Breeding in Europe. Netherlands: Springer Science \& Business Media; 2000

[27] Hancock JF. Plant Evolution and the Origin of Crop Species. USA: CABI; 2012

[28] Jauhar PP, Xu SS, Baenziger PS. Haploidy in cultivated wheats: Induction and utility in basic and applied research. Crop Science. 2009;49(3):737-755

[29] Devos K, Costa de Oliveira A, Xu X, Estill J, Estep M, Jogi A, et al. Structure and organization of the wheat genome-the number of genes in the hexaploid wheat genome. In: Paper presented At the 11th International Wheat Genetics Symposium; Brisbane, Australia. 2008

[30] Ishida Y, Hiei Y, Komari T. High efficiency wheat transformation mediated by Agrobacterium tumefaciens. In: Advances in Wheat Genetics: From Genome to Field. Tokyo: Springer; 2015. pp. 167-173

[31] Ishida $Y$, Tsunashima M, Hiei Y, Komari T. Wheat (Triticum aestivum L.) transformation using immature embryos. In: Agrobacterium Protocols. New York: Springer; 2015. pp. 189-198

[32] Myburg A, Cawood M, Wingfield B, Botha A-M. Development of RAPD and SCAR markers linked to the Russian wheat aphid resistance gene Dn2 in wheat. Theoretical and Applied Genetics. 1998;96(8):1162-1169

[33] Ellis JG, Lagudah ES, Spielmeyer W, Dodds PN. The past, present and future of breeding rust resistant wheat. Frontiers in Plant Science. 2014;5:641

[34] Nsabiyera V, Qureshi N, Bariana HS, Wong D, Forrest KL, Hayden MJ, et al. Molecular markers for adult plant leaf 
rust resistance gene Lr48 in wheat. Molecular Breeding. 2016;36(6):65

[35] Xu X, Yuan D, Li D, Gao Y, Wang Z, Liu Y, et al. Identification of stem rust resistance genes in wheat cultivars in China using molecular markers. PeerJ. 2018;6:e4882

[36] Kumar S, Sehgal SK, Kumar U, Prasad PV, Joshi AK, Gill BS. Genomic characterization of drought tolerancerelated traits in spring wheat.

Euphytica. 2012;186(1):265-276

[37] Alaux M, Rogers J, Letellier T, Flores R, Alfama F, Pommier C, et al. Linking the International Wheat Genome Sequencing Consortium bread wheat reference genome sequence to wheat genetic and phenomic data. Genome Biology. 2018;19(1):111

[38] Nelson WM, Bharti AK, Butler E, Wei F, Fuks G, Kim H, et al. Whole-genome validation of highinformation-content fingerprinting. Plant Physiology. 2005;139(1):27-38

[39] Philippe R, Choulet F, Paux E, Van Oeveren J, Tang J, Wittenberg AH, et al. Whole genome profiling provides a robust framework for physical mapping and sequencing in the highly complex and repetitive wheat genome. BMC Genomics. 2012;13(1):47

[40] Gupta P, Mir R, Mohan A, Kumar J. Wheat genomics: Present status and future prospects. International Journal of Plant Genomics. 2008;2008:36. Article ID: 896451. http://dx.doi. org/10.1155/2008/896451, https:// www.hindawi.com/journals/ ijpg/2008/896451/

[41] Jae-Han S, Kim K-H, Shin S, Choi I, Kim H-S, Cheong Y-K, et al. Development of SCAR markers for Korean wheat cultivars identification. Plant Breeding and Biotechnology. 2014;2(3):224-230

[42] Li C, Bai G, Chao S, Wang Z. A high-density SNP and SSR consensus map reveals segregation distortion regions in wheat. BioMed Research International. 2015;2015:10. Article ID 830618. http://dx.doi. org/10.1155/2015/830618, https:// www.hindawi.com/journals/ bmri/2015/830618/

[43] Rimbert H, Darrier B, Navarro J, Kitt J, Choulet F, Leveugle M, et al. High throughput SNP discovery and genotyping in hexaploid wheat. PLoS One. 2018;13(1):e0186329

[44] Zhang X, Zhou M, Ren L, Bai G, Ma H, Scholten OE, et al. Molecular characterization of Fusarium head blight resistance from wheat variety Wangshuibai. Euphytica. 2004;139(1):59-64

[45] Zhang H, Nasuda S, Endo TR. Identification of AFLP markers on the satellite region of chromosome 1BS in wheat. Genome. 2000;43(5):729-735

[46] Sandhu D, Sidhu D, Gill KS. Identification of expressed sequence markers for a major gene-rich region of wheat chromosome group 1 using RNA fingerprinting-differential display. Crop Science. 2002;42(4):1285-1290

[47] Schnurbusch T, Paillard S, Schori A, Messmer M, Schachermayr G, Winzeler $\mathrm{M}$, et al. Dissection of quantitative and durable leaf rust resistance in Swiss winter wheat reveals a major resistance QTL in the Lr34 chromosomal region. Theoretical and Applied Genetics. 2004;108(3):477-484

[48] Leonova I, Laikova L, Popova O, Unger O, Börner A, Röder M. Detection of quantitative trait loci for leaf rust resistance in wheat-T. timopheevii/T. tauschii introgression lines. Euphytica. 2007;155(1-2):79-86

[49] Faris JD, Haen KM, Gill BS. Saturation mapping of a gene-rich recombination hot spot region in wheat. Genetics. 2000;154(2):823-835 
[50] Weng Y, Lazar M. Comparison of homoeologous group- 6 short arm physical maps of wheat and barley reveals a similar distribution of recombinogenic and generich regions. Theoretical and Applied Genetics. 2002;104(6-7):1078-1085

[51] Qi L, Cao M, Chen P, Li W, Liu D. Identification, mapping, and application of polymorphic DNA associated with resistance gene Pm21 of wheat. Genome. 1996;39(1):191-197

[52] Joshi CP, Nguyen HT. RAPD (random amplified polymorphic DNA) analysis based intervarietal genetic relationships among hexaploid wheats. Plant Science. 1993;93(1-2):95-103

[53] Cherukuri DP, Gupta SK, Charpe A, Koul S, Prabhu KV, Singh RB, et al. Molecular mapping of Aegilops speltoides derived leaf rust resistance gene Lr28 in wheat. Euphytica. 2005;143(1-2):19-26

[54] Torada A, Koike M, Mochida K, Ogihara Y. SSR-based linkage map with new markers using an intraspecific population of common wheat. Theoretical and Applied Genetics. 2006;112(6):1042-1051

[55] Huang X, Cloutier S, Lycar L, Radovanovic N, Humphreys D, Noll J, et al. Molecular detection of QTLs for agronomic and quality traits in a doubled haploid population derived from two Canadian wheats (Triticum aestivum L.). Theoretical and Applied Genetics. 2006;113(4):753-766

[56] Schmolke M, Zimmermann G, Buerstmayr H, Schweizer G, Miedaner T, Korzun V, et al. Molecular mapping of Fusarium head blight resistance in the winter wheat population Dream/ Lynx. Theoretical and Applied Genetics. 2005;111(4):747-756

[57] Muthamilarasan M, Prasad M. An overview of wheat genome sequencing and its implications for crop improvement. Journal of Genetics. 2014;93(3):619-622
[58] Shi X, Ling H-Q. Current advances in genome sequencing of common wheat and its ancestral species. The Crop Journal. 2018;6(1):15-21

[59] Berkman PJ, Lai K, Lorenc MT, Edwards D. Next-generation sequencing applications for wheat crop improvement. American Journal of Botany. 2012;99(2):365-371

[60] Jia J, Zhao S, Kong X, Li Y, Zhao G, He W, et al. Aegilops tauschii draft genome sequence reveals a gene repertoire for wheat adaptation. Nature. 2013;496(7443):91

[61] Ling H-Q, Zhao S, Liu D, Wang J, Sun H, Zhang C, et al. Draft genome of the wheat A-genome progenitor Triticum urartu. Nature. 2013;496(7443):87

[62] Choulet F, Alberti A, Theil S, Glover N, Barbe V, Daron J, et al. Structural and functional partitioning of bread wheat chromosome 3B. Science. 2014;345(6194):1249721

[63] Cavanagh CR, Chao S, Wang S, Huang BE, Stephen S, Kiani S, et al. Genome-wide comparative diversity uncovers multiple targets of selection for improvement in hexaploid wheat landraces and cultivars. Proceedings of the National Academy of Sciences. 2013;110(20):8057-8062

[64] Saintenac C, Zhang D, Wang S, Akhunov E. Sequence-based mapping of the polyploid wheat genome. G3: Genes, Genomes, Genetics, g3. 2013;005819:113

[65] Kulwal P, Singh R, Balyan H, Gupta P. Genetic basis of pre-harvest sprouting tolerance using single-locus and two-locus QTL analyses in bread wheat. Functional \& Integrative Genomics. 2004;4(2):94-101

[66] Kumar N, Kulwal P, Balyan H, Gupta P. QTL mapping for yield and 
yield contributing traits in two mapping populations of bread wheat. Molecular Breeding. 2007;19(2):163-177

[67] Raman H, Raman R, Wood R, Martin P. Repetitive indel markers within the ALMT1 gene conditioning aluminium tolerance in wheat (Triticum aestivum L.). Molecular Breeding. 2006;18(2):171-183

[68] Jefferies S, Pallotta M, Paull J, Karakousis A, Kretschmer J, Manning S, et al. Mapping and validation of chromosome regions conferring boron toxicity tolerance in wheat (Triticum aestivum). Theoretical and Applied Genetics. 2000;101(5-6):767-777

[69] Huseynova IM, Rustamova SM, Mammadov AC. Identification of Dreb 1 genes involved in drought tolerance in wheat (Triticum L.). Photosynthesis Research for Food, Fuel and the Future. Springer; 2013. pp. 552-555

[70] Tóth B, Galiba G, Fehér E, Sutka J, Snape JW. Mapping genes affecting flowering time and frost resistance on chromosome $5 \mathrm{~B}$ of wheat. Theoretical and Applied Genetics. 2003;107(3):509-514

[71] Mohler V, Lukman R, Ortiz-Islas S, William M, Worland AJ, Van Beem $\mathrm{J}$, et al. Genetic and physical mapping of photoperiod insensitive gene PpdB1 in common wheat. Euphytica. 2004;138(1):33-40

[72] Ma L, Zhou E, Huo N, Zhou R, Wang $\mathrm{G}$, Jia J. Genetic analysis of salt tolerance in a recombinant inbred population of wheat (Triticum aestivum L.). Euphytica. 2007;153(1-2):109-117

[73] Liu X, Smith C, Gill B, Tolmay V. Microsatellite markers linked to six Russian wheat aphid resistance genes in wheat. Theoretical and Applied Genetics. 2001;102(4):504-510

[74] Liu X, Smith C, Gill B. Identification of microsatellite markers linked to
Russian wheat aphid resistance genes

Dn4 and Dn6. Theoretical and Applied Genetics. 2002;104(6-7):1042-1048

[75] Lapitan NL, Peng J, Sharma V. A high-density map and PCR markers for Russian wheat aphid resistance gene Dn7 on chromosome 1RS/1BL. Crop

Science. 2007;47(2):811-818

[76] Spielmeyer W, Sharp P, Lagudah E. Identification and validation of markers linked to broad-spectrum stem rust resistance gene $\mathrm{Sr} 2$ in wheat (Triticum aestivum L.). Crop Science. 2003;43(1):333-336

[77] Paull J, Pallotta M, Langridge P. RFLP markers associated with Sr22 and recombination between chromosome 7A of bread wheat and the diploid species Triticum boeoticum. Theoretical and Applied Genetics. 1994;89(7-8):1039-1045

[78] Seah S, Bariana H, Jahier J, Sivasithamparam K, Lagudah E. The introgressed segment carrying rust resistance genes Yr17, Lr37 and Sr38 in wheat can be assayed by a cloned disease resistance gene-like sequence. Theoretical and Applied Genetics. 2001;102(4):600-605

[79] Feuillet C, Messmer M, Schachermayr G, Keller B. Genetic and physical characterization of the LR1 leaf rust resistance locus in wheat (Triticum aestivum L.). Molecular and General Genetics MGG. 1995;248(5):553-562

[80] Sacco F, Suarez E, Naranjo T. Mapping of the leaf rust resistance gene $\mathrm{Lr} 3$ on chromosome $6 \mathrm{~B}$ of Sinvalocho MA wheat. Genome. 1998;41(5):686-690

[81] Schachermayr G, Siedler H, Gale M, Winzeler H, Winzeler M, Keller B. Identification and localization of molecular markers linked to the Lr9 leaf rust resistance gene of wheat. Theoretical and Applied Genetics. 1994;88(1):110-115 
[82] Schachermayr G, Feuillet C, Keller B. Molecular markers for the detection of the wheat leaf rust resistance gene Lr10 in diverse genetic backgrounds. Molecular Breeding. 1997;3(1):65-74

[83] Cherukuri D, Gupta S, Charpe A, Koul S, Prabhu K, Singh R, et al. Identification of a molecular marker linked to an Agropyron elongatumderived gene Lr19 for leaf rust resistance in wheat. Plant Breeding. 2003;122(3):204-208

[84] Neu C, Stein N, Keller B. Genetic mapping of the Lr20 Pm1 resistance locus reveals suppressed recombination on chromosome arm 7AL in hexaploid wheat. Genome. 2002;45(4):737-744

[85] Huang L, Brooks SA, Li W, Fellers JP, Trick HN, Gill BS. Mapbased cloning of leaf rust resistance gene Lr21 from the large and polyploid genome of bread wheat. Genetics. 2003;164(2):655-664

[86] Hiebert CW, Thomas JB, Somers DJ, McCallum BD, Fox SL. Microsatellite mapping of adult-plant leaf rust resistance gene Lr22a in wheat. Theoretical and Applied Genetics. 2007;115(6):877-884

[87] Gupta SK, Charpe A, Prabhu KV, Haque QMR. Identification and validation of molecular markers linked to the leaf rust resistance gene Lr19 in wheat. Theoretical and Applied Genetics. 2006;113(6):1027-1036

[88] Spielmeyer W, McIntosh R, Kolmer J, Lagudah E. Powdery mildew resistance and Lr34/Yr18 genes for durable resistance to leaf and stripe rust cosegregate at a locus on the short arm of chromosome 7D of wheat. Theoretical and Applied Genetics. 2005;111(4):731-735

[89] Seyfarth R, Feuillet C, Schachermayr G, Winzeler M, Keller B. Development of a molecular marker for the adult plant leaf rust resistance gene Lr35 in wheat. Theoretical and Applied Genetics. 1999;99(3-4):554-560

[90] Helguera M, Khan I, Dubcovsky J. Development of PCR markers for the wheat leaf rust resistance gene Lr47. Theoretical and Applied Genetics. 2000;100(7):1137-1143

[91] Hiebert C, Thomas J, McCallum B. Locating the broad-spectrum wheat leaf rust resistance gene $\operatorname{Lr} 52$ (LrW) to chromosome $5 \mathrm{~B}$ by a new cytogenetic method. Theoretical and Applied Genetics. 2005;110(8):1453-1457

[92] Aghaee-Sarbarzeh M, Singh H, Dhaliwal H. A microsatellite marker linked to leaf rust resistance transferred from Aegilops triuncialis into hexaploid wheat. Plant Breeding. 2001;120(3):259-261

[93] Cuthbert PA, Somers DJ, Brulé-Babel A. Mapping of Fhb2 on chromosome 6BS: A gene controlling Fusarium head blight field resistance in bread wheat (Triticum aestivum L.). Theoretical and Applied Genetics. 2007;114(3):429-437

[94] Buerstmayr H, Lemmens M, Hartl L, Doldi L, Steiner B, Stierschneider M, et al. Molecular mapping of QTLs for Fusarium head blight resistance in spring wheat. I. Resistance to fungal spread (Type II resistance). Theoretical and Applied Genetics. 2002;104(1):84-91

[95] Gilsinger J, Kong L, Shen X, $\mathrm{Ohm} \mathrm{H}$. DNA markers associated with low Fusarium head blight incidence and narrow flower opening in wheat. Theoretical and Applied Genetics. 2005;110(7):1218-1225

[96] Paillard S, Schnurbusch T, Tiwari R, Messmer M, Winzeler M, Keller B, et al. QTL analysis of resistance to Fusarium head blight in Swiss winter wheat 
(Triticum aestivum $\mathrm{L}$.). Theoretical and Applied Genetics. 2004;109(2):323-332

[97] Clarke B, Hobbs M, Skylas D, Appels R. Genes active in developing wheat endosperm. Functional \& Integrative Genomics. 2000;1(1):44-55

[98] Gill BS, Appels R, Botha-Oberholster A-M, Buell CR, Bennetzen JL, Chalhoub $\mathrm{B}$, et al. A workshop report on wheat genome sequencing: International Genome Research on Wheat Consortium. Genetics. 2004;168(2):1087-1096

[99] Benson DA, Karsch-Mizrachi I, Lipman DJ, Ostell J, Rapp BA, Wheeler DL. GenBank. Nucleic Acids Research. 2000;28(1):15-18

[100] Clarke B, Lambrecht M, Rhee SY. Arabidopsis genomic information for interpreting wheat EST sequences. Functional \& Integrative Genomics. 2003;3(1-2):33-38

[101] Barakat A, Matassi G, Bernardi G. Distribution of genes in the genome of Arabidopsis thaliana and its implications for the genome organization of plants. Proceedings of the National Academy of Sciences. 1998;95(17):10044-10049

[102] Sandhu D, Gill KS. Genecontaining regions of wheat and the other grass genomes. Plant Physiology. 2002;128(3):803-811

[103] Kellogg EA. Relationships of cereal crops and other grasses. Proceedings of the National Academy of Sciences. 1998;95(5):2005-2010

[104] Ahn S, Tanksley S. Comparative linkage maps of the rice and maize genomes. Proceedings of the National Academy of Sciences. 1993;90(17):7980-7984

[105] Künzel G, Korzun L, Meister A. Cytologically integrated physical restriction fragment length polymorphism maps for the barley genome based on translocation breakpoints. Genetics. 2000;154(1):397-412

[106] Moore G, Devos K, Wang Z, Gale $M$. Cereal genome evolution: Grasses, line up and form a circle. Current Biology. 1995;5(7):737-739

[107] Van Deynze AE, Nelson JC, Yglesias ES, Harrington SE, Braga DP, McCouch SR, et al. Comparative mapping in grasses. Wheat relationships. Molecular and General Genetics MGG. 1995;248(6):744-754

[108] Barakat A, Carels N, Bernardi G. The distribution of genes in the genomes of Gramineae. Proceedings of the National Academy of Sciences. 1997;94(13):6857-6861

[109] Carels N, Barakat A, Bernardi G. The gene distribution of the maize genome. Proceedings of the National Academy of Sciences. 1995;92(24):11057-11060

[110] Bi RM, Jia HY, Feng DS, Wang HG. Transgenic wheat (Triticum aestivum L.) with increased resistance to the storage pest obtained by Agrobacterium tumefaciens--mediated. Sheng wu gong cheng xue bao $=$. Chinese Journal of Biotechnology. 2006;22(3):431-437

[111] Tovkach A, Ryan PR, Richardson AE, Lewis DC, Rathjen TM, Ramesh S, et al. Transposon-mediated alteration of TaMATE1B expression in wheat confers constitutive citrate efflux from root apices. Plant Physiology. 2013;161(2):880-892

[112] Moore JW, Herrera-Foessel S, Lan C, Schnippenkoetter W, Ayliffe M, Huerta-Espino J, et al. A recently evolved hexose transporter variant confers resistance to multiple pathogens in wheat. Nature Genetics. 2015;47(12):1494

[113] Yu TF, Xu ZS, Guo JK, Wang YX, Abernathy B, Fu JD, et al. Improved drought tolerance in wheat plants 
overexpressing a synthetic bacterial cold shock protein gene $S e C s p A$. Scientific Reports. 2017;7:44050

[114] Moghaieb RE, Sharaf AN, Soliman $\mathrm{MH}$, El-Arabi NI, Momtaz OA. An efficient and reproducible protocol for the production of salt tolerant transgenic wheat plants expressing the Arabidopsis AtNHX1 gene. GM Crops \& Food. 2014;5(2):132-138

[115] Hensel G, Marthe C, Kumlehn J. Agrobacterium-mediated transformation of wheat using immature embryos. In: Wheat Biotechnology. New York, NY: Humana Press; 2017. pp. 129-139

[116] Wang K, Liu H, Du L, Ye X. Generation of marker-free transgenic hexaploid wheat via an Agrobacteriummediated co-transformation strategy in commercial Chinese wheat varieties. Plant Biotechnology Journal. 2017;15(5):614-623

[117] Pérez-Piñeiro P, Gago J, Landín M, Gallego PP. Agrobacterium-mediated transformation of wheat: General overview and new approaches to model and identify the key factors involved. In: Transgenic Plants-Advances and Limitations. Rijeka, Croatia: Intech Open Access Publisher; 2012. p. 326

[118] Abid N, Maqbool A, Malik KA. Screening commercial wheat (Triticum aestivum L.) varieties for Agrobacterium mediated transformation ability. Pakistan Journal of Agricultural Sciences. 2014;51(1):51

[119] Rashid HAMID, Khan MH, Chaudhry Z, Bano RAISA, Raja NI. An improved Agrobacterium mediated transformation system in wheat. Pakistan Journal of Botany. 2012;44(1):297-300

[120] Chugh A, Vikrant S, Mahalakshmi A, Khurana P. A novel approach for Agrobacterium-mediated germ line transformation of Indian bread wheat (Triticum aestivum) and pasta wheat (Triticum durum). Journal of Phytology. 2012;4(2):22-29

[121] Richardson T, Thistleton J, Higgins TJ, Howitt C, Ayliffe M. Efficient Agrobacterium transformation of elite wheat germplasm without selection. Plant Cell, Tissue and Organ Culture (PCTOC). 2014;119(3):647-659

[122] Bińka A, Orczyk W, NadolskaOrczyk A. The Agrobacteriummediated transformation of common wheat (Triticum aestivum L.) and triticale (x Triticosecale Wittmack): Role of the binary vector system and selection cassettes. Journal of Applied Genetics. 2012;53(1):1-8

[123] Rana IA, Loerz H, Schaefer W, Becker D. Over expression of chitinase and chitosanase genes from Trichoderma harzianum under constitutive and inducible promoters in order to increase disease resistance in wheat (Triticum aestivum $\mathrm{L}$ ). Molecular Plant Breeding. 2012;3(1):37-49

[124] Rana IA, Salomon S, Schäfer W, Becker D. Downregulation of Glucan Synthase-Like (TaGSL) genes in wheat leads to inhibition of transgenic plant regeneration. In Vitro Cellular \& Developmental Biology-Plant. 2014;50(6):696-706

[125] Tian B, Talukder SK, Fu J, Fritz AK, Trick HN. Expression of a rice soluble starch synthase gene in transgenic wheat improves the grain yield under heat stress conditions. In Vitro Cellular \& Developmental Biology-Plant. 2018;54(3):216-227

[126] Qin JB, Wang Y, Zhu CQ. Biolistic transformation of wheat using the HMW-GS 1Dx5 gene without selectable markers. Genetics and Molecular Research. 2014;13(2):4361-4371

[127] Hamada H, Linghu Q, Nagira Y, Miki R, Taoka N, Imai R. An in planta 
biolistic method for stable wheat transformation. Scientific Reports. 2017;7(1):11443

[128] Sucher J, Boni R, Yang P, Rogowsky P, Büchner H, Kastner C, et al. The durable wheat disease resistance gene Lr34 confers common rust and northern corn leaf blight resistance in maize. Plant Biotechnology Journal. 2017;15(4):489-496

[129] Wang W, Pan Q, He F, Akhunova A, Chao S, Trick $\mathrm{H}$, et al. Transgenerational CRISPR-Cas9 activity facilitates multiplex gene editing in allopolyploid wheat. The CRISPR Journal. 2018;1(1):65-74

[130] Upadhyay SK, Kumar J, Alok A, Tuli R. RNA-guided genome editing for target gene mutations in wheat. G3: Genes, Genomes, Genetics. 2013;3(12):2233-2238

[131] Ismagul A, Yang N, Maltseva E, Iskakova G, Mazonka I, Skiba Y, et al. A biolistic method for high-throughput production of transgenic wheat plants with single gene insertions. BMC Plant Biology. 2018;18(1):135

[132] Viana ML, Sant'ana LP. Biotechnology: The role of science and technology upon society. Unisanta Science and Technology. 2017;5(2):63-65

[133] Alberts B, Johnson A, Lewis J, Walter P, Raff M, Roberts K. Molecular Biology of the Cell. 2002 4th ed: International Student Edition: Routledge

[134] Ou-Lee T-M, Turgeon R, Wu R. Expression of a foreign gene linked to either a plant-virus or a Drosophila promoter, after electroporation of protoplasts of rice, wheat, and sorghum. Proceedings of the National Academy of Sciences. 1986;83(18):6815-6819

[135] Lörz H, Baker B, Schell J. Gene transfer to cereal cells mediated by protoplast transformation. Molecular and General Genetics MGG. 1985;199(2):178-182

[136] Zale JM, Agarwal S, Loar S, Steber C. Evidence for stable transformation of wheat by floral dip in Agrobacterium tumefaciens. Plant Cell Reports. 2009;28(6):903-913

[137] Shan Q, Wang Y, Li J, Zhang Y, Chen K, Liang Z, et al. Targeted genome modification of crop plants using a CRISPR-Cas system. Nature Biotechnology. 2013;31(8):686

[138] Zhang Y, Liang Z, Zong Y, Wang Y, Liu J, Chen K, et al. Efficient and transgene-free genome editing in wheat through transient expression of CRISPR/Cas9 DNA or RNA. Nature Communications. 2016;7:12617

[139] Bregitzer P, Blechl AE, Fiedler D, Lin J, Sebesta P, De Soto JF, et al. Changes in high molecular weight glutenin subunit composition can be genetically engineered without affecting wheat agronomic performance. Crop Science. 2006;46(4):1553-1563

[140] Shewry P, Tatham A. Disulphide bonds in wheat gluten proteins. Journal of Cereal Science. 1997;25(3):207-227

[141] Tosi P, Masci S, Giovangrossi A, D’Ovidio R, Bekes F, Larroque O, et al. Modification of the low molecular weight (LMW) glutenin composition of transgenic durum wheat: Effects on glutenin polymer size and gluten functionality. Molecular Breeding. 2005;16(2):113-126

[142] Altpeter F, Vasil V, Srivastava V, Vasil IK. Integration and expression of the high-molecular-weight glutenin subunit $1 \mathrm{Ax} 1$ gene into wheat. Nature Biotechnology. 1996;14(9):1155

[143] Permingeat HR, Alvarez ML, Cervigni GD, Ravizzini RA, Vallejos RH. Stable wheat transformation 
obtained without selectable markers. Plant Molecular Biology. 2003;52(2):415-419

[144] Puchta H. Marker-free transgenic plants. Plant Cell, Tissue and Organ Culture. 2003;74(2):123-134

[145] Srivastava V, Ow DW. Markerfree site-specific gene integration in plants. Trends in Biotechnology. 2004;22(12):627-629

[146] Hellens R, Mullineaux P, Klee $\mathrm{H}$. Technical focus: A guide to Agrobacterium binary $\mathrm{Ti}$ vectors. Trends in Plant Science. 2000;5(10):446-451

[147] Thole V, Worland B, Snape JW, Vain P. The pCLEAN dual binary vector system for Agrobacterium-mediated plant transformation. Plant Physiology. 2007;145(4):1211-1219

[148] Ben-Saad R, Ben-Ramdhan W, Zouari N, Azaza J, Mieulet D, Guiderdoni E, et al. Marker-free transgenic durum wheat $\mathrm{cv}$. Karim expressing the AlSAP gene exhibits a high level of tolerance to salinity and dehydration stresses. Molecular Breeding. 2012;30(1):521-533

[149] Gao X, Zhang L, Zhou S, Wang C, Deng X, Zhang H, et al. AtMYB12 gene: A novel visible marker for wheat transformation. Molecular Biology Reports. 2011;38(1):183-190

[150] Ogawa T, Kawahigashi H, Toki S, Handa $\mathrm{H}$. Efficient transformation of wheat by using a mutated rice acetolactate synthase gene as a selectable marker. Plant Cell Reports. 2008;27(8):1325-1331

[151] Fox JL. Whatever Happened to GM Wheat?. Nature Biotechnology. Nature Publishing Group; 2009(11):974-976. DOI: $10.1038 / \mathrm{nbt1109-974}$

[152] Wilson WW, Roald H, Lund J. Excellence in Teaching Award. North
Dakota State University. 2015:2011. www. ag.ndsu.edu/agecon/people/bios/wilson

[153] McGarth M. New super yield GM wheat trials get go ahead. Science and Environment. 2017. Available from: https://www.bbc.com/news/ science-environment-38814837

[154] Sramkova ZU, Gregova ED, Sturdík ER. Genetic improvement of wheat-A review. Nova Biotech. 2009;9:27-51

[155] Birzer T, Badgery W. Organic wheat farming in Australia: Issues farmers face. Australian Farm Business Management Journal. 2006;3(2):1

[156] Bhalla PL. Genetic engineering of wheat-current challenges and opportunities. Trends in Biotechnology. 2006;24(7):305-311

[157] Jones HD. Wheat transformation: Current technology and applications to grain development and composition. Journal of Cereal Science. 2005;41(2):137-147

[158] Xia L, Ma Y, He Y, Jones HD. GM wheat development in China: Current status and challenges to commercialization. Journal of Experimental Botany. 2011;63(5):1785-1790

[159] Goutam U, Kukreja S, Tiwari R, Chaudhury A, Gupta R, Dholakia B, et al. Biotechnological approaches for grain quality improvement in wheat: Present status and future possibilities. Australian Journal of Crop Science. 2013;7(4):469 



\title{
Morphophysiological and Photosynthetic Reactions of Wheat (T. aestivum L.) and Its Wild Congeners to Drought Condition In Vivo and In Vitro
}

\author{
Nina Terletskaya, Meruert Kurmanbayeva and \\ Ulzhan Erezhetova
}

\begin{abstract}
The results of the complex analysis of different wheat species tolerance to drought stress in vivo at different levels of organization as well as in vitro on callus cultures, which was conducted, are presented. The objects of research are as follows: species of wheat-T. monococum $\mathrm{L}$. $\left(\mathrm{A}^{\mathrm{u}}\right)$, T. dicoccum Shuebl. $\left(\mathrm{A}^{\mathrm{u}} \mathrm{B}\right)$, T. polonicum $\mathrm{L}$. $\left(\mathrm{A}^{\mathrm{u}} \mathrm{B}\right)$, T. aethiopicum Jakubz. $\left(\mathrm{A}^{\mathrm{u}} \mathrm{B}\right)$, T. macha Dek.et.Men. ( $\left.\mathrm{A}^{\mathrm{u}} \mathrm{BD}\right)$, T. compactum Host. ( $\left.\mathrm{A}^{\mathrm{u}} \mathrm{BD}\right)$, and T. aestivum $\mathrm{L}$. ( $\left.\mathrm{A}^{\mathrm{u}} \mathrm{BD}\right)$. The methods of this research are physiological, biotechnological, and cytological. The focus was on nonspecific reactions of cereals to osmotic stress, and species-specific changes according to growth and anatomical and photosynthetic parameters which depend on studied species ploidy were shown. It was shown that results of testing of plant tissues in vivo and in vitro are comparable. It demonstrated the criterions for selection of drought-tolerant forms. Optimal selection criteria were identified, and more drought-resistant wheat species were identified.
\end{abstract}

Keywords: wheat, species, leaves, callus, drought, morphophysiology, anatomy, photosynthesis

\section{Introduction}

According to the UN [1], desert or dry lands represent about half of terrestrial environments worldwide. Lack of water has become a key stressor. The continued growth of the human population and deterioration of the ecological balance necessitate intensifying research in plant vulnerability and adaptive capacity under adverse conditions to enhancing productivity of the most important crops andabove all—of wheat [2-4].

The understanding of how drought affects plants is an actual necessity now. Soil drought develops with a decrease in moisture reserves in the soil to a constant wilting. During atmospheric drought, water reserves in the soil may not reach a critical level, but the relative humidity of the air, which decreases to $30 \%$ and below, can 
cause intense transpiration. The combination of soil and atmospheric droughts is particularly damaging to plants. Short-term, tough, "shock"-type impacts affect primarily the structural organization of the plant. Slowly increasing and long-term effects of an unfavorable factor affect the functional organization of the plant, the sphere of basal metabolism. The hardest effects are those vegetative and generative organs which are affected by drought from the beginning of their formation.

The genetic potential used in wheat breeding today is insufficient, and data on the nature of the drought tolerance of wild relatives of wheat may open up new possibilities for searching and creating promising breeding material. The tribe Triticeae, in which hard bread belongs, has great potential for stress tolerance. Wild members of the tribe, among which there are halophytes, grow in a wide range of conditions throughout the world and have large genetic variations [5, 6]. Effective diagnostics of wild-growing species of wheat and species of limited economic importance make it possible to form a more complete picture of their possible use in breeding and genetic programs and ways to preserve biodiversity [7]. The introduction of the new species with great potential constitutive adaptability into the culture (the direction of a "change of species") along with the genetic potential of cultivated species requires intensive research owing to the multiple unsuccessful attempts to increase stress tolerance, maturation rate, and photosynthetic productivity of plants [8].

Currently, wild congeners of wheat and their derivative forms are most often considered as sources of disease and pest-resistant genes. Much less often, these species are involved in biochemical and morphophysiological studies [5]. Studies which are devoted to the identification of the resource potential and patterns of inheritance of wheat resistance to extreme stress are fragmentary. So far, there is very little information about the structure of photosynthetic tissue and the quantitative anatomy in species from different wheat species $[9,10]$. Literature data indicate that the tetraploid species in this respect are the least studied, although the diversity and distribution area are widely presented [11]. Comparative studies of different wheat species for differences of morphologic and physiologic structures in both wild relatives and cultivated will contribute to obtaining new information to more effectively identify the limiting units of the production process.

The selection process involved factors of changes in the structure, size, and duration of the photosynthetic apparatus, but the activity of the photosynthetic apparatus remained at a level close to the original (Evans Paradox) [12, 13]. The few literature data on the relationship between the intensity of photosynthesis, parameters of the structure of the photosynthetic apparatus, growth characteristics of the assimilation surface, and the level of wheat ploidy suggest that modern types of wheat with different numbers of chromosomes and the origin of the genomic set are significantly different from the ancestor forms in terms of growth parameters, quantitative characteristics of the structure of the leaf mesophyll, and its photosynthetic activity. The observed differences arose as a result of changes in ploidy and the genomic composition of the nucleus during the evolution of the genus Triticum and are associated with rearrangements of the internal structure of the phototrophic leaf tissues and changes in the functional activity of a single chloroplast. The change in the number and size of cells optimizes the structure of phototrophic leaf tissues in tetra- and hexaploid wheat species, which leads to an increase in the internal assimilation surface and, consequently, leaf conductivity for $\mathrm{CO}_{2}$ and a decrease in photosynthesis intensity in modern wheat species compared to ancestral forms and Aegilops species [14]. Therefore, studies aimed at finding plants with a developed and active photosynthetic apparatus for their involvement in the breeding process are also still very relevant [15-18]. 
Thus, it was shown that a high density of pubescence is characteristic of drought-resistant forms, and for diploid species the presence the genes of control of leaf pubescence was determined $[18,19]$. Probably, each of the elements of the genome of polyploidy wheat has its own genetic control system of leaf pubescence. The wheat may have homoallellic genes, functionally degenerate or functionally complementary, which also increase the total number of genes involved in the control of this adaptive trait [20].

In the Triticeae tribe, diploid species are characterized by a shorter stomatal cell length compared with tetra- and hexaploid species [21]. Larger guard cells were found in spring wheat varieties (Triticum aestivum L.) and are associated with spring-type developmental alleles (Vrn-A1a), while the smallest ones are associated with developmental winter-type alleles (Vrn-A1b) on chromosome 5A.

The effect of chromosomes 1A, 3A, 4A, 5A, 1B, 5B, 6D, 7A, and 7D in different wheat varieties on the linear dimensions of stomata is also shown [6]. It was also noted that there is a significant correlation between the variation in the size and density of the stomata of wheat and its yield, both in normal and arid growing conditions [14]. Lamari found a significant effect of the genetic component on the variation in the density of the stomata of the wheat leaf [22].

It is known that the level of ploidy of plants, as an indicator related to cell size, is responsible for the thickness of the lamina [23]. The parameters of the leaf plates, determined by the genotype, are directly related to photosynthesis-negative correlations were found between the intensity of photosynthesis and the ratio of the mesophyll cell size to the ploidy level of the nuclear genome [24]. However, the size of the leaf surface, being a genetically determined trait, is largely corrected by specific environmental conditions.

Drought tolerance is a complex trait which is a combined function of various morphological (leaf emergence and flowering, coleoptile length, leaf area, leaf rolling, wax content, awns, stomatal density, root characteristics, cell membrane stability, etc.) [7], physiological (transpiration rate, water use efficiency, stomatal conductance, osmotic adjustment, relative water content, leaf turgor, etc.), and different biochemical characters [25].

Physiological functions of plants are closely related to their morphological and anatomic features. The dehydration of tissues which is arising during drought changes the course of physiological biochemical processes that in turn affects growth processes, anatomy, and morphology of plants. The lower leaves play an important role at the first stages of development, when the issue of survival of sprout in stressful conditions is actually resolved and the root system is created. Leaves of the upper layers (stem leaves) have crucial importance in photo assimilatory work of a plant, especially during of spike and grain formation-a critical period which is determining the size of losses of potential productivity in the conditions of insufficient water supply $[15,16]$.

The effect of abiotic stressors on the growth of leaves of seedlings entails changes (both upward and downward) in the thickness of the adaxial and abaxial epidermises, the diameter of the vascular leaf bundles, and also the decrease in the diameter and size of stomata [25-28].

Anatomical and morphological changes that allow plants to withstand stressful effects are mainly focused on maintaining water use efficiency and ensuring optimal carbon metabolism for plant resistance to drought. Therefore, a change in the anatomical characteristics of a leaf under drought conditions can be considered as a significant manifestation of the regulation of photosynthesis at the morphological level.

Accordingly, the degree of change can be used as a criterion of adaptability, which can be guided by the choice of forms for the expansion of work on the introduction and hybridization in arid climatic conditions. Thus, for the survival and growth of a plant under drought stress, the degree of survival and growth of leaves is extremely 
important. If leaf growth under stress conditions occurs normally, then the process of photosynthesis does not stop, and the plants are able to produce seed progeny, even if they significantly reduce yields relative to optimal conditions. However, if the leaves that function at the time of the onset of stressful conditions die off faster than new ones develop, the plant may die. At the same time, stress-tolerant forms surpass stress-susceptible in a number of quantitative indicators: the area, the mass of leaves, and the total content in them of structural units of the photosynthetic apparatus of different orders. According to the degree of change of these parameters in stressful conditions, the leaf apparatus shows its reaction to the action of negative factors.

Tolerant forms in wheat are also characterized by higher mobility in changing the typical composition of the cell population of the leaf mesophyll and, respectively, the shape of assimilating cells depending on external conditions during the leaf growth period [29]. The summary of the main directions on the functional significance of the leaf surface is that they can be grouped into two blocks: maintaining the structural and functional status of the leaf and optimizing the energy supply of photosynthesis [30].

Water deficiency contributes to a faster differentiation of tissues, with a slower overall growth, which leads to the development of xeromorphism [31]. It is believed that with a larger leaf surface, evaporation of water increases, and the resistance of plants to its deficiency decreases [32]. According to Kumakov [33], the fluctuations in yield over the years are mainly due to the enormous variabilities in leaf surface and photosynthetic potentials. A smaller volume of plant cells allows them to more easily withstand the stress that occurs when cells are squeezed during dehydration [34]. Genkel [35] indicated that in the case when xeromorphism develops under the influence of water deficiency, it correlates with drought resistance.

At the same time, a different reaction of the morphometric characteristics of the internal structure of the leaf to osmotic stress is shown. Under conditions of lack of moisture against the background of a general decrease in the size of cells, an increase in the thickness of the vascular tissue and cell wall can be observed [36]. Researchers have observed such changes as a significant decrease in leaf thickness, an increase in cuticle thickness, both an increase and decrease in xylem diameter, a reduction in phloem diameter and size of vascular bundles, and a decrease in leaf thickness and total area of the leaf mesophyll, size of stomata, and epidermis thickness for different wheat varieties, compared with the control $[26,37]$.

The reduction of the leaf blade area during drought is usually accompanied by an increase in the mesophyll layers and the development of palisade tissue, which allows the plant to more effectively resist dehydration [38]. Palisade parenchyma is the most high-performance type of tissue and makes the main contribution to leaf photosynthesis [39]. Developing on both sides of the leaf, it contributes to providing the plant with plastic substances while reducing the area of the photosynthesizing surface, in some way compensating for the small leaf surface of plants, which have an isolateral type of mesophyll.

Many mesophyll cells of wheat leaf plates are characterized by strong branching in cell walls, which is a necessary condition for maintaining the optimal ratio of cell surface to its volume as well as the presence of a significant proportion of intercellular spaces during evolution [40]. It was noted that during dry periods in some forms, an increase in the leaf mesophyll thickness may occur as a manifestation of the protective mechanism. In addition, it occurs due to an increase in the volume of the air cavities [41]. In plants with a loose mesophyll, an adequate supply of oxygen and carbon dioxide may be accumulated in the intercellular space, which is necessary for photosynthesis and respiration. The development of sclerenchyma around conductive bundles and the presence of columnar tissue are also one sign of the xeromorphic structure of the leaf. It is assumed that the features of growth and the lanceolate form of a plate of a leaf of wheat, where the layers of the mesophyll are 
closely interconnected with conducting beams, significantly limit the diffusion of carbon dioxide to the chloroplasts of mesophyll cells [42].

It was discovered that T. aestivum contains $73-74 \%$ of chlorophyll-carrying cells in the lower tiers, while in the flag list, their share is lower and amounts to only $59 \%$ [43]. The evidence that the leaf blades of different tiers are of different quality is the fact that in the leaves of the upper phytomeres of the shoot, a certain unification of the mesophyll cells takes place and the proportion of cells with a pronounced cellular form significantly increases [40]. Such an organization of the leaf mesophyll can, in particular, contribute to the expansion of the adaptive potential of a particular species or variety to the emerging agroclimatic conditions. In general, under conditions of growing season that are different from optimal, those forms whose conditions of origin and natural habitat are characterized by a similar temperature regime and amount of precipitation with growing conditions at the moment are advantageous. This may be due to the presence of genetically fixed features that are adaptive in the geographic and climatic zone of their origin [8].

It is well known that the economic loss of the crop is greatest if the plant was subjected to stress in the juvenile stage [44]. Lack of precipitation and rapid drying of the soil can cause a quick death of a young plant. Therefore, great importance in studies of stress tolerance of agricultural crops is attached to the study of changes in the morphology and anatomy of both the root system and the leaf apparatus of wheat seedlings. It is also extremely important to study the reaction of the photosynthetic apparatus of different types of wheat to the osmotic and salt stress effects at the early stages of development. Experiments on seedlings for many decades have been an effective model system for studying a variety of physiological processes in plants, but as far as we know, there are few reports about the effects of different level water stresses on photosynthetic and metabolites activity of wheat seedlings [45].

Literature data show that during drought, both the length and width of the flag leaf and other plant morphological parameters for all wheat genotypes are significantly reduced, which, of course, affects the grain productivity. In a number of studies, a close positive correlation has been established between the size ratio of flag and subflag leaf sizes and the economic drought tolerance of varieties [46]. However, knowledge is limited on how effectively leaves of the top tier leaves, flag leaf in particular, can function under stress conditions or what adaptations could allow such functioning [25].

Callus cultures now are a convenient model object for the study of physiological processes occurring in plant cells under the influence of stress factors. Both in vivo and in vitro, cells in the light, synthesizing chlorophyll, can also acquire the ability to photosynthetically absorb carbon, that is, to implement a photoautotrophic diet typical for an intact plant.

Since embryogenesis of representatives of the Poaceae family is a photomorphophysiological process, figuring out how stressful conditions affect the process of photomorphogenesis in vitro is of practical importance in terms of developing new test methods for assessing stress tolerance in the laboratory, and fundamental is the identification of cytophysiological conditions for the formation of photoautotrophic embryonic calluses, totipotent cells which are able to develop in various ways of morphogenesis in vitro. In the literature there are also several studies on the physiological state of photosynthetic potato and wheat cells cultivated in vitro [47, 48]. In this regard, the study of the formation of in vitro photosynthetic function is necessary for understanding the nature of the reactions of the photosynthetic apparatus of isolated tissues to stressors. Knowledge of these mechanisms will allow us to more fully characterize the relationship of photosynthetic parameters in vivo and in vitro.

This work is part of the comprehensive studies conducted to study the collection of wheat congeners, including various physiological aspects of their resistance to 
abiotic stresses for effective involvement in breeding and genetic programs as the starting material for interspecific crosses.

Therefore, the study is certainly relevant.

Research objectives:

1. Analysis of morphophysiological and photosynthetic parameters of different wheat species under drought conditions.

2. Cytological analysis of the first leaf blades of various wheat species under drought conditions.

3. Analysis of photosynthetic parameters of the first leaves of different wheat species under drought conditions.

4. Morphophysiological and cytological analysis of the flag leaves of different wheat species under drought conditions.

5. Analysis of the influence of drought on the photomorphophysiological parameters of different wheat species in vitro.

\section{Materials and methods}

Six species of wheat, which differ in genomic composition and origin, from the Institute of Plant Biology and Biotechnology collection, were studied: T. monococum L. $\left(\mathrm{A}^{\mathrm{u}}\right)$, T. dicoccum Shuebl. $\left(\mathrm{A}^{\mathrm{u}} \mathrm{B}\right)$, T. polonicum L. $\left(\mathrm{A}^{\mathrm{u}} \mathrm{B}\right)$, T. aethiopicum Jakubz. $\left(\mathrm{A}^{\mathrm{u}} \mathrm{B}\right)$, T. compactum Host. ( $\left.\mathrm{A}^{\mathrm{u}} \mathrm{BD}\right)$, and T. aestivum $\mathrm{L}$. ( $\left.\mathrm{A}^{\mathrm{u}} \mathrm{BD}\right)$.

In the laboratory evaluation of 10-day-old seedlings, Kozhushko's [49] methods were used as a basis. Stress conditions for seedlings were created by them exposing to $17.6 \%$ sucrose solution, visual differences in samples in growth and biomass accumulation. Control seedlings were grown in water. The experiments were carried out at a temperature of $26 \pm 2{ }^{\circ} \mathrm{C}$ and illumination of 3000 lux.

The plants which are grown in the field to the tillering stage out have been transferred to vegetative vessels of 5 liters per each of 5 plants in three replications and at regular watering were grown up to the boot stage begins. Further, a part of plants was exposed to an artificial wilting by the termination of watering during formation of a flag leaf within 7 days. The other part continued to be grown in the conditions of optimum water supply- $60 \%$ of full moisture capacity. To assess the photosynthetic activity (FA) of the flag leaf on the third day, the fluorescence indices of the leaves were recorded in spring planting plants. After 5 days, the fluorescence indices of the third, fourth, fifth, and sixth leaves were registered in plants in winter planting plants. The first two leaves by this point have lost the ability to photosynthesize. On the seventh day, linear measurements of the length and area of flag and subflag leaves were carried out. By a weight method, the length and the area of flag and subflag leaves in control and stressful conditions were measured.

Conservation of plants was carried out by the method of Strasburger-Flemming: fixation was performed in $70 \%$ ethyl alcohol, and preservative fluid is a mixture of alcohol-glycerol-water in a ratio of 1:1:1. Anatomical specimens were prepared with a microtome having a freezing unit TOC-2. Sections were placed in glycerine and balsam in accordance with conventional techniques of Prozina [50], Permyakova [51], and Barykina [52]. The thickness of the anatomical sections was 10 to 15 microns. Micrographs of anatomic sections were made on a microscope with a camera MC 300 CAM V400/1.3 M (Austria). 
The total water content of the leaf blades was calculated from the below formula.

TWC $=(a-b)$; where $a$ is the initial mass of leaves $(\mathrm{mg})$ and $\sigma$ is the leaf mass after drying at $105^{\circ} \mathrm{C}(\mathrm{mg})$ [49].

The specific surface density of the leaf (SSDL) was calculated as the ratio of the wet weight to the unit area of the sheet.

Chlorophyll was extracted in $96 \%$ ethanol using purified glass sand to homogenize the samples. After centrifugation at $4^{\circ} \mathrm{C}$ (at 14,000 rpm), the chlorophyll a and $\mathrm{b}$ concentrations were determined with a spectrophotometer at 665 and $649 \mathrm{~nm}$, respectively, with a Genesis 10 UV Scanning (ThermoScientific, USA). The concentrations were calculated according to Lichtenthaler [53].

To determine the photosynthetic $\mathrm{CO}_{2} / \mathrm{H}_{2} \mathrm{O}$ gas exchange, the sample of the sheet fragment was placed in a room temperature-cured sheet cell described earlier by Parnik [54], illuminated by a fiber-optic light guide from the illuminator (KL 1500 LCD, Shott, Germany) with halogen lamp (150 Bт, Philips, Netherlands) with the density of the light flux of PAR in the field of the object $2000 \mathrm{м \kappa E} /\left(\mathrm{cm}^{2}\right)$. The stationary $\mathrm{CO}_{2}$ gas exchange of the sheet was measured with an infrared gas analyzer (LI-820, LiCor, USA) in an open single-channel scheme. Transpiration was determined by the Lysk principle [55].

For the production of callus culture and plant regeneration, the technique of Gaponenko et al. [56], developed for wheat and barley, was used. The calluses of each studied wheat species were transplanted to the proliferation media of calluses (MC with addition of 2,4-D at a concentration of $1 \mathrm{mg} / \mathrm{L}$ ) in 20-25 days, optimal ( $\mathrm{pH}$ 5.6-5.7). To test the method of obtaining an actively photosynthesizing callus culture, calluses on the third passage were placed on media with a concentration of 2.4-D reduced to $1 \mathrm{mg} / \mathrm{L}$ in three variants of sucrose concentration (30, 20 and $10 \mathrm{mg} / \mathrm{L})$ and exposed to light in the conditions of the light-cultural room, where the temperature is $25^{\circ} \mathrm{C}$ and the humidity is $75-80 \%$. Some calluses continued to be cultivated in the dark. After culturing under these conditions for 20 days, the calluses were weighed and subjected to a cytological analysis. The addition of stressors (polyethylene glycol-16\% $\mathrm{w} / \mathrm{v}$ ) simulated drought. Callus, cultured on a medium without a stressor, served as a control. In Petri dishes, 6-12 calluses were planted for each variant of the medium.

Cytological studies of callus tissues were carried out on pressed temporary preparations. The material was fixed in a freshly prepared Clark reagent (3 parts 96\% ethyl alcohol: 1 part glacial acetic acid), where it was stored for 12-24 h. All leaf blades were examined microscopically at 10× magnification (Micros; Austria), photographed with a video camera (YONGXIN OPTICS CAM V200) and analyzed with a computer program (YONGXIN OPTICS Scope Photo version 2.4) with an increase in the $\times 10$ and $\times 40$ lens.

The data of the experiment were analyzed statistically using Udolskaya's method [57]. Samples for analysis were means of three samples for each treatment.

\section{Experimental data generalization and analysis}

\subsection{Analysis of morphophysiological and photosynthetic parameters of different wheat species under drought conditions}

Examination of the impact of drought stress on the growth characteristics of seedlings of six different wheat species revealed significant species-specific differences in the reduction of growth of the first leaf and roots [58] (Table 1).

It was shown that induced drought suppressed the growth of the first leaf more than root growth of the six different wheat species seedlings. These results 
demonstrate the important role of the actively functioning root system of wheat under stressful conditions [58].

The relationship of root/leaf linear sizes (an important indicator of stress) of different wheat species also increased under drought conditions. T. polonicum, T. aestivum, and T. compactum had the greatest increase in this ratio. The root/leaf relationship for T. dicoccum and T. aethiopicum remained virtually unchanged under stress.

The decrease in the surface area of the leaves was a response to drought (Table 2). Maximum values under drought were noted in T. dicoccum (83\%) and T. compactum (86\%) species.

The tendency to decrease the water content of the leaves under stresses confirmed the results of determining the relative water content (Table 2). The largest content of water with respect to control in leaves under arid conditions was characterized by T. compactum (88\%), T. dicoccum (76\%), and T. aethiopicum (71\%).

\subsection{Cytological analysis of the first leaf blades of various wheat species under drought conditions}

The distribution of trichomes of adaxial and abaxial epidermis and the effect of osmotic stress on the change in their length were studied on the outer surface of a sheet of 10-day-old seedlings of different wheat species [10]. An increase in

\begin{tabular}{lcccc}
\hline \multirow{2}{*}{ Species } & \multicolumn{2}{c}{ Length, \% of control } & \multicolumn{2}{c}{ Ratio root/leaf, \% } \\
\cline { 2 - 5 } & Leaf & Root & Control & Drought \\
\hline T. monococcum & $80.9 \pm 4.5^{*}$ & $89.5 \pm 2.3^{*}$ & $56.3 \pm 3.0$ & $62.3 \pm 3.1$ \\
\hline T. dicoccum & $82.8 \pm 6.4^{*}$ & $93.6 \pm 2.5$ & $41.6 \pm 2.4$ & $47.0 \pm 2.3$ \\
\hline T. polonicum & $87.8 \pm 4.0^{*}$ & $127.2 \pm 3.0^{* *}$ & $43.7 \pm 1.9$ & $63.3 \pm 3.2^{* *}$ \\
\hline T. aethiopicum & $85.5 \pm 4.2^{*}$ & $92.6 \pm 2.5$ & $34.3 \pm 2.0$ & $31.7 \pm 2.0$ \\
\hline T. compactum & $76.7 \pm 2.7^{* *}$ & $157.9 \pm 3.8^{* *}$ & $35.9 \pm 1.9$ & $73.9 \pm 3.9^{* *}$ \\
\hline T. aestivum & $56.0 \pm 2.2^{* *}$ & $78.3 \pm 2.0^{* *}$ & $38.9 \pm 2.0$ & $54.5 \pm 3.5^{* *}$ \\
\hline
\end{tabular}

Note: ${ }^{*}$ and ${ }^{* *}$ indicate significant differences at $p \leq 0.05$ and $p \leq 0.01$, respectively. Means \pm standard deviations are presented.

Table 1.

Relative growth of the first leaf and roots of seedlings of different wheat species under drought conditions (17.6\% sucrose, $72 \mathrm{~h}$ ).

\begin{tabular}{ccccccc}
\hline Species & \multicolumn{3}{c}{ Area, $\mathbf{c m}^{2}$} & \multicolumn{3}{c}{ Relative water cut, \% } \\
\cline { 2 - 6 } & Control & Drought & $\begin{array}{c}\text { \% to } \\
\text { control }\end{array}$ & Control & Drought & $\begin{array}{c}\text { \% to } \\
\text { control }\end{array}$ \\
\hline T. monococcum & $3.03 \pm 0.45$ & $2.03 \pm 0.30$ & 67 & $1.04 \pm 0.12$ & $0.50 \pm .08^{* *}$ & 48 \\
\hline T. dicoccum & $3.48 \pm 0.52$ & $2.90 \pm 0.44$ & 83 & $1.73 \pm 0.23$ & $1.32 \pm 0.20$ & 76 \\
\hline T. polonicum & $3.56 \pm 0.53$ & $2.61 \pm 0.39$ & 73 & $1.83 \pm 0.28$ & $1.29 \pm 0.15$ & 71 \\
\hline T. aethiopicum & $4.30 \pm 0.65$ & $3.28 \pm 0.49$ & 76 & $2.73 \pm 0.43$ & $2.06 \pm 0.30$ & 75 \\
\hline T. compactum & $3.31 \pm 0.50$ & $2.85 \pm 0.43$ & 86 & $1.40 \pm 0.18$ & $1.23 \pm 0.15$ & 88 \\
\hline T. aestivum & $4.35 \pm 0.65$ & $3.01 \pm 0.45$ & 69 & $1.64 \pm 0.28$ & $0.92 \pm 0.12$ & 56 \\
\hline $\begin{array}{l}\text { Note: } \text { plus } \text { /minus sign in the tables shows the relative error of the mean value }{ }^{*} \text { and }{ }^{* *} \text { indicate significant differences } \\
\text { at } p \leq 0.05 \text { and } p \leq 0.01, \text { respectively. }\end{array}$
\end{tabular}

Table 2.

The area of the first leaf of seedlings of different wheat species under drought conditions (17.6\% sucrose solution, $72 h$ ). 
the length of the trichomes with increasing ploidy wheat was noted; the longest trichomes were noted for hexaploid T. aestivum and the shortest for diploid type of T. monococcum (Figure 1). The largest number of trichomes per $1 \mathrm{~mm}^{2}$ as on the adaxial and abaxial epidermis with an average of characteristic values in the absence of stress was observed in the species T. monococcum (44.9 \pm 5.7 and 81.8 \pm 3.7 , respectively), . dicoccum $(53.0 \pm 5.5$ and $67.6 \pm 4.8)$ and T. aestivum $(42.0 \pm$ 3.5 and $61.5 \pm 4.0$ ). At the same, all wheat species had greater hairiness of abaxial epidermis, except for T. aethiopicum and T. compactum, in which the hairiness of the upper and lower surfaces of the leaf did not differ.

There is a marked change in leaf pubescence seedlings of all species under drought conditions; this is consistent with literature data [47]. Under drought conditions for species such as T. aethiopicum, T. compactum and Taestivum, there was noted tendency to increase the length of the trichomes of adaxial leaf surface (for species T. compactum, and T. aestivum difference was statistically significant), whereas for the species T. aethiopicum, T. compactum increased the length of the trichomes of both surfaces of the leaf. For species T. monococcum, there was a statistically significant reduction in the length of the trichomes of adaxial epidermis.

It was noted that an increase in ploidy increases the length of the stomata from $39.0 \mu \mathrm{m}$ at T. monococcum to $72.4 \mu \mathrm{M}$ at T. aestivum. Especially there was a clear dependence for the adaxial surface of leaf (Figure 2).

It was shown that the number of stomata per $1 \mathrm{~mm}^{2}$ axial leaf epidermis of all the species is bigger than the abaxial surface (from $40.6 \pm 3.9$ to $90.9 \pm 7.0$ and from $30.2 \pm 2.9$ to $62.7 \pm 4.3$, respectively). There was a downward trend in the number of stomata per $1 \mathrm{~mm}^{2}$ of leaf surface with increasing ploidy wheat. An exception is the hexaploid T. aestivum; its adaxial surface in the number of stomata per unit area

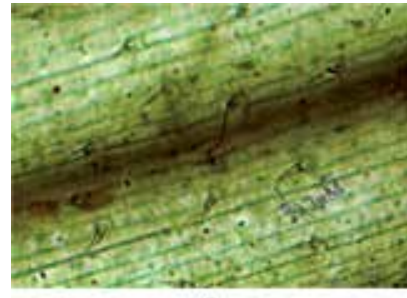

a

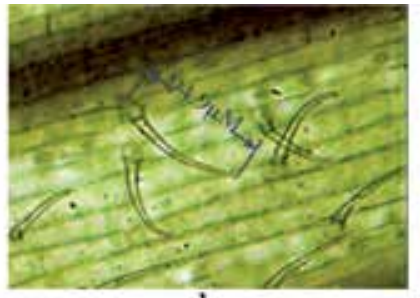

b

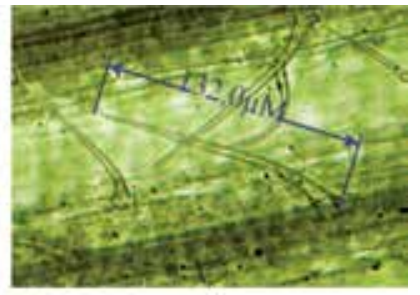

c

Figure 1.

The differences in trichome length depending on the ploidy of wheat species, magnification $10 \times$.

(a) T. monococum $\left(A^{u}\right)$; (b) T. aethiopicum $\left(A^{u} B\right)$; and (c) T. aestivum $\left(A^{u} B D\right)$.

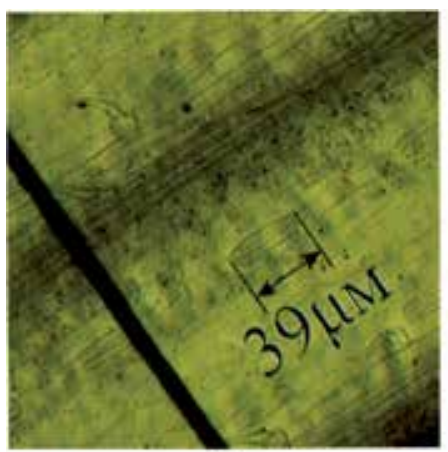

a

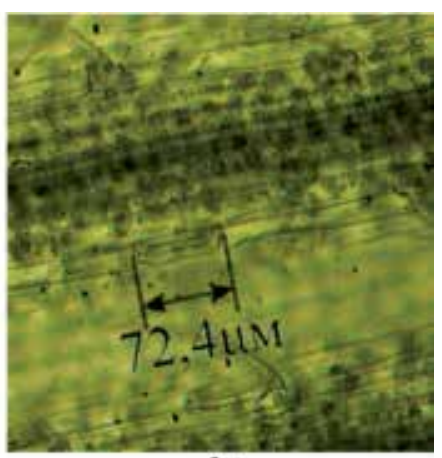

b

Figure 2.

The differences in stomata length depending on the ploidy of wheat species, magnification $10 \times$.

(a) T. monococum $\left(A^{u}\right)$ and (b) T. aestivum $\left(A^{u} B D\right)$. 
exceeds the tetraploid species. The total area of stomata was: for adaxial surface, from 5 to $12 \%$; for abaxial, from 3 to $5 \%$ of leaf area $\left(1 \mathrm{~mm}^{2}\right)$; and for T. aestivum, it was also maximal [10].

It was revealed that the effect of the stressors not only leads to the closure of stomata but also to their deformation-compression, bending, reducing linear value of the width and length, or, alternatively, swelling and "mucilaginized" for less stable forms, which causes a slight increase in the linear values of the width. In drought conditions there was a significant decrease in the parameters of length and width of stomata adaxial epidermis of species T. aestivum.

It was noted for the species T. dicoccum and T. aethiopicum the decrease in the magnitude of the specific density of leaf surface SDLS in stressful conditions was the most significant (Figure 3). Probably, the mesophyll of the first leaf of these species was packed less tightly in drought conditions than in control.

For a detailed understanding of the mechanisms of changing leaf density in osmotic stress, anatomical studies of the internal structure of leaf blades of 10-day seedlings of the studied wheat species were carried out.

This species was differenced in a number of anatomical parameters (Table 3).

From the presented data, it follows that the greatest thickening of both the abaxial and adaxial epidermis under stress conditions is characteristic of the species T. dicoccum, T. polonicum, and T. aethiopicum. A similar arrangement of mesophyll cells allows us to characterize the type of structure of leaf mesophyll in all studied wheat species as a loose cellular-isolateral-palisade. It is characteristic for the T. aethiopicum and T. aestivum under drought conditions (thickening of mesophyll was $115.3 \%$ and $117.4 \%$, respectively, to control). In this experiment drought stress causes thickening of the central veins of almost all studied species except for wheat T. aestivum. As follows from the presented data, in most of the species except for T. monococcum, T. aestivum and size of the central vascular bundle during drought stress was increased, which is an indicative of its high adaptation ability to the drought. Consequently, indicators such as an increase in the stress of the sizes of protective and mechanical tissues, as well as mesophyll, can serve as criteria for selecting stressresistant forms of wheat. By analyzing the data virtually in all considered anatomical parameters of the leaves, we can say of a higher adaptive capacity of tetraploid wheat species T. dicoccum, T. polonicum and T. aethiopicum than hexaploid [10].

\subsection{Analysis of photosynthetic parameters of the first leaf blades of various wheat species under drought conditions}

A more uniform distribution of chloroplasts in the cells of the leaf blade in the absence of stress was observed. Chloroplasts were concentrated in the areas of vascular bundles under stressful conditions (Figure 4).

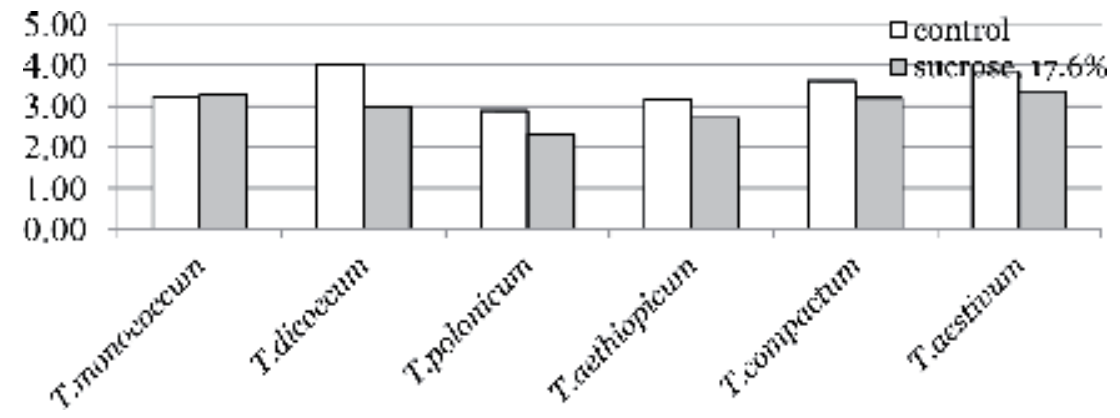

Figure 3.

SSDL of leaf blades of different wheat species of in stress conditions, $g / \mathrm{dm}^{2}$. 
Morphophysiological and Photosynthetic Reactions of Wheat (T. aestivum L.) and Its Wild... DOI: http://dx.doi.org/10.5772/intechopen.86340

\begin{tabular}{|c|c|c|c|c|c|}
\hline Species & $\begin{array}{l}\text { The } \\
\text { thickness of } \\
\text { the adaxial } \\
\text { epidermis }\end{array}$ & $\begin{array}{l}\text { The } \\
\text { thickness of } \\
\text { the abaxial } \\
\text { epidermis }\end{array}$ & $\begin{array}{l}\text { The } \\
\text { thickness } \\
\text { of the } \\
\text { mesophyll }\end{array}$ & $\begin{array}{c}\text { The thickness } \\
\text { of the central } \\
\text { vein }\end{array}$ & $\begin{array}{c}\text { Size of the } \\
\text { central } \\
\text { vascular } \\
\text { bundle }\end{array}$ \\
\hline & \multicolumn{5}{|c|}{ Control } \\
\hline T. monococcum & $38.25 \pm 2.50$ & $31.50 \pm 1.98$ & $117.48 \pm 17.80$ & $490.57 \pm 0.90^{*}$ & $39,408.14^{*}$ \\
\hline T. dicoccum & $37.25 \pm 2.02$ & $38.80 \pm 2.01$ & $158.22 \pm 2.30^{*}$ & $480.61 \pm 1.80^{*}$ & $32,614.23^{*}$ \\
\hline T. polonicum & $32.77 \pm 0.65$ & $26.57 \pm 3.31$ & $146.89 \pm 0.98^{*}$ & $470.62 \pm 3.40^{*}$ & $23,235.22^{*}$ \\
\hline T. aethiopicum & $39.07 \pm 1.70$ & $36.97 \pm 2.10$ & $117.34 \pm 0.90^{*}$ & $490.57 \pm 2.30^{*}$ & $39,408.14^{*}$ \\
\hline T. compactum & $32.60 \pm 3.04$ & $34.82 \pm 2.60$ & $105.73 \pm 4.60$ & $377.47 \pm 7.80$ & $11,309.73$ \\
\hline \multirow[t]{2}{*}{ T. aestivum } & $36.65 \pm 1.42$ & $27.94 \pm 1.40$ & $106.18 \pm 3.80$ & $411.71 \pm 2.30$ & $33,979.45$ \\
\hline & \multicolumn{5}{|c|}{ Drought } \\
\hline T. monococcum & $37.25 \pm 1.70$ & $32.75 \pm 0.50$ & $144.29 \pm 0.60$ & $481.36 \pm 0.70$ & $28,952.92$ \\
\hline T. dicoccum & $42.25 \pm 1.70^{*}$ & $40.05 \pm 0.80^{*}$ & $145.25 \pm 0.80$ & $529.91 \pm 1.90^{*}$ & $33,575.91^{*}$ \\
\hline T. polonicum & $43.80 \pm 0.80^{*}$ & $39.37 \pm 0.70^{*}$ & $145.23 \pm 0.50$ & $553.59 \pm 6.20^{*}$ & $54,739.11^{*}$ \\
\hline T. aethiopicum & $41.80 \pm 0.80^{*}$ & $39.37 \pm 0.70^{*}$ & $135.23 \pm 0.50$ & $553.59 \pm 6.20^{*}$ & $34,739.22^{*}$ \\
\hline T. compactum & $38.98 \pm 0.20$ & $35.47 \pm 0.50$ & $138.03 \pm 2.90$ & $488.26 \pm 4.50$ & $22,167.12$ \\
\hline T. aestivum & $31.67 \pm 2.80$ & $28.94 \pm 1.60$ & $124.67 \pm 0.70$ & $374.99 \pm 3.50$ & $16,361.22$ \\
\hline
\end{tabular}

Note: plus/minus sign in the tables shows the relative error of the mean value; ${ }^{*},{ }^{* *}$ indicate significant differences at $\underline{p} \leq 0.05$ and $p \leq 0.01$ respectively.

Table 3.

Morphometric parameters of the first leaves of different wheat species under control and drought stress conditions ( $17.6 \%$ sucrose solution, $72 \mathrm{~h}$ ).

Earlier, it was shown that the chlorophyll content in leaf blades was species-specific in the absence of stress, but it was independent of the ploidy level of the species studied, but T. aestivum had the highest concentration of chlorophyll $(a+b)$ in leaf blades under normal conditions (control). Under stressful conditions the chlorophyll content of all studied species except for T. compactum and T. aethiopicum decreased significantly (by 75-84\%), but for T. dicoccum it was increased [45] (Figure 5).

The ratio of chlorophyll a/b in our experiments was stable, independent of the changes in total chlorophyll content, suggesting that the osmotic stress applied in this study did not cause significant structural changes in the photosynthetic apparatus of seedlings of different wheat species [46].

The study of photosynthetic $\mathrm{CO}_{2}$ gas exchange, attributed to the chlorophyll $(\mathrm{a}+\mathrm{b})$ content in the leaf, revealed that the assimilation index remained practically unchanged under drought conditions only in T. dicoccum (Figure 6).

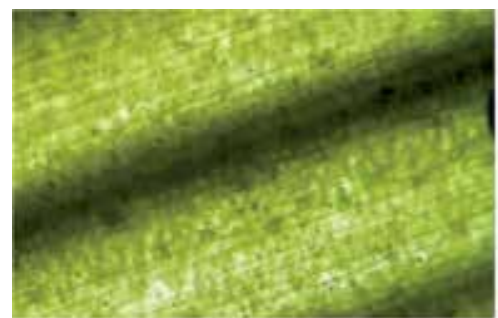

a

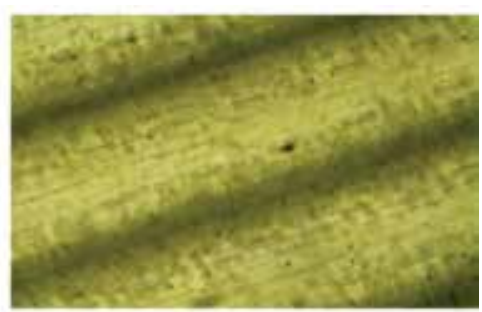

b

Figure 4.

Coloring of leaf blades of T. monococcum seedlings under (a) control and (b) drought stress conditions (17.6\% sucrose solution, $72 \mathrm{~h}$ ), magnification $10 \times$. 
Transpiration of leaves, correlated to the chlorophyll content $(a+b)$, during drought, increased in T. aestivum and in T. dicoccum and in T. dicoccum-almost four times (Figure 7).

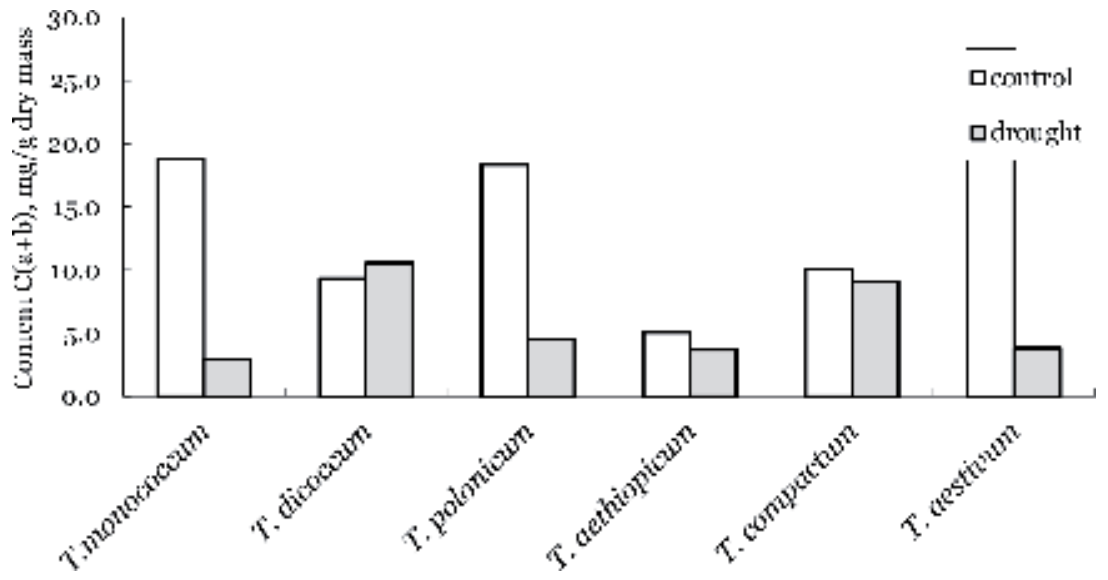

Figure 5.

Concentrations of chlorophyll $(\mathrm{a}+\mathrm{b})$ under control and drought conditions $(17.6 \%$ sucrose solution, $72 \mathrm{~h})$. Note: Different letters above the bars represent significant differences at $p \leq 0.05$.

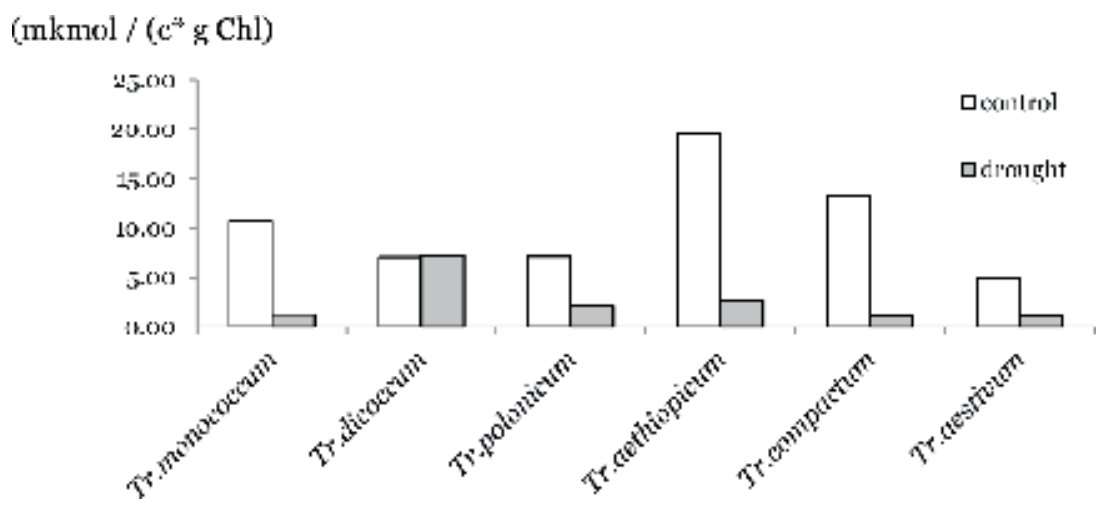

Figure 6.

The level of $\mathrm{CO}_{2}$ assimilation under control and drought conditions (17.6\% sucrose solution, $\left.72 \mathrm{~h}\right)$ (mkmol/(c* $g$ Chl).

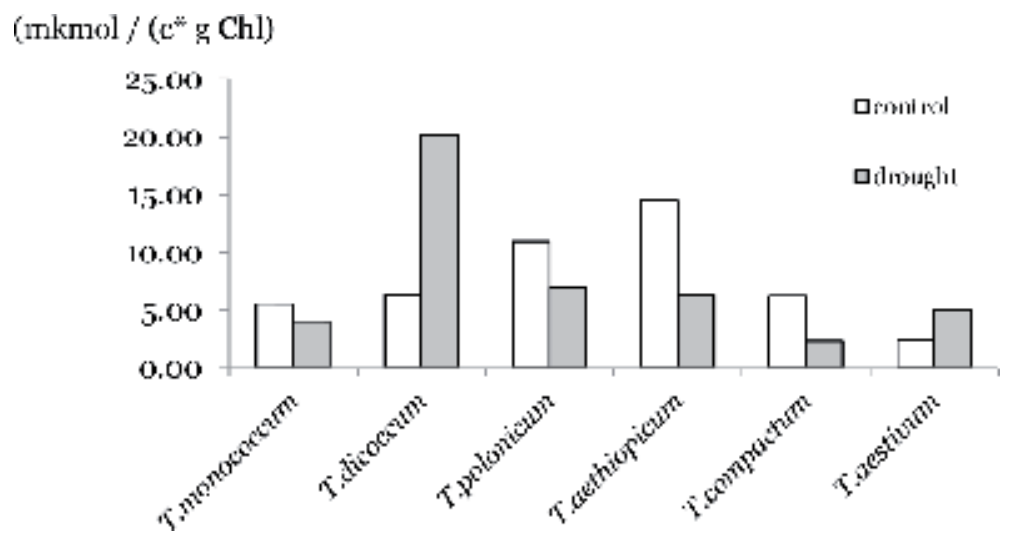

Figure 7.

Intensity of transpiration of different wheat species under control and drought conditions (17.6\% sucrose solution, $72 \mathrm{~h})\left(\mathrm{mmol} / \mathrm{c}^{*} \mathrm{~g}\right.$ Chl $)$. 
These results are consistent with literature data in which the increase in transpiration intensity in conditions of water deficiency in the Saratovskaya-29 strain correlates with the specificity of response to osmotic stress, which is not typical for most plants but is one of the signs of high drought resistance of this variety [59]. Perhaps this sign is a pronounced indicator of drought resistance and for the species T. dicoccum.

We can also assume that one of the reasons for the increase in the rate of transpiration, the renewal of growth, and the active functioning of the leaf in the $T$. aestivum and T. dicoccum species under induced drought conditions was the increase in water inflow from the roots, which is provided by the active work of the little stress-damaged root system of these species.

Reduction of stomatal conductance not only reduces water losses during transpiration but also increases the efficiency of its use. Using a parameter, usually in the literature denoted as WUE (water use efficiency, ratio of intensity of assimilation of $\mathrm{CO}_{2}$ /transpiration) or TE (transpiration efficiency) $[36,60]$, we estimated how great the loss of water by the plant is by assimilating a unit of carbon. The results of our experiments showed a significant reduction in the vegetative WUE both under artificial drought stress conditions (Figure 8).

The change in the specific surface density of the leaf (SSDL) was evaluated. A negative relationship was found between the indices of the SSDL and the WUE. But if under control conditions, it was $r=-0.6^{* *}$ and under the conditions of induced drought, it decreased by half $\left(r=-0.3^{*}\right)$, which indicates the importance of taking into account the structural changes in leaf blades in connection with the efficiency of water exchange under stressful conditions.

Besides, we used the "saturation pulse" method for the detection of the effects of drought on photosynthesis of leaves different wheat species. As shown [45], most species had higher and light-dependent thermal dissipation (Y(NPQ)) under induced drought than in controls, indicating the presence of lesions in FS II. But there were no significant differences in the maximum quantum yield of PSII (Fv/Fm ratio).

\subsection{Morphophysiological and cytological analysis of the flag leaf blades of various wheat species under drought conditions}

It was revealed that the length of the two upper leaves of plants did not change significantly under the influence of drought and is made up by the flag sheet from $81.7 \%$ (T. aethiopicum) to $107.5 \%$ ( . dicoccum) to control (according to the subflag sheet-104.9\% (T. dicoccum) to the control) [60]. The area of the two upper leaves

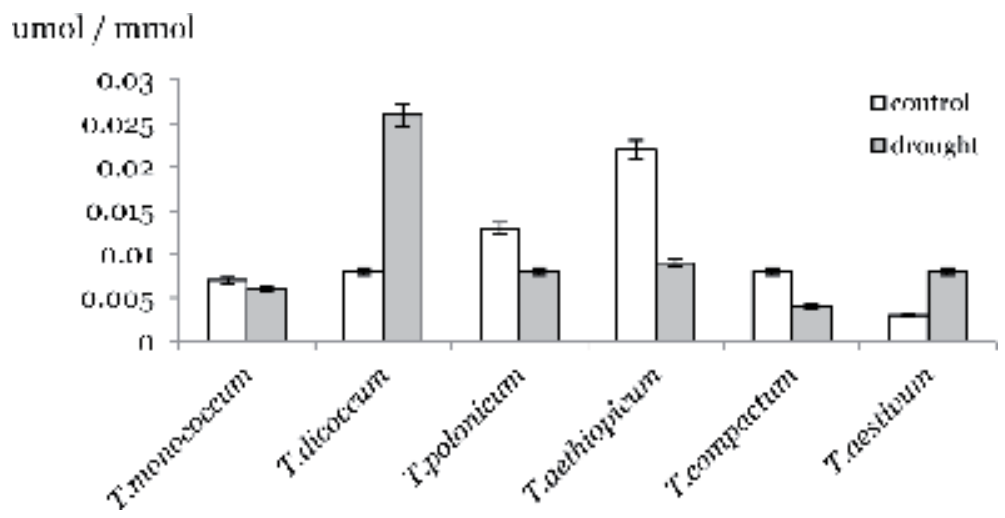

Figure 8.

Change in plant WUE of different wheat species under control and drought conditions (17.6\% sucrose solution, $72 \mathrm{~h}$ ), umol/mmol. 
of the studied wheat species was more strongly affected by the growth conditions. Thus, according to the flag sheet, the area under drought conditions was from $41.3 \%$ (T. aethiopicum) to $79.1 \%$ (T. aestivum) to control; the area of the subflag leaf is from $58.9 \%$ (T. monococcum) to $101.2 \%$ (T. dicoccum) to the control (Table 4).

Observed increases of flag and subflag leaves area at tetra- and hexaploid species in comparison with a diploid T. monococcum can be a consequence of increase of total number of cells counting on a leaf, increase of the number of cellular divisions and an intensifications of division and stretching processes [33, 35].

Such species as T. aestivum and T. dicoccum were characterized by the largest area of a subflag leaf (91 and 101\% to control, respectively), with some decrease for ratio of the flag/subflag area under drought from 125.5 to $109.1 \%$ in T. aestivum and from 86.6 to $66.2 \%$ in T. dicoccum, but remain quite high. Thus, change of a ratio of a flag/ subflag is directly connected with preservation of functional abilities of a subflag leaf and with extent of development of a flag leaf under drought conditions. At more tolerance species decrease in this indicator was the smallest (Table 4).

Structural transformations of leaves observed in different phases of plant ontogeny under drought are described as changes in the direction of amplification of xeromorphism [40]. The flag leaf may be inferior in length and density of pubescence to the rest [38]. According to our data [35], in di- and tetraploid species, the upper side of the flag leaf is pubescent less than the lower side. On the upper side of the leaf, the hairs are concentrated mainly on the veins, keeping the same density throughout the entire width of the leaf blade. In this case, more hairs occur on the central vein and less-on the lateral. On the lower side of the leaf, the trichomes are placed evenly over the surface, both on the veins, and between them.

The drought that occurred during the formation of the flag leaf had a significant impact not only on the density of pubescence of the leaf blades but also on the length of trichomes of some species (Table 5). In the case of the diploid species, T. monococcum, trichome length reduction in both adaxial and abaxial epidermises was noted, while tetraploid species T. dicoccum and T. aethiopicum showed an increase in adaxial epidermal trichomes length. But in T. aethiopicum and T. aestivum, we show an increase of the abaxial trichomes length, and in the species $T$. aestivum, it is expressed in greatest extent.

It is known that the larger the stomata and the smaller the cells, the more xeromorphous the species [41]. In accordance with our data [35], the largest xeromorphism of the flag leaf is also characteristic for tetraploid wheat species. The regularity of the location of a larger number of stomata on the lower (abaxial) epidermis of the leaf blade was remained. As in our experiment on seedlings [10], the stomata size was dependent on the ploidy of wheat species. The deficiency of soil moisture did not significantly affect the length of the stomata of most of the studied forms, which indicates a significant genetic stability of this trait [61].

The importance for the vital activity of plants of the internal structure of the flag leaf, carrying out basic water and gas exchange, during critical periods from 20 days to flowering up to 10 days after flowering and during the period of grain filling, is unconditional. In the absence of a stress, the maximum values of adaxial epidermis characterized the species as T. dicoccum and T. aestivum (33.49 and $34.00 \mu \mathrm{M}$, respectively) regardless of their ploidy. The maximum values of abaxial epidermis were at hexaploid species of T. compactum (26.45 $\mu \mathrm{M})$ [35] (Table 6).

The maximum thickness of a mesophile is noted at a tetraploid of T. dicoccum $(352.89 \mu \mathrm{M})$. The tetraploids of T. dicoccum and T. aethiopicum had a maximum thickness of the central vein $(951.60,931.57$, and $926.86 \mu \mathrm{M}$, respectively). And the biggest size of the central conducting bundle is noted at a diploidic species of T. monococcum and a hexaploid of T. compactum (35,155.73 and 38,424.32 $\mu$, respectively). 
Morphophysiological and Photosynthetic Reactions of Wheat (T. aestivum L.) and Its Wild... DOI: http://dx.doi.org/10.5772/intechopen.86340

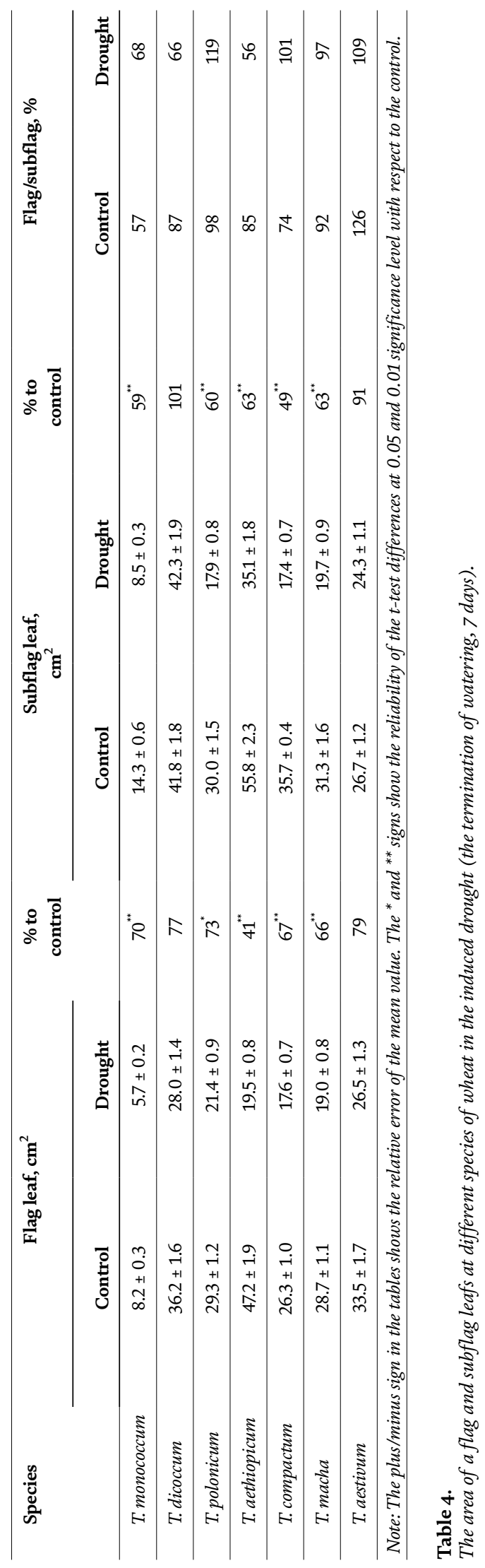




\begin{tabular}{lcccc}
\hline \multirow{2}{*}{ Species } & \multicolumn{4}{c}{ The length of the trichomes, $\boldsymbol{\mu}$} \\
\cline { 2 - 5 } & \multicolumn{2}{c}{ Adaxial epidermis } & \multicolumn{2}{c}{ Abaxial epidermis } \\
\cline { 2 - 5 } & Control & Drought & Control & Drought \\
\hline T. monococcum & $35.5 \pm 1.7$ & $21.2 \pm 2.6^{* *}$ & $44.0 \pm 4.3$ & $21.1 \pm 3.5^{* *}$ \\
\hline T. dicoccum & $21.4 \pm 3.1$ & $30.1 \pm 1.4^{* *}$ & $32.1 \pm 3.8$ & $32.2 \pm 2.1$ \\
\hline T. polonicum & $19.4 \pm 2.4$ & $18.7 \pm 2.4$ & $23.5 \pm 2.6$ & $22.7 \pm 2.7$ \\
\hline T. aethiopicum & $54.8 \pm 0.9$ & $59.8 \pm 2.6$ & $65.5 \pm 1.8$ & $44.3 \pm 4.4^{* *}$ \\
\hline T. compactum & $21.7 \pm 2.5$ & $21.0 \pm 3.4$ & $22.5 \pm 0.7$ & $20.1 \pm 2.9$ \\
\hline T. aestivum & $72.8 \pm 3.4$ & $34.2 \pm 1.5^{* *}$ & $21.8 \pm 4.1$ & $74.5 \pm 4.2^{* *}$ \\
\hline
\end{tabular}

Note: The plus/minus sign in the tables shows the relative error of the mean value. The *, ${ }^{* *}$ signs show the reliability of the t-test differences at 0.05 and 0.01 significance level with respect to the control.

Table 5.

Change the size of trichomes of flag leafs blades of different species of wheat depending on the influence of stress factors (the termination of watering, 7 days).

\begin{tabular}{lccccc}
\hline Species & $\begin{array}{c}\text { Width of } \\
\text { adaxial } \\
\text { epidermis }\end{array}$ & $\begin{array}{c}\text { Width of } \\
\text { abaxial } \\
\text { epidermis }\end{array}$ & $\begin{array}{c}\text { Thickness of } \\
\text { a mesophile }\end{array}$ & $\begin{array}{c}\text { Thickness of } \\
\text { the central } \\
\text { vein }\end{array}$ & $\begin{array}{c}\text { The size of } \\
\text { the central } \\
\text { conducting } \\
\text { bundle }\end{array}$ \\
\hline T. monococcum & $20.5 \pm 0.6$ & $19.8 \pm 0.1$ & $210.5 \pm 1.9$ & $457.8 \pm 3.3$ & $35,155.7^{*}$ \\
\hline T. dicoccum & $33.5 \pm 0.4^{* *}$ & $19.8 \pm 0.1$ & $352.9 \pm 3.3^{*}$ & $951.6 \pm 7.9^{* *}$ & $24,859.6$ \\
\hline T. polonicum & $29.3 \pm 1.9^{*}$ & $22.2 \pm 0.0^{*}$ & $209.2 \pm 2.6$ & $409.4 \pm 4.8$ & $29,054.3^{*}$ \\
\hline T. aethiopicum & $27.4 \pm 0.2^{*}$ & $16.8 \pm 0.1$ & $252.7 \pm 3.1$ & $931.6 \pm 5.9^{* *}$ & $18,594.8$ \\
\hline T. compactum & $27.4 \pm 0.3^{*}$ & $26.5 \pm 0.1^{* *}$ & $134.8 \pm 2.2$ & $512.9 \pm 4.9$ & $38,424.3^{*}$ \\
\hline T. aestivum & $34.0 \pm 0.9^{* *}$ & $19.2 \pm 0.01$ & $215.3 \pm 2.2$ & $520.1 \pm 4.5$ & $22,244.7$ \\
\hline & & Drought (the termination of watering, 7 days $)$ & \\
\hline T. monococcum & $30.2 \pm 0.6^{* *}$ & $17.0 \pm 0.8$ & $90.5 \pm 1.7$ & $298.7 \pm 3.7$ & 8807.1 \\
\hline T. dicoccum & $28.1 \pm 0.5^{*}$ & $24.8 \pm 0.7^{*}$ & $141.9 \pm 2.3^{*}$ & $577.9 \pm 5.6^{*}$ & $19,775.1^{*}$ \\
\hline T. polonicum & $28.9 \pm 0.7^{*}$ & $18.8 \pm 0.6$ & $65.1 \pm 0.9$ & $789.2 \pm 3.2^{* *}$ & $18,612.9$ \\
\hline T. aethiopicum & $22.7 \pm 0.3$ & $18.3 \pm 0.2$ & $99.1 \pm 1.8$ & $371.1 \pm 3.9$ & $18,612.9$ \\
\hline T. compactum & $29.4 \pm 0.3^{*}$ & $21.5 \pm 0.1$ & $163.5 \pm 2.1^{*}$ & $510.3 \pm 4.7^{*}$ & $18,612.9$ \\
\hline T. aestivum & $26.0 \pm 0.4$ & $24.0 \pm 0.3^{*}$ & $183.5 \pm 2.2^{*}$ & $483.2 \pm 4.4^{*}$ & $20,991.8^{*}$ \\
\hline Note: phis/minus & & Control & \\
\hline
\end{tabular}

Note: plus/minus sign in the tables shows the relative error of the mean value; ${ }^{*}{ }^{* *}$ indicate significant differences at $p \leq 0.05$ and $p \leq 0.01$ respectively.

Table 6.

Morphometric parameters of a flag leafs of different species of wheat in control and drought conditions, $\mu$.

In control the maximum thickness of a mesophile is noted for the tetraploid T. dicoccum $(352.89 \mu \mathrm{M})$. The tetraploids T. dicoccum and T. aethiopicum had also a maximum thickness of the central vein (951.60, 931.57 and $926.86 \mu \mathrm{M}$, respectively).

The drought exerted various impacts on parameters of a flag leaf of the studied wheat species. In hexaploid group the average value of thickness of a mesophyll increased by $50-56 \%$ in comparison with tetra- and diploids, respectively. 
On the flag leaf, we did not find such clear relations by formation of anatomical parameters with ploidy under stress as on the seedlings. This may be due to the different quality of leaf blades of different tiers. Since the conditions for the formation of the upper leaves, in contrast to the lower ones, vary to a very wide extent, respectively, the morphological characteristics of the leaves of the upper tiers have a much greater range of variation. At the hexaploid species, more "degrees of protection" to a lack of moisture than di- and tetraploid were obeserved. In general, the anatomical structure of the leaves of various wheat species under the influence of drought is labile and reflects the degree of adaptation of individual species.

As appears from the submitted data, in control conditions we could see the impact on formation of the area of a leaf thickness of adaxial (top) epidermis, thickness of the central vein $\left(r=0.7^{*}\right)$, and indirectly influenced thickness of a mesophyll ( $r=0.4)$ (Figure 9).

But the drought that completely leveled the importance of thickness of the top epidermis has reduced the importance of a mesophyll $(r=0.3)$ and the central vein $\left(r=0.5^{*}\right)$ but has brought to the forefront influence of the sizes of the central conducting bundle $\left(r=0.9^{* *}\right)$ and thickness of abaxial (lower) epidermis $\left(r=0.6^{*}\right)$.

As the lower epidermis of a leaf is not covered with a cuticle and it has bigger quantity of stomas than the top, what making it the main location of gas exchange and transpiration, its thickening at drought is an important adaptation sign.

The decrease in the sizes of the main conducting bundle at a drought is directly connected with reduction of the sizes of area of a xylem which is directly responsible for the ability of plants to absorb water and to carry out nutrients, changing the diameter of a vessel. Consequently, such indicators as thickness of abaxial (lower) epidermis and the size of the central conducting bundle are correlatively connected with growth indicators of a flag leaf in case of a drought and do not depend on the ploidy of the studied species. Thus, it is eaten out of the maximal capability to adaptation to drought conditions in the late stages of ontogeny of a flag leaf of T. dicoccum and $T$. aestivum wheat species.

\subsection{Analysis of the influence of drought on the photomorphophysiological parameters of different wheat species in vitro}

Embryogenic photomorphogenic calluses for all studied types of wheat were obtained. The lowest percentage of callusogenesis from immature embryos was noted in the diploid species T. monococcum (14.6\%), and hexaploid forms were characterized by the highest frequency of callusogenesis (87-91\%).

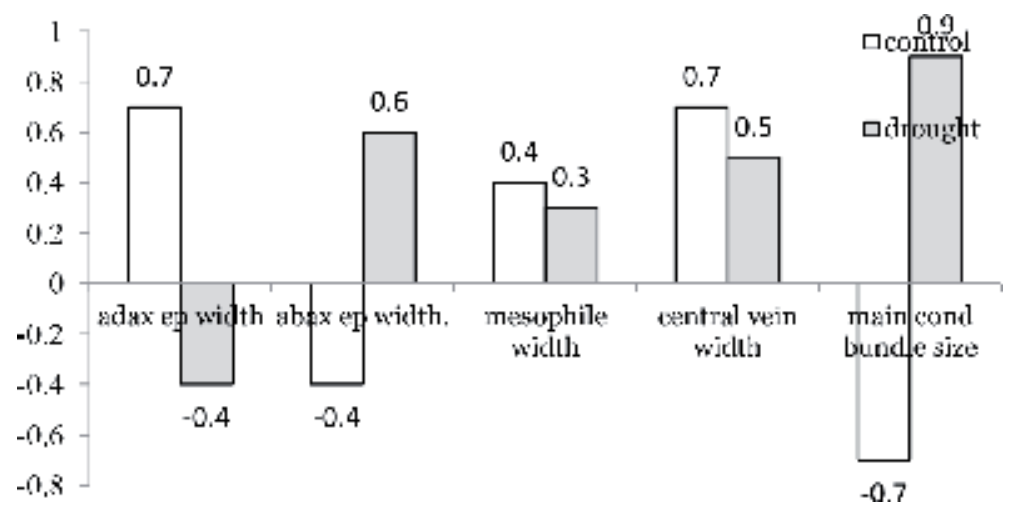

Figure 9.

Influence of drought on correlative interactions between the leaf area and basic anatomic parameters of a flag leaf. 
It was revealed that the growth rates of callus tissue in the studied species and hybrids of wheat in the dark and in the light differed on media differing in the level of carbohydrate nutrition. At $20 \mathrm{~g} / \mathrm{L}$, the accumulation of biomass, as a rule, was the greatest $(83-117 \%)[62,63]$.

A comparative analysis of the morphophysiological characteristics of calluses, which was cultivated in the dark and in the light, showed that the calli growing in the dark had a disordered loose structure, callus tissue watered, easily disintegrating into individual cells.

At 20\% sucrose concentration in the nutrient medium, we pronounced zones of formation of morphogenic structures in calluses were revealed. They lacked almost no chlorophyll in the absence of lighting, but when the callus was exposed, they were green. The isodiametric shape of the cells, the intensely colored cytoplasm, and the tight adherence of the cells to each other made it possible to characterize the cells of such callus as meristematically active, with photomorphogenic light, which also agrees with the literature data [53]. In the light, in the greening meristematic zones, chlorophyll-containing areas (CCA) of formation of tracheid structures and conducting beams are clearly marked, which indicates the onset of the regeneration process (Figure 10). These processes were characteristic of the calluses of all the species studied. Thus, it is possible to draw a positive conclusion about the possibility of obtaining strains of the photoheterotrophic callus culture from heterotrophic calli of various wheat species with optimum light conditions and carbohydrate composition of the nutrient medium.

It was shown that the onset of the formation of chlorophyll in callus indicates the onset of morphogenesis. Optimum conditions for intensive formation of green

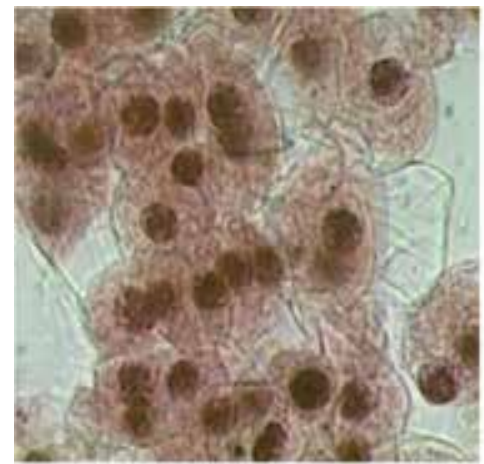

a

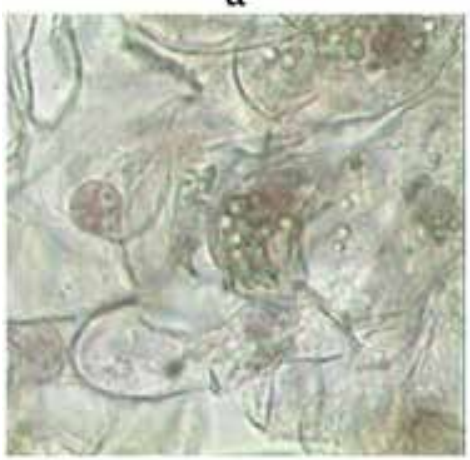

c

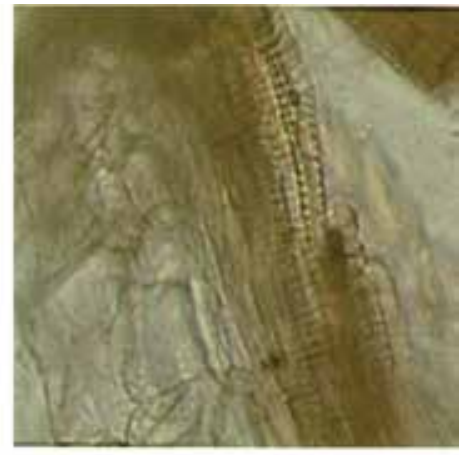

b

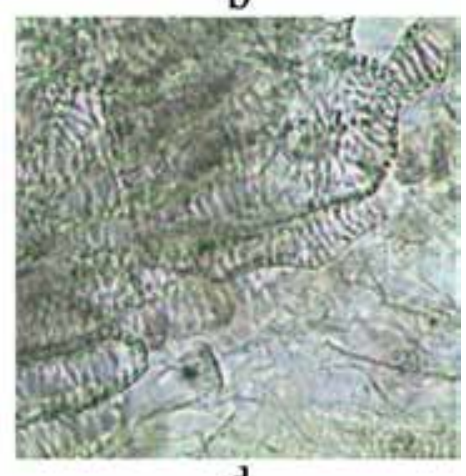

d

Figure 10.

Cells of calli growing at $20 \%$ sucrose concentration, magnification $40 \times$. (a) meristematic cells of morphogenic callus growing in the dark; (b) site of formation of tracheid structures; (c) chloroplasts in callus cells in the light; and (d) green zone of regeneration start. 
pigments in cells were $20 \mathrm{~g} / \mathrm{L}$ sucrose in a nutrient medium and stimulation of callus tissues by illumination. Most of the calluses had a high regenerative capacity during further cultivation for 2-3 weeks. At the same time, the correlation between the accumulation of callus biomass in the studied wheat species and their regenerative capacity under optimized conditions was quite high $\left(-\mathrm{r}=0.9^{* * *}\right)$ (Figure 11).

Reliable correlation between the average size of the main spike of the studied wheat species in the field (averaged perennial data) and the ability to accumulate biomass by calluses of these species in vitro was $r=1^{* * *}$ (Figure 12a), and correlation between the main spike and ability of callus tissues to regenerate a plants $\mathrm{r}=0.7^{* *}$ was revealed (Figure $12 \mathrm{~b}$ ).

Thus, these results show that the optimization of the conditions for the cultivation of calluses of various types of wheat has been achieved both for obtaining photomorphogenic callus culture and plant regeneration and for obtaining callus tissue of sufficient biomass for various experiments, including resistance to abiotic stresses in vitro. According to the results of this research, the Patent of the Republic of Kazakhstan No. 1642 for the utility model "Method for obtaining of photosynthesizing callus culture of wheat" in 2016 was obtained.

The analysis of drought effect on the callus tissues of different wheat species showed that calluses of tetraploid species of T. dicoccum, T. polonicum, T. aethiopicum, and hexaploid T. aestivum in control conditions were significantly superior to other species in terms of the growth of raw biomass. In drought conditions in tetraploid wheat forms, biomass depression was also less pronounced than in others (Figure 13).

We showed that photomorphogenic calluses even in stressful conditions formed several greening loci (Figure 14a). Chloroplasts in zones of somatic embryogenesis were similar to chloroplasts of leaf mesophyll cells. But in contrast to intact plants, in which chloroplasts are usually located near the cell walls, in the callus cells, the arrangement of chloroplasts is chaotic (Figure 14b).

The most active processes of photomorphogenesis under stress conditions are found in callus developing in the light, which have a relatively small increase in the biomass of cell colonies. This reflects the negative genetic mechanism of interaction between growth processes and photosynthesis in the formation of plant tissue in vitro and is consistent with the literature data [64].

Thus, a large percentage of regenerating plants under conditions of induced drought in vitro was noted in species T. dicoccum (67\%) and T. aestivum (50\%). With prolonged exposure to stress, plasmolysis observed in most of the studied forms and the proportion of vacuolated cells that lie in the lower part of the callus and contact with the nutrient medium was decreased. The increase in the duration

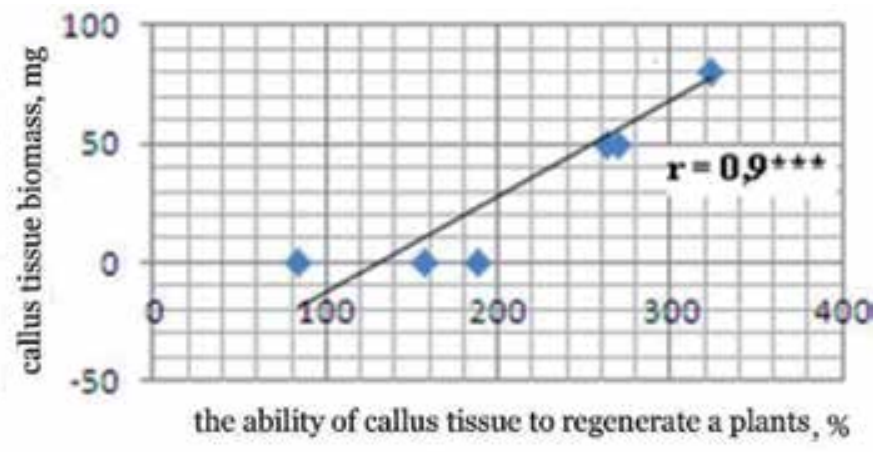

Figure 11.

The correlations between the accumulation of biomass and the regenerative capacity of callus tissues of various wheat species in vitro. 


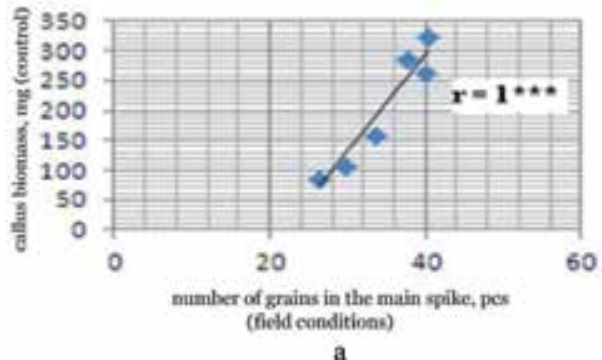

a

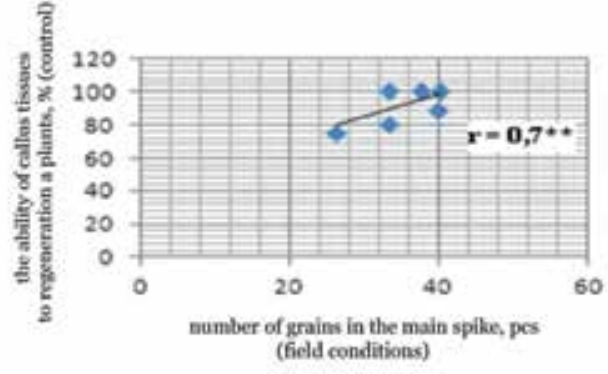

b

Figure 12.

Correlation links between (a) regenerative ability of callus tissues and (b) biomass of calluses of different wheat species and number of grains in the main spike (average long-term data).

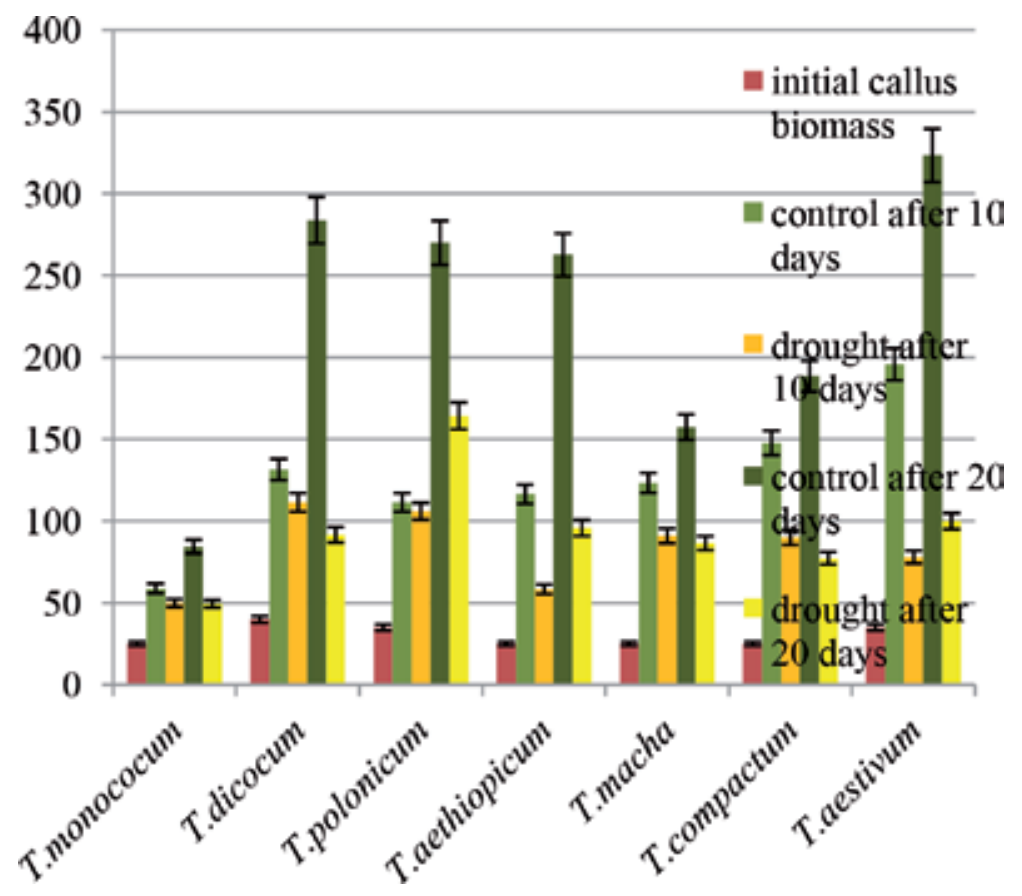

Figure 13.

Growth of biomass of calli of various wheat species in vitro in control and induced drought (PEG-60oo, $16 \%$ (weight/volume)) conditions.

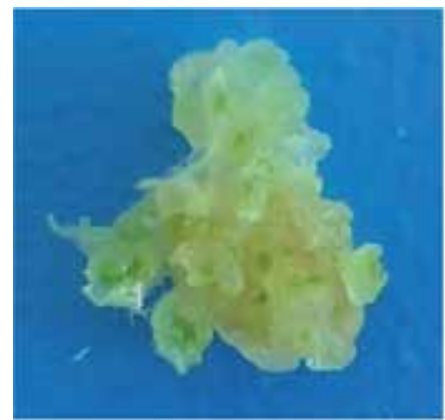

a

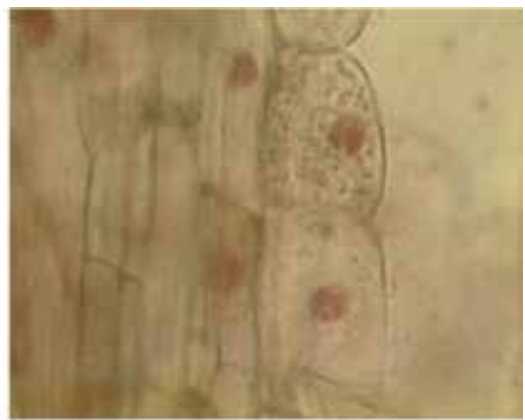

b

Figure 14.

Regeneration processes (hemogenesis) in callus tissue of wheat, magnification $40 \times$. (a) Numerous regeneration zones in callus tissue and (b) chloroplasts in callus cells. 


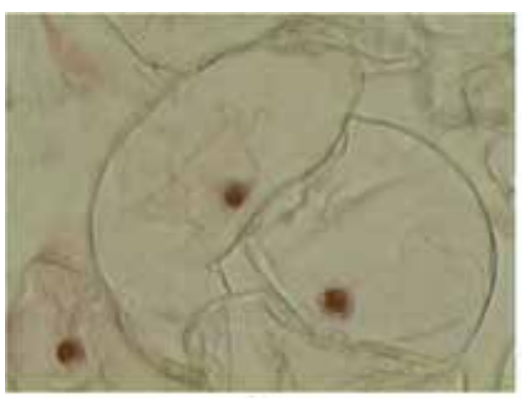

a

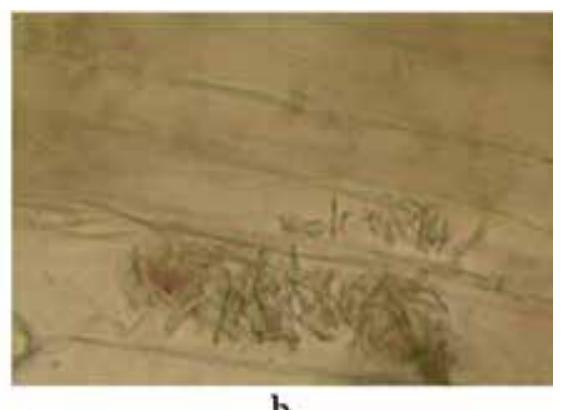

b

Figure 15.

Processes of degeneration of photomorphogenic callus tissue of wheat under conditions of induced drought, magnification $40 \times$. (a) Plasmolysis in large vacuolated cells of T. compactum and (b) destruction of CCA in callus cells of T. polonicum.

of the stressful action led to the processes of degeneration of the photomorphogenic tissues and the destruction of CCA and trachea-like structures, primarily in the calluses of less stable species (Figure 15).

The destruction of synthesized pigments and the cessation of their synthesis de novo indicate a stress-induced disturbance of the mechanisms coordinating the formation of pigments and their protein carriers. In general, the proportion of callus cells containing chloroplasts, as well as the osmotic characteristics of callus cells, can serve as indicators of the photomorphogenetic competence of the species under stress conditions in vitro. The T. dicoccum and T. aestivum species, in which the formation of CCA under stress conditions prevailed over the processes of rhizogenesis, can be considered the most resistant to drought stress in vitro.

\section{Conclusion}

The present study, which involved wheat species with different genome contents, includes a complex analysis of photosynthetic apparatus resistance to drought stress in vivo at different levels of organization as well as in vitro on callus cultures, which was conducted for the first time.

Six species of wheat were studied: T. monococum $\mathrm{L} .\left(\mathrm{A}^{\mathrm{u}} \mathrm{A}^{\mathrm{u}}\right)$, T. dicoccum Shuebl. $\left(\mathrm{A}^{\mathrm{u}} \mathrm{A}^{\mathrm{u}} \mathrm{BB}\right)$, T. polonicum $\mathrm{L}$. $\left(\mathrm{A}^{\mathrm{u}} \mathrm{A}^{\mathrm{u}} \mathrm{BB}\right)$, T. aethiopicum Jakubz. $\left(\mathrm{A}^{\mathrm{u}} \mathrm{A}^{\mathrm{u}} \mathrm{BB}\right)$, T. compactum Host. ( $\left.A^{\mathrm{u}} \mathrm{A}^{\mathrm{u}} \mathrm{BBDD}\right)$, and T. aestivum L. ( $\left.\mathrm{A}^{\mathrm{u}} \mathrm{A}^{\mathrm{u}} \mathrm{BBDD}\right)$.

The new results were obtained. These experiments revealed a number of common nonspecific mechanisms regulating growth and photosynthetic activity of the leaf apparatus of seedlings of different wheat species seedlings under drought stress. Furthermore, species-specific differences in the response to induced drought were demonstrated. Drought stress had effect on the leaf apparatus of juvenile plants. Among the wheat species with different origins, levels of ploidy and genomic composition, a variety of evolutionary mechanisms for protection against exposure to stressors in the form of tolerance, were identified in tetraploid species and especially $T$. dicoccum.

T. dicoccum as well as T. aestivum species also had the largest under flag leaf area at late stages of ontogeny. They also had in comparison with other studied species the maximum flag leaf area under drought conditions compared to optimal ones. The changes in flag/subflag ratio appeared to be closely connected with subflag functionality retention as well as with flag development level under stress conditions. The more tolerant forms showed less decrease of this ratio under drought. 
Changes in growth activity of different wheat species appeared to be connected changes in photosynthetic apparatus work under stress conditions. Also different mechanisms developed with evolution can be involved in resistant processes against abiotic factors influence.

The study of photosynthetic $\mathrm{CO}_{2}$ gas exchange at the background of significant decrease of assimilation and transpiration of most studied species showed high levels of these parameters in T. dicoccum as well as T. aestivum samples. The significant decrease of plant WUE was described under drought stress. A negative relationship was found between the indices of the SSDL and the WUE, which decreased under stress conditions, which indicates the importance of taking into account the structural changes in leaf blades in connection with the efficiency of water exchange under stressful conditions.

The anatomic features of inner and external surfaces of leaves of all studied wheat species growing under optimal and stress conditions were described. Most of studied anatomic parameters of seedlings testified higher adaptation ability of tetraploid wheat species compared to hexaploid species. The enlargement of resistant and mechanical tissues and mesophyll size appeared to be a good criteria of stress-tolerant form selection at early growth stages.

Leaf blades of hexaploid species have more adaptive mechanisms than leaf blades of di- and tetraploid species at late growth stages. It was revealed that abaxial epidermis thickness and central conducting bundle size correlate with flag size under drought conditions. So these parameters can become suitable criteria of selection of wheat drought-tolerant forms. T. dicoccum as well as T. aestivum had the highest adaptive potential to drought according to data on the anatomy of leaves of upper tiers.

The maximum in vitro callusogenesis frequency was detected in immature embryo culture of hexaploid species, the minimum of diploid species T. monococcum. The tetraploid species calluses had higher weight than calluses of other species. The species specific of CCA formation was shown. It was revealed that callusogenesis, morphogenesis, and CCA formation parameters were lower in mature embryo culture than in culture, developed from immature embryos.

Optimization of different wheat species callus culture cultivation was reached for the purpose of photomorphogenic callus culture production. Significant correlation between studied species callus weight and regeneration capacity was found out. Correlations between crop yield and growth parameters of callus culture of those species under optimized conditions of in vitro cultivation were shown.

The results of the present project may be applied in plant physiology, genetics, biotechnology, and plant breeding. The developed approaches may be used for screening of wheat selection collection for drought-tolerant forms. These methods provide and sustain morphophysiological, anatomic, physiological, and biotechnological markers at different stages of ontogenesis in callus cultures in vitro.

The tetraploid species calluses had higher weight than calluses of other species. The species specific of CCA formation was shown. It was revealed that callusogenesis, morphogenesis, and CCA formation parameters were lower in mature embryo culture than in culture, developed from immature embryos.

Optimization of different wheat species callus culture cultivation was reached for the purpose of photomorphogenic callus culture production. Significant correlation between studied species callus weight and regeneration capacity was found out. As a result of the study, a new "method of photosynthetic active wheat callus culture production" was developed.

Thus, tetraploid wheat species, and especially the T. dicoccum, can be successfully used as sources of drought resistance in interspecific corosses in wheat breeding programs. 
Morphophysiological and Photosynthetic Reactions of Wheat (T. aestivum L.) and Its Wild... DOI: http://dx.doi.org/10.5772/intechopen.86340

The results of present research are widely presented in multi-author monography and some scientific articles. It may be applied in plant physiology, genetics, biotechnology, and plant breeding. The developed approaches may be used for limit stage of production process revealed as well as for screening of wheat selection collection for drought-tolerant forms. These methods provide and sustain morphophysiological, anatomic, physiological, and biotechnological markers at different stages of ontogenesis in callus cultures in vitro.

\section{Acknowledgements}

This research was supported by the Ministry for Science and Education of Kazakhstan.

We are grateful to Dr. Nina Khailenko for her excellent consultation assistance and important experimental suggestions.

\section{Conflict of interest}

The authors declare that they have no conflict of interests.

\section{Author details}

Nina Terletskaya ${ }^{1,2 *}$, Meruert Kurmanbayeva ${ }^{2}$ and Ulzhan Erezhetova ${ }^{2}$

1 Institute of Plant Biology and Biotechnology, Almaty, Kazakhstan

2 Al-Farabi Kazakh National University, Almaty, Kazakhstan

*Address all correspondence to: teni02@mail.ru

\section{IntechOpen}

(C) 2019 The Author(s). Licensee IntechOpen. This chapter is distributed under the terms of the Creative Commons Attribution License (http://creativecommons.org/licenses/ by/3.0), which permits unrestricted use, distribution, and reproduction in any medium, provided the original work is properly cited. (cc) BY 


\section{References}

[1] Climate and Disaster Resilience/ United Nations Development Programme. 2015. Available from: http://www.undp.org/content/undp/ en/home/ourwork/climate-anddisasterresilience/overview.html

[2] Gupta RI. A view of researches on steady management of land resources in Central Asia. In: The IKARDA Program in Central Asia and Transcaucasia, Series 1, KGMSHI_ORP, Tashkent, Uzbekistan. 2009

[3] El-Shafey NM, Raifa AH, Mahmoud MAG, El-Sheihy O. Pre-exposure to gamma rays alleviates the harmful effect of drought on the embryo-derived rice calli. Australian Journal of Crop Science. 2009;3(5):268-277

[4] Mafakheri A, Siosemardeh A, Bahramnejad B, Struik PC, Sohrabi Y. Effect of drought stress on yield, proline and chlorophyll contents in three chickpeas cultivars. Australian Journal of Crop Science. 2010;4:580-585

[5] Kilchevsky AV, Khotyleva LV, Lenesh VA, Yurenkova SI, Kartel NA, Shapturenko MN. Genetic bases of plant breeding. In: Kiltshevsky AV, Khotyleva LV, editors. Book of Private Plant Genetics. Vol. 2. Minsk: Belorusskaya Navuka; 2010. 579 p

[6] Hyeon-Hye K, Gregory DG, Raymond MW, John CS. Stomatal conductance of lettuce grown under or exposed to different light qualities. Annals of Botany. 2004;94:691-967

[7] Guo R, Hao WP, Gong DZ, Zhong XL, Gu FX. Effects of water stress on germination and growth of wheat, photosynthetic efficiency and accumulation of metabolites. Chapter 13. In: Soriano MC, editor. Soil Processes and Current Trends in Quality Assessment. licensee InTech; 2013. pp. 367-380. Available from: http://www. intechopen.com/books
[8] Zhuchenko AA. Ecological Genetics of Cultivated Plants and Problems Agrosphere (Theory and Practice). Vol. 1. Moskow: Agrorus; 2004. 689 p

[9] Hramtsova EV. Transformation of internal structure and functional activity of the photosynthetic device of a leaf at species and sorts of Triticum in the course of evolution [thesis]. Kazan, Russia. 2004

[10] Terletskaya NV, Kurmanbayeva MS. Change of leaf anatomical parameters of different species of wheat seedlings under conditions of drought and salt stress. Pakistan Journal of Botany. 2017;49(3):857-865

[11] Shikhmuradov AZ. Bioresource potential and genetic environmental aspects of sustainable representatives of the genus Triticum L. to salt stress [thesis]. Russia: Derbent; 2014

[12] Evans LT, Dunstone R. Some physiological aspects of evolution in wheat. Australian Journal of Biological Sciences. 1970;23:725-741

[13] Fischer RA, Edmeades GO. Breeding and cereal yield progress. Crop Science. 2010;50:85-98. DOI: 10.1371/journal. pone. 0066428

[14] Aminian R, Mohammadi S, Hoshmand SA, Khodambashi M. The genetic analysis of stomatal frequency and size, stomatal conductance, photosynthetic rate and yield in wheat (Triticum aestivum L.) using substitution lines series. Wheat Information Service. 2010;110:25-34

[15] Mohammadi M, Karimizadeh RA, Naghavi MR. Selection of bread wheat genotypes against heat and drought tolerance based on chlorophyll content and stem reserves. Journal of Agriculture \& Social Science. 2009;5:119-122 
[16] Maxwell K, Johnson GN.

Chlorophyll fluorescence-A practical guide. Journal of Experimental Botany. 2000;51(345):659-668. DOI: 10.1093/ jexbot/51.345.659

[17] DeEll JR, Toivonen PMA, editors. Practical Applications of Chlorophyll Fluorescence in Plant Biology. USA: Kluwer Academic Publishers; 2003. pp. $32-71$

[18] Krupnov VA, Tsapaykin AP, Lobachev YV, Ishina GF. Components of the yield and quality of grain of shortstalked spring durum wheat in the Volga region. Doklady Vashnil. 1990;2:2-4

[19] Sharma PM, Bowman M, Madden SL, Rauscher FJ, Sukumar S. Genes \& Development. 1994;8:720-731

[20] Zubairova US, Doroshkov AV. Wheat leaf epidermal pattern as a model for studying the influence of stress conditions on morphogenesis. Vavilovskii Zhurnal Genetiki i Selektsii. 2018;22(7):837-844. DOI: 10.18699/ VJ18.32-o

[21] Limin AE, Fowler DB. Inheritance of cell size in wheat (Triticum aestivum $\mathrm{L}$.) and its relationship to the vernalization loci. Theoretical and Applied Genetics. 2001;103(2):277-281. DOI: $10.1007 / \mathrm{s} 00122-001-0550-4$

[22] Lamari NP, Fayt VI, Naguliak OI. Relationship between stomatal leaf characteristics and frost resistance of bread wheat. Collected Scientific Articles of PBGI-NCSCI. 2014;24(64):6-17

[23] Gudkova GN. Study of leaves of cereals in terms of selection problems. Bulletin of the Adygei State University. Series 4: Natural and Mathematical and Technical Science. 2013;2(119):22-27

[24] Jellings AJ, Leech RM. Anatomical variation in first leaves of nine Triticum genotypes, and its relationship to photosynthetic capacity. The New Phytologist. 1984;96(3):371-382. DOI: 10.1111/j.1469-8137.1984.tb03573.x

[25] Zhu XG, Long SP, Ort DR. Improving photosynthetic efficiency for greater yield. Annual Review Plant Biology. 2010;61:235-261

[26] Amin SA, Fathullah CN, Maoulood PM. Morphological and anatomical responses of four wheat cultivars to water stress. Zanco Journal of Pure and Applied Science. 2015;27(3):41-48

[27] Atabayeva S, Nurmahanova A, Minocha S, Ahmetova A, Kenzhebayeva S, Aidosova S. The effect of salinity on growth and anatomical attributes of barley seedling (Hordeum vulgare L.). African Journal of Biotechnology. 2013;12(18):2366-2377. DOI: $10.5897 /$ AJB2013.12161

[28] Cárcamo HJ, Bustos RM, Fernández FE, Bastías EI. Mitigating effect of salicylic acid in the anatomy of the leaf of Zea mays L. lluteño ecotype from the Lluta Valley (Arica-Chile) under $\mathrm{NaCl}$. Idesia (Arica dic.). 2012;30(3):55-63

[29] Kavelenova LM, Kravtseva AP, Trubnikov AM, Yuankov NV. To the possibilities of assessing the functional activity of leaflets of woody plants. Proceedings of the RAS Samara Scientific Centre. 2013;15(3-7):2333-2336

[30] Flexas J, Diaz-Espejo A, Galmés J, Kaldenhoff R, Medrano H, RibasCarbo M. Rapid variations of mesophyll conductance in response to changes in $\mathrm{CO} 2$ concentration around leaves. Plant, Cell \& Environment. 2007;30:1284-1298

[31] Maksimov NA. Selected works on drought resistance and winter hardiness. T.1. Water regime and drought resistance of plants. Moskow: AS USSR; $1952.575 \mathrm{p}$ 
[32] Popova OA. Anatomic structure of leaves of some early spring blossoming of plants of East Transbaikalia. Scientific Notes of ZABGGPU. 2013;1(48):37-45

[33] Kumakov VA. The correlative relations between bodies of a plant in the course of forming of a harvest. Russian Journal of Plant Physiology. 1980;2:975-985

[34] Oertly JJ. The effect of cell size on cell collapse under negative turgor pressure. Plant Physiology. 1986;124(3-4):365-370

[35] Genkel PA. Physiology Heat and Drought Resistances of Plants. Moskow: Science; $1982.280 \mathrm{p}$

[36] Guerfel M, Baccouri O, Boujnah D, Chaibi W, Zarrouk M. Impacts of water stress on gas exchange, water relations, chlorophyll content and leaf structure in the two main Tunisian olives (Olea europaea L.) cultivars. Scientia Horticulturae. 2009;119:257-263. DOI: 10.1016/j.scienta.2008.08.006

[37] Petrov PI, Kocheva KV, Petrova AS, Georgive GI. Ion leakage and leaf anatomy of barley plant subjected to dehydration. Genetics and Plant Physiology. 2012;2(1-2):15-23

[38] Vasilevskaja VK. Osobennosti stroenija afill'nyh kserofitov. Izvestiya Akademii Nauk Turkmenskoi SSR Seriya Biologicheskikh Nauk. 1955;3:35-43

[39] Mokronosov AT, Bagautdinova RI, Bubnova EA, Kobeleva IV. Fotosinteticheskij metabolizm v palisadnoj i gubchatoj tkanjah lista. Russian Journal of Plant Physiology. 1973;21(6):1132-1138

[40] Dashtoyan YV, Stepanov SA, Kasatkin MY. Mesophile structure of a leaf blade of wheat. Bulletin of the
Botanical garden of the Saratov State University. 2013;11:209-219

[41] Panfilova OV, Golyaev OD. Adaptation of currant to action of a drought and abnormally high temperatures (review). Modern Gardening. 2015;2:88-98. Available from: http://journal.vniispk.ru/

[42] Parker MC, Ford MA. The structure of the mesophyll of flag leaves in three Triticum species. Annals of Botany. 1982;49(2):165-177

[43] Berezina OV, Korchagin YY. To a technique of assessment of mesostructure of a leaf of species of the sort Triticum (Poaceae) in connection with features of a structure of its chlorophyllbearing cells. The Boat Magazine. 1987;72(4):535-541

[44] Rakhmankulova ZF, Mayevskaya SN, Nikolaev MK, Shuyskaya EV, Voronin PY. Strengthening of photosynthesis in leaves of sprouts of corn after a shortterm drought. News of KGTU. 2012;27:113-122

[45] Terletskaya N, Zobova N, Stupko V, Shuyskaya E. Growth and photosynthetic reactions of different species of wheat seedlings under drought and salt stress. Periodicum Biologorum. 2017;119(1):37-45. DOI: 10.18054/pb.v119i1.4408

[46] Biswal AK, Kohli A. Cereal flag leaf adaptations for grain yield under drought: Knowledge status and gaps. Molecular Breeding. 2013;31(4):749-766. DOI: 10.1007/s11032-013-9847-7

[47] Bykov OD, Kazakova EA. Photosynthesis in primary callus culture of potato. In: Proceedings of the International Conference "Photosynthesis and photobiology". 16-73 June 1991; Pushchino. 1991. pp. 106-107 
[48] Stupko VJ, Zobova NV, Gaevskij NA. Biophysical approach to assess stress resistance of spring wheat. Siberian Bulletin of Agricultural Science. 2013;1:18-23

[49] Kozhushko NN. Diagnostics stability of plant resistance to stress. In: Udovenko GV, editor. Methodical Guidance. Leningrad: VIR; 1988. 89 p

[50] Prozina MN. Botanical

Microtechnique. Moscow: MSU; 1960

[51] Permyakova AI. Microtechnique. Moscow: MSU; 1988

[52] Barykina RP. Guide on botanical microtechnique. In: Basics and Methods. Moscow: MSU; 2004

[53] Lichtenthaler HK. Chlorophylls and carotenoids: Pigments of photosynthetic biomembranes. Methods in Enzymology. 1987;148:350-382. DOI: $10.1016 / 0076-6879(87) 48036-1$

[54] Pyarnik TR, Keeberg OF, EYa Y. High-speed exposure chamber for the study of photosynthesis with the help of 14CO2. Plant Physiology. 1987;34:837-845

[55] Laisk AH. Kinetics of Photosynthesis and Photorespiration of C3 Plants. Moscow: Nauka; 1977. 195 p

[56] Gaponenko AK, Malikova NI, Ohrimenko GN, Sozinov AA. Obtaining somaclonal lines in cereals (Triticum aestivum L. \& Hordeum vulgare L.). Reports of the USSR Academy of Sciences. 1985;283:1471-1475

[57] Udolskaya NL. Introduction to Biometrics. Alma-Ata, Science of the Kazakh SSR; 1976. 83 p.

[58] Terletskaya NV, Khailenko NA. Osmotic stress effect on different cytological characters of roots and grown parameters in different wheat species. Annual Research \& Review in Biology. 2015;5(4):347-356

[59] Effects of limited introgressions from Triticum timopheevii Tausch. into the genome of bread wheat (Triticum aestivum L.) on physiological and biochemical traits under normal watering and drought. Vavilovskii Zhurnal Genetiki i Selektsii - Vavilov Journal of Genetics and Breeding. 2015;19(5):574-580. DOI 10.18699/ VJ15.074.

[60] Terletskaya NV, Zobova NV, Stupko VY, Iskakova AB, Lugovtsova SY, Kurmanbaeva MS. Study of the stability of photosynthetic apparatus of soft wheat (T. aestivum L.) and its wild relatives to abiotic stressors in vivo and in vitro. Almaty: IP Volkova; 2017. $172 \mathrm{p}$

[61] Adhikary SK, Alam MZ, Haider SA, Paul NK.Leaf anatomical characters in relation to grain yield of wheat (Triticum aestivum L.) cultivars. Journal of Bio-Science. 2007;15:153-158

[62] Terletskaya N, Zobova N, Stupko V, Iskakova A, Lugovtsova S. Abiotic stresses and callus tissue photomorphogenesis of different wheat species. In Vitro Cellular \& Developmental Biology-Animal. 2017;53(1):56-57

[63] Terletskaya NV, Stupko VY, Iskakova AB, Zobova NV, Gaevsky NA. Photomorphogenesis of wheat embryogenic calli under edaphic stress conditions. Proceedings of the RAS Ufa Scientific Centre. 2018;5(3):43-51

[64] Kabashnikova L. Photosynthetic Apparatus and Productivity Potential of Cereals. Minsk: Belorusskaya Navuka; 2011. 327 p 



\title{
Improving Dual-Purpose Winter Wheat in the Southern Great Plains of the United States
}

\author{
Frank Maulana, Joshua D. Anderson, Twain J. Butler \\ and Xue-Feng $M a$
}

\begin{abstract}
This chapter covers the production and breeding status of winter wheat (Triticum aestivum L.) used for early-season animal grazing and late-season grain production in the Southern Great Plains of the United States. Besides, in the chapter, the current production status and needs, the drawbacks of current cultivars, breeding strategies of the crop, novel genomics tools, and sensor technologies that can be used to improve dual-purpose winter wheat cultivars were presented. We will focus on traits that are, in general, not required by cultivars used for grain-only production but are critical for cool-season forage production.
\end{abstract}

Keywords: seedling vigor, regrowth vigor, grazing tolerance, seedling drought and heat stress tolerance, forage yield, grain yield, winter wheat

\section{Introduction}

Wheat (Triticum aestivum L.) is an important crop grown not only for grain in the world but also for forage production in some countries, such as the United States, Argentina, and Australia, during the cool-season months [1-4]. It is a good source of high-quality forage when other forage species are low in quantity and quality [5]. In the Southern Great Plains of the United States, especially in Oklahoma and Texas, winter wheat is often grown as a dual-purpose crop for both forage and grain production.

According to the United States Department of Agriculture (USDA)'s National Agricultural Statistics Service, about 9-11 million acres of winter wheat were planted annually in Oklahoma and Texas, but a significant portion of them were not harvested because of being used as winter pasture or poor production (Table 1). However, we were not able to get the precise acreage estimate of dual-purpose winter wheat that has been grazed over winter but still harvested for grain. According to a survey, approximately $40 \%$ of wheat acreage in Oklahoma was utilized as dual purpose for both forage grazing and grain production [5].

Compared to a grain-only production system, wheat used for winter grazing is often planted several weeks early, when air temperature is still high in the autumn. However, dual-purpose winter wheat often encounters seedling establishment challenges because of an excessive period of biotic and abiotic stresses resulting from early planting. In addition, wheat planted for forage also suffers grazing stress. 


\begin{tabular}{lcccc}
\hline Year & \multicolumn{2}{c}{ Oklahoma } & \multicolumn{2}{c}{ Texas } \\
\cline { 2 - 5 } & $\begin{array}{c}\text { Planted } \\
\text { (million acres) }\end{array}$ & $\begin{array}{c}\text { Harvested } \\
\text { (million acres) }\end{array}$ & $\begin{array}{c}\text { Planted } \\
\text { (million acres) }\end{array}$ & $\begin{array}{c}\text { Harvested } \\
\text { (million acres) }\end{array}$ \\
\hline 2010 & 5.2 & 3.9 & 5.7 & 3.8 \\
\hline 2011 & 5.1 & 3.2 & 5.3 & 1.9 \\
\hline 2012 & 5.4 & 4.3 & 5.6 & 2.9 \\
\hline 2013 & 5.6 & 3.4 & 6.3 & 2.4 \\
\hline 2014 & 5.3 & 2.8 & 6.0 & 2.3 \\
\hline 2015 & 5.3 & 3.8 & 6.1 & 2.6 \\
\hline 2016 & 5.0 & 3.5 & 5.0 & 2.4 \\
\hline 2017 & 4.5 & 2.9 & 4.7 & 1.6 \\
\hline 2018 & 4.3 & 2.0 & 4.7 & \\
\hline Source: Crop & production (May 2018), USDA, National Agricultural Statistics Service, Southern Plains Regional \\
Field Office. & & & & \\
\hline
\end{tabular}

Table 1.

Winter wheat planted and harvested annually in Oklahoma and Texas.

Therefore, dual-purpose wheat cultivars should adapt to early planting and animal grazing. In this chapter, we will discuss the traits that are critical for dual-purpose winter wheat cultivars and how they could be improved.

\section{Wheat cultivars used for dual-purpose production}

The best cultivars for grain-only production may not be the best for dualpurpose production; therefore, it is crucial to select cultivars that are suitable for a grazing and grain system. Winter wheat cultivars planted in the Southern Great Plains of the United States show significant variation in forage yield [6]. Wheat cultivars that are suitable for grazing and grain should demonstrate both high forage yield and grain yield with tolerance to grazing stress and various other seedling stresses, such as heat, drought, disease, and insect stresses.

However, most current winter wheat cultivars being grown for dual-purpose use were developed for high grain yield and quality [7]. Autumn-winter forage yield, early-planting-associated seedling stresses, grazing tolerance, and regrowth ability have never been the focus of breeding programs because (1) forage yield is often negatively correlated with grain yield, (2) early planting stresses such as seedling heat and drought stresses may not be well evaluated because of climate variability of growing seasons, and (3) evaluation of grazing tolerance and forage yield is quite challenging because of lack of grazing facilities for effective grazing response selection in most wheat breeding programs. A common practice used in developing dual-purpose wheat cultivars is to use simulated grazing (i.e., clipping), which is very different from animal grazing in terms of grazing stresses encountered by the crop [5]. Therefore, proper breeding approaches should be followed to develop cultivars that have competitive autumn-winter forage yield while maintaining comparative grain yield. In addition to many agronomic traits that are generally required for grain production, wheat cultivars ideally grown in dual-purpose production systems should have seedling drought and heat stress tolerance, robust early seedling vigor, regrowth vigor, grazing tolerance, and Hessian fly (Mayetiola destructor) resistance. 


\section{Management practices of dual-purpose winter wheat}

\subsection{Early planting for increased forage yield}

When moisture is available, early planting increases autumn biomass production. In the Southern Great Plains of the United States, farmers can grow winter wheat for forage-only, grain-only, or both forage and grain production [8]. Wheat used for grazing (forage-only or dual-purpose wheat) has been typically planted in early September, while wheat for grain-only production is planted in October. Planting in October minimizes disease and insect infestation, which is prevalent on early-planted wheat [9]. Disease and insect infestation on early-planted wheat can adversely reduce grain yield. There is generally a trade-off between forage production and grain yield when choosing a planting date. Previous research showed that planting 2-4 weeks earlier than the planting date of grain-only wheat can significantly increase autumn forage production by extending the vegetative growth period. In contrast, delaying planting (from September 10 to 30 ) has shown to increase grain yield by $18 \%$ but reduce forage production by $68 \%$ because the crop does not get enough time before winter to accumulate forage biomass [5]. Therefore, the focus of improving wheat for dual-purpose production is to develop cultivars with increased forage production while minimizing grain yield loss trade-off after grazing.

\subsection{Proper grazing management to minimize grain yield loss}

In a dual-purpose wheat production system, ideal grazing management is the key to ensure both high forage yield and high grain yield because grazing has shown to reduce the number of plant tillers, which are crucial for grain production after grazing. In general, grazing starts at least 60 days after planting, when the crown root system is fully developed, to prevent wheat plants from being uprooted by grazing animals [10]. Therefore, whole-plant sampling should be done to assess root development before cattle grazing is initiated. Estimated forage yield at grazing initiation is approximately $1700 \mathrm{~kg} \mathrm{DM} / \mathrm{ha}$. Depending on the environmental conditions, grazing is done in the autumn, spring, or both. However, overgrazing should be avoided to prevent winterkill and reduced grain yield [10]. Grazing should be terminated when green canopy cover falls below $50 \%$ in autumn and $60 \%$ during late winter. Green canopy coverage is crucial for recovery from grazing, to maintain sufficient photosynthetic activity for increased forage biomass and grain production [11].

As a general recommendation, grazing must be stopped no later than the first hollow stem (FHS) stage, a growth stage in which hollow stem is visible above the root system and below the developing head [5]. Failure to stop grazing after FHS results in significant grain yield losses because of the damage to the reproductive structures by grazing [7, 8, 11-14]. Fieser et al. [11] found that grazing 2 weeks after the first FHS reduced grain yield by $10 \%$, with an additional $10 \%$ each week, thereafter. Therefore, dual-purpose winter wheat cultivars with late FHS development will extend the grazing period during spring.

\subsection{Other management practices for a successful dual-purpose production system}

Other management practices, such as increased seeding rates and increased fertilizer rates, should also be considered to ensure a productive dual-purpose system. Greater seeding rates can not only increase forage yield but also stabilize grain yield, as some plants and tillers are lost from cattle trampling during grazing. When winter wheat is used for grazing, seeding rates (112-135 $\mathrm{kg} \mathrm{ha}^{-1}$ ) should be $50-100 \%$ greater 
than that of wheat grown for grain only $\left(65-85 \mathrm{~kg} \mathrm{ha}^{-1}\right)[15,16]$. Similarly, increasing fertilizer application rates for nutrients essential to plant growth, such as nitrogen $(\mathrm{N})$ and phosphorus $(\mathrm{P})$, is crucial for the success of dual-purpose winter wheat [16]. Grazing tends to deplete nutrients, such as $\mathrm{N}$ and $\mathrm{P}$, accumulated in the aboveground biomass; as such, it is a general practice to increase fertilizer application rates for wheat grown for grazing. Nitrogen is one of the most important nutrients, which plays a significant role in regrowth after grazing [17]. Phosphorus application at planting has also shown to increase tillering and forage yield [16]. A common practice is to apply fertilizer nutrients at or before planting; however, care should be taken to not over apply and damage wheat seedlings. A general recommendation is to apply $56 \mathrm{~kg} \mathrm{ha}^{-1}$ of diammonium phosphate (DAP, 18-46-0) by either banding or broadcasting at planting, or by topdressing after plants have completely covered the ground, followed by topdressing with an additional $56 \mathrm{~kg} \mathrm{ha}^{-1}$ of $\mathrm{N}$ fertilizer (urea 46-0-0 or urea ammonium nitrate 33-0-0) when grazing is stopped. Soil sampling before planting to test for $\mathrm{pH}$ and available soil nutrients is helpful in determining the amount of nutrients needed [16].

Early planting also increases the potential risk from damage associated with insects. Fall armyworm (Spodoptera frugiperda) can be especially devastating to early-planted wheat [18]. Fall armyworm does not overwinter in Oklahoma; however, moths are typically blown north by the predominant southern winds during the early fall season and can lay eggs that hatch into larvae that consume forage [18]. Wheat seedlings not yet tillered are most at risk since the larvae can consume the forage to ground level and the seedlings are not able to regrow. The fall armyworm lifecycle completes in 3-4 weeks; thus, several generations can hatch before frost [18]. Scouting early and often is recommended until a killing frost has occurred. As a general rule, pesticide application to control fall armyworm is required about $40 \%$ of the time. Larvae populations can be highly concentrated and sporadic, so pesticide applications are often necessary only along the field perimeters or where moths first land. A treatment threshold is two to four larvae per linear foot of row, and greater control is achieved in small larvae [18].

Early-planted wheat is also at increased risk from sucking insects such as Hessian fly, Russian wheat aphid (Diuraphis noxia), and wheat curl mite (Aceria tosichella). These insects are not particularly damaging themselves; however, they are vectors for various viruses, such as Wheat streak mosaic virus, and Triticum mosaic virus, which can be potentially devastating for grain production [19] although causing minor loss in forage yield. Control measures are limited, as few tolerant varieties are available and pesticide applications are typically ineffective. Typical control is achieved from later planting dates and maintaining "green-free" fields for a minimum of 14 days before planting; however, these control measures are often not used when wheat is grown for forage.

\section{Improving traits of wheat cultivars desirable for dual-purpose production systems}

\subsection{Seedling drought and heat stress tolerance}

In the Southern Great Plains of the United States, farming is generally waterlimited, as drought occasionally occurs and impacts the whole agricultural system. Wheat grown for dual-purpose use often encounters seedling establishment challenges because of drought and heat stresses at the seedling stage. According to current climate predictions, water will become scarce by the year 2025 and more farming land will be drought-stressed [20]. Previous studies have found yield losses 
associated with drought stress during the early vegetative growth of wheat to be as high as $79.7 \%[21,22]$. During the seedling stage, the stress can reduce the photosynthetic activity and respiration rate of seedlings, eventually causing them to die because of excessive dehydration [23-25].

Similarly, heat stress continues to be a pressing challenge to the crop. It is anticipated that the average global temperature will increase by $1-4^{\circ} \mathrm{C}$ by the end of the twenty-first century [26]. Heat stress affects the growth and development of wheat by impairing its morphological, physiological, and biochemical processes [24, 27-31]. The stress can impair the thylakoid membrane and photosystem II, a very important compartment of the plant cell involved in photosynthetic activity $[23,32,33]$. Therefore, development of seedling drought- and heat-tolerant cultivars is crucial for wheat being used in dual-purpose production systems in the region.

The two stresses at seedling stage are very difficult to phenotype under field conditions because of their genetic complexity, weather variability, interaction between the two stresses, and interaction with the environment. Generally, manual phenotyping of the stresses is tedious and time-consuming; in addition, stress response and data quality largely depend on plant growth and weather conditions. For this reason, marker-assisted selection (MAS) of the traits should be adopted once quantitative trait loci (QTLs) or genes are identified.

To date, QTL studies for drought tolerance have focused on either the flowering or the grain-filling stage of wheat [34-38] with few studies being done at the seedling stage. Similarly, QTLs for heat tolerance during the vegetative or the grain-filling stage have been discovered [32, 39, 40]. Recently, a QTL study for seedling heat tolerance was conducted under controlled growth chamber conditions using winter wheat cultivars collected across the Great Plains of the United States [41]. This study detected multiple QTLs in different chromosomes spreading across the wheat genome [41]. The molecular markers identified to date will facilitate the selection of seedling drought and heat tolerance during dual-purpose wheat breeding.

\subsection{Early-seedling vigor and regrowth vigor}

Robust early-seedling vigor and regrowth vigor traits are important for both forage and grain production because early-seedling vigor indicates the initial forage yield, while regrowth vigor reflects grazing tolerance and grain yield potential $[5,10]$. For example, one previous study reported improved dry matter accumulation and grain yield from wheat lines with strong early-seedling vigor [42]. Over the years, seedling height and dry biomass weight have been used as good indicators of early-seedling vigor in different crop species, including wheat [43], maize (Zea mays) [44], and rice (Oryza sativa) [45]. In addition, early-seedling and regrowth vigor traits enhance the competitive ability of cultivars against invading weed species.

However, phenotyping early-seedling and regrowth vigor traits using phenotypic selection under field conditions is challenging because the traits are polygenic in nature and they are very hard to characterize. Therefore, identification of reliable molecular markers associated with the traits would facilitate cultivars' development using MAS. Currently, little research is being done to understand the genetic architecture of the early-seedling vigor and regrowth vigor that are negligible to grain-only production systems but crucial to cool-season wheat pasture in dualpurpose production systems. In addition, there is a need to employ high-throughput phenotyping technologies to characterize early-seedling vigor and regrowth vigor. Recently, unmanned aerial vehicles (UAVs) have been developed and adopted for use in large-scale phenotyping. However, the UAVs are not amenable to capturing high-resolution images of small plants such as seedlings because they were designed to fly at specified altitudes above the ground, making it difficult to record detailed 
information for small plants $[46,47]$. Alternatively, small plants can be characterized using ground-based automated platforms at high-throughput phenotyping scales [48-50]. Image-based phenotyping offers a feasible tool to capture high-resolution images for evaluating seedling traits. Therefore, MAS and high-throughput phenotyping methods should be adopted to improve breeding efficiency of dual-purpose wheat cultivars with desired early-seedling vigor and regrowth vigor.

\subsection{Grazing tolerance}

Grazing tolerance is an important trait for sustainable production of autumnwinter forage biomass under forage-only and dual-purpose management systems. This trait is even more complex in nature; as such, it is extremely difficult to evaluate under field conditions. Presently, little work has been done to understand and to assess grazing tolerance in wheat. In alfalfa (Medicago sativa), grazing tolerance involves many interrelated morphological and physiological traits that interact with grazing activities and environmental conditions [51, 52]. Over the years, grazing tolerance has often been assessed by the survival of the plants after grazing or simulated clipping. However, evaluation of grazing tolerance using simulated clipping has not been successful in alfalfa $[51,52]$. Counce et al. found no correlation between alfalfa's response to clipping and its response to grazing [52]. These studies concluded that the best way to phenotype grazing tolerance is to expose plants to stresses caused by the grazing animals rather than by simulated grazing [53]. The same principal could be applied to selecting grazing tolerance in wheat. However, most wheat breeding programs do not use grazing tolerance as a selection trait during the early stages of cultivar development because of limited grazing facilities.

Selection of grazing-tolerant plants is more effective under continuous stocking compared to selection based on morphological traits [51]. The "standard test protocol," whereby intensive grazing was incorporated with continuous stocking, was developed in alfalfa [51]. This protocol is currently used in phenotyping grazing tolerance by both public and private alfalfa breeders and in cultivar evaluation programs in the United States and other countries. However, it is still uncertain whether this protocol is applicable to the annual crop wheat. To date, there is no reliable phenotyping method that can efficiently assess variation in grazing tolerance during dual-purpose wheat breeding. No molecular markers associated with grazing tolerance have been identified for use in MAS. Therefore, QTL mapping or marker-trait association of grazing tolerance is needed before MAS becomes a feasible tool in selecting grazing tolerance of dual-purpose wheat.

\subsection{Hessian fly resistance}

The Hessian fly is one of the most destructive pests of wheat in the world, including the dual-purpose-wheat-growing areas in the Southern Great Plains of the United States. The fly can significantly reduce grain yield and quality by damaging leaves and stems of wheat in fall and spring. Its outbreaks have become more common in the last decade [54]. The fly preferably attacks wheat, but other cereal crops can also be the hosts [55].

Over the years, fly-free planting dates have been identified in some wheatgrowing areas of the United States for managing Hessian fly. Wheat planted after the fly-free date is less likely to be infested [55]. However, it is impractical to delay planting for wheat grown for winter grazing in dual-purpose production systems. Although Hessian fly populations can be controlled by management practices such as stubble destruction and crop rotation, growing varieties resistant to the fly is the most economical strategy [55]. 
In the dual-purpose-wheat-growing areas, the chance of a Hessian fly outbreak is much greater than in areas growing wheat for grain only because of the extended growing season resulting from early sowing. No-till practice also increases the risk of widespread Hessian fly occurrence in general [55]. Therefore, developing cultivars that are resistant to the fly is critical for securing wheat production.

During the last two decades, great progress has been made in identifying Hessian fly biotypes, mapping and transferring resistant genes, characterizing resistant germplasm, and developing genetic markers for MAS [54-58]. To date, at least 18 Hessian fly biotypes have been classified, and at least 34 Hessian fly-resistant genes have been described in wheat and its relatives [57]. A few major resistant genes have been precisely mapped and effectively used in breeding wheat cultivars resistant to the Hessian fly using MAS $[57,58]$. As selecting genotypes resistant to the Hessian fly is impractical in the field, MAS will be the most effective approach in breeding wheat cultivars resistant to the fly, and it has become a common practice in several wheat breeding programs in the Southern Great Plains of the United States.

\subsection{Other traits significantly affecting grain yield}

Besides the major traits discussed above that could significantly affect forage yield, winter wheat should also have a package of comprehensive traits required for grain production. The common traits that significantly affect grain yield and quality include resistance to various diseases and pests, tolerance to various abiotic stresses, lodging resistance, and high grain yield and quality. The most common diseases and pests include powdery mildew, leaf rust, stripe rust, Wheat streak mosaic virus, Fusarium head blight, wheat curl mite, greenbug, and Russian wheat aphid [59], and the most common abiotic stresses are drought and heat stresses at the flowering and grain-filling stages. Most of these traits have been the focuses of QTL or gene mapping in the wheat research community, and diagnostic molecular markers are available for MAS [59]; thus, they are not the focus of this chapter.

\section{Adopting novel technologies to improve wheat cultivars desirable for dual-purpose production systems}

\subsection{Genomic tools}

Plant breeders have attempted to use genomic markers to increase selection efficiency and accelerate breeding cycles. Molecular markers facilitate selection of important traits or genes that are interesting to breeders; thus, they play a major role in the genetic improvement of crop plants $[60,61]$. In wheat, a vast number of QTLs or genes have been mapped, and markers tightly linked to the genes have been validated for MAS [59]. Marker-assisted selection has been very useful for selecting some traits that are hard to phenotype in the field. However, markers being used in breeding are still restricted to traits that are controlled by major genes, which have relatively large effects [59]. Unfortunately, only rarely have studies been done on forage-relevant traits, such as seedling drought and heat tolerance, early-seedling vigor, regrowth vigor, and grazing tolerance, which are critical for forage yield in dual-purpose production systems. Therefore, QTL mapping or marker-trait association of forage traits needs to be conducted for MAS in dual-purpose wheat breeding. The recent release of the wheat reference genome sequence [62] will undoubtedly accelerate marker discoveries of any traits that are of interest.

As most forage traits, such as grazing tolerance, are very complex in nature, genomic selection (GS) could be a good alternative option in dual-purpose wheat 
breeding. Genomic selection is a form of MAS whereby the breeding values of individuals with only genotype data are predicted using marker effects estimated from individuals with both genotypes and phenotypes from a training population. Although MAS is considered more efficient than phenotypic selection [63, 64], it has not been effective for complex traits [65]. In addition, MAS is not applicable across populations with different genetic backgrounds, and it requires significant efforts in marker-trait analysis to identify large-effect QTLs. In contrast, GS does not require marker-trait analysis, and it is suitable for complex traits. Therefore, GS is regarded as a better option than MAS $[66,67]$.

Moreover, GS has shown to improve genetic gain, reduce phenotyping costs, and accelerate the development of new cultivars by reducing the selection cycle [68]. So far, a number of GS models, including ridge regression best linear unbiased prediction (RR-BLUP) [69], Gaussian kernel (GAUSS) [69], and Bayesian LASSO (least absolute shrinkage and selection operator) [70], have been developed. Studies of the GS models in forage traits of dual-purpose wheat showed moderate to high prediction accuracies, ranging from 0.34 to 0.74 , suggesting that at least some of the forage traits can be predicted with acceptable accuracy in wheat breeding (Maulana et al., unpublished data). Therefore, given the complexity of the forage traits to be selected and resource limitation, GS provides an alternative approach to facilitate trait selection during dual-purpose winter wheat breeding.

\subsection{Sensor technologies for phenotyping forage yield traits}

Forage biomass yield is one of the major target traits to improve in dual-purpose wheat breeding. However, manual phenotyping of the forage yield by harvesting and weighing forage samples at field breeding scales is not amenable in practice. Physical measurements of plant height and biomass estimation in different forage species have been performed using rising plate meters, capacitance meters, and meter sticks [71-74]. However, not only are these methods laborious and time-consuming, but it is also difficult to develop a reliable estimation model with them [75].

Recently, remote sensing has been developed and used successfully to predict plant height and forage biomass using ultrasonic, laser, and spectral sensors in different forage species [75-78]. The remote sensors greatly facilitate biomass estimation in field breeding because they are able to estimate biomass of a large sampling area within a short period of time. One of the parameters that has been most commonly used to predict biomass is the normalized difference vegetation index (NDVI). Normalized difference vegetation index has been employed in biomass estimation in several crops, such as wheat, maize, rice, bermudagrass (Cynodon dactylon), and alfalfa, with correlations between NDVI and biomass ranging from 0.52 to 0.84 [79]. These correlations suggest that NDVI is a good predictor of aboveground biomass. The prediction accuracies can be further increased when prediction models incorporate NDVI with proximal sensors, such as ultrasonic and laser height measurements [75].

In addition, forage nutritive values can also be predicted by modeling plant crude protein (CP) contents using a hyperspectral passive spectrometer [80]. Forage quality analysis has often been performed using near-infrared spectroscopy (NIRS) [81]. Positive high correlations were observed between CP measurements from NIRS and CP estimates from a hyperspectral reflectance model in wheat, bermudagrass, and tall fescue [80]. Therefore, sensor phenotyping platforms greatly increased the breeding efficiency, and facilitated the selection of forage biomass and quality traits during dual-purpose winter wheat breeding. 


\section{Summary}

Winter wheat is an important crop grown in the Southern Great Plains of the United States. It is often grown for grazing during the cool-season months, when most forage species are not productive, and for grain under a dual-purpose or grain-only management system. The profit of managing wheat as a dual-purpose crop is usually better than managing it as a grain-only or forage-only crop when growing conditions are favorable because of alternative income options from livestock and/or grain. However, winter wheat cultivars grown for dual-purpose use are mostly developed for high grain yield only. Therefore, there is a need to develop wheat cultivars desirable for dual-purpose production systems in the region. The traits, such as seedling vigor, seedling tolerance to various stresses, and grazing tolerance, highlighted in this chapter, in general, are not required by or not important for cultivars used for grain-only production, but they are critical for cultivars desired for both cool-season grazing and end-season grain yield in dual-purpose production systems. Novel genomics tools will provide resources to increase the selection efficiencies of complex forage traits, and sensor technologies will significantly facilitate large-scale field phenotyping and selection. Therefore, it is expected that winter wheat cultivars can be improved desirably for dual-purpose production systems in the Southern Great Plains of the United States.

\section{Acknowledgements}

The authors sincerely thank Andrea Mongler for critical reading of the book chapter.

\section{Conflict of interest}

The authors declare no conflicts of interest.

\section{Author details}

Frank Maulana, Joshua D. Anderson, Twain J. Butler and Xue-Feng Ma*

Noble Research Institute, Ardmore, OK, USA

*Address all correspondence to: xma@noble.org

IntechOpen

(C) 2019 The Author(s). Licensee IntechOpen. This chapter is distributed under the terms of the Creative Commons Attribution License (http://creativecommons.org/licenses/ by/3.0), which permits unrestricted use, distribution, and reproduction in any medium, provided the original work is properly cited. (cc) BY 


\section{References}

[1] MacKown CT, Carver BF, Edwards JT. Variation in crude protein and in vitro dry matter digestion of wheat forage. Crop Science. 2011;51:878-891

[2] MacKown CT, Northup BK. Crude protein and nitrate concentrations of fall forage for stocker cattle: Wheat vs. perennial cool-season grasses. Crop Science. 2010;50:2140-2147

[3] Arzadún MJ, Arroquy JI, Laborde HE, Brevedan RE. Effect of planting date, clipping height, and cultivar on forage and grain yield of winter wheat in Argentinean Pampas. Agronomy Journal. 2006;98:1274-1279

[4] Dove H, Kirkegaard J, Kelman W, Sprague S, McDonald S, Graham J. Integrating dual-purpose wheat and canola into high-rainfall livestock systems in south-eastern Australia. 2. Pasture and livestock production. Crop and Pasture Science. 2015;66: 377-389

[5] Hossain I, Epplin FM, Krenzer EG. Planting date influence on dual-purpose winter wheat forage yield, grain yield, and test weight. Agronomy Journal. 2003;95:1179-1188

[6] Kim KS, Anderson JD, Newell MA, Grogan SM, Byrne PF, Baenziger PS, et al. Genetic diversity of great plains hard winter wheat germplasm for forage. Crop Science. 2016;56:2297-2305

[7] Khalil IH, Carver BF, Krenzer EG, MacKown CT, Horn GW. Genetic trends in winter wheat yield and test weight under dual-purpose and grain-only management systems. Crop Science. 2002;42:710-715

[8] Redmon LA, Horn GW, Krenzer EG, Bernardo DJ. A review of livestock grazing and wheat grain yield:
Boom or bust? Agronomy Journal. 1995;87:137-147

[9] Carver B, Khalil I, Krenzer E, MacKown C. Breeding winter wheat for a dual-purpose management system. Euphytica. 2001;119:231-234

[10] Edwards J, Carver B, Horn G, Payton M. Impact of dual-purpose management on wheat grain yield. Crop Science. 2011;51:2181-2185

[11] Fieser B, Horn G, Edwards J, Krenzer E Jr. Timing of grazing termination in dual-purpose winter wheat enterprises. The Professional Animal Scientist. 2006;22:210-216

[12] Winter S, Thompson E. Grazing duration effects on wheat growth and grain yield. Agronomy Journal. 1987;79:110-114

[13] Horn GW. Growing cattle on winter wheat pasture: Management and herd health considerations. Veterinary Clinics: Food Animal Practice.

2006;22:335-356

[14] Edwards J, Horn G. First Hollow Stem: A Critical Growth Stage for Dual-Purpose Producers. Oklahoma Cooperative Extension Service; Stillwater, USA: Oklahoma State University; 2010. PSS-2147

[15] Lollato R, Duncan S. Managing Wheat for Forage and Grain: The Dual-Purpose System. Kansas State University Research and Extension eUpdate. 2016. Available from: https:// webapp.agron.ksu.edu/agr_social/ eupdates/eUpdate080516.pdf.

[Accessed: 02 August 2019]

[16] Lollato RP, Marburger D, Holman JD, Tomlinson P, Presley D, Edwards JT. Dual Purpose Wheat: Management for Forage and Grain Production. Oklahoma State University, Stillwater, USA: 
Oklahoma Cooperative Extension

Service; 2017. PSS-2178

[17] Edwards J, Godsey C, Raun B, Taylor R. Fall nitrogen requirements for winter wheat. Oklahoma State University Department of Plant and Soil Sciences Production Technology Report. 2006;18:10

[18] Royer TA, Giles KL. Common Small Grain Caterpillars in Oklahoma. Oklahoma State University, Stillwater, USA: Oklahoma Cooperative Extension Service; 2017. EPP-7094

[19] Hunger B, Kochenower R, Royer T, Olson J, Edwards J. Wheat Streak Mosaic, High Plains Disease and Triticum Mosaic: Three Virus Diseases of Wheat in Oklahoma. Oklahoma State University, Stillwater, USA: Oklahoma Cooperative Extension Service; 2017. EPP-7328

[20] Nezhadahmadi A, Prodhan ZH, Faruq G. Drought tolerance in wheat. The Scientific World Journal. 2013;2013:610721. DOI: $10.1155 / 2013 / 610721$

[21] Tuberosa R, Salvi S. Genomicsbased approaches to improve drought tolerance of crops. Trends in Plant Science. 2006;11:405-412. DOI: 10.1016/j.tplants.2006.06.003

[22] Sivamani E, Bahieldin A, Wraith JM, Al-Niemi T, Dyer WE, Ho THD, et al. Improved biomass productivity and water use efficiency under water deficit conditions in transgenic wheat constitutively expressing the barley HVA1 gene. Plant Science. 2000;155:1-9. DOI: 10.1016/S0168-9452(99)00247-2

[23] Ristic Z, Bukovnik U, Prasad PVV. Correlation between heat stability of thylakoid membranes and loss of chlorophyll in winter wheat under heat stress. Crop Science. 2007;47:2067-2073. DOI: 10.2135/ cropsci2006.10.0674
[24] Cossani CM, Reynolds MP. Physiological traits for improving heat tolerance in wheat. Plant Physiology. 2012;160:1710-1718

[25] Dhanda S, Sethi G, Behl R. Inheritance of seedling traits under drought stress conditions in bread wheat. Cereal Research Communications. 2002;30:293-300

[26] Driedonks N, Rieu I, Vriezen WH. Breeding for plant heat tolerance at vegetative and reproductive stages. Plant Reproduction. 2016;29:67-79. DOI: 10.1007/s00497-016-0275-9

[27] Paliwal R, Röder MS, Kumar U, Srivastava J, Joshi AK. QTL mapping of terminal heat tolerance in hexaploid wheat (T. aestivum L.). Theoretical and Applied Genetics. 2012;125:561-575

[28] Chaturvedi AK, Bahuguna RN, Shah D, Pal M, Jagadish SVK. High temperature stress during flowering and grain filling offsets beneficial impact of elevated $\mathrm{CO}\left({ }_{2}\right)$ on assimilate partitioning and sink-strength in rice. Scientific Reports. 2017;7:8227. DOI: 10.1038/s41598-017-07464-6

[29] Feng B, Liu P, Li G, Dong ST, Wang FH, Kong LA, et al. Effect of heat stress on the photosynthetic characteristics in flag leaves at the grain-filling stage of different heatresistant winter wheat varieties. Journal of Agronomy and Crop Science. 2014;200:143-155. DOI: 10.1111/jac.12045

[30] El-Rawy MAE, Youssef M. Evaluation of drought and heat tolerance in wheat based on seedling traits and molecular analysis. Journal of Crop Science and Biotechnology. 2014;17:183-189. DOI: 10.1007/ s12892-014-0053-x

[31] Ni Z, Li H, Zhao Y, Peng H, Hu Z, Xin $\mathrm{M}$, et al. Genetic improvement of 
heat tolerance in wheat: Recent progress in understanding the underlying molecular mechanisms. The Crop Journal. 2018;6:32-41. DOI: 10.1016/j. cj.2017.09.005

[32] Talukder SK, Babar MA, Vijayalakshmi K, Poland J, Prasad PVV, Bowden R, et al. Mapping QTL for the traits associated with heat tolerance in wheat (Triticum aestivum L.). BMC Genetics. 2014;15:97

[33] Ristic Z, Bukovnik U, Momčilović I, Fu J, Prasad PV. Heat-induced accumulation of chloroplast protein synthesis elongation factor, EF-Tu, in winter wheat. Journal of Plant Physiology. 2008;165:192-202

[34] Gahlaut V, Jaiswal V, Tyagi BS, Singh G, Sareen S, Balyan HS, et al. QTL mapping for nine drought-responsive agronomic traits in bread wheat under irrigated and rain-fed environments. PLoS One. 2017;12:e0182857. DOI: 10.1371/journal.pone.0182857

[35] Shi S, Azam FI, Li H, Chang X, Li B, Jing R. Mapping QTL for stay-green and agronomic traits in wheat under diverse water regimes. Euphytica. 2017;213:246. DOI: 10.1007/ s10681-017-2002-5

[36] Li X, Xia X, Xiao Y, He Z, Wang D, Trethowan R, et al. QTL mapping for plant height and yield components in common wheat under water-limited and full irrigation environments. Crop and Pasture Science. 2015;66:660-670. DOI: 10.1071/CP14236

[37] Sukumaran S, Reynolds MP, Sansaloni C. Genome-wide association analyses identify qtl hotspots for yield and component traits in durum wheat grown under yield potential, drought, and heat stress environments. Frontiers in Plant Science. 2018;9:81. DOI: 10.3389/fpls.2018.00081

[38] Mwadzingeni L, Shimelis H, Rees DJG, Tsilo TJ. Genome-wide association analysis of agronomic traits in wheat under drought-stressed and non-stressed conditions. PLoS One. 2017;12:e0171692. DOI: 10.1371/journal. pone. 0171692

[39] Mason RE, Mondal S, Beecher FW, Pacheco A, Jampala B, Ibrahim AM, et al. QTL associated with heat susceptibility index in wheat (Triticum aestivum L.) under shortterm reproductive stage heat stress. Euphytica. 2010;174:423-436

[40] Vijayalakshmi K, Fritz AK, Paulsen GM, Bai G, Pandravada S, Gill BS. Modeling and mapping QTL for senescence-related traits in winter wheat under high temperature. Molecular Breeding. 2010;26:163-175. DOI: $10.1007 /$ s11032-009-9366-8

[41] Maulana F, Ayalew H, Anderson JD, Kumssa TT, Huang W, Ma XF. Genomewide association mapping of seedling heat tolerance in winter wheat. Frontiers in Plant Science. 2018;9:1272. DOI: 10.3389/fpls.2018.01272

[42] Ellis R. Seed and seedling vigour in relation to crop growth and yield. Plant Growth Regulation. 1992;11:249-255

[43] Regan K, Siddique K, Turner N, Whan B. Potential for increasing early vigour and total biomass in spring wheat. II. Characteristics associated with early vigour. Australian Journal of Agricultural Research. 1992;43:541-553

[44] Rehman H, Iqbal H, Basra SMA, Afzal I, Farooq M, Wakeel A, et al. Seed priming improves early seedling vigor, growth and productivity of spring maize. Journal of Integrative Agriculture. 2015;14:1745-1754

[45] Lu XL, Niu AL, Cai HY, Zhao Y, Liu JW, Zhu YG, et al. Genetic dissection of seedling and early vigor in a recombinant inbred line population of rice. Plant Science. 2007;172:212-220. DOI: 10.1016/j.plantsci.2006.08.012 
[46] Shi Y, Thomasson JA, Murray SC, Pugh NA, Rooney WL, Shafian S, et al. Unmanned aerial vehicles for highthroughput phenotyping and agronomic research. PLoS One. 2016;11:e0159781. DOI: 10.1371/journal.pone.0159781

[47] Yang G, Liu J, Zhao C, Li Z, Huang Y, $\mathrm{Yu} \mathrm{H}$, et al. Unmanned aerial vehicle remote sensing for field-based crop phenotyping: Current status and perspectives. Frontiers in Plant Science. 2017;8:1111-1126. DOI: 10.3389/ fpls.2017.01111

[48] Lee U, Chang S, Putra GA, Kim H, Kim DH. An automated, highthroughput plant phenotyping system using machine learning-based plant segmentation and image analysis. PLoS One. 2018;13:e0196615. DOI: 10.1371/ journal.pone.0196615

[49] Berger B, de Regt B, Tester M. High-throughput phenotyping of plant shoots. In: Normanly J, editor. HighThroughput Phenotyping in Plants. Methods in Molecular Biology, Methods and Protocols. Vol. 918. Totowa, NJ: Humana Press; 2012. p. 9-20. DOI: 10.1007/978-1-61779-995-2_2

[50] Crimmins MA, Crimmins TM. Monitoring plant phenology using digital repeat photography. Environmental Management. 2008;41:949-958

[51] Smith S Jr, Bouton J, Singh A, McCaughey W. Development and evaluation of grazing-tolerant alfalfa cultivars: A review. Canadian Journal of Plant Science. 2000;80:503-512

[52] Counce P, Bouton J, Brown R. Screening and characterizing alfalfa for persistence under mowing and continuous grazing. Crop Science. 1984;24:282-285

[53] Bouton J, Hoveland C, Gates R, editors. Use of the grazing animal in forage breeding. In: Proceedings of the XVIll International Grassland Congress. 1997
[54] Chen MS, Echegaray E, Whitworth RJ, Wang H, Sloderbeck PE, Knutson A, et al. Virulence analysis of Hessian fly populations from Texas, Oklahoma, and Kansas. Journal of Economic Entomology. 2009;102:774-780

[55] Royer TA, Edwards JT, Giles KL. Hessian Fly Management in Oklahoma Winter Wheat. Oklahoma State University, Stillwater, USA: Oklahoma Cooperative Extension Service; 2009. EPP-7086

[56] Cox T, Hatchett J. Hessian flyresistance gene $\mathrm{H} 26$ transferred from Triticum tauschii to common wheat. Crop Science. 1994;34:958-960

[57] Tan CT, Yu H, Yang Y, Xu X, Chen M, Rudd JC, et al. Development and validation of KASP markers for the greenbug resistance gene $\mathrm{Gb} 7$ and the Hessian fly resistance gene $\mathrm{H} 32$ in wheat. Theoretical and Applied Genetics. 2017;130:1867-1884

[58] Li G, Wang Y, Chen MS, Edae E, Poland J, Akhunov E, et al. Precisely mapping a major gene conferring resistance to Hessian fly in bread wheat using genotyping-by-sequencing. BMC Genomics. 2015;16:108

[59] Liu S, Rudd JC, Bai G, Haley SD, Ibrahim AM, Xue Q, et al. Molecular markers linked to important genes in hard winter wheat. Crop Science. 2014;54:1304-1321

[60] Semagn K, Bjørnstad Å, Ndjiondjop M. An overview of molecular marker methods for plants. African Journal of Biotechnology. 2006;5:2540-2568

[61] Collard BC, Mackill DJ. Markerassisted selection: An approach for precision plant breeding in the twentyfirst century. Philosophical Transactions of the Royal Society, B: Biological Sciences. 2007;363:557-572 
[62] Appels R, Eversole K, Feuillet C, Keller B, Rogers J, Stein N, et al. Shifting the limits in wheat research and breeding using a fully annotated reference genome. Science.

2018;361:eaar7191. DOI: 10.1126/ science.aar7191

[63] Castro AJ, Capettini F, Corey A, Filichkina T, Hayes PM, Kleinhofs A, et al. Mapping and pyramiding of qualitative and quantitative resistance to stripe rust in barley. Theoretical and Applied Genetics. 2003;107:922-930

[64] Xu Y, Crouch JH. Marker-assisted selection in plant breeding: From publications to practice. Crop Science. 2008;48:391-407

[65] Bernardo R. Genomewide selection with minimal crossing in self-pollinated crops. Crop Science. 2010;50:624-627

[66] Heffner EL, Sorrells ME, Jannink JL. Genomic selection for crop improvement. Crop Science. 2009;49(1):1-12

[67] Lorenz AJ, Chao S, Asoro FG, Heffner EL, Hayashi T, Iwata H, et al. Genomic selection in plant breeding: Knowledge and prospects. Advances in Agronomy. 2011;110:77-123

[68] Heffner EL, Lorenz AJ, Jannink J-L, Sorrells ME. Plant breeding with genomic selection: Gain per unit time and cost. Crop Science. 2010;50:1681-1690

[69] Endelman JB. Ridge regression and other kernels for genomic selection with $\mathrm{R}$ package rrBLUP. The Plant Genome. 2011;4:250-255

[70] Park T, Casella G. The Bayesian LASSO. Journal of the American Statistical Association. 2008;103:681-686

[71] Sanderson MA, Rotz CA, Fultz SW, Rayburn EB. Estimating forage mass with a commercial capacitance meter, rising plate meter, and pasture ruler. Agronomy Journal. 2001;93:1281-1286

[72] Fehmi J, Stevens J. A plate meter inadequately estimated herbage mass in a semi-arid grassland. Grass and Forage Science. 2009;64:322-327

[73] Dougherty M, Burger JA, Feldhake CM, AbdelGadir A. Calibration and use of plate meter regressions for pasture mass estimation in an Appalachian silvopasture. Archives of Agronomy and Soil Science. 2013;59:305-315

[74] Tucker CJ. A critical review of remote sensing and other methods for non-destructive estimation of standing crop biomass. Grass and Forage Science. 1980;35:177-182

[75] Pittman JJ, Arnall DB, Interrante SM, Moffet CA, Butler TJ. Estimation of biomass and canopy height in bermudagrass, alfalfa, and wheat using ultrasonic, laser, and spectral sensors. Sensors. 2015;15:2920-2943

[76] Fricke T, Wachendorf M. Combining ultrasonic sward height and spectral signatures to assess the biomass of legume-grass swards. Computers and Electronics in Agriculture. 2013;99:236-247

[77] Fricke T, Richter F, Wachendorf M. Assessment of forage mass from grassland swards by height measurement using an ultrasonic sensor. Computers and Electronics in Agriculture. 2011;79:142-152

[78] Scotford I, Miller P. Combination of spectral reflectance and ultrasonic sensing to monitor the growth of winter wheat. Biosystems Engineering. 2004;87:27-38

[79] Freeman KW, Girma K, Arnall DB, Mullen RW, Martin KL, Teal RK, et al. By-plant prediction of corn forage biomass and nitrogen uptake at various 
Improving Dual-Purpose Winter Wheat in the Southern Great Plains of the United States DOI: http://dx.doi.org/10.5772/intechopen.86417

growth stages using remote sensing and plant height. Agronomy Journal. 2007;99:530-536

[80] Pittman JJ, Arnall DB, Interrante SM, Wang N, Raun WR, Butler TJ.

Bermudagrass, wheat, and tall fescue crude protein forage estimation using mobile-platform, active-spectral and canopy-height data. Crop Science.

2016;56:870-881

[81] Norris K, Barnes R, Moore J, Shenk J. Predicting forage quality by infrared replectance spectroscopy. Journal of Animal Science.

1976;43:889-897 



\title{
Wheat Production in India: Trends and Prospects
}

\author{
Sendhil Ramadas, T.M. Kiran Kumar \\ and Gyanendra Pratap Singh
}

\begin{abstract}
Trends in Indian wheat production before and after the inception of the All India Coordinated Research Project (AICRP) on wheat have been analyzed to show its significant progress over the years. A brief intercountry comparison of productivity, production and area coupled with regional comparison within India has been attempted to give an idea about the contribution of country and regions, respectively, for global and national food security. The milestones in Indian wheat programme and research outcomes were highlighted post-AICRP along with the vision and strategies set for 2050 against diverse production challenges. Regional disparities, zone-wise production constraints and research programmes for achieving the set production target were briefed. The chapter concludes with possible interventions in strengthening the complete wheat value chain for ensuring food security for the future generation.
\end{abstract}

Keywords: wheat, AICRP on wheat, vision 2050, yield gaps, trends

\section{Introduction}

Cereals play a pivotal role to satisfy the global food demand of growing population, particularly in developing nations where cereal-based production system is the only predominant source of nutrition and calorie intake $[1,2]$. The nutririch cereal is grown in diversified environments; globally wheat occupies around 217 million hectares holding the position of highest acreage among all crops with an annual production hovering around 731 million tonnes [3]. Wheat (Triticum aestivum L.) is one of the principal cereal crops grown worldwide and one of the important staples of nearly 2.5 billion of world population. Wheat is the major staple food crop, providing almost half of all calories in the region of North Africa and West and Central Asia. Being next to rice, wheat constitutes one of the key sources of protein in least developed countries and middle-income nations and in terms of calories and dietary intake. The crop being cultivated as winter and spring in the world, winter wheat is grown in cold countries like Europe, the USA, Australia, Russian Federation, etc., while spring wheat is grown in Asia and in some parts of the USA.

India, being blessed and enriched with a diverse agroecological condition, ensuring food and nutrition security to a majority of the Indian population through production and steady supply particularly in the recent past, is the 
second largest producer of wheat worldwide [4-6]. The crop has been under cultivation in about 30 million hectares (14\% of global area) to produce the alltime highest output of 99.70 million tonnes of wheat (13.64\% of world production) with a record average productivity of $3371 \mathrm{~kg} / \mathrm{ha}$ [7]. Having a significant share in consumption of food basket with a $36 \%$ share in the total food grains produced from India and ensuring not only food security but also nutrition security, wheat is extensively procured by the government and distributed to a majority of the population; it ensures not only food security but also nutrition security. The cereal is one of the cheapest sources of energy, provides a major share of protein $(20 \%)$ and calorie intake (19\%) from consumption. Wheat is accessible across the country and consumed as various processed forms from prehistoric times [4].

After independence, India was net deficit in food production and had to import wheat for domestic consumption. During 1966-1967, India adopted new strategy which led the 'Green Revolution', especially in the production of wheat and rice. Coordinated research and several developmental and food security-based programmes in various phases have made the nation to progress closer towards 'food and nutrition for all' by achieving record and surplus production of wheat. After the Green Revolution, the nation has maintained strategic distance from famine even during unfavorable weather conditions. The impact of the All India Coordinated Research Project (AICRP) on wheat improvement is explicit and contributed significantly to the nation's food security [8].

\section{AICRP on wheat: an overview}

The All India Coordinated Wheat Improvement Project (AICWIP) was started in 1965 at the Indian Agricultural Research Institute (IARI), New Delhi, the nodal centre of the coordinated research. The AICWIP is one of the largest crop improvement network projects which set the dawn for the 'Green Revolution' in India. Under this project, several high-yielding wheat varieties have been developed which became extensively popular and adopted by the farming community. For instance, C 306, HD 2009, WL 711, UP 262, HUW 234, HD 2189, WH 147, Lok 1, HI 617 (Sujata), HD 2285, HD 2329, PBW 343, Raj 3765, PBW 502, HD 2733, HD 2967, HD 3086, DBW 17, PBW 550, GW 273, GW 322 and GW 496 in bread wheat and Raj 1555, PBW 34, HI 8498 and PDW 233 in durum wheat were developed and became the popular deliverables of the project. Apart from the aforementioned varieties, viz., NP 4, Kalyansona, Sonalika, Sharbati Sonora, WL 711, HD 1220, HD 1931 'SIB', HD 2009, HD 2172, UP 262, etc., developed through the AICWIP were also cultivated beyond national borders. Several changes happened post inception of the AICWIP, and during 2017, the project has been renamed as the All India Coordinated Research Project (AICRP) on Wheat and Barley with ICAR-Indian Institute of Wheat and Barley Research as its headquarter based at Karnal (Haryana). It is a premier organization under the aegis of ICAR coordinating the multidisciplinary and multilocation testing of varieties in different AICRP centres across the different ecosystems for enhancing and sustaining the wheat production [8]. At present, there are 29 funded centres located in different agroclimatic regions across the country supporting the multidisciplinary research. The project, hitherto, has contributed in the release of around 448 high-yielding improved wheat varieties comprising bread, durum and dicoccum wheat. Over the years, prominent improvements have been made in the development arena post inception of the coordinated project (Figure 1). 


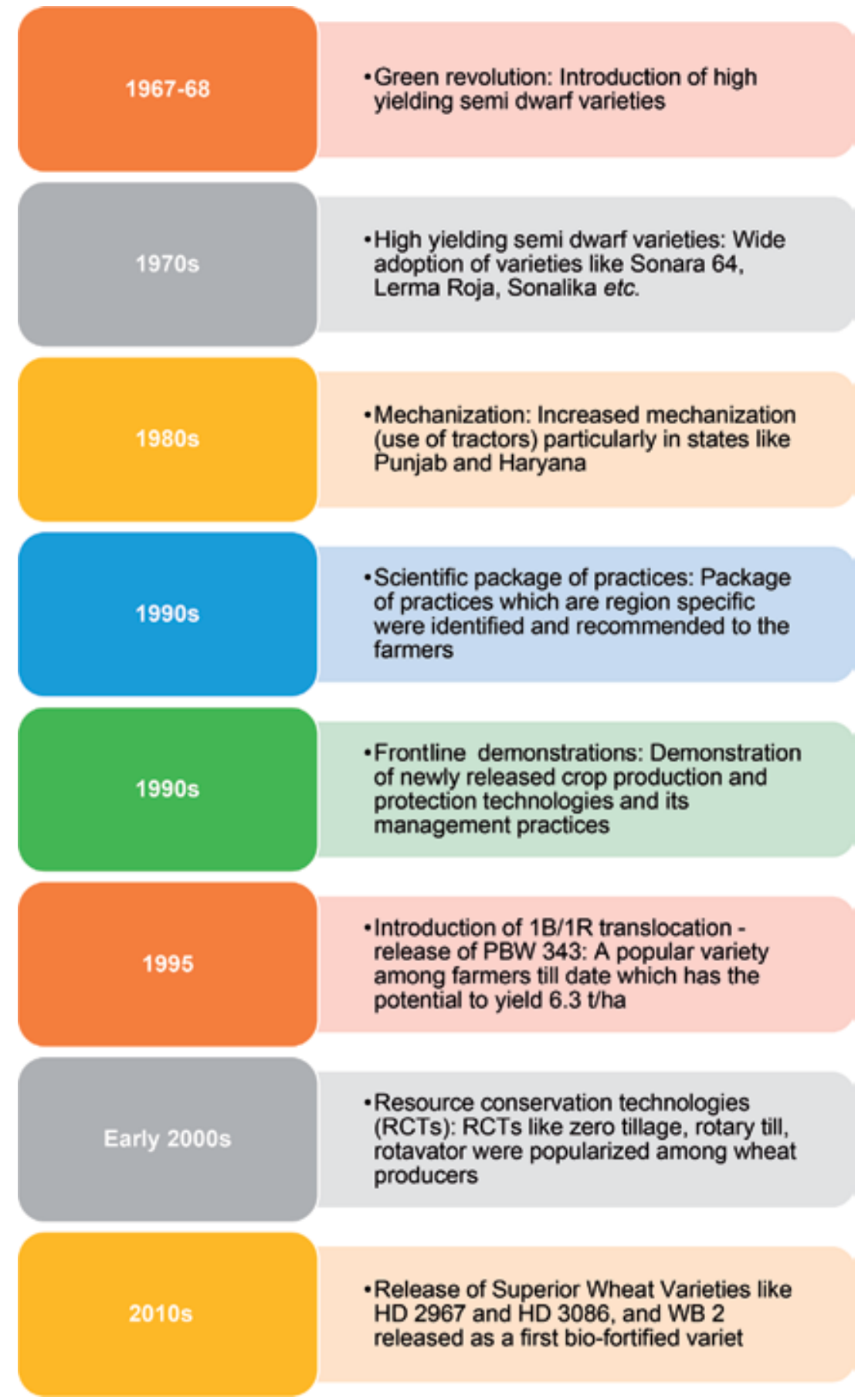

Figure 1.

Major developments in the country post inception of the AICRP.

Since the establishment of the AICRP, the productivity of wheat has increased by 2.5 -folds (308\%: +2.54 tonnes/ha) as furnished in Figure 2 . A decadal analysis of productivity growth across major food commodities indicates that wheat production growth has outperformed rice and pulses for the past 5 decades since 1950. Overall scenario indicated that wheat production has grown at 4.72 percent per annum since 1950, the highest among other food grains [9]. 


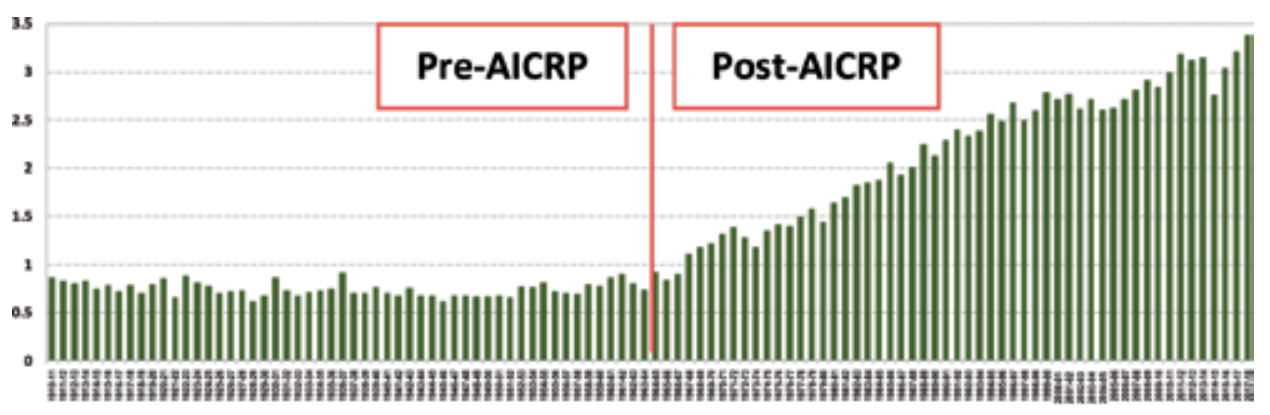

Figure 2.

Productivity trend in Indian wheat pre-and post-AICRP.

\section{Current status of area, production and yield of Indian wheat}

In India wheat crop is cultivated in Rabi season. It is normally sown during November and harvested between March and April. Tables 1 and 2 furnish recent scenario in wheat area, production and productivity. The cultivated area under wheat at national level has shown increasing trend, from 29.04 million hectare to 30.54 million hectare with a magnitude of 1.5 million hectare (5\%) net gain in terms of area. Uttar Pradesh has largest share in area with 9.75 million hectare (32\%), followed by Madhya Pradesh (18.75\%), Punjab (11.48\%), Rajasthan (9.74\%), Haryana (8.36\%) and Bihar $(6.82 \%)$. However, a major expansion in wheat area was observed in the states such as Jharkhand (51\%), Madhya Pradesh (27\%) and Rajasthan (13\%). The sharp rise in minimum support price and government's procurement are the two important drivers which led to significant increase in the area under wheat cultivation [10].

The production of wheat has also showed an increasing trend, from 87.39 to 94.57 million tonnes from 2012-2013 to 2017-2018 with a magnitude of 7.18 million tonnes $(8.22 \%)$. The major source of this increase in production is mainly attributed to expansion in area followed by marginal increase in productivity. Uttar Pradesh still holds the position of largest producer in the country accounting for about 28 million tonnes which is roughly $30 \%$ of the total production. Around 85 million tonnes $(90 \%)$ of wheat has been produced from traditional wheat-growing regions such as Uttar Pradesh, Punjab, Haryana, Madhya Pradesh, Bihar and Rajasthan [10]. The maximum quantum jump has been noticed in Madhya Pradesh and Jharkhand which almost doubled their production from 9.45-16.32 million tonnes to $0.22-0.38$ million tonnes. However, 1.4 million tonnes reduction was noticed in Uttar Pradesh during the same period which is a matter of serious concern.

The national productivity trend for wheat showed a marginal improvement, which has increased from $3009 \mathrm{~kg} / \mathrm{ha}$ to $3100 \mathrm{~kg} / \mathrm{ha}$ from 2012-2013 to 2017-2018 (Table 2). This rise in productivity is due to adoption of high-yielding varieties coupled with other inputs. The traditional wheat-growing states Punjab and Haryana have highest productivity than the national productivity [10]. The maximum increase in productivity has been observed in nontraditional wheat-growing states like West Bengal (23\%), Himachal Pradesh (19.28\%) and Assam (16.39\%). However, the productivity of Haryana has declined which pose a serious matter of concern.

Quinquennial data on wheat area, production and yield for India indicates that there is a variation in crop acreage that declined to 29.58 million hectare (Figure 3). However, the production of wheat has increased significantly from 95.85 to 99.70 million tonnes. Increase in production was largely attributed to rise in productivity levels registered across the wheat-growing regions. 
Wheat Production in India: Trends and Prospects

DOI: http://dx.doi.org/10.5772/intechopen.86341

\begin{tabular}{|c|c|c|c|c|c|c|}
\hline \multirow[t]{2}{*}{ State/UT } & \multicolumn{2}{|c|}{ Area (million ha) } & \multirow[t]{2}{*}{$\begin{array}{c}\text { Change } \\
(\%)\end{array}$} & \multicolumn{2}{|c|}{$\begin{array}{c}\text { Production (million } \\
\text { tonnes) }\end{array}$} & \multirow[t]{2}{*}{$\begin{array}{c}\text { Change } \\
(\%)\end{array}$} \\
\hline & $\begin{array}{c}2008-2009 \\
\text { to } \\
2012-2013\end{array}$ & $\begin{array}{c}2013-2014 \\
\text { to } \\
2017-2018\end{array}$ & & $\begin{array}{c}2008-2009 \\
\text { to } \\
2012-2013\end{array}$ & $\begin{array}{c}2013-2014 \\
\text { to } \\
2017-2018\end{array}$ & \\
\hline Assam & 0.05 & 0.02 & -52.35 & 0.06 & 0.03 & -43.40 \\
\hline Bihar & 2.16 & 2.08 & -3.57 & 4.63 & 4.86 & 4.98 \\
\hline Chhattisgarh & 0.10 & 0.10 & 0.59 & 0.12 & 0.14 & 13.22 \\
\hline Gujarat & 1.12 & 1.09 & -2.85 & 3.20 & 3.22 & 0.60 \\
\hline Haryana & 2.50 & 2.55 & 2.21 & 11.35 & 11.24 & -0.93 \\
\hline Himachal Pradesh & 0.36 & 0.34 & -4.26 & 0.53 & 0.66 & 24.79 \\
\hline Jammu and Kashmir & 0.29 & 0.29 & 1.83 & 0.44 & 0.48 & 10.52 \\
\hline Jharkhand & 0.12 & 0.19 & 50.99 & 0.22 & 0.38 & 70.04 \\
\hline Karnataka & 0.25 & 0.19 & -25.30 & 0.23 & 0.20 & -13.23 \\
\hline Madhya Pradesh & 4.52 & 5.73 & 26.76 & 9.45 & 16.32 & 72.72 \\
\hline Maharashtra & 1.01 & 1.05 & 4.79 & 1.61 & 1.48 & -8.27 \\
\hline Punjab & 3.52 & 3.51 & -0.40 & 16.25 & 16.61 & 2.21 \\
\hline Rajasthan & 2.63 & 2.98 & 12.99 & 8.12 & 9.31 & 14.62 \\
\hline Uttar Pradesh & 9.66 & 9.75 & 0.94 & 29.33 & 27.93 & -4.77 \\
\hline Uttarakhand & 0.38 & 0.34 & -9.89 & 0.85 & 0.81 & -4.64 \\
\hline West Bengal & 0.32 & 0.29 & -8.33 & 0.85 & 0.80 & -5.94 \\
\hline Others & 0.04 & 0.04 & -20.64 & 0.12 & 0.12 & -3.54 \\
\hline All India & 29.04 & 30.54 & 5.16 & 87.39 & 94.57 & 8.22 \\
\hline
\end{tabular}

Table 1.

Statewise quinquennial average of area and production of wheat.

\begin{tabular}{lccc}
\hline State/UT & 2008-2009 to 2012-2013 & 2013-2014 to 2017-2018 & Change (\%) \\
\hline India & 3009 & 3100 & 3.03 \\
\hline Punjab & 4617 & 4738 & 2.61 \\
\hline Haryana & 4544 & 4407 & -3.01 \\
\hline Others & 3083 & 3331 & 8.05 \\
\hline Rajasthan & 3038 & 3133 & 3.12 \\
\hline Gujarat & 2845 & 2922 & 2.69 \\
\hline Uttar Pradesh & 2724 & 2867 & 5.23 \\
\hline Madhya Pradesh & 2698 & 2843 & 5.38 \\
\hline West Bengal & 2241 & 2754 & 22.90 \\
\hline Uttarakhand & 2144 & 2375 & 10.76 \\
\hline Bihar & 2091 & 2339 & 11.87 \\
\hline Jharkhand & 1790 & 2005 & 12.01 \\
\hline Himachal Pradesh & 1602 & 1911 & 19.28 \\
\hline Jammu and Kashmir & 1511 & 1656 & 9.58 \\
\hline Maharashtra & 1466 & 1400 & -4.53 \\
\hline Assam & 1180 & 1373 & 16.39 \\
\hline Chhattisgarh & 1149 & 1328 & 15.59 \\
\hline Karnataka & 914 & 1057 & 15.64 \\
\hline & & & \\
\hline
\end{tabular}

Table 2.

Statewise quinquennial average of wheat yield $(\mathrm{kg} / \mathrm{ha})$. 


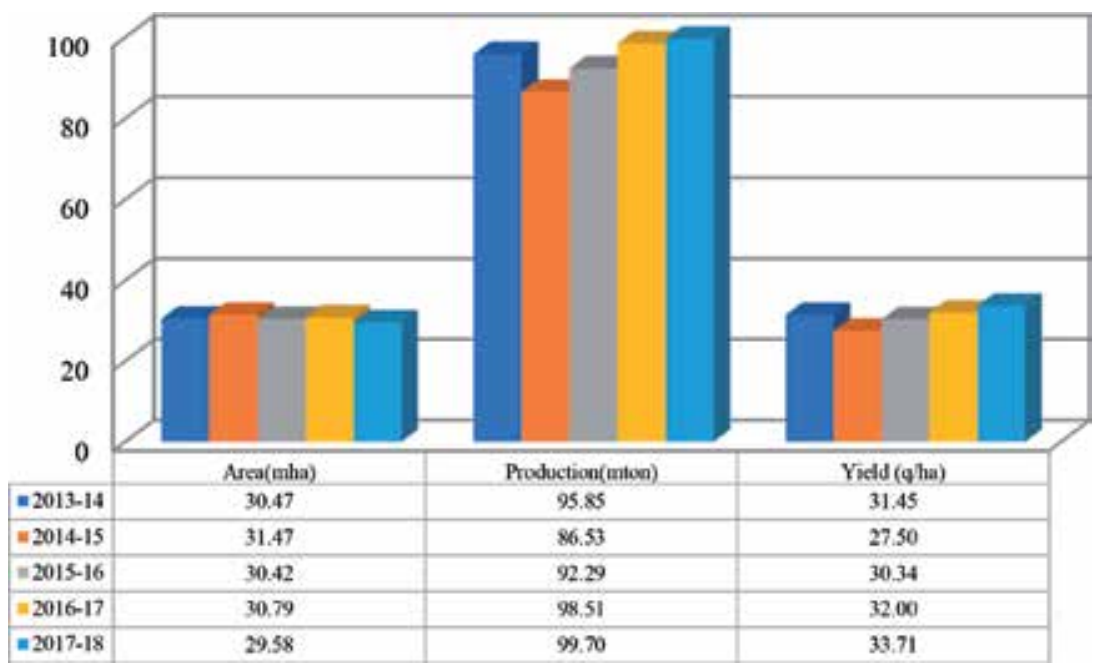

Figure 3.

Quinquennial scenario in area, production and yield of wheat.

\section{Global scenario of area, production and yield of wheat}

Wheat is one of the predominant staple foods and a main cereal crop of many diets around the world. Table 3 furnishes the current scenario of area, production and yield of wheat in the world. Globally wheat is cultivated in an area about

\begin{tabular}{|c|c|c|c|}
\hline Countries & $\begin{array}{c}\text { Area } \\
\text { (million ha) }\end{array}$ & $\begin{array}{c}\text { Production } \\
\text { (million tonnes) }\end{array}$ & $\begin{array}{c}\text { Yield } \\
\text { (tonnes/ha) }\end{array}$ \\
\hline China & $\begin{array}{c}24.51 \\
(11.14)\end{array}$ & $\begin{array}{l}134.33 \\
(17.60)\end{array}$ & 5.48 \\
\hline India & $\begin{array}{l}29.58 \\
(14.00)\end{array}$ & $\begin{array}{l}99.70 \\
(12.91)\end{array}$ & 3.37 \\
\hline Russia & $\begin{array}{c}27.34 \\
(12.43)\end{array}$ & $\begin{array}{c}84.99 \\
(11.14)\end{array}$ & 3.11 \\
\hline USA & $\begin{array}{l}15.19 \\
(6.90)\end{array}$ & $\begin{array}{l}47.35 \\
(6.21)\end{array}$ & 3.12 \\
\hline Canada & $\begin{array}{c}8.98 \\
(4.08)\end{array}$ & $\begin{array}{l}29.98 \\
(3.93)\end{array}$ & 3.34 \\
\hline Ukraine & $\begin{array}{c}6.64 \\
(3.02)\end{array}$ & $\begin{array}{l}26.98 \\
(3.54)\end{array}$ & 4.06 \\
\hline Pakistan & $\begin{array}{c}8.97 \\
(4.08)\end{array}$ & $\begin{array}{c}26.67 \\
(3.50)\end{array}$ & 2.97 \\
\hline Australia & $\begin{array}{l}12.25 \\
(5.57)\end{array}$ & $\begin{array}{l}21.30 \\
(2.79)\end{array}$ & 1.74 \\
\hline Turkey & $\begin{array}{c}7.8 \\
(3.55)\end{array}$ & $\begin{array}{l}21.00 \\
(2.75)\end{array}$ & 2.69 \\
\hline Kazakhstan & $\begin{array}{l}11.91 \\
(5.41)\end{array}$ & $\begin{array}{l}14.80 \\
(1.93)\end{array}$ & 1.24 \\
\hline World & 220 & 763.06 & 3.47 \\
\hline
\end{tabular}

Note: Figure within parenthesis indicates the percent to world.

Table 3.

Area, production and yield of major wheat-producing countries (2017-2018). 


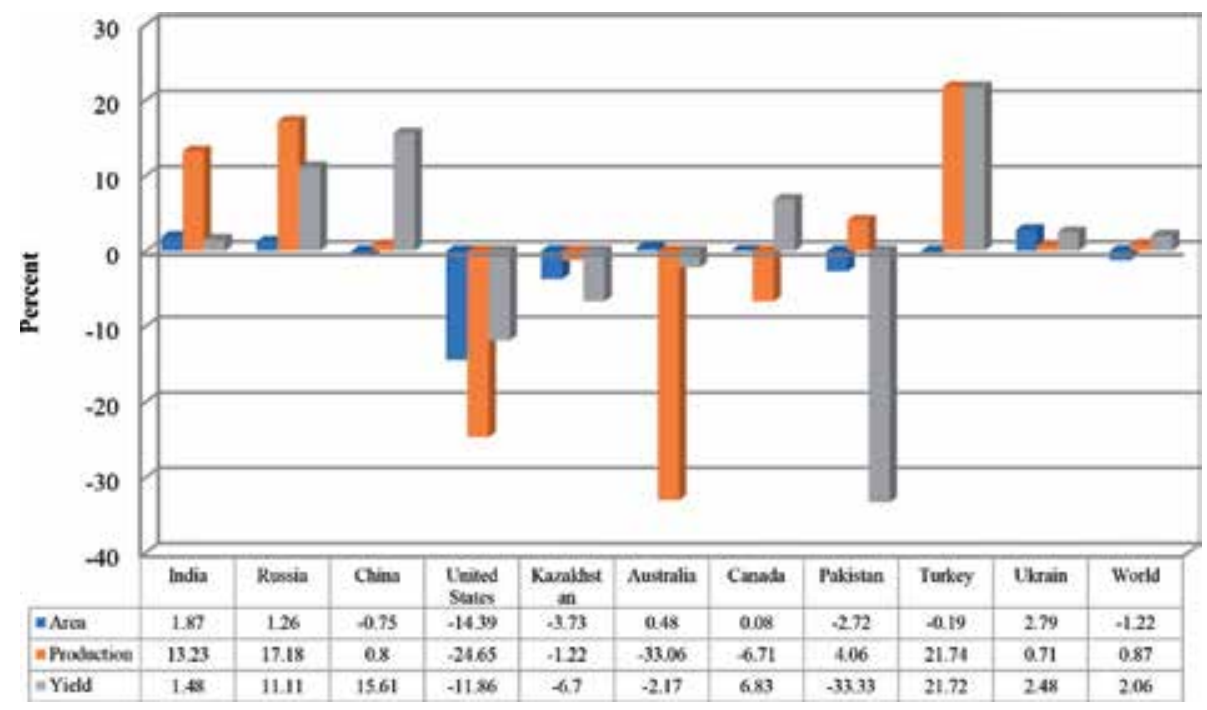

Figure 4.

Annual growth in area, production and yield (2017-2018 over 2016-2017).

220 million hectares with a record production of 763.06 million tonnes of grain. Maximum area under wheat is in India (14\%), followed by Russia (12.43\%), China (11.14\%) and the USA (6.90\%) which altogether accounts for about $45 \%$ of global area. However, China is the major producer of wheat with a record production of 136 million tonnes, followed by India (98.51mt), Russia (85mt) and the USA $(47.35 \mathrm{mt})$. Around 449 million tonnes $(58 \%)$ of wheat has been produced from traditional wheat-growing countries like China, India, Russia, the USA, Canada, Ukraine and Pakistan. The average yield per hectare is maximum in New Zealand (10 tonnes/ha), followed by Zambia ( 7 tonnes/ha) and Mexico (6 tonnes/ha). However, the average wheat yield in major wheat-growing countries is significantly low, and only China has maximum yield ( 5.48 tonnes/ha) followed by Ukraine, India and the USA. Despite India's productivity being on par with the world average, the per day productivity is relatively high $(20 \mathrm{~kg} /$ day $)$ in comparison to other countries, viz. the USA, Uzbekistan, Hungary, Poland, Italy, Bulgaria and Romania, which predominantly cultivates winter wheat with crop cycle hovering around 275 days. However, in India, in comparison to its competing country, China, the per day productivity is almost the same. It should be noted that the winter wheatcultivating countries do not deal with any other crop in a year, while in India, in which spring wheat cultivation occurs around 150 days duration, farmers has the choice to grow at the maximum two sole crops apart from wheat [8].

The global wheat production has increased around 7 million tonnes $(0.9 \%)$ in the year 2017-2018 in comparison to its past. The major source for the increase in production is mainly attributed to increase in productivity followed by marginal increase in area in major wheat-growing countries (Figure 4).

\section{Regional disparity in Indian wheat production}

At the national level, there is a shift in area, production and yield under wheat during 2008-2009 to 2012-2013 vis-à-vis 2013-2014 to 2017-2018. Currently, wheat acreage is around 30 million hectares. Comparing the past two periods, the change was more prominent in wheat production, followed by area and yield (Tables $\mathbf{1}$ and 2 ). The average change in production was around $9 \%$. The country on an average produced 


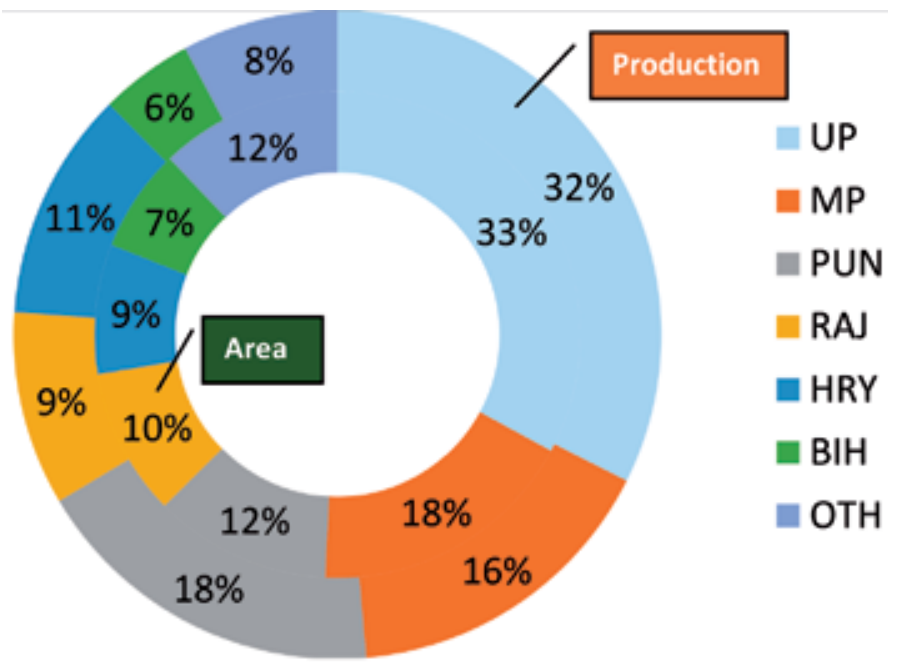

Figure 5.

Statewise comparison of wheat area and production (2017-2018).

7.3 million tonnes more than the past period. The major wheat-growing states like Punjab, Madhya Pradesh and Rajasthan have witnessed positive change in area and yield and production [6]. Surprisingly, Jharkhand registered positive change in area, yield and production, while Haryana and Uttar Pradesh, the major traditional wheatgrowing states, witnessed a negative change in production due to negative change in yield. Regional disparities in area and yield had a significant impact on the wheat production. Average production in Madhya Pradesh showed an increase by 6.87 million tonnes, followed by Rajasthan (1.2 million tonnes). However, the production has declined in Uttar Pradesh (1.41 million tonnes) and Haryana (0.11 million tonnes).

Statewise comparison of area and production for 2017-2018 shows that Uttar Pradesh, Punjab, Madhya Pradesh and Haryana were the major contributors to the national production (Figure 5). However, Punjab, Haryana and Uttar Pradesh retained the status of higher productivity for many years. The scope for additional production of these states has been limited due to stagnation of wheat acreage and yield. This indicates that these states almost reached their saturation in wheat cultivation and production. Potential exists for states like Rajasthan and Madhya Pradesh to explore for additional wheat production in the coming years. Area under these states has to increase in yield at farmers' field so as to attain higher production. The current production from these states is around 29 million tonnes which has to be doubled by 2050 with an overall production target of 140 million tonnes [11-13].

\section{Production constraints and challenges for wheat production}

Production constraints are manifold and vary from crop to crop and between regions. Burgeoning population vis-à-vis increasing demand for food; growing competition for cultivable land, irrigation water and energy; intensive cropping especially in the Indo-Gangetic Plains resulting in irrational use of resources; pestenvironment interaction; reduction of natural resource base; declining total factor productivity; and yield plateau (Figure 6) are the prominent challenges put forth against crop production [11-14]. Wheat production not only faces the above routine challenges, but the intensity gets magnified in the context of climate change owing to its vulnerability [15-18]. 


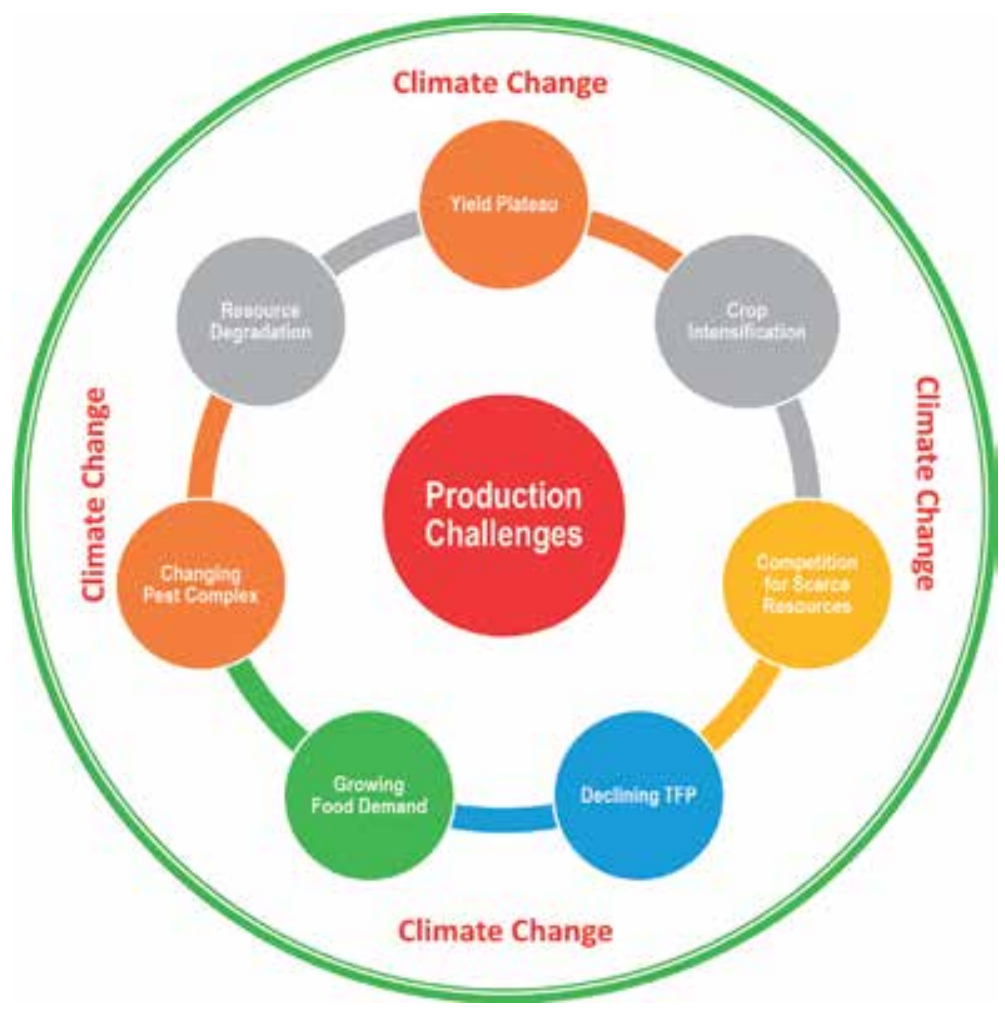

Figure 6.

Production challenges in Indian setting.

\subsection{Climatic vulnerability}

In India a significant part of wheat area is under heat stress, and Gangetic plains and central and peninsular India are the most heat-stressed regions, whereas it is moderate in northwestern parts of Indo-Gangetic Plains [19]. Variability in climate is also one of the biggest environmental threats to Indian agriculture, potentially impacting the wheat production and security. In India, it has been predicted that with every rise in $1^{\circ} \mathrm{C}$ temperature, the wheat production will be decreased by 4-6 million tonnes. Rainfed wheat will experience a reduction in yield with 9-25\% profit loss for every $2-3.5^{\circ} \mathrm{C}$ rise in temperature [20].

\subsection{Excessive use of inputs and land resources}

After the Green Revolution, the productivity of wheat has been significantly increased with the increase in input usage, plant protection chemicals and irrigated areas. The excessive use of fertilizer, chemicals and irrigation has degraded the fertility of the soil and also caused a reduction in groundwater table. The monocropping system led to deterioration in soil quality. If the current trend continues, the country will face a serious problem in utilization of scarce natural resources.

\subsection{Salt-affected and problematic soils}

In India about 4.5 million hectares salt affected area is under wheat cultivation posing a major problem for canal irrigated areas [21]. Even though soil amendments and proper drainage are the more constructive solution, pace of reclamation is not substantial. This will significantly reduce the wheat yield. 


\subsection{Pest and disease complex}

As year passes, the pests of wheat have developed some resistance even though controlled under contingent situation. If not, a new range of pests and diseases have been emerging putting a serious constraint on the wheat productivity.

\subsection{Availability of improved seed}

Adoption system and germplasm dissemination in India have been made in formal (organized) and informal (unorganized) ways [22]. Even though new improved varieties are developed and made available to farmers by NARS around, $80 \%$ of all seeds are saved by the farmers [19]. Further, a majority of farmers in India have lack of awareness of improved wheat varieties due to weak linkages [19]. The development and diffusion of improved varieties are crucial for achieving target production of wheat.

\subsection{Price volatility}

Volatility in prices of agricultural commodities has received considerable attention in the recent past among producers, consumers and policy makers. Price fluctuations create an uncertain farming situation threatening wheat production and have a negative impact on the welfare of wheat growers. Further, volatility in prices of wheat in international market hinders the smooth flow of trade across nations.

\subsection{Decline in farm size}

Over the years, a visible declining trend in farm holding size has been observed and is another major concern for the nation as a whole. This is caused by fragmentation of farmland owing to nuclear family system and decline in cultivable area due to urbanization. Estimate from the agricultural census (2010-2011) reports that

\begin{tabular}{ll}
\hline Zone & Major production constraints \\
\hline $\begin{array}{l}\text { Northern hills } \\
\text { zone }\end{array}$ & $\begin{array}{l}\text { Lack of accessibility of seed of newly released variety, Phalaris minor, small land } \\
\text { holdings, high cost of inputs, non-availability of farm machinery, yellow rust, birds, } \\
\text { lack of knowledge among the farmers about recent technologies, imbalanced use of } \\
\text { fertilizer, lack of irrigation facilities }\end{array}$ \\
\hline $\begin{array}{l}\text { Northwestern } \\
\text { plains zone }\end{array}$ & $\begin{array}{l}\text { High cost of inputs, low price of wheat, erratic power supply, Phalaris minor, low } \\
\text { organic matter in the soil, poor quality of seeds, non-availability of labour, untimely } \\
\text { rain, Chenopodium album, non-availability of electricity }\end{array}$ \\
\hline $\begin{array}{l}\text { Northeastern } \\
\text { plains zone }\end{array}$ & $\begin{array}{l}\text { Small land holdings, inadequacy of seeds of newly released variety, lack of } \\
\text { information among the farmers about recently developed new technologies, late } \\
\text { sowing, temperature fluctuations during growth, high-priced inputs, poor quality of } \\
\text { seeds, non-availability of labour, low organic matter in the soil, non-availability of } \\
\text { farm machinery }\end{array}$ \\
\hline Central zone & $\begin{array}{l}\text { Non-availability of labour, imbalanced use of fertilizer, high temperature at maturity, } \\
\text { limited accessibility to seed of newly released variety, temperature fluctuation during } \\
\text { crop growth, high cost of inputs, lack of irrigation facilities, small land holding, } \\
\text { decline in water table, untimely rain }\end{array}$ \\
\hline $\begin{array}{l}\text { Low price of wheat, irregular power supply, high cost of inputs, non-availability of } \\
\text { labour, non-availability of electricity, higher rate of custom hiring, untimely rain, lack } \\
\text { of facilities of canal irrigation, poor accessibility to seeds of newly released variety, } \\
\text { temperature fluctuation during crop growth }\end{array}$ \\
\hline
\end{tabular}

Table 4.

Zone-wise production constraints in wheat. 
the average operational holding in India was 1.16 ha. Among major wheat-growing states, average operational holding was highest in the case of Punjab (3.77 ha) and lowest in Bihar (0.39 ha). Declining farm size and conversion of farmland to residential area are the major setbacks with respect to food production in general and wheat production in particular.

\subsection{Declining total factor productivity}

A major concern among policy makers is the declining total factor productivity over the years owing to stagnating yield levels with increased use of inputs and resource services. It is a major concern in the intensive cropping areas wherein ricewheat is widely under cultivation. This can be countered by adoption of improved technologies coupled with the use of optimal resources.

The constraints in wheat production are region-specific (Table 4), and it requires setting research priorities to address them. Rust, infestation of weeds such as Phalaris minor, wild oat, late sowing, low plant population, etc., were identified as the major constraints across wheat-growing zones.

\section{Production target set for $\mathbf{2 0 5 0}$ and strategies for increasing the productivity}

With a limited scope for increasing the crop acreage besides the production threats and challenges at the forefront $[12,13]$, the production target has been fixed at $140 \mathrm{mt}$ by 2050 (Figure 7) [11]. Under stable wheat acreage and given the optimistic production target, the existing average yield has to be increased from 33 to 47 Qtls/ha by 2050. Concerted research should focus to break the yield barriers in gradual manner and develop genotypes tailored for specific wheat-growing regions.

The following are the strategies set for increasing the crop productivity to achieve the set target of 140 million tonnes [9, 23, 24]:

- Improvement of wheat under conventional methods

a. Exploitation of heterosis for developing the hybrids

b. Pre-breeding programme by broadening the varieties' genetic base

i. Capitalizing exotic germplasm and extensive utilization

ii. Precision phenotyping of germplasm

iii. Mining novel alleles for genes of known function

iv. Production of segregating populations for lines of interest identified in primary germplasm screens

v. Use of existing landrace $x$ elite segregating populations to identify QTL controlling traits of interest

vi. Production of NILs for QTL and allelic variants

vii. Assessing agronomic performance of NILs

viii. Development of informative genetic markers and their use in commercial wheat breeding programmes 


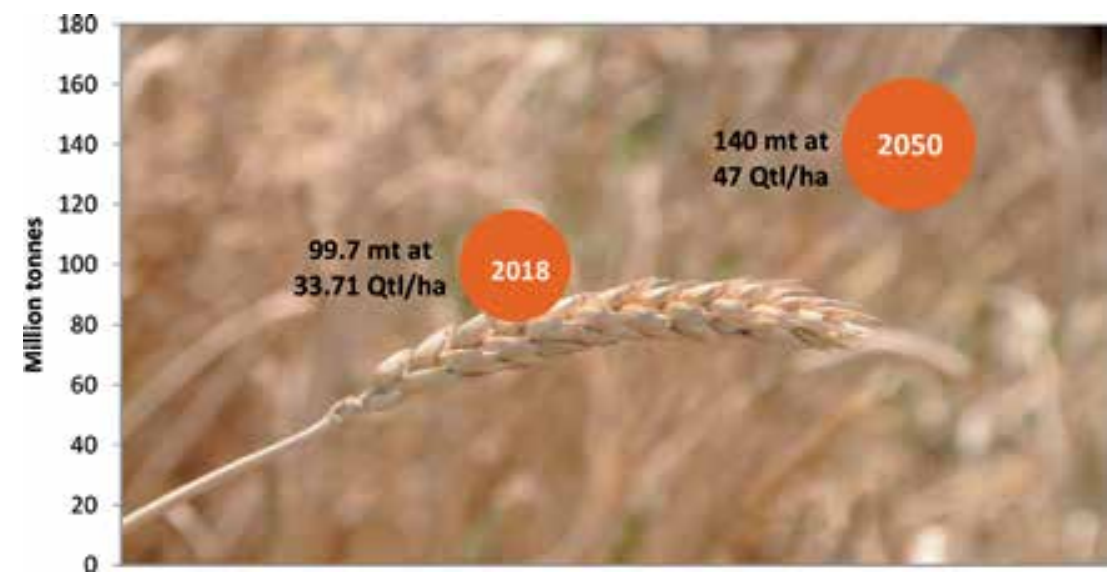

Figure 7 .

Existing production and target for 2050.

c. Development of new plant types

i. Desired canopy structure

ii. Rapid leaf area development

iii. Rapid nutrient uptake

iv. Increasing lodging resistance (robust stem)

- Biotechnological interventions

a. Marker-assisted breeding

b. Wheat genome sequence and associated genomic tools

i. Allele mining on the basis of probing germplasm sets for specific gene sequences

ii. Innumerable new molecular markers in genomic regions of choice to facilitate large-scale cloning of new genes

iii. A plethora of approaches for understanding the function of each and every gene

iv. Understanding temporal and tissue-specific gene expression in response to developmental and environmental cues

v. Uncovering molecular basis of complex adaptation syndromes including tolerance to various abiotic stresses

vi. Designing of a genome-wide perfect marker system based on SNPs in entire gene space of the species

c. Potential of wheat transgenics and possibilities of greater public acceptance

d.Functional characterization of genome 
- Tackling disease resistance

- Tackling abiotic stress-climate change

- Resource management

- Quality improvement

- Policy reorientation [6]
a. Price policy
b.Seed policy
c. Credit policy

- Institutional innovations like e-National Agriculture Market

- Extension: transfer of technology

a. Economic assessment of various improved technologies for upscaling and outscaling

b. Promotion of resource conservation technologies [25]

c. Awareness among farmers of new improved varieties and production technologies for yield as well as income enhancement $[26,27]$

d.Wheat atlas: creation and updating regional-level database on parameters like area, production, yield, yield gaps and input usage.

e. Analysis of benefit-cost ratio (BCR) in wheat production and development

f. Access to critical inputs for timely sowing like improved seeds particularly in eastern UP, Bihar, Jharkhand and Chhattisgarh; access to fertilizers, irrigation water and farm machinery [28]

g. Infrastructure development (roads, storage structures, market)

\section{Conclusion}

Agriculture transformation is of utmost importance for regional development. Cutting-edge research involving multidiscipline is the need of the hour and is expected to develop superior genotypes breaking the yield barrier. Despite being cost-intensive, development is mandatory which warrants for higher public and private investment in R\&D. In addition, productivity has to be increased through massive efforts from extension personnel who serve as change agents among the farming community. A reorientation in price policy (fair price system benefiting both producers and consumers, deficient payment system to producers for difference between the market and procurement price and cash transfers to producers under colossal loss), seed policy (quality seed production and ensuring its availability for all) and credit policy (timely distribution with minimum 
administrative work) is highly required to support the existing production system and to carry forward. Increased access to input and output markets, revamped distributions systems, investment in rural infrastructures and skilling of the rural labour force will help immensely to increase the crop productivity. On the whole, a synergy between research-extension-policy-institutions will play an impending role to achieve the desired level of production as well as to ensure food security for future generation. The realization of the expected increase in production in agriculture will only be possible with high efficiency, high quality, resistance to biotic and abiotic stresses and by offering them to the service of the farmer by improving the stable varieties in breeding programmes.

\section{Author details}

Sendhil Ramadas ${ }^{1 *}$, T.M. Kiran Kumar ${ }^{2}$ and Gyanendra Pratap Singh ${ }^{1}$

1 ICAR-Indian Institute of Wheat and Barley Research, Karnal, India

2 ICAR-Central Soil Salinity Research Institute, Karnal, India

*Address all correspondence to: r.sendhil@icar.gov.in

\section{IntechOpen}

(C) 2019 The Author(s). Licensee IntechOpen. This chapter is distributed under the terms of the Creative Commons Attribution License (http://creativecommons.org/licenses/ by/3.0), which permits unrestricted use, distribution, and reproduction in any medium, provided the original work is properly cited. (cc) BY 


\section{References}

[1] Nikos A, Jelle B. World agriculture towards 2030/2050: The 2012 revision. ESA Working Paper No. 12-03. Rome: Food and Agriculture; 2012

[2] Shiferaw B, Smale M, Braun HJ, Duveiller E, Reynolds M, Muricho G. Crops that feed the world 10. Past successes and future challenges to the role played by wheat in global food security. Food Security. 2013;5:291-317. DOI: 10.1007/s12571-013-0263-y

[3] USDA. United States Department of Agriculture [Internet] 2018. Available from: http://www.fas.usda.gov [Accessed: January 22, 2019]

[4] Sharma I, Sendhil R. Domestic production scenario of wheat. In: Souvenir of Roller Flour Millers Federation of India Platinum Jubilee Celebration; 2015. pp. 18-20

[5] Sharma I, Sendhil R. Wheat Production in India-A Decadal Synopsis [Internet]. 2016. Available from: http://www.FnBnews.com [Accessed: 15 January 2019]

[6] Sharma I, Sendhil R, Chatrath R. Regional disparity and distribution gains in wheat production. In: Souvenir of $54^{\text {th }}$ AIW\&B Workers Meet; Gujarat: Sardarkrushinagar Dantiwada Agricultural University; 2015

[7] MoA\&FW. Ministry of Agriculture and Farmers Welfare, Government of India [Internet]. 2018. Available from: https://eands.dacnet.nic.in/Advance Estimate/4th_Adv_Estimates2017-18_ Eng.pdf [Accessed: 25 December 2018]

[8] Sharma I, Sendhil R, Chatrath R. Deciphering the role of wheat production and protection technologies for food and nutrition security. In: Souvenir of $53^{\text {rd }}$ All India Wheat \& Barley Research Workers' meet and International Seminar on Enhancing
Wheat \& Barley Production with special emphasis on Nutritional Security; Jabalpur: Jawaharlal Nehru Krishi Vishwa Vidyalaya (JNKVV); 2014

[9] Sharma I, Sendhil R, Gupta OP, Singh R. Status of Wheat in India. In: Wheat: Recent Trends on Production Strategies of Wheat in India; Jabalpur and ICARIIWBR: Jawaharlal Nehru Krishi Vishwa Vidyalaya (JNKVV); 2014. pp. 1-13

[10] Sendhil R, Singh R, Sharma I. Exploring the performance of wheat production in India. Journal of Wheat Research. 2012;4:37-44

[11] ICAR-IIWBR. Vision 2050. Karnal: ICAR-Indian Institute of Wheat and Barley Research; 2015. pp. 1-48

[12] Sharma I, Chatrath R, Sendhil R. Challenges, target and strategies for sustainable wheat production for food security and nutrition. Indian Farming. 2013;63:3-6, 17

[13] Sharma I, Sendhil R, Singh R. India's food production towards 2050-Challenges, opportunities and strategies. Agriculture Today. 2013:146-151

[14] Sendhil R, Balaji SJ, Ramasundaram P, Kumar A, Singh S, Chatrath R, et al. Doubling farmers income by 2022: Trends, challenges, pathway and strategies. Research Bulletin No: 40. Karnal: ICAR-Indian Institute of Wheat and Barley Research; 2018. pp. 1-54

[15] Sharma I, Chatrath R, Kumar S, Sendhil R. The challenges of climatic drift on productivity of wheat in India. In: Subbaiah, Prajapati GV, editors. Water Management and Climate Smart Agriculture (Vol 1-3). Gujarat: Junagadh Agricultural University; 2015

[16] Sendhil R, AnkitaJha AK, Singh S. Extent of vulnerability in wheat 
producing agro-ecologies of India: Tracking from indicators of crosssection and multi-dimension data. Ecological Indicators. 2018;89:771-780. DOI: 10.1016/j.ecolind.2018.02.053

[17] Sharma I, Sendhil R, Venkatesh $\mathrm{K}$. Managing risk in wheat production against weather anomalies. Agriculture Today. 2015:90-92

[18] Singh GP, Chatrath R, Kumar S, Sendhil R. Impact of climate change on wheat production \& strategies for ensuring food security in India. In: Souvenir Released during the International Conference on Climate Change Adaptation and Biodiversity; Port Blair: Ecological Sustainability and Resource Management for Livelihood Security; 2016

[19] Joshi AK, Mishra B, Chatrath R, Ortiz Ferrara G, Singh RP. Wheat improvement in India: Present status, emerging challenges and future prospects. Euphytica. 2007;157:431-446. DOI: $10.1007 / \mathrm{s} 10681-007-9385-7$

[20] Aggarwal PK. Global Climate Change and Indian Agriculture-Case Studies from the ICAR Network Project. New Delhi: Indian Council of Agricultural Research; 2009

[21] Singh KN, Chatrath R. Salinity tolerance. In: Reynolds MP, OrtizMonasterio JI, McNab A, editors. Application of Physiology in Wheat Breeding. Mexico: CIMMYT; 2001. pp. 101-110

[22] Joshi AK, Kumari M, Singh VP, Reddy CM, Kumar S, Rane J, et al. Stay green trait: Variation, inheritance and its association with spot blotch resistance in spring wheat (Triticum aestivum L.). Euphytica. 2007;153:59-71. DOI: $10.1007 / \mathrm{s} 10681-006-9235-\mathrm{z}$

[23] Sharma I, Chatrath R, Sendhil R. Research, policy and institutional dynamics in enhancing wheat production \& productivity in India. In: Shetty PK, Ayyappan S, Swaminathan MS, editors. Climate Change and Sustainable Food Security. National Institute of Advance Studies. New Delhi: Bangalore and Indian Council of Agricultural Research; 2013. ISBN: 978-81-87663-76-8

[24] Tiwari R, Venkatesh K, Sendhil R. Wheat. In: Chopra VL, editor. Breeding Field Crops 2: Advances. Houston-USA: Studium Press LLC; 2014. pp. 53-66

[25] Kumar A, Singh R, Singh S, Sendhil R, Chand R, Pandey JK. Impact of resource conservation technologies in Haryana. Journal of Community Mobilization and Sustainable

Development. 2017;12:257-264

[26] Sendhil R, Kumar A, Singh S, Chatrath R, Singh GP. Framework for doubling the income of wheat producers' by 2022: Trends, pathway and drivers. Indian Journal of Economics and Development. 2017;13:1-8

[27] AAnuj Kumar RS, Singh R, Singh S, Shukla RS, Sharma I. Yield gaps in wheat production-Magnitudes, sources and narrowing them for socio-economic change. In: Wheat: Recent Trends on Production Strategies of Wheat in India. Karnal: JNKVV, Jabalpur and ICARIIWBR; 2014. pp. 165-175

[28] Singh GP, Sendhil R, Chatrath R. Doubling farmers income in northeastern region of India by 2022: A roadmap for wheat producers. In: Souvenir Released during the $56^{\text {th }}$ All India Wheat \& Barley Research Workers' Meet; Varanasi: BHU; 2017 


\title{
Rice Grain Quality: Current Developments and Future Prospects
}

\author{
Neerja Sharma and Renu Khanna
}

\begin{abstract}
Grain quality of rice is more complex than other cereals, since it is mostly consumed as whole grain in countries where it serves as a staple food. Quality characteristics are major determinants of market price and include milling, physical appearance, cooking, sensory, palatability, and nutritional value. A better understanding of the factors that control these quality characteristics will be useful for developing new breeding strategies. In this chapter, we will review the progress made toward improvement of important grain quality traits along with their genetic basis. This chapter will also give innovative insights into the knowledge gained through new tools that integrate grain quality with high yield in the present scenario of diminishing natural resources and environmental fluctuations.
\end{abstract}

Keywords: rice, cooking traits, sensory quality, appearance quality, genetic basis, nutritional quality

\section{Introduction}

Rice is the staple food of half of human population globally and fulfills over $21 \%$ calorific requirement of world population. About $90 \%$ of the rice is produced and consumed in Asia. During 1960s to 1970 when the major rice producing countries relied on rice as a subsistence crop, the major emphasis was on high yield. As these countries attained food security and standard of living of the rice eating population improved, consumers became conscious about grain quality. Their potential as exporters of surplus rice produced, gave a further impetus to grain quality research. The world population is expected to reach 9.8 billion from the current 7.6 billion by 2050 (The World Population Prospects: The 2017 Revision, published by the UN Department of Economic and Social Affairs). The current challenge to rice improvement programs is to feed the ever-growing population with diminishing natural resources and environmental fluctuations on one-hand and varieties that have grain quality that the consumer demands, on the other. The economic value and the consumer acceptance/preference of a rice variety depend on rice grain quality [1-3]. Rice grain quality is a complex trait and is therefore difficult to define comprehensively. Rice quality comes from a polygenic group of traits that are affected by environmental factors, crop management and the resulting interactions among these. It involves the physical appearance, milling quality, cooking, sensory and nutritional value. The emphasis laid on each of these traits depends 
on regional consumer preference, market demand, and intended functional use. For instance, consumers in North Asia prefer short and bold rice grains with low amylose, whereas in several states of India, most parts of Pakistan and Iran prefer long, slender grains having intermediate amylose content [4]. One of the major challenges facing the rice improvement programs is to have simple, robust, high throughput methods for assessing various quality traits that can reflect consumer preference. We review here the key grain quality traits and the classical and modern methods used in rice improvement programs to evaluate them. A comprehensive list of quality evaluation methods for different parameters is given in Table 1.

\begin{tabular}{|c|c|c|}
\hline S. No. & Quality parameter & Recent quality evaluation method(s) \\
\hline \multicolumn{3}{|c|}{ Cooking and eating quality } \\
\hline 1. & $\begin{array}{l}\text { Apparent amylose } \\
\text { content }\end{array}$ & $\begin{array}{l}\text { HPLC-SEC [5] } \\
\text { DSC }[6] \\
\text { NIRS }[7,8]\end{array}$ \\
\hline 2. & Cooking time & $\begin{array}{l}\text { Measured indirectly by estimating gelatinization } \\
\text { temperature using DSC [6] }\end{array}$ \\
\hline 3. & Kernel elongation & None \\
\hline 4. & Grain volume expansion & None \\
\hline 5. & $\begin{array}{l}\text { Gelatinization } \\
\text { temperature }\end{array}$ & $\begin{array}{l}\text { Measurement of starch gelatinization by DSC, } \\
\text { photometric method, alkali photometry, or RVA } \\
\text { pasting curve [9] }\end{array}$ \\
\hline 6. & Pasting properties & $\begin{array}{l}\text { Brabender visco-amylograph, micro Visco-analyzer } \\
{[10,11]}\end{array}$ \\
\hline \multicolumn{3}{|c|}{ Textural and sensory quality } \\
\hline 7. & Gel consistency & None \\
\hline 8. & Texture profiling & $\begin{array}{l}\text { Instron hardness testing. Parallel plate plastometer, } \\
\text { consistometer, texturometer, hardness tester, } \\
\text { viscoelastograph, tensipresser, surface tensiometer, } \\
\text { Kramer shear or texture press, extrusion and back } \\
\text { extrusion, puncture test }\end{array}$ \\
\hline 9. & Sensory evaluation & None \\
\hline 10. & Aroma profiling & $\begin{array}{l}\text { Detection and quantification of 2-acetyl-1-pyrroline by } \\
\text { GC-MS [3] } \\
\text { Detection of total volatile metabolome by GC-MS }\end{array}$ \\
\hline 11. & Rancidity test & $\begin{array}{l}\text { Detection of free fatty acids by titration or colorimetry } \\
\text { [12] }\end{array}$ \\
\hline \multicolumn{3}{|c|}{ Nutritional quality } \\
\hline 12. & Protein content & NIRS [13] \\
\hline 13. & Lipid content & Metabolomics approach using LC-MS [14] or GC-MS \\
\hline 14. & Resistant starch content & None \\
\hline 15. & $\begin{array}{l}\text { Nonstarch } \\
\text { polysaccharide content } \\
\text { and dietary fiber content }\end{array}$ & CE [15], HPLC coupled with mass spec detector \\
\hline 16. & Micronutrients & AAS, ICP-OES, ICP-MS $[16,17]$, XRF \\
\hline 17. & Digestibility & Time-resolved NMR [18] \\
\hline
\end{tabular}

Table 1.

Summary of evaluation methods used for determining rice quality. 


\section{Rice quality traits}

\subsection{Appearance quality}

Major factors determining market value are immediately discernible by the consumers and include physical properties like, whiteness, translucence, uniform shape and yield of edible polished grain. Visual characters of rice grains like grain dimensions, chalk, color and whole grain recovery are important attributes that affect the choice of consumers' and millers. Therefore, these are among some of the first selection criteria in varietal improvement programs [19-21]. Grain size depends on the length of the grain in its greatest dimension, while grain shape is based on length-to-breadth ratio [20]. The classification of rice samples based on size and shape is not standardized across different countries and different marketing areas $[22,23]$. The routine classification system used by the International Rice Research Institute (IRRI) breeding programs for grain size is as follows: short $(\leq 5.50 \mathrm{~mm})$, medium/intermediate $(5.51-6.60 \mathrm{~mm})$, long $(6.61-7.50 \mathrm{~mm})$, and very long $(>7.50 \mathrm{~mm})$. Similarly, the grain shapes of rice can be described based on the length-to breadth ratio values, and the classification used in IRRI is: bold $(\leq 2.0)$, medium (2.1-3.0), and slender (>3.0) [23]. Chalky areas in rice grains present on the dorsal (white belly), ventral side (white back) or in the center are opaque white parts of the endosperm and generally, associated with poor quality in many rice markets thus these grains have lower market acceptability [24]. Classification of the grains is based on the proportion of the grain that is chalky: none (0\%), small $(<10 \%)$, medium $(10-20 \%)$, and large $(>20 \%)[23,25,26]$. The starch granules in the chalky areas of the grain have air spaces between them, are small and less compact compared to bigger and tightly packed granules in translucent areas and hence are more prone to breakage during milling [27, 28]. Chalk thus affects both the esthetic value and head rice yield decreasing the marketability of rice. Chalk is caused by both environment and genetic factors. Increase in nighttime air temperatures during grain filling stage can increase chalk and reduce head rice yields $[29,30]$. Rice grain dimensions are conventionally measured using transparent rulers, vernier calipers and photographic enlargers [31], while the proportion of grain that is chalky is visually scored. Measuring of grain dimensions using manual methods is both labor intensive and time-consuming. Moreover, visual scoring of chalk involves subjectivity. Now-a-days, image analysis methods are being used in advanced laboratories that are very convenient and objective [31-33].

Yin et al. [34] divided the dimensions of grain shape into grain length, grain width, length-to-width ratio, grain area, grain circumference, grain diameter, and grain roundness. Several important genes have been characterized in previous studies that control grain shape traits, e.g., GS3 [35] affecting grain length, qSW5/GW5/ GSE5 [14, 36, 37] affecting grain width, GL7/GW7 [38] shaping both grain length and grain width. In various studies across different environments and genetic backgrounds, a major effect quantitative trait loci (QTL) for grain length, GS3 was identified near the centromeric region of chromosome $3[12,35,39,40]$. However, a functional marker in the second exon of GS3 was identified that explains 80-90\% of the kernel length variation [41]. Bai et al. [42] identified four QTLs for grain length on chromosomes 3 and 7; and 10 QTLs for grain width and 9 QTLs for grain thickness on chromosomes 2, 3, 5, 7, 9 and 10, respectively. A total of 28 QTLs were detected, of which numerous were reported for the first time. Four major and six minor QTLs for grain shape were also identified in their study. Later on, $q G L 7$ was narrowed down to an interval covering a $258 \mathrm{~kb}$ region in the Nipponbare genome between InDel marker RID711 and SSR marker RM6389, and co-segregated with 
InDel markers RID710 and RID76. The dimensions of grain shape were dissected by Yin et al. [34] into grain length, grain width, length-to-width ratio, grain area, grain circumference, grain diameter, and grain roundness. By contrast, a few QTLs for grain chalkiness have been finely mapped and characterized functionally. Chalk5 was the first cloned and functionally characterized gene that controls rice grain chalkiness which encodes a vacuolar $\mathrm{H}+$-translocating pyrophosphatase [43]. Two methods are commonly applied for genetic dissection of these complex traits: QTL mapping in bi-parental recombinant populations and genome-wide association studies (GWAS) using diverse varieties. In general, genetic diversity and mapping resolution are limitations in the bi-parental linkage approach, while conventional GWAS is often mystified by complicated population structure and low power to map the low-frequency alleles [44, 45]. Genome-wide high-resolution mapping for the traits of grain shape and grain chalkiness was performed by Gong et al. [46] in hybrid rice using multiple collaborative populations for joint analyses.

\subsection{Milling quality}

Milling yield is an important quality character especially from the commercial standpoint [47]. It includes milled rice yield and head rice yield. Milling yield is the estimate of the quantity of total milled rice obtained from a unit of rough rice (paddy) and produced by removing the hulls, germ, and most of the bran. It includes intact and broken kernels and generally expressed as percentage [48]. Head rice is the intact or "whole" kernels and includes milled kernels having equal to or more than three-fourth length. The economic value of broken kernels is only $50-60 \%$ that of head rice, supporting the immense impact it has on marketability. Bran consists of several layers of outer covering of the endosperm. These layers include the pericarp, testa (seed coat), the nucellus and the aleurone, including the germ, are collectively called bran. Both, the degree of milling, which is an estimate of the degree to which the bran layers are removed from the endosperm, and fissuring of grains contribute to the percentage of broken kernels and hence, determine the overall milling quality [49]. Fissures or cracks in the grains weaken the strength of the grain and predispose them to break when exposed to mechanical forces during milling process [50]. Post-harvest drying of rice is one of the greatest factors that affect the percentage of broken kernels. Alternate wetting and drying of grains, drying at high temperatures and non-equilibrated grains before polishing lead to a decrease in head rice recovery [51-55]. Milling quality is determined with the help of laboratory-sized mills. They include dehuskers that remove husk, polishers or Test Rice Whitening Machine and graders, indent cylinders and shaker tables to segregate broken kernels from milled rice. Lam and Proctor [56] determined that linoleic and oleic acids were the main fatty acids released during milled rice surface lipids hydrolysis. Limited number of QTLs has been identified for milling quality. Two have been fine mapped but none has been cloned so far [57].

\subsection{Cooking and sensory quality}

Rice is mainly consumed as polished grain in contrast to other staple cereals like wheat and maize that are consumed after the grain is ground to flour. Therefore, the quality characters of rice grain assume greater importance. The chief component of milled rice grain is starch which constitutes approximately $78 \%$ (14\% moisture) or $90 \%$ (dry weight) of the endosperm [58]. Thus, the properties of starch mainly determine the cooking and eating quality of rice grains. Three important traits of starch that determine the cooking and organoleptic properties of rice grain are: apparent amylose content (AAC), gelatinization temperature (GT) and gel consistency. 
The amylose fraction, essentially the linear polymer of glucose, forms only a small component of starch. The other major form of starch is the highly branched amylopectin molecule. Amylose is an important quality trait of rice and is considered as an indirect predictor of cooking and sensory quality [59-61]. Iodine-binding assay, generally used for measuring amylose content, also detects long-chain amylopectin in addition to 'true' amylose [62]. Hence, amylose is referred to as apparent amylose content (AAC). AAC of starch ranges from 0.8 to $1.3 \%$ in waxy rice, whereas it constitutes $8-37 \%$ [58] in non-waxy rice, the rest being amylopectin. AAC is directly proportional to water absorption, volume expansion, fluffiness, hardness and inversely proportional to cohesiveness, tenderness, stickiness and glossiness of cooked rice. Based on AAC, rice can be classified as: waxy (0-2\%), very low (3-9\%), low (10-19\%), intermediate (20-25\%), and high (>25\%) [10]. Despite overestimating the actual amylose content and other limitations, iodinebinding assay that produces blue iodine-amylose complex when iodine binds to gelatinized rice flour which is quantified using a spectrophotometer, remains the method of choice for determining AAC. The two methods approved for the estimation of amylose content in milled rice are: the AACCI Method61-03.01 and ISO Method 6647-1:2015 [63, 64]. Auto-analyzers are also being used for routine amylose estimations in several rice improvement programs [65].

In general, the AAC is related to sensory quality of cooked rice however, there are varieties that have the same AAC but differ in their cooked rice hardness [66]. To account for such differences, a complementary test called gel consistency (GC) is routinely used [32]. It measures the length moved by rice flour gel, before it sets. Rice is classified into three GC groups based on gel length: hard and very flaky $(\leq 40 \mathrm{~mm})$, medium and flaky $(41-60 \mathrm{~mm})$, and soft $(>61 \mathrm{~mm})$. The differences in GC groups are explained on the basis of the proportion of hot water soluble amylose compared to that of insoluble amylose. The varieties with higher proportion of hot water insoluble amylose exhibit hard GC $[67,68]$. Studies have indicated that long-chain amylopectin that remains in the gelatinized starch granule is probably the hot water insoluble amylose [69, 70]. According to Matsue et al. [71], amylose and protein content, amylographic characteristics, and even palatability showed significant difference depending on the position of spikelets in a panicle.

Conventional genetic studies have revealed that AAC is under the control of one major gene with several modifiers [56]. Among non-waxy parents, high amylose is completely dominant over low or intermediate amylose, and intermediate is dominant over low [72]. With the advent of molecular marker technology, it is now easy to apprehend complex quantitative traits [73]. Amylose content is reported to be mainly controlled by the waxy gene locus $(W x)$ present on chromosome 6 , which encodes the granule-bound starch synthase (GBSS) [74].This enzyme is required for amylose synthesis, and several alleles are encoded by the $W x$ locus $[75,76]$. Three alleles of the waxy gene- $W x, W x^{a}$ and $W x^{b}$ are known, which exist in waxy (sticky) rice, indica and japonica sub-species, respectively. The activity of the encoded protein, GBSS differs in different genetic backgrounds [77]. A single nucleotide polymorphism (SNP) at the splice site of intron 1 differentiates low amylose varieties from intermediate and high varieties. This SNP defines the $W x^{a}$ and $W x^{b}$ alleles for high and low amylose, respectively [78]. In the $W x^{\text {in }}$ allele [76] it was identified that an SNP in exon 6, results in an amino acid substitution from serine to tyrosine that distinguishes high and intermediate amylose varieties [75].

Gelatinization temperature (GT) is another important physicochemical parameter that ranges from 55 to $80^{\circ} \mathrm{C}$ and provides information regarding the cooking time of rice and its texture [79]. The temperature at which the semi-crystalline structure of starch begins to melt in hot water with loss of birefringence is termed GT [1]. GT is classified into three classes: low $\left(55-69^{\circ} \mathrm{C}\right)$, intermediate $\left(70-74^{\circ} \mathrm{C}\right)$ or high 
$\left(75-79^{\circ} \mathrm{C}\right)$ [27]. GT is dependent on the amylopectin fine structure of starch with higher proportion of short chains (DP 6-12) decreasing the GT [80, 81]. Consumer preferences are varied throughout the world but varieties with intermediate GT are mostly preferred [82]. The two most commonly used methods for GT determination are: alkali spreading value (ASV) and Differential Scanning Calorimetry (DSC).

ASV is based on the disintegration of starch granules present in milled rice grains in dilute $\mathrm{KOH}$. The extent of disintegration is numerically scored on a scale of 1-7 $[31,68]$. Though ASV is a high throughput method for the determination of GT, it is an indirect and subjective test. In contrast, DSC is an instrumental method based on measuring in real time, the first peak of the endotherm as the starch granules gelatinize $[6,83,84]$. DSC is a precise but an expensive method for measuring GT and cannot be routinely used to screen thousands of breeding lines in rice improvement programs. GT is also determined by an amylograph method [85] which tracks the viscosity changes that take place when rice flour-water slurry is heated with continuous stirring and was approved as the AACCI Method 61-01.01. The temperature at which the viscosity of $20 \%$ slurry begins to rise, determines the GT. The instrument used extensively in advanced rice quality labs is Rapid Viscoamylograph (RVA) [1]. It determines the viscosity changes during the heating and cooling of relatively small rice flour samples (6 g) AACCI Method 61-02.01.

A QTL corresponding to the alk locus was identified by Fan et al. [35], having a major effect on alkali spreading value. Alk/alk codes for starch synthase IIa (SSIIa) which is responsible for the vital differences in amylopectin chain length distribution [81]. Specifically, four haplotypes are able to distinguish between low and high GT. But a marker which is able to identify genotypes with the intermediate class of GT has yet to be discovered. GT is classified into two groups by allelic variation in SSlla $[81,86]$. The SNPs in SSlla define four haplotypes [87, 88] and two haplotypes associate with high and two with low GT. Varieties having intermediate GT are found in all haplotype groups [89], thereby suggesting that another locus interacts with SSlla to produce the intermediate phenotype. SNP mutations in the rice alk gene have been shown to alter the amylose content in grains [88]. Although several alleles of Waxy/waxy and Alk/alk genes linked with different forms of starch have been identified [87], other starch biosynthesis genes in addition to Waxy/waxy and Alk/alk also affect rice cooking and eating quality. However, starch structure does not clarify all the variation in rice grain quality parameters present in all rice germplasm [90].

Aroma is a prized sensory trait of cooked rice that increases its market value. Among more than 100 identified volatile compounds, 2-acetyl-1-pyrroline (2-AP) is the major chemical compound contributing to the fragrance of Basmati rice, Jasmine rice and Pandanus leaves [91-94]. Aroma is traditionally detected by smelling after reaction with $0.1 \mathrm{M} \mathrm{KOH}$. However, this method is subjective and is also harmful to the nasal cavity of the analyst upon continuous and prolonged exposure. To solve this problem, gas chromatography coupled with flame ionization detector (GC-FID) or mass spectrometry (GC-MS) is being used in advanced rice breeding facilities. However, these methods are expensive and involve high running and maintenance costs. Therefore, molecular markers related to 2-AP are routinely used in rice breeding programs working on aroma.

Genetics studies of aroma have been an attractive research topic and many researchers studied it by employing various sensory tests. A few scientists like Reddy and Reddy [95] described two to three recessive or dominant genes that determine the fragrance, but most researchers believe that Basmati fragrance is under the control of a single recessive gene $[96,97]$. Almost two decades of attempts to know the genetics of aroma at molecular level concluded in mapping of a single locus $(f g r)$ on chromosome 8. QTL mapping [98, 99] followed by fine mapping [94], sequence 
analysis and complementation test [100] have helped to determine that Betaine Aldehyde Dehydrogenase (BADH2) gene possessing 15 exons and 14 introns is the fragrance causing gene $(f g r)$. Several studies have suggested that a recessive allele of BADH2 carrying fragment deletions, badh2 includes 7 bp deletion in 2nd exon, an 8 bp deletion in 7th exon and an 803 bp deletion between exons 4 and 5 [101, 102]. This characterization of fragrant and non-aromatic rice varieties suggested that these events might have occurred after the divergence of aromatic and non-aromatic varieties from the common ancestor. On the other hand, the functional $B A D H 2$ converts $\mathrm{AB}$-ald (presumed 2-AP precursor) into GABA (4-aminobutyraldehyde) in non-fragrant rice and the non-functional $\mathrm{BADH} 2$ causes accumulation of $\mathrm{AB}$-ald and thereby enhances 2-AP biosynthesis in fragrant rice [100]. A study by Kovach et al [103] suggested that Basmati cultivars were nearly identical to the ancestral japonica haplotype across $5.3 \mathrm{Mb}$ region flanking BADH2 thereby, demonstrating the close evolutionary relationship of Basmati cultivars with japonica varietal group. Due to instability in expression of Badh2 gene and complexity in fragrance determination, marker assisted selection (MAS) is considered to be a useful tool for screening this trait.

Detailed studies were done by Sood and Siddiq [104] on the geological distribution of kernel elongation gene(s) in rice and reported that varieties showing high kernel elongation on cooking were known to be traditionally cultivated in the northwest part of undivided India. Kernel elongation upon cooking is an endosperm character significantly influenced by factors like environment, aging, etc. Basmati rices are characterized by doubling of kernel length upon cooking. Despite being an important trait, not many reports are available on the inheritance of kernel elongation on cooking. Among the limited number of studies on this trait, one study had reported identification of a QTL between two RFLP markers viz., RZ323 and RZ562 and mapped it at a distance of $14.6 \mathrm{cM}$ on chromosome 8 [105].

\subsection{Nutritional quality}

Rice is consumed as a staple for providing sustenance to its consumers'. With improving purchasing power of the rice consumers' post green revolution, nutritional quality of rice gained importance. As starch is the main constituent of milled rice grain, it is the major source of energy and affects its nutritional quality. It has been reported that starch is digested at different rates in human gastro-intestinal tract [106]. The digestibility of starch is measured by estimating the rise in blood glucose level of humans upon consumption of a food containing $50 \mathrm{~g}$ available carbohydrates compared to a standard solution containing 50 g glucose [107-109]. This glycemic response is reported as glycemic index (GI). However, estimation of GI involves low-throughput and expensive clinical assays, therefore, it is not routinely used in screening for low GI rices [110]. In vitro estimation of nutritional fractions of starch can be carried out by estimating the content of total sugars, total starch, rapidly digestible starch, slowly digestible starch and resistant starch [111, 112]. Apart from starch, the other major macronutrients present in milled rice grain are: storage proteins $(7 \%)$, storage lipids $(<1 \%)$ and non-starch polysaccharides (NSPs, trace amounts). These macronutrients significantly affect the nutritional quality, textural and sensory traits, and functional properties [113] even though they constitute minor components of milled rice grain. Storage proteins are major source of proteins in developing countries, are hypoallergenic and possess superior amino acid composition [114]. The Kjeldahl method with modifications to accommodate smaller sample sizes (AACCI Method 46-13.01) [63] is widely used method for the estimation of total proteins. Individual amino acids can be quantified after acid hydrolysis using pre-column derivatization with a fluorescent derivatizing reagent 
followed by HPLC separation $[115,116]$. Rice lipids serve nutritional and functional role. They provide protection against cardiovascular diseases and cancer [117] and also affect the pasting properties. Crude fat in rice grains is routinely analyzed using a standard method (AACCI Method 30-10.01). The fatty acid composition of the bran layer can also be analyzed using gas-liquid chromatography (GLC) [118]. NSPs are concentrated in the bran layer and only trace amounts are detected in the milled rice grains but have nutritional importance because of their unique composition compared to other cereals [109].

Nutritional components such as minerals, vitamins and phytochemicals are concentrated in the bran layer and are either absent or present at low levels in milled grains. The iron and zinc content are generally low and some of which is lost during milling. So a modest increase in these levels in rice would provide a significant nutritional boost to the hundreds of millions of people who depend on it. Hence there is an imperative need for a shift in emphasis toward development of nutritionally high quality rice. This is achieved by evaluating the available germplasm lines for micro nutrient content and by generation of knowledge regarding their inheritance pattern to use in future breeding programs. Micronutrients are being quantified by using atomic absorption spectroscopy (AAS), X-ray fluorescence spectrometry (XRF), inductively coupled plasma-mass spectrometry (ICP-MS), laser-induced breakdown spectroscopy (LIBS), and inductively coupled plasmaoptical emission spectrometry (ICP-OES) $[16,17]$.

Integration of marker assisted breeding with conventional breeding creates a possibility to track the introgression of nutritional quality associated QTLs and genes into a popular/elite cultivar from various germplasm sources [119]. Two consistent QTLs for protein content in milled rice were reported by Zhong et al. [120] as $q \operatorname{Pr} 1$ and $q P r 7$ and located in the marker interval of RM493-RM562 and RM445-RM418 on chromosome 1 and 7, respectively. Gande et al. [121] identified 24 candidate genes namely OsNAC, OsZIP8a, OsZIP8c and OsZIP4b showed significant phenotypic variance of 4.5, 19.0, 5.1 and 10.2\%, respectively. The QTL associated with increased grain protein content has been cloned and designated as Gpc-B1 [122].

\section{Future prospects}

Rice quantity and quality are directly or indirectly influenced by decrease in suitable arable land due to increase in urbanization, urban migration, soil deterioration and problems relating to climate fluctuations. Rice eating and cooking quality traits appear to be simple but the genetic machinery is too complex and needs to be deciphered. Rice appearance quality is a complex trait and involves interaction between quality and yield and also between quality and environment. Grain chalkiness is of primary concern since it affects milling, appearance, eating and cooking qualities [123]. To reduce chalkiness, genotypes with low chalk formation at high temperature after heading can be identified and utilized through MAS. Biochemical, physiological and molecular mechanisms have to be worked out by identifying and cloning chalkiness functional genes. The most challenging issue facing milling industry is to obtain high head rice recovery, since it is directly related to profitability to both the farmers and millers. Genetic understanding of milling quality is still limited [57]. Improvement of milling quality requires (i) search for QTLs with large effect (ii) robust and accurate analytical tools to measure the trait (iii) improvement in postharvest handling and storage techniques (iv) Breeding efforts through MAS. With the expeditious progress in functional genomics and development of high throughput genotyping technologies, more number of rice functional genes will be cloned in the future. 
Increased awareness among the rice consuming population toward sensory and nutritional traits makes it necessary to develop evaluation techniques that can directly correlate with the consumer perception. To improve eating and sensory quality of rice it is important to integrate methods in textural analysis and rheology with taste and flavor metabolomics. Nutritional quality of rice is another trait that needs to be included in rice improvement programs. Rice has an important role to play to mitigate the impact of non-communicable diseases like diabetes. Since starch forms about $90 \%$ of milled rice grain weight, its structure (amylose content, branching pattern) and digestibility (resistant starch) affect its nutritional quality. Clinical evaluation of rice digestibility is difficult, therefore, methods for accurate in vitro estimations should be developed and validated in vivo. Available germplasm can be screened for resistant starch, amylose content, digestibility, and other health-promoting properties [110]. Cooking and processing methods have a major impact on digestibility and eating quality [33]. Further research is needed to assess how these cooking and processing techniques affect the structural, physical-chemical, and mechanical properties of rice. Robust and innovative modeling approaches that link the physical-chemical changes that occur during cooking (amylose leaching, gelatinization, water absorption) with rice grain digestibility and nutritional value and consumer demands could help in identifying the key determinants of rice grain cooking and sensory quality.

\title{
Author details
}

\author{
Neerja Sharma* and Renu Khanna \\ Department of Plant Breeding and Genetics, Punjab Agricultural University, \\ Ludhiana, Punjab, India
}

*Address all correspondence to: neerjasharma@pau.edu

\section{IntechOpen}

(C) 2019 The Author(s). Licensee IntechOpen. This chapter is distributed under the terms of the Creative Commons Attribution License (http://creativecommons.org/licenses/ by/3.0), which permits unrestricted use, distribution, and reproduction in any medium, provided the original work is properly cited. (cc) BY 


\section{References}

[1] Champagne ET, Bett KL, Vinyard BT, McClung AM, Barton FE, Moldenhauer KA, et al. Correlation between cooked rice texture and Rapid Visco Analyser measurements. Cereal Chemistry. 1999;76:764-771

[2] Juliano BO. Rice Chemistry and Quality. Manila, Philippines: Phil Rice; 2003. pp. 199-251

[3] Fitzgerald MA, Hamilton NRS, Calingacion MN, Verhoeven HA, Butardo VM. Is there a second fragrance gene in rice? Plant Biotechnology Journal. 2008;6:416-423

[4] Calingacion M, Laborte A, Nelson A, Resurreccion A, Concepcion JC, et al. Diversity of global rice markets and the science required for consumer-targeted rice breeding. PLoS One. 2014;9:e85106. DOI: 10.1371/journal.pone.0085106

[5] Jane JL, Chen JF. Effect of amylose molecular size and amylopectin branch chain length on paste properties of starch. Cereal Chemistry. 1992;69:60-65

[6] Biliaderis CG, Page CM, Maurice TJ, Juliano BO. Thermal characterization of rice starches: A polymeric approach to phase transition of granular starch. Journal of Agricultural and Food Chemistry. 1986;34:6-24

[7] Villareal CP, De La Cruz NM, Juliano BO. Rice amylose analysis by near-infrared transmittance spectroscopy. Cereal Chemistrty. 1994;71:292-296

[8] Delwiche SR, Bean MM, Miller RE, Webb BD, Williams PC. Apparent amylosecontent of milled rice by nearinfraredreflectancespectroscopy. Cereal Chemistry. 1995;72:182-187

\section{[9] Dang JMC, Bason ML. AACCI} approved methods technical committee report: Collaborative study on a method for determining the gelatinization temperature of milled rice flour using the rapid visco analyser. Cereal Foods World. 2014;59:31-34

[10] Champagne ET, Bett KL, Vinyard BT, McClung AM, Barton FE II, Moldenhauer K, et al. Correlation between cooked rice texture and rapid visco analyses measurements. Cereal Chemistry. 1999;76:764-771

[11] McKenzie KS, Rutger JN. Genetic analysis of amylose content, alkali spreading score, and grain dimensions in rice. Crop Science. 1983;23:306-311

[12] Wang HL, Wan XY, Bi JC, Wang JK, Jiang L, Chen LM, et al. Quantitative analysis of fat content in rice by nearinfrared spectroscopy technique. Cereal Chemistry. 2006;83:402-406

[13] Lapchareonsuk R, Sirisomboon P. Sensory quality evaluation of rice using visible and shortwave near-infrared spectroscopy. International Journal of Food Properties. 2015;18:1128-1138

[14] Liu J, Chen J, Zheng X, Wu F, Lin Q, Heng Y, et al. GW5 acts in the brassinosteroid signalling pathway to regulate grain width and weight in rice. Nature Plants. 2017;3:17043

[15] Mantovani V, Galeotti F, Maccari F, Volpi N. Recent advances in capillary electrophoresis separation of monosaccharides, oligosaccharides, and polysaccharides. Electrophoresis. 2018;39:179-189

[16] Hansen TH, Laursen KH, Persson DP, Pedas P, Husted S, Schjoerring JK. Microscaled high-throughput digestion of plant tissue samples for multi-elemental analysis. Plant Methods. 2009;5:12

[17] Wheal MS, Fowles TO, Palmer LT. A cost-effective acid digestion method using closed polypropylene tubes for inductively coupled plasma optical 
emission spectrometry (ICP-OES) analysis of plant essential elements. Analytical Methods. 2011;3:2854-2863

[18] Dona AC, Pages G, Gilbert RG, Gaborieau M, Kuchel PW. Kinetics of in vitro digestion of starches monitored by time-resolved $1 \mathrm{H}$ nuclear magnetic resonance. Biomacromolecules. 2009;10:638-644

[19] Adair CR, Beachell HM, Jodon NE, Johnston TH, Thysell JR, Green VE Jr. Rice breeding and testing methods in the United States. In: Rice in the United States: Varieties and Production. Washington, DC: United States Department of Agriculture; 1966. pp. 19-64

[20] Graham R. A Proposal for IRRI to Establish a Grain Quality and Nutrition Research Center. Report No.: 44. Los Baños, Philippines; 2002

[21] Tomlins K, Manful J, Gayin J, Kudjawu B, Tamakloe I. Study of sensory evaluation, consumer acceptability, affordability and market price of rice. Journal of the Science of Food and Agriculture. 2007;87:1564-1575. DOI: $10.1002 /$ jsfa. 2889

[22] Codex Alimentarius Commission. Codex Standard for Rice; 1995

[23] Dela Cruz NM, Khush GS. Rice grain quality evaluation procedures. In: Singh RK, Singh US, Khush GS, editors. Aromatic Rices. New Delhi, India: Mohan Primlani; 2000. pp. 15-28

[24] Fitzgerald MA, Resurreccion AP. Maintaining the yield of edible rice in a warming world. Functional Plant Biology. 2009;36:1037. DOI: 10.1071/ FP09055

[25] Ikehashi H, Khush GS. Methodology of assessing appearance of the rice grain, including chalkiness and whiteness. In: Workshop on Chemical Aspects of Rice Grain Quality. Los
Baños, Philippines: International Rice Research Institute; 1979. pp. 223-230

[26] Guangrong L. Detection of chalk degree of rice based image processing. In: Proceedings of the International Conference on Intelligence Science and Information Engineering (ISIE); 20-21 August 2011; Wuhan, China. 2011. pp. 515-518

[27] Lisle AJ, Martin M, Fitzgerald MA. Chalky and translucent rice grains differ in starch composition and structure and cooking properties. Cereal Chemistry. 2000;77:627-632

[28] Melissa AF, McCouch SR, Hall RD. Not just a grain of rice: The quest for quality. Trends in Plant Science. 2009;14:133-139

[29] Counce P, Bryant R, Bergman C, Bautista R, Wang Y, Siebenmorgen T, et al. Rice milling quality, grain dimensions, and starch branching as affected by high night temperatures. Cereal Chemistry. 2005;82:645-648

[30] Cooper N, Siebenmorgen T, Counce P. Effects of nighttime temperature during kernel development on rice physicochemical properties. Cereal Chemistry. 2008;85:276-282

[31] Little RR, Hilder GB, Dawson EH. Differential effect of dilute alkali on 25 varieties of milled white rice. Cereal Chemistry. 1958;35:111-126

[32] Cagampang GB, Perez CM, Juliano BO. A gel consistency test for eating quality of rice. Journal of the Science of Food and Agriculture. 1973;24:1589-1594

[33] Yu L, Turner MS, Fitzgerald M, Stokes JR, Witt T. Review of the effects of different processing technologies on cooked and convenience rice quality. Trends in Food Science and Technology. 2017;59:124-138 
[34] Yin C, Li H, Li S, Xu L, Zhao Z, Wang J. Genetic dissection on rice grain shape by the two-dimensional image analysis in one japonica-indica population consisting of recombinant inbred lines. Theoretical and Applied Genetics. 2015;128:1969-1986

[35] Fan C, Xing Y, Mao H, Lu T, Han B, $\mathrm{Xu} \mathrm{C}$, et al. Gs3, a major qtl for grain length and weight and minor qtl for grain width and thickness in rice, encodes a putative transmembrane protein. Theoretical and Applied Genetics. 2006;112:1164-1171

[36] Shomura A, Izawa T, Ebana K, Ebitani T, Kanegae H, Konishi S, et al. Deletion in a gene associated with grain size increased yields during rice domestication. Nature Genetics. 2008;40:1023-1028

[37] Duan P, Xu J, Zeng D, Zhang B, Geng M, Zhang G, et al. Natural variation in the promoter of GSE5 contributes to grain size diversity in rice. Molecular Plant. 2017;10:685-694

[38] Wang K, Wambugu PW, Zhang B, Wu AC, Henry RJ, Gilbert RG. The biosynthesis, structureandgelatinization properties of starches from wild and cultivated African rice species (Oryza barthii and Oryza glaberrima). Carbohydrate Polymers. 2015;129:92-100

[39] Wan X, Wan J, Jiang L, Wang J, Zhai H, Weng J, et al. QTL analysis for rice grain length and fine mapping of an identified QTL with stable and major effects. Theoretical and Applied Genetics. 2006;112:1258-1270

[40] Zhou LQ, Wang YP, Li SG. Genetic analysis and physical mapping Lk-4(t), a major gene controlling grain length in rice, with a $\mathrm{BC}_{2} \mathrm{~F}_{2}$ population. Yi Chuan Xue Bao. 2006;33:72-79

[41] Fan C, Yu S, Wang C, Xing Y. A causal $\mathrm{c}$-a mutation in the second exon of $g s 3$ highly associated with rice grain length and validated as a functional marker. Theoretical and Applied Genetics. 2009;118:465-472

[42] Bai X, Luo L, Yan W, Kovi MR, Zhan W, Xing Y. Genetic dissection of rice grain shape using a recombinant inbred line population derived from two contrasting parents and fine mapping a pleiotropic quantitative trait locus qgl7. BMC Genetics. 2010;11:16

[43] Li JY, Wang J, Zeigler RS. The 3000 rice genomes project: New opportunities and challenges for future rice research. GigaScience. 2014;3:8

[44] Myles S, Peiffer J, Brown PJ, Ersoz ES, Zhang Z, Costich DE, et al. Association mapping: Critical considerations shift from genotyping to experimental design. Plant Cell. 2009;21:2194-2202

[45] Nordborg M, Weigel D. Nextgeneration genetics in plants. Nature. 2008;456:720-723

[46] Gong J, Miao J, Zhao Y, Zhao Q, Feng Q, Zhan Q, et al. Dissecting the genetic basis of grain shape and chalkiness traits in hybrid rice using multiple collaborative populations. Molecular Plant. 2017;10:1353-1356

[47] Bergman CJ, Bhattacharya KR, Ohtsubo KI. Rice end-use quality analysis. In: Champagne ET, editor. Rice Chemistry and Technology. St. Paul, Minnesota: The American Association of Cereal Chemists; 2004

[48] Cruz D, Khush GS. Rice grain quality evaluation procedures. In: Singh RK, Singh US, Khush GS, editors. Aromatic Rices. New Delhi, India: Oxford and IBH Publishing Co. Pvt. Ltd; 2000. pp. 15-18

[49] Bhattacharya KR. Analysis of rice quality. In: Bhattacharya KR, editor. Rice 
Quality. Cambridge, UK: Woodhead Publishing Ltd; 2011. pp. 431-530

[50] Swamy YMI, Bhattacharya KR. Breakage of rice during milling 1. Types of cracked and immature grains. Journal of Food Science and Technology. 1982;19:106-111

[51] Banaszek MM, Siebenmorgen TJ. Head rice yield reduction rates caused by moisture sorption. Arkansas Farm Research. 1990;39:4-8

[52] Cnossen AG, Jiménez MJ, Siebenmorgen TJ. Rice fissuring response to high drying and tempering temperatures. Journal of Food Engineering. 2003;9:61-69

[53] Cnossen AG, Siebenmorgen TJ. The glass transition temperature concept in rice drying and tempering: Effect on milling quality. Transactions of the American Society of Agricultural Engineers. 2000;43:1661-1667

[54] Jindal VK, Siebenmorgen TJ. Effects of rice kernel thickness on head rice yield reduction due to moisture adsorption. Transactions of the American Society of Agricultural Engineers. 1994;37(2):487-490

[55] Kocher MF, Siebenmorgen TJ, Norman RJ, Wells BR. Rice kernel moisture content variation at harvest. Transactions of the American Society of Agricultural Engineers. 1990;33:541-548

[56] Kumar I, Khush GS. Inheritance of amylose content in rice (Oryza sativa L.). Euphytica. 1988;38:261-269

[57] Bao JS. Genes and QTLs for rice grain quality improvement. In: Yan WG, Bao JS, editors. Rice-Germplasm, Genetics and Improvement. Rijeka, Croatia: IntechOpen; 2014. pp. 239-278

[58] Champagne ET, Wood DF, Juliano BO, Betchell DB. The rice grain and its gross composition. In: Champagne ET, editor. Rice: Chemistry and Technology. St Paul, USA: AACC; 2004. pp. 93-94

[59] Juliano BO. Physicochemical properties of starch and protein in relation to grain quality and nutritional value of rice. In: IRRI Rice Breeding. Los Banos, Philippines: IRRI; 1972. pp. 389-405

[60] Li H, Prakash S, Nicholson TM, Fitzgerald MA, Gilbert RG. The importance of amylose and amylopectin fine structure for textural properties of cooked rice grains. Food Chemistry. 2016;196:702-711

[61] Juliano BO. Structure, chemistry, and function of the rice grain and its fractions. Cereal Foods World. 1992;37:772

[62] Juliano BO. A simplified assay for milled-rice amylose. Cereal Science Today. 1971;16:334-340

[63] AACC. International Approved Methods of Analysis. St. Paul, MN: Association for American Cereal Chemists (AACC International); 2009

[64] International Organization for Standardization. ISO 6647-2:2007Rice Determination of Amylose Content-Part 2: Routine Methods. Geneva: International Organization for Standardization; 2007

[65] Juliano BO, Perez CM, Blakeney AB, Castillo T, Kongseree N, Laignelet B, et al. International cooperative testing on the amylose content of milled rice. Starch. 1981;33:157-162

[66] Perez CM, Juliano BO. Indicators of eating quality for non-waxy rices. Food Chemistry. 1979;4:185-195

[67] Bhattacharya KR. Physicochemical basis of eating quality of rice. Cereal Foods World. 2009;54:18-28

[68] Bhattacharya KR, Sowbhagya CM, Indudhara Swamy YM. Importance of 
insoluble amylose as a determinant of rice quality. Journal of the Science of Food and Agriculture. 1978;29:359-364

[69] Takeda Y, Hizukuri S, Juliano BO. Structures of rice amylopectins with low and high affinities for iodine. Carbohydrate Research. 1987;168:79-88

[70] Horibata T, Nakamoto M, Fuwa H, Inouchi N. Structural and physicochemical characteristics of endosperm starches from rice cultivars recently bred in Japan. Journal of Applied Glycoscience. 2004;51:303-313

[71] Matsue Y, Odahara K, Hiramatsu M. Differences in protein content, amylose content and Pala in relation to location of grains within rice panicle. Japanese Journal of Crop Science. 1994;63:271-277

[72] Kumar I, Khush GS. Genetic analysis of different amylose levels in Rice. Crop Science. 1987;27:1167. DOI: 10.2135/cropsci1987.0011183X0027000 60016x

[73] Fan CC, Yu XQ, Xing YZ, Xu CG, Luo LJ, Zhang Q. The main effects, epistatic effects and environmental interactions of qtls on the cooking and eating quality of rice in a doubled-haploid line population. Theoretical and Applied Genetics. 2005;110:1445-1452

[74] Smith AM, Denyer K, Martin C. The synthesis of the starch granule. Annual Review of Plant Physiology and Plant Molecular Biology. 1997;48:67-87

[75] Chen M-H, Bergman CJ, Pinson SRM, Fjellstrom RG. Waxy gene haplotypes: Associations with apparent amylose content and the effect by the environment in an international rice germplasm collection. Journal of Cereal Science. 2008;47:536-545

[76] Mikami I, Uwatoko N, Ikeda Y, Yamaguchi J, Hirano HY, Suzuki Y, et al.
Allelic diversification at the wx locus in landraces of Asian rice. Theoretical and Applied Genetics. 2008;116:979-989

[77] Fitzgerald MA, Bergman CJ, Resurreccion AP, Möller J, Jimenez R, Reinke RF. Addressing the dilemmas of measuring amylose in Rice. Cereal Chemistry. 2009;86:492-498. DOI: 10.1094/CCHEM-86-5-0492

[78] Isshiki M, Nakajima M, Okagaki RJ, Wessler SR, Izawa T, Shimamoto K. A naturally occurring functional allele of the rice waxy locus has a GT to TT mutation at the $5^{\prime}$ splice site of the first intron. The Plant Journal. 1998;15:133-138

[79] Juliano BO. Polysaccharides, proteins and lipids of rice. In:

Juliano BO, editor. Rice, Chemistry and Technology. St Paul, MN: American Association of Cereal Chemists; 1985. pp. 59-60

[80] Slade L, Levine H. Non-equilibrium melting of native granular starch:

Part I. Temperature location of the glass transition associated with gelatinisation of A-type cereal starches. Carbohydrate Polymers. 1988;8:183-208

[81] Umemoto T, Yano M, Satoh H, Shomura A, Nakamura Y. Mapping of a gene responsible for the difference in amylopectin structure between japonica-type and indica type rice varieties. Theoretical and Applied Genetics. 2002;104:1-8

[82] Khush GS, Paule CM, DeLa Cruz MN. Rice quality evaluation and improvement at IRRI. In: Proceedings of the Workshop on Chemical Aspects of Rice Grain Quality. Los Banos, Laguna, Philippines: International Rice Research Institute; 1979. pp. 21-31

[83] Normand FL, Marshall WE.

Differential scanning calorimetry of whole grain milled rice and milled rice flour. Cereal Chemistry. 1989;66:317-321 
[84] Normand FL, Marshall WE. Thermal-properties of whole grain milled rice and milled rice flour studied by differential scanning calorimetry. Cereal Foods World. 1988;33:663-663

[85] Halick JV, Beachell HM, Stansel JW, Kramer HH. A note on the determination of gelatinization temperature of rice varieties. Cereal Chemistry. 1960;37:670

[86] Bao JS, Corke H, Sun M. Nucleotide diversity in starch synthase IIa and validation of single nucleotide polymorphisms in relation to starch gelatinization temperature and other physicochemical properties in rice (Oryza sativa L.). Theoretical and Applied Genetics. 2006;113:1171-1183

[87] Waters DLE, Henry RJ, Reinke RF, Fitzgerald MA. Gelatinization temperature of rice explained by polymorphisms in starch synthase. Plant Biotechnology Journal. 2006;4:115-122

[88] Umemoto T, Aoki N. Singlenucleotide polymorphisms in rice starch synthase IIa that alter starch gelatinisation and starch association of the enzyme. Functional Plant Biology. 2005;32:763-768

[89] Cuevas RP, Daygon VD, Corpuz HM, Reinke RF, Waters DLE, et al. Melting the secrets of gelatinisation temperature in rice. Functional Plant Biology. 2010;37:439-447

[90] Kharabian-Masouleh A, Waters DLE, Reinke RF, Ward RA, Henry RJ. SNP in starch biosynthesis genes associated with nutritional and functional properties of rice. Science Reporter. 2013;2:557

[91] Buttery RG, Ling LC, Juliano BO. 2-Acetyl-1-pyrroline: An important aroma component of cooked rice. Chemistry \& Industry. 1982;23:958-959
[92] Buttery RG, Ling LC, Juliano BO, Turnbaugh JG. Cooked rice aroma and 2-acetyl-1-pyrroline. Journal of Agricultural and Food Chemistry. 1983;31:823-826

[93] Buttery RG, Ling LC, Mon TR. Quantitative analysis of 2-acetyl-1pyrroline in rice. Journal of Agricultural and Food Chemistry. 1986;34:112-114

[94] Chen S, Wu J, Yang Y, Shi W, $\mathrm{Xu} \mathrm{M}$. The $f g r$ gene responsible for rice fragrance was restricted within $69 \mathrm{~kb}$. Plant Science. 2006;171:505-514

[95] Reddy VD, Reddy GM. Genetic and biochemical basis of scent in rice (Oryza sativa L.). Theoretical and Applied Genetics. 1987;73:699-700

[96] Sood BC, Siddiq EA. A rapid technique for scent determination in rice. Indian Journal of Genetics and Plant Breeding. 1978;38:268-271

[97] Jin QS, Waters D, Cordeiro GM, Henry RJ, Reinke RF. A single nucleotide polymorphism (SNP) marker linked to the fragrance gene in rice (Oryza sativa L.). Plant Science. 2003;165:359-364

[98] Ahn SN, Bollich CN, Tanksley SD. RFLP tagging of a gene for aroma in rice. Theoretical and Applied Genetics. 1992;84:825-828

[99] Lorieux M, Petrov M, Huang N, Guiderdoni E, Ghesquière A. Aroma in rice: Genetic analysis of a quantitative trait. Theoretical and Applied Genetics. 1996;93:1145-1151

[100] Chen S, Yang Y, Shi W, Ji Q, He F, Zhang Z, et al. Badh2, encoding betaine aldehyde dehydrogenase, inhibits the biosynthesis of 2-acetyl-1-pyrroline, a major component in rice fragrance. Plant Cell. 2008;20:1850-1861

[101] Bradbury L, Henry R, Jin Q, Reinke RF, Waters DLE. A perfect marker for fragrance genotyping in rice. Molecular Breeding. 2005;16:279-283 
[102] Shi W, Yang Y, Chen S, Xu M. Discovery of a new fragrance allele and the development of functional markers for the breeding of fragrant rice varieties. Molecular Breeding. 2008;22:185-192

[103] Kovach MJ, Calingacion MN, Fitzgerald MA, McCouch SR. The origin and evolution of fragrance in rice (Oryza sativa L.). Proceedings of the National Academy of Science. 2009;106:14444-14449

[104] Sood BC, Siddiq EA. Geographical distribution of kernel elongation gene(s) in rice. Indian Journal of Genetics. 1980;40:439-442

[105] Ahn SN, Bollich CN, McClung AM, Tanksley SD. RFLP analysis of genomic regions associated with cooked-kernel elongation in rice. Theoretical and Applied Genetics. 1993;87:27-32

[106] Marsh K, Brand-Miller J. State of arts reviews: Glycemic index, obesity and chronic disease. American Journal of Lifestyle Medicine. 2008;2:142-150

[107] Wolever TMS. Glycaemic index: a physiological classification of dietary carbohydrate. In: CAB International Book Archive, Titles From 2005, 2006, 2007. Wallingford, UK: CABI Publishing; 2006

[108] Trinidad TP, Mallillin AC, Encabo RR, Sagum RS, Felix AD, Juliano BO. The effect of apparent amylose content and dietary fiber on the glycemic response of different varieties of cooked milled rice and brown rice. International Journal of Food Sciences and Nutrition. 2013;64:89-93

[109] Jenkins DJ, Wolever TM, Taylor RH, Barker H, Fielden H, Baldwin JM, et al. Glycemic index of foods: A physiological basis for carbohydrate exchange. The American Journal of Clinical Nutrition. 1981;34:362-366
[110] Butardo VM Jr, Nese S, Juliano Bienvenido O. Improving rice grain quality: State-of-the-art and future prospects. In: Sreenivasulu N, editor. Rice Grain Quality: Methods and Protocols, Methods in Molecular Biology. 2019, 1892. DOI: 10.1007/978-1-4939-8914-0_2

[111] Englyst HN, Kingman SM, Cummings JH. Classification and measurement of nutritionally important starch fractions. European Journal of Clinical Nutrition. 1992;46:S33-S50

[112] Englyst KN, Englyst HN, Hudson GJ, Cole TJ, Cummings JH. Rapidly available glucose in foods: An in vitro measurement that reflects the glycemic response. The American Journal of Clinical Nutrition. 1999;69:448-454

[113] Butardo VM Jr, Sreenivasulu N, Jeon $\mathrm{K}$. Tailoring grain storage reserves for a healthier rice diet and its comparative status with other cereals. International Review of Cell and Molecular Biology. 2016;323:31-70

[114] Shih FF. Rice proteins. In: Champagne ET, editor. Rice: Chemistry and Technology. 3rd ed. Inc, St. Paul, $\mathrm{MN}$ : American Association of Cereal Chemistry; 2004. pp. 143-162

[115] Cohen SA. Amino acid analysis using precolumn derivatization with 6-aminoquinolyl-Nhydroxysuccinimidylcarbamate. In: Cooper C, Packer N, Williams K, editors. Amino Acid Analysis Protocols. Totowa, NJ: Humana Press; 2000. pp. 39-47

[116] Cohen SA, Michaud DP. Synthesis of a fluorescent derivatizing reagent, 6-amino quinolyl-N-hydroxy succinimidylcarbamate, and its application for the analysis of hydrolysate amino acids via highperformance liquid chromatography. Analytical Biochemistry. 1993;211:279-287 
[117] Godber JS, Juliano BO. Rice

lipids. In: Champagne ET, editor. Rice: Chemistry and Technology. 3rd ed. St. Paul, MN: American Association of Cereal Chemistry; 2004. pp. 163-190

[118] Lugay JC, Juliano BO. Fatty acid composition of rice lipids by gasliquid chromatography. Journal of the American Oil Chemists' Society. 1964;41:273-275

[119] Mahender A, Anandan A, Kumar Pradhan S, Pandit E. Rice grain nutritional traits and their enhancement using relevant genes and QTLs through advanced approaches. Springerplus. 2016;5:2086. DOI: $10.1186 /$ s40064-016-3744-6

[120] Zhong M, Wang L, Yuan J, Luo L, Xu C, He YQ. Identification of QTL affecting protein and amino acid contents in rice. Rice Science. 2011;18:187-195

[121] Gande NK, Kundur PJ, Soman R, Ambati R, Ashwathanarayana R, Bekele BD, et al. Identification of putative candidate gene markers for grain zinc content using recombinant inbred lines (RIL) population of IRRI38 $\mathrm{X}$ Jeerigesanna. African Journal of Biotechnology. 2014;13:657-663

[122] Uauy C, Brevis J, Dubcovsky J. The high grain protein content gene $G p c$ $B 1$ accelerates senescence and has pleiotropic effects on protein content in wheat. Journal of Experimental Botany. 2006;57:2785

[123] Siebenmorgen TJ, Grigg BC, Lanning SB. Impacts of pre-harvest factors during kernel development on rice quality and functionality. Annual Review of Food Science and Technology. 2013;4:101-115 



\title{
Neglected and Underutilized Legume Crops: Improvement and Future Prospects
}

\author{
Jacob Popoola, Omena Ojuederie, Conrad Omonhinmin and \\ Adegoke Adegbite
}

\begin{abstract}
Sustainable agricultural productivity is hampered by over-dependency on major staple crops, neglect and underutilization of others, climate change, as well as land deterioration. Challenges posed by these limiting factors are undoubtedly contributing to global food insecurity, increased rural poverty, and malnutrition in the less developed countries. Miscellaneous neglected and underutilized grain legumes (MNUGLs) are crops primarily characterized by inherent features and capabilities to withstand the effects of abiotic stress and climate change, significantly replenish the soil, as well as boost food and protein security. This chapter provides insight into the benefits of MNUGLs as food and nutritional security climate smart crops, capable of growing on marginal lands. Exploring and improving MNUGLs depend on a number of factors among which are concerted research efforts, cultivation and production, as well as utilization awareness across global populace geared toward reawakening the interest on the abandoned legumes. The emergence of the clustered regularly interspaced short palindromic repeat (CRISPR/cas9) technology combined with marker-assisted selection (MAS) offers great opportunities to improve MNUGLs for sustainable utilization. Advances in improvement of MNUGLs using omic technologies and the prospects for their genetic modification were highlighted and discussed.
\end{abstract}

Keywords: climate change, CRISPR/cas9, food security, marker-assisted selection (MAS), omic technologies, underutilized grain legumes

\section{Introduction}

The world is confronted with the challenges of climate change, terrorism, and poverty, among other factors, which hinder food production, food availability, as well as food and nutritional security. Globally, food insecurity and low supply in many areas are threatening the human population and survival in the areas where terrorism and transborder and internal displacement of persons are entrenched in many parts of the world. Food as an important commodity for survival is under threat, and if survival strategies are not devised, the catastrophe will be overbearing. A number of crop species are becoming extinct from our agricultural and forest fields, while some others are declining both in cultivation and utilization. A review of global food security indicates re-strategizing crop genetic improvement and production agronomy toward grain legumes to identify climate-resilient species and 
varieties with enhanced grain features $[1,2]$. This is highly desirable considering the significant roles that grain legumes play in the food cultures around the world as veritable sources of quality protein, natural medicine, animal fodder, natural fertilizers, and environmental restoration products, alongside the well-established soil enrichment property of symbiosis with nitrogen-fixing bacteria [3].

In order to meet the global food demands, focus should be on promoting the cultivation and utilization of other crops which have been neglected and underexploited but have the potential to enhance food and nutrition security especially in the developing countries of sub-Saharan Africa. With the recent negative impact of climate change being experienced globally, Africa is the most affected as a region that depends on rain-fed agriculture. The effect of increased drought on agricultural crops has led to yield reductions at harvest, death of livestock, and loss of income and jobs in some parts of Africa especially in Somalia, Kenya, and Ethiopia. This has drastically increased the level of malnutrition and food insecurity. Most of the staple crops are unable to withstand the harsh environmental changes currently taking place. Nevertheless, miscellaneous neglected and underutilized grain legumes (MNUGLs) are more advantageous over the conventional staple crops. These MNUGLs are often linked to the cultural heritage of their places of origin, well adapted to precise agroecological areas, harsh environments, and marginal lands. They also perform well in traditional production systems with little or no external inputs [4-6].

The chapter will cover some selected minor grain legumes with huge potentials to boost protein security in period of hunger and malnutrition in the sub-Saharan Africa and elsewhere. The species are known by many appellations such as miscellaneous, neglected, underutilized, underexploited, and under-researched, among others. These MNUGLs could be further improved using recent advancements in omic technologies for better acceptance and utilization as well as for improved food security.

\section{What are miscellaneous, neglected and underutilized grain legumes (MNUGLs?)}

Globally, neglected and underutilized species (NUS) are often identified based on their local usefulness, localized domestication, adaptation coupled with general abandonment by mainstream agricultural researchers, extension services, plant breeders, donors, technology providers, policy- and decision-makers, as well as consumers $[2,6]$. NUS are classically identified based on certain criteria which include the following:

1. Local importance in consumption and production systems

2. Adaptation to agroecological niches/marginal areas

3. Representation by ecotypes/landraces

4. Cultivation and utilization based only on indigenous knowledge

5. Rare representation in ex situ collections

6. Uncoordinated attention from national agricultural and biodiversity conservation policies, research, and development

7. Neglect by mainstream market system 
In reality and broad consideration, a large percentage of such NUS are underutilized legume crops. As such these legume species are classified as minor grain legumes, though consumed as food and forage crops in many parts of the world. Thus, we can refer to this category of legume crops as MNUGLs. On global distribution, these species are endemic to the tropical regions of the world. Several reports and findings have established that MNUGLs are droughttolerant, endure and thrive under harsh environments, highly adaptable to varying ecogeographical settings, and withstand or mitigate conditions such as heat, drought, diseases, frost, cold, and insect pest attack $[1,5,7]$. These qualities could be scientifically explored for crop improvement and sustainable utilization. Apart from these good qualities, MNUGLs also contain high-quality proteins and micronutrients which are comparable to those found in conventional legumes. They are also indispensable in crop rotation strategies to fertilize agricultural soils.

\section{General background information: grain legumes}

Grain legumes belong to the family Fabaceae of the Angiospermae and are considered rich in high-quality proteins with significant impacts on the nutrition, diet, and health of many people across the world. The family Fabaceae is divided into grain legumes and pasture/forage legumes. The grain legumes are grown mainly as pulses providing food for humans, while pasture legumes are cultivated to feed domestic animals. Based on plant utility and economy, legumes are categorized into major and minor species. Major legumes are popular and common with well-established domestication and cultivation, agronomic practices, utilization, and conservation. Examples include soybean (Glycine max L.), cowpea (Vigna unguiculata L.), groundnut (Arachis hypogaea L.), common beans (Phaseolus vulgaris L.), pea (Pisum sativum L.), and chicken pea (Cicer arietinum L.), among others. Minor legumes are less known, less exploited, neglected, and considered underutilized. Several species in this category include winged bean (Psophocarpus tetragonolobus L.), pigeon pea (Cajanus cajan L.), lablab (Lablab purpureus L.), lima bean (Phaseolus lunatus L.), jack and sword bean (Canavalia sp.), mung bean (Vigna mungo L.), bambara groundnut (Vigna subterranea L.), marama bean (Tylosema esculentum L.), kersting's groundnut (Kerstingiella geocarpa Harms), African yam bean (AYB) (Sphenostylis stenocarpa Harms), and rice bean (Vigna angularies L.). The wild species of the minor grain legumes include kersting's groundnut (Kerstingiella geocarpa Harms), marama bean (Tylosema esculentum), and the wild Vigna species such as $V$. ambacensis, V. vexillata, V. luteola, V. oblongifolia, and V. racemosa, among others. These species are found in many African countries and could be exploited for food, medicine, agriculture (as cover crops and fodder), and more importantly for genetic improvement of cowpea and related species $[8,9]$.

A review of literatures indicated that most of the MNUGLs have been relegated to unimportant underutilized crops grown by the older generation of farmers $[5,10]$. Thus, sizeable and valuable genetic resources housed within MNUGLs would have been lost due to neglect and lack of concerted focused research. Several authors have highlighted the usefulness of MNUGLs as food security in lean times as farmers in rural areas make a living on the species $[11,12]$. Presently, there is no available genome sequence of MNUGLs species which could be utilized for successful breeding and for specific purposes. 


\subsection{Brief description on some selected MNUGLs}

\subsubsection{African yam bean (Sphenostylis stenocarpa Ex. A. Rich Harms)}

The African yam bean (Sphenostylis stenocarpa) with somatic chromosome number $2 \mathrm{n}=22$ is a dicotyledonous species [13]. AYB is an important food crop in tropical Africa with great medicinal values and pesticidal potential [14]. AYB contains approximately 29 and 19\% crude protein in its grain and tuber, respectively, though lower than that of soybean (38\%) [15]. The seeds are edible like the common beans and cowpea (Vigna unguiculata), and the tubers are richer in protein than Irish potatoes and 10 times the amount in cassava tubers $[16,17]$. The whole seed is also rich in potassium $(649.49 \mathrm{mg} / 100 \mathrm{~g})$ and phosphorus $(241.21 \mathrm{mg} / 100 \mathrm{~g})$ [16]. The most prominent minerals in AYB whole seeds were reported as magnesium (454.16 mg/100 g), potassium ( $398.25 \mathrm{mg} / 100 \mathrm{~g}$ ), and phosphorous $(204.86 \mathrm{mg} / 100 \mathrm{~g})$ with appreciable amounts of calcium $(37.44 \mathrm{mg} / 100 \mathrm{~g})$ and iron (11.70 mg/100 g) [18]. Similarly, Ojuederie and Balogun [18] confirmed the average proximate parameters of AYB seeds to include protein (22.40\%), fat (1.90\%), total carbohydrate $(56.40 \%)$, total ash $(3.60 \%)$, and moisture $(11.80 \%)$ with a caloric value of $1396.10 \mathrm{Kjg}^{-1}$. Some of the accessions evaluated in their study had up to $25 \%$ protein (TSs 41, TSs150, and TSs152). An inverse relationship was detected between the concentrations of protein and carbohydrate. Higher carbohydrate content of $62.50 \%$ was obtained in accession TSs153, with a protein content of $19.30 \%$ [18]. The pods and seeds are resistant to major pests of cowpea such as cowpea pod borer (Maruca vitrata) and cowpea weevil (Callosobruchus maculatus) [19, 20]. This resistance was attributed to the lectin present in the seeds as confirmed in the study of Ojuederie [21] who reported high levels of lectin in the seeds of AYB especially for accessions TSs68 (73.34 $\mathrm{Lu} \mathrm{mg}^{-1}$ ) and TSs5 (66.87 $\mathrm{Lu} \mathrm{mg}^{-1}$ ). Valuable diversities that can be explored for diverse utilization purposes have also been reported in AYB [9, 22, 23].

\subsubsection{Bambara groundnut (Vigna subterranea)}

Bambara groundnut (Vigna subterranea) is less used in many parts of Africa, yet its nutritional and health benefits are well established [24]. It is the fourth crop among the grain legume crops after the well-known groundnut, cowpea, and soybean. In recent times, there has been renewed interest for cultivation of $V$. subterranea in the arid savannah zones to mitigate the effect of stress and increase protein supply to people of that region [24]. Bambara groundnut is resistant to drought, withstands stress, contains higher nutrients than other legumes, and is known to produce good yield even when grown on poor soils [25]. The protein composition contains 6-43\% globulin, $14-71 \%$ albumin, 1.6-2.2\% prolamins, and 3.3-5.2\% glutelins [26]. Bambara groundnut gets about $51-67 \%$ of their $\mathrm{N}$ nutrition from symbiotic fixation; hence the crop could serve as high-protein forage for livestock [24, 26].

\subsubsection{Winged bean (Psophocarpus tetragonolobus)}

Psophocarpus tetragonolobus popularly known as winged bean with somatic chromosome number of $2 \mathrm{n}=18$ is one of the old legumes [27]. Winged bean is a multipurpose legume plant with all parts being edible and useful as medicine in tropics of Asia, Africa, and Latin America. It is grown in many parts of the humid tropics, including Central and South America, the Caribbean, Africa, Oceania, and Asia [28]. All parts of the plant are considered rich in vitamins, minerals, protein, and secondary metabolites such as phenolic and flavonoids [28]. Leaves are usually eaten like spinach, flowers are used in salads, tubers are eaten raw or cooked, while 
seeds are consumed when cooked [29]. In addition, winged bean is highly resistant to biotic and abiotic stresses and thus capable of growing under varying environmental conditions. It is now a toast of many scientists trying to explore its rich potentials $[28,30]$. The seeds of winged bean also exhibit tolerance to storage pests [31]. Apart from its seeds, the tubers/roots are also nutritious and rich in protein of about 20\%, while the leaves and flowers are also high in protein (10-15\%) [32].

\subsubsection{Lima bean (Phaseolus lunatus L.)}

Lima bean is grown for its edible seeds and as leafy vegetable in the Caribbean, Peru, Mexico, and Asian regions [33,34]. Rich in protein, lima beans are resistant to viral and rust diseases and withstand insect pests, drought, and abiotic stress [35]. The species also tolerates different levels of aluminum and manganese toxicity which can be exploited to advance the sustainable utilization of other legumes [36].

\subsubsection{Hyacinth bean (Lablab purpureus L.)}

Hyacinth bean (Lablab purpureus L.) is cultivated for its edible seeds and pods. It is mainly grown in Africa and Asia as source of food in the form of vegetable, green pods, and seeds [37]. Several field trials suggested that the species is drought tolerant and water efficient and produces high yield [37,38]. The protein content is comparable to that of soybean. Reports also indicate that L. purpureus has potential to be a source of pharmaceuticals and nutraceutical as medicine and traditional medicine in Asia and Africa [37].

\subsubsection{Jack bean (Canavalia ensiformis L.)}

Canavalia ensiformis known as jack bean is the most economically important species in the genus Canavalia, with enormous potentials to serve as food for both humans and livestock [39]. It is widely distributed in Africa, Asia, and America, with large-scale cultivation reported in Congo and Angola [39]. It is rich in protein and thrives well in poor and acidic soils. Jack bean is mainly grown for its nutritious pods, seeds, and as fodder. It is a forage crop with high green manure capacity to enrich the soils and also to control soil erosion. The crop tolerates adverse environment, drought, heat, and leached soils; also it resists pest attacks [40]. The leaf of jack bean contains crude proteins and fiber comparable to other legumes [15, 39, 40]. Jack bean possesses deep root system which enables the plant to penetrate deeply into the soil which enables it to withstand very dry conditions. Raw jack bean contains toxic compounds such as tannin, phytate, saponins, canavanine, concanavalin A (hemagglutinin), and trypsin inhibitors [40].

\subsubsection{Sword bean (Canavalia gladiata L.)}

Sword bean (Canavalia gladiata L.) is another species in the genus Canavalia of the Fabaceae family with rich potentials likely to be adopted as an important source of food, leafy vegetable, medicine, forage, and as cover crop. It is a vigorous perennial climber plant usually cultivated as an annual. Reports indicated that sword bean originated from the Asian continent and is now known in the tropics as an introduced species. The red sword bean is one of the edible beans of China reportedly rich in antioxidant polyphenols with great medicinal uses [41, 42]. Furthermore, the seed coat of the bean is rich in gallic acid and its derivatives, mainly gallotannins, a common trait found in legume polyphenols [41]. The chemical composition of seeds of sword bean has been reported and compares quite well 
with soybean [43-45]. Average yield ranges from 720 to $1500 \mathrm{~kg} / \mathrm{ha}$ which can be compared with soybean yield of 600-1000 kg/ha [43, 46]. The fruits mature in 6-10 months after planting. The sword bean is relatively resistant to attack from pests and diseases [43].

\subsubsection{Pigeon pea (Cajanus cajan L. Millsp)}

Cajanus cajan, commonly known as pigeon pea, is an erect, perennial shrub, or woody plant widely grown in the tropical regions [47]. Pigeon pea is mainly cultivated for its edible seed grains as well as feed, forage, and fuel. It has a diploid genome with somatic chromosome number of $2 n=22$ [47]. Most farmers depend on C. cajan as alternative source of protein to support workers and families during lean times [47]. The plant grows well in areas with low rainfall and varying climatic conditions. It is a drought-tolerant crop capable of withstanding poor soil and abiotic stress [48]. Diversity exists in seed coat color, size, texture, and taste. The leaves are source of medicine in combination with other plants such as mango and lemon to treat malaria and typhoid fever. The dried woody stem is used as firewood for cooking by women in farms. Its seed protein content is high (20-22\%) and is quite rich in vitamins such as vitamin B and minerals which can promote health [47].

\subsubsection{Kersting's groundnut (Kerstingiella geocarpa Harms)}

Kersting's groundnut is an indigenous legume grown in Africa for its edible seeds. It is considered rich in nutritional proteins and minerals. Its protein content of $12.9 \%$ is higher than that of bambara groundnut (12.1\%) and cowpea (7.1\%), while the total amino acid content of the seed is $42 \%$ [49]. It is a likely alternative source of quality protein for feed and food in the tropics [50, 51]. The crop can withstand drought, pest, and diseases. It adapts to varying ecological conditions of tropical Africa. However, only the elderly farmers cultivate this crop as alternative source of protein, and as such it has been neglected and underutilized in several African countries.

\subsection{Research efforts and constraints to the global cultivation and adoption of MNUGLs}

MNUGLs are increasingly becoming rare across the world with their associated valuable genetic resources disappearing rapidly in all their natural ranges. Therefore, there is the need for a paradigm shift from present scenario of neglect to sustainable cultivation, exploitation, and utilization of the species. In recent years, grain legume stakeholders had advocated for an increased global cultivation and production of MNUGLs toward sustainable solution to food and protein security, plus agricultural and environmental restoration $[1,52]$. Similarly, significant efforts are ongoing to increase genomic resources and apply innovative breeding techniques to improve the nutritional quality and yield of legume crops, alongside enhanced resilience to climate change $[1,53]$. MNUGLs are highly adapted to agroecological niches/marginal areas having capacity to contribute considerably to global protein security and productive agricultural practices and alleviate rural poverty, among others. The potential genetic resources available among and within the MNUGLs have not been properly explored to advance sustainable utilization for future food and nutritional security as well as biodiversity maintenance to alleviate the negative effects of climate change and abiotic stress. Likewise, the possibilities of the species to withstand abiotic stress even in the face of biological limiting factors are important to their continued use and survival. In order to prevent total 
genetic erosion/loss of valuable genetic resources and exploit MNUGLs for present and future food, nutrition, and protein security, a holistic approach needs to be adopted to improve the species.

Constraints limiting the sustainable cultivation and utilization of MNUGLs include long cooking time of seeds, growth habit requiring mandatory staking, intensive labor requirements, and lack of staking materials [22, 54, 55]. Others are low product market demand, poor seed quality, high cost of labor, postharvest diseases, and anti-nutritional factors (ANF) [55]. The constraints to cultivation and utilization of MNUGLs, breeding intervention approaches, and possible solutions are presented in Table 1.

\subsection{Genetic potentials of MNUGLs}

In recent times, the Food and Agriculture Organization (FAO) of the United Nations estimated that around 800 million people particularly in the developing countries suffer from food and nutrition insecurity [82]. The Sustainable Development Goals (SDGs) of the 2030 Agenda adopted by the United Nations in September 2015 (https://sustainabledevelopment.un.org/) also aimed at having zero hunger as one of its SDGs by abolishing hunger and malnutrition especially in the less developed world (https://sustainabledevelopment.un.org/sdg2). A tactical approach to addressing this challenge is to promote biodiversity and utilization of the neglected and underutilized crop species in the dietary and food pattern of the people $[5,82,83]$. The MNUGLs could increase food production levels, diversify the human diet, and enhance sustainable utilization of broad spectrum of climate smart crops $[6,82,84]$. Additionally, MNUGLs are rich in nutrients and health-enhancing composites that are capable of preventing malnutrition and some chronic diseases $[1,52,55,82]$. Awareness programs in local communities around the world on the rich potentials of MNUGLs and their inclusion in local diets could also be an effective tool to improve human nutrition and health. MNUGLs could be exploited to achieve optimum utilization to meet human nutritional needs in the developing world.

Though huge genetic potentials exist among and within MNUGLs, genetic erosion or loss of valuable genetic resources is alarming. The discovery and utilization of untapped potential genetic resources within the minor crop gene pool deserve research attention. Concerted research efforts are therefore needed to prevent the continuous loss of genetic resources among the MNUGLs. Recent reports indicate that development of effective phenotyping and breeding approaches constitute a challenge among the MNUGLs [1]. Modern breeding efforts to improve disease resistance, quality, and yield are also constrained by low level of genetic diversity available to breeding programs $[1,52]$. Though fairly large genetic diversity exists in seeds of grain legumes in gene banks, such diversities have not been fully utilized in active breeding programs $[1,85,86]$. Large quantities of these minor grain legumes are reportedly available in Africa [87] which if properly harnessed could mitigate the effect of malnutrition and poverty in sub-Saharan Africa. The diversity existing among the seeds of the species are worthy of research attention for food, agriculture, and medicine (Figure 1).

\subsection{Genetic improvement and prospects of MNUGL}

Genetic and breeding efforts to improve the underutilized and neglected legume crops in architecture, period of maturation, yield, and nutritional contents have not recorded commiserate level of success as expected [88, 89]. Traditional hybridization and other breeding techniques, though have been used for some desired 


\begin{tabular}{|c|c|c|c|c|c|}
\hline 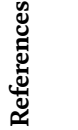 & 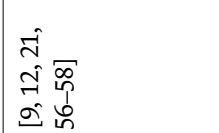 & 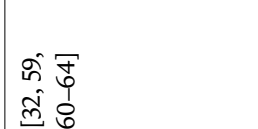 & $\begin{array}{l}\mathbb{6} \\
0 \\
0 \\
\tilde{ల} \\
\tilde{0}\end{array}$ & $\stackrel{\infty}{\infty}$ & $\begin{array}{l}\bar{e} \\
\hat{0} \\
\hat{\sigma}\end{array}$ \\
\hline 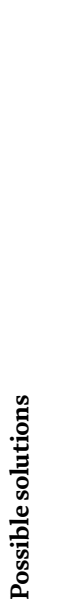 & 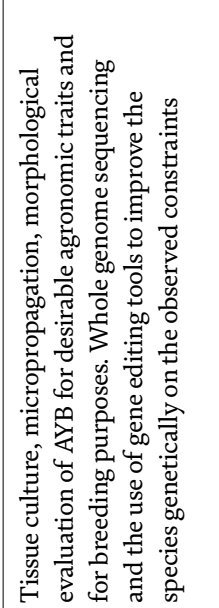 & 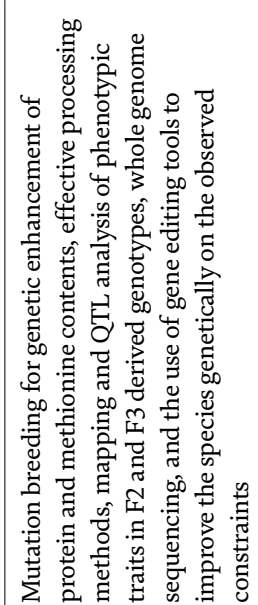 & 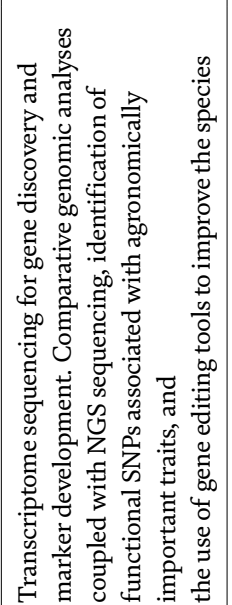 & 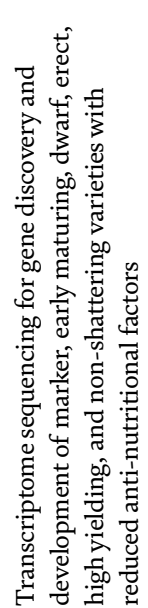 & 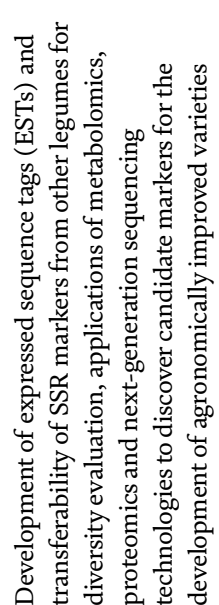 \\
\hline 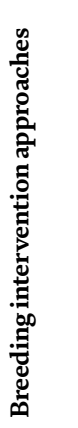 & 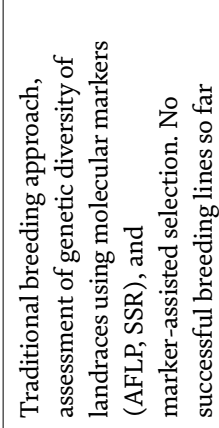 & 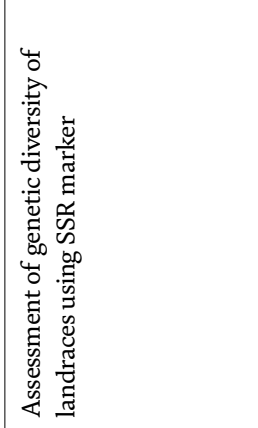 & 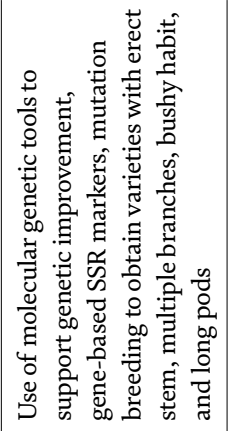 & 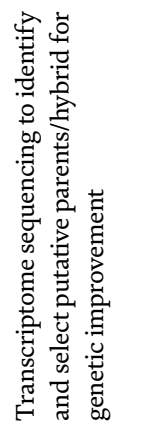 & 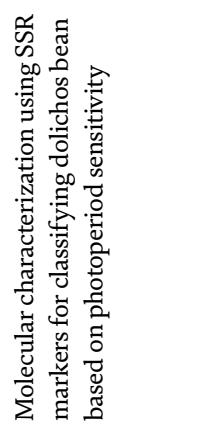 \\
\hline & 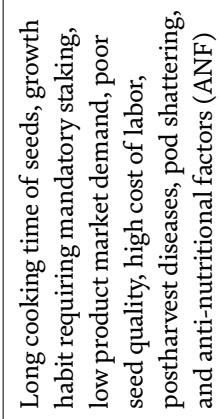 & 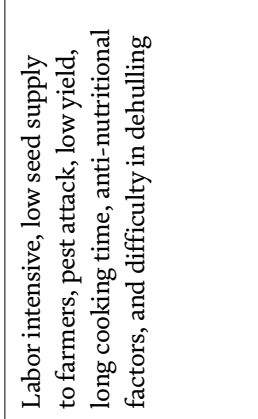 & 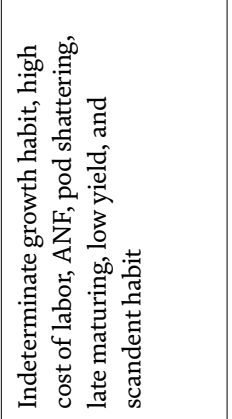 & 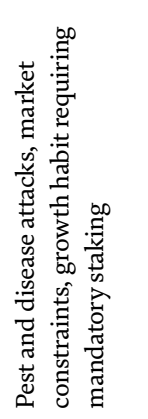 & 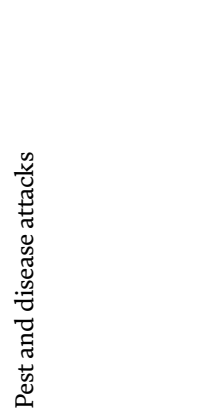 \\
\hline 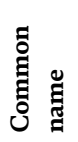 & 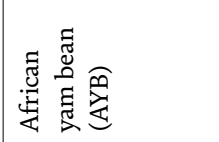 & 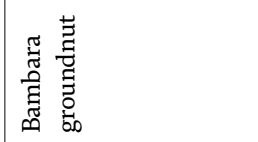 & 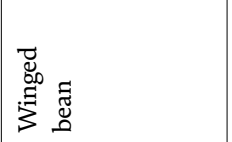 & 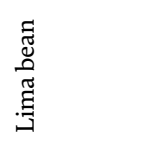 & 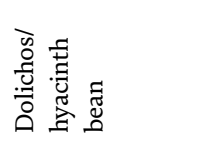 \\
\hline 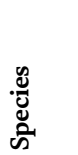 & 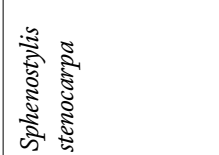 & हूँ & 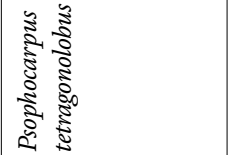 & 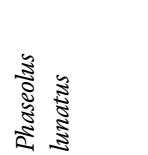 & 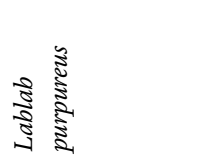 \\
\hline
\end{tabular}


Neglected and Underutilized Legume Crops: Improvement and Future Prospects DOI: http://dx.doi.org/10.5772/intechopen.87069

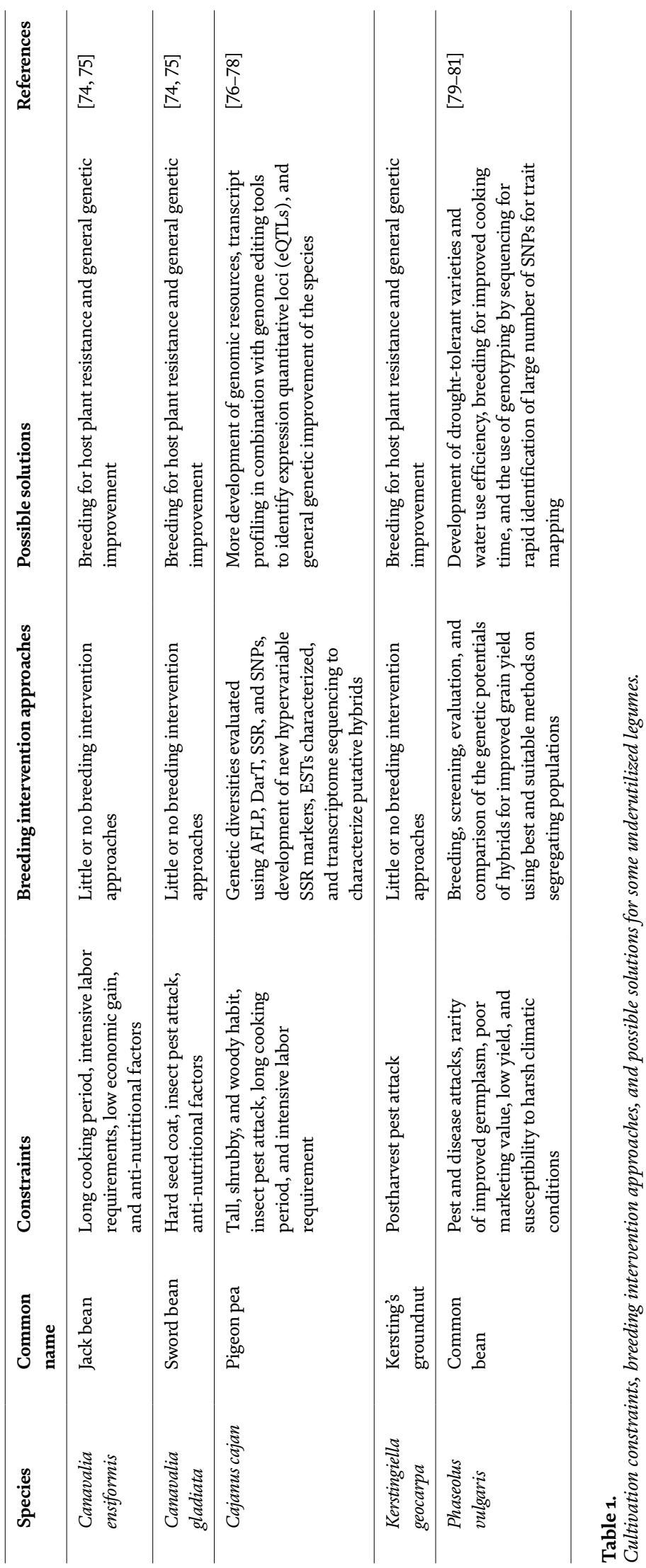



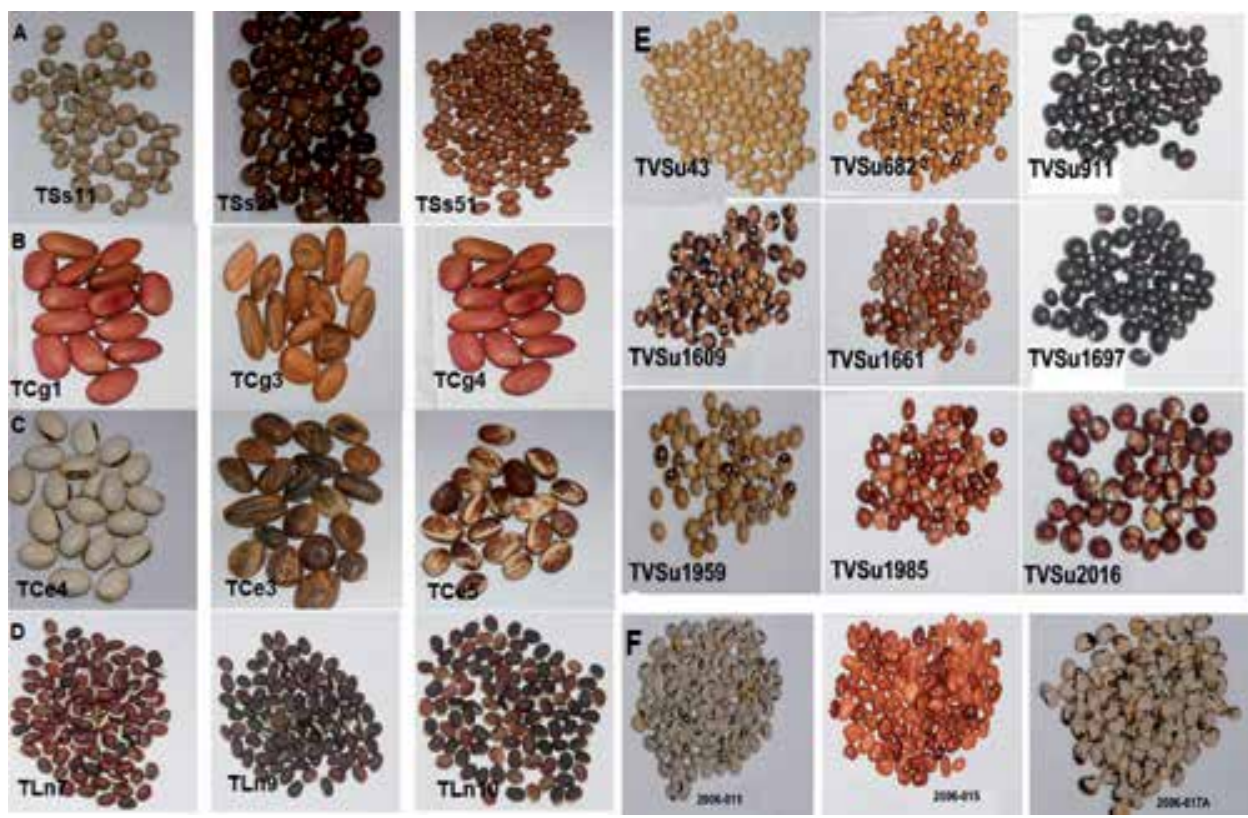

Figure 1.

Some selected underutilized and neglected legumes showing diversity in their seeds. (A) African yam bean (Sphenostylis stenocarpa Ex. A. Rich Harms). (B) Sword bean (Canavalia gladiata L.). (C) Jack bean (Canavalia ensiformis L.). (D) Hyacinth bean (Lablab purpureus L.). (E) Bambara groundnut (Vigna subterranean L. Verdc.). (F) Lima bean (Phaseolus lunatus L.). Source of seeds: Genetic Resources Centre of the International Institute of Tropical Agriculture (IITA), Ibadan, Nigeria.

intentions, are yet to translate to desired results. Few successful crosses have been recorded so far on MNUGLs. Few successes have been reported on Cajanus cajan and some species $[90,91]$. Reproductive barriers such as embryo abortion have been reported in many MNUGLs as limiting factors to genetic enhancement/improvement. However, tissue culture and micropropagation could be further employed to overcome such barriers with capacity to generate fertile haploid plants $[5,6]$.

Advancement in DNA technology has enhanced our understanding on the huge potentials available in the genome of many plant species and particularly the underutilized legumes. Several genomic breakthroughs involving genetic engineering of cereal crops have been reported [92, 93]. DNA-based methods are reliable and have been employed to identify, trace, and certify plant genealogies, origins, and phylogenetic relationships [94, 95]. DNA barcoding has been applied to identify and characterize some underutilized and neglected legumes such as Lablab purpureus, Tylosema esculentum, Vigna subterranea, V. vexillata, and Vigna unguiculata [96, 97].

The use of molecular markers for marker-assisted selection (MAS) or breeding programs has played significant roles in the assessment of the level of genetic diversity or relatedness among various species of underutilized legumes $[9,98]$. Globally, different DNA techniques such as random amplified polymorphic DNA (RAPD), amplified fragment length polymorphisms (AFLPs), inter simple sequence repeats (ISSR), single feature polymorphisms (SFP), single-nucleotide polymorphisms (SNP), and chloroplast gene RBCL, among others, have been employed to evaluate the genetic relationships and diversities among neglected underutilized species $[85,99,100]$. RAPD and ISSR markers were used for genetic diversity studies in winged bean by Mohanty et al. [101]. The study linked the physiological and phytochemical parameters to the genotypes investigated. Distinct winged bean novel lines were identified, and the information from analysis of photosynthesis 
rate, photosynthetic yield, and stomatal conductance data revealed two clusters in correspondence with the phytochemical affinities of the genotypes. The use of SSR, SNP, and genotype by sequencing (GBS) for the studies of phylogenetic relationships and genetic diversities among the MNUGLs is rare due to lack of sequence information; hence RAPD and AFLP were used for such species, and attempts were made in transferability of specific SSR markers in cowpea for genetic diversity studies in underutilized legumes by other authors as in the case of African yam bean [12].

Globally, complexity of plant genomes had led to advancement in genome sequencing, determination of polyploidy, genome size, repetitive DNA sequences, and transposable elements toward genetic engineering of plants to generate useful products apart from innate uses $[102,103]$. Transposable elements (TEs) are ubiquitous in flowering plant genomes of which higher percentage of such genomes are occupied by TEs [104]. Studies have shown that TEs via their amplification, methylation, and recombination contribute to the restructuring of plant genomes, epigenomes, centromeric regions, and evolution of new genes for novel genetic functions $[99,105,106]$. Identification of TEs in a species is critically significant to the understanding of their functional roles [107]. Therefore, detail description of TEs is a major procedure to precisely identify specific genes and evaluate association between genes and TEs in a complex sequenced genome [107]. Such studies have not been applied on MNUGLs to understand the role of transposons in long duration of seed cooking of most of the MNUGLs and expressivity of secondary nutritional metabolites. We believe that such studies will have an overall influence on the genetic manipulation of the MNUGLs, understanding of potential gene-TE interaction, identification of active TEs for functional genomics, and development of TE-based molecular markers for genotyping studies. Currently, sophisticated sequencing genomic approaches such as de novo transcriptome sequencing are being utilized to identify and describe key genes responsible for varied economic, nutritional, physiological, and pharmaceutical uses of plant species $[30,88,108,109]$. Transcriptome sequence analysis is one of the molecular tools that can also be applied to MNUGLs for improvement purposes. It is hoped that some of these tools will be employed in due course, not only to analyze genetic diversity among the MNUGLs but also to identify key genes that will be potentially useful for breeding and utilization purposes. Genes that are useful for varied needs could be identified, described, and extracted from the MNUGLs, thus ensuring the sustainable utilization of the species. Proteomics and genomics are increasingly being applied to unravel a number of genetic constraints and proffer robust solutions toward their sustainable production and utilization $[24,110]$. These areas combined with metabolomics offers great possibility in the quest for improvement of MNUGLs. Consequently, the application of molecular breeding tools such as marker-assisted selection, genomic selection (GS), and genome-wide association (GWAS) has been appraised to influence scientific efforts for improving grain yield of orphan crops in the developing countries $[111,112]$. These of course, including next-generation sequencing (NGS), have greatly enhanced the improvement of many commercial crops which the MNUGLs can also benefit from.

Recent advancement in omic technologies such as genomics, proteomics, transcriptomics, and metabolomics has equally enhanced our understanding of the genetic structure of plant species, as well as the expression of genes through transcriptomic/proteomic profiling and their role in the overall metabolism of plants $[32,113]$. Recently Vatanparast et al. [32] used transcriptome sequencing to develop SSR and SNP markers for winged bean (Psophocarpus tetragonolobus) and also gave insights into the divergence of the Kunitz-type trypsin inhibitors, which are essential anti-nutritional factors in winged bean and other legumes. Transcriptome 
sequencing is inexpensive and a reliable method for efficient and rapid identification of molecular markers in underutilized plant species [32]. Future prospects also lie in the adoption of high-throughput tools including gene editing, GWAS, and clustered regularly interspaced short palindromic repeat (CRISPR), among others, toward genetic improvement of the species for sustainable cultivation, production, and utilization.

\section{Conclusions}

Significant improvement and scientific breakthroughs have been reported on many crop species based on molecular characterization, linkage genetic maps, MAS, and genomics, which cannot be said of MNUGLs [114, 115]. MAS in combination with the traditional hybridization techniques provides clear-cut potential to enhance the overall improvement of plant species. The areas of genomics and proteomics are rapidly expanding in the field of food and agriculture, medicine, and environment. Though few genomic studies have been conducted on some MNUGLs, proteomics and metabolomics have not been employed to explore the rich potentials available in MNUGLs. Generally, these sets of grain legumes have not been subjected to biotechnological techniques/solutions including sophisticated tissue culture micropropagation and genetic engineering which offer great opportunities to improve the species for sustainable utilization. Genome editing provides the possibility to modify the genomes of the MNUGLs particularly for plant architecture, hardness of the seeds, and anti-nutritional factors. The emergence of the CRISPR technology supports this position to possibly enhance the genomes of MNUGLs for higher productivity and utilization via removal of the constraints. Added to this advancement is the use of high-throughput targeted genotyping using next-generation sequencing to effectively unravel the rich diversity potentials available among the MNUGLs. Through proteomic analysis, essential genes and their pathways can be discovered. This is of utmost importance considering the present increased changes in climatic conditions leading to abiotic stresses such as drought and extreme temperatures. MNUGLs are known to be resilient crops capable of withstanding unfavorable environmental conditions. Proteomics therefore offers plant breeders the opportunity to study the broad spectrum of proteins present in underutilized plant species and could give a clue on specific proteins produced by MNUGLs under abiotic stresses, as well as information relating to nutritional and yield traits. On global research funds and activities, research funds are usually not available for these species as many funding agencies or organizations are skeptical about their sustainable utilization and overall benefits to human and environment and hence to the organizations. Stakeholders including policy-makers and plant breeders, among others, should as a matter of urgent priority consider the MNUGLs as important crops for research and development toward food and nutritional security as well as socioeconomic development of rural areas where these species are abundantly available.

\section{Conflict of interest}

Authors declare no conflict of interests. 


\section{Author details}

Jacob Popoola ${ }^{1 *}$, Omena Ojuederie ${ }^{2}$, Conrad Omonhinmin ${ }^{1}$ and Adegoke Adegbite ${ }^{3}$

1 Biotechnology Cluster Group, Department of Biological Sciences, College of Science and Technology, Covenant University, Ota, Ogun State, Nigeria

2 Food Security and Safety Niche Area, Faculty of Natural and Agricultural Sciences, North West University, Mafikeng Campus, Mafikeng, South Africa

3 Department of Biological Sciences, Ondo State University of Science and Technology, Okitipupa, Nigeria

*Address all correspondence to: jacob.popoola@covenantuniversity.edu.ng

\section{IntechOpen}

(C) 2019 The Author(s). Licensee IntechOpen. This chapter is distributed under the terms of the Creative Commons Attribution License (http://creativecommons.org/licenses/ by/3.0), which permits unrestricted use, distribution, and reproduction in any medium, provided the original work is properly cited. (cc) BY 


\section{References}

[1] Considine MJ, Siddique KHM, Foyer $\mathrm{CH}$. Nature's pulse power: Legumes, food security and climate change. Journal of Experimental Botany. 2017;68(8):1815-1818. PubMed PMID: 28499041. PMCID: PMC5429020. Epub 2017/05/13. eng

[2] Padulosi S, Thompson J, Rudebjer P. Fighting Poverty, Hunger and Malnutrition with Neglected and Underutilized Species: Needs, Challenges and the Way Forward. Rome, Italy: Bioversity International; 2013

[3] Singh RJ, Chung GH, Nelson RL. Landmark research in legumes. Genome. 2007;50(6):525-537. PubMed PMID: 17632574. Epub 2007/07/17. eng

[4] Li Y, Ruperao P, Batley J, Edwards D, Khan T, Colmer TD, et al. Investigating drought tolerance in chickpea using genome-wide association mapping and genomic selection based on wholegenome resequencing data. Frontiers in Plant Science. 2018;9:190

[5] Cullis C, Kunert KJ. Unlocking the potential of orphan legumes. Journal of Experimental Botany. 2017;68(8): 1895-1903. PubMed PMID: 28003311. Epub 2016/12/23. eng

[6] Mabhaudhi T, Chimonyo VGP, Chibarabada TP, Modi AT. Developing a roadmap for improving neglected and underutilized crops: A case study of South Africa. Frontiers in Plant Science. 2017;8:2143. PubMed PMID: 29312397. PMCID: PMC5735103. Epub 2018/01/10. eng

[7] Hnatuszko-Konka K, Kowalczyk T, Gerszberg A, Wiktorek-Smagur A, Kononowicz AK. Phaseolus vulgarisrecalcitrant potential. Biotechnology Advances. 2014;32(7):1205-1215. PubMed PMID: 24953179. Epub 2014/06/24. eng
[8] Popoola JO, Adebambo A, Ejoh AS, Agre P, Adegbite AE, Omonhinmin CA. Morphological diversity and cytological studies in some accessions of Vigna vexillata (L.) A. Richard. Annual Research and Review in Biology. 2017;19(5):1-12

[9] Ojuederie OB, Balogun MO, Fawole I, Igwe DO, Olowolafe MO. Assessment of the genetic diversity of African yam bean (Sphenostylis stenocarpa Hochst ex. A Rich. Harms) accessions using amplified fragment length polymorphism (AFLP) markers. African Journal of Biotechnology. 2014;13(18):1850-1858

[10] Ofosu IW, Ellis WO, Nsiah K, Oduro IN. Neglected and underutilized legumes (NULs) hazards and probabilistic risks associated with some selected dietary lectins. Journal of Food Security. 2017;5(6):212-222

[11] Omonhinmin CA, Ogunbodede OO. Genetic diversity, taxonomy and legumins implications of seed storage protein profiling in Fabaceae. African Journal of Biotechnology. 2013;12(17):36-42

[12] Shitta NS, Abberton MT, Adesoye AI, Adewale DB, Oyatomi O. Analysis of genetic diversity of African yam bean using SSR markers derived from cowpea. Plant Genetic Resources. 2016;14(1):50-56

[13] Popoola JO, Obembe OO, Adegbite AE. Cytological studies on some accessions of African yam bean (AYB) (Sphenostylis stenocarpa Hochst. Ex. A. Rich. Harms). International Research Journal of Plant Science. 2011;2(8):249-253

[14] Machuka JS, Okeola OG, Chrispeels MJ, Jackai LE. The African yam bean seed lectin affects the development of the cowpea weevil 
but does not affect the development of larvae of the legume pod borer. Phytochemistry. 2000;53(6):667674. PubMed PMID: 10746879. Epub 2000/04/04. eng

[15] Oboh HA, Muzquiz M, Burbano C, Cuadrado C, Pedrosa MM, Ayet G, et al. Anti-nutritional constituents of six underutilized legumes grown in Nigeria. Journal of Chromatography. A. 1998;823(1-2):307-312. PubMed PMID: 9818409. Epub 1998/11/18. eng

[16] Oshodi AA, Ipinmoroti KO, Adeyeye EI. Functional properties of some varieties of African yam bean (Sphenostylis stenocarpa) flour-III. International Journal of Food Sciences and Nutrition. 1997;48(4):243250. PubMed PMID: 9349440 . Epub 1997/07/01. eng

[17] Onyeike EN, Omubo-Dede TT. Effect of heat treatment on the proximate composition, energy values, and levels of some toxicants in African yam bean (Sphenostylis stenocarpa) seed varieties. Plant Foods for Human Nutrition (Dordrecht, Netherlands). 2002;57(3-4):223-231. PubMed PMID: 12602931. Epub 2003/02/27. eng

[18] Ojuederie OB, Balogun MO. Genetic variation in nutritional properties of African yam bean Sphenostylis stenocarps (Hochst ex. A. Rich. Harms) accessions. Nigerian Journal of Agriculture, Food and Environment. 2017;13(1):180-187

[19] Machuka J, Okeola OG. One- and two-dimensional gel electrophoresic identification of African yam bean seed proteins. Journal of Agricultural and Food Chemistry. 2000;48(6):22962299. PubMed PMID: 10888540 . Epub 2000/07/11. eng

[20] Okeola OG, Machuka J. Biological effects of African yam bean lectins on Clavigralla tomentosicollis (Hemiptera: Coreidae). Journal of Economic Entomology. 2001;94(3):724-729.
PubMed PMID: 11425030. Epub 2001/06/27. eng

[21] Ojuederie O, Balogun M, Abberton M. Mechanism for pollination in African yam bean. African Crop Science Journal. 2016;24(4):405-416

[22] Popoola J, Adegbite A, Obembe O, Adewale B, Odu B. Morphological intraspecific variabilities in African yam bean (AYB) (Sphenostylis stenocarpa ex. A. Rich) Harms. Scientific Research and Essays. 2011;6(3):507-515

[23] Adewale B, Kehinde O, Aremu C, Popoola J, Dumet D. Seed metrics for genetic and shape determinations in African yam bean [Fabaceae] (Sphenostylis stenocarpa Hochst. Ex. A. Rich.) harms. African Journal of Plant Science. 2010;4(4):107-115

[24] Aliyu S, Massawe F, Mayes S. Beyond landraces: Developing improved germplasm resources for underutilized species-A case for Bambara groundnut. Biotechnology and Genetic Engineering Reviews. 2014;30(1-2):127141. PubMed PMID: 25603880. Epub 2015/01/22. eng

[25] Chibarabada TP, Modi AT, Mabhaudhi T. Nutrient content and nutritional water productivity of selected grain legumes in response to production environment. International Journal of Environmental Research and Public Health. 2017;14(11):1-17. PubMed PMID: 29072620. PMCID: PMC5707939. Epub 2017/10/27. eng

[26] Hillocks R, Bennett C, Mponda O. Bambara nut: A review of utilisation, market potential and crop improvement. African Crop Science Journal. 2012;20(1):1-16

[27] Bottino P, Maire C, Goff L. Tissue culture and organogenesis in the winged bean. Canadian Journal of Botany. 1979;57(17):1773-1776 
[28] Yang S, Grall A, Chapman MA. Origin and diversification of winged bean (Psophocarpus tetragonolobus (L.) DC.), a multipurpose underutilized legume. American Journal of Botany. 2018;105(5):888-897. PubMed PMID: 29874397. Epub 2018/06/07. eng

[29] Amoo I, Adebayo O, Oyeleye A. Chemical evaluation of winged beans (Psophocarpus tetragonolobus), Pitanga cherries (Eugenia uniflora) and orchid fruit (Orchid fruit myristic a). African Journal of Food, Agriculture, Nutrition and Development. 2006;6(2):1-12

[30] Singh V, Goel R, Pande V, Asif MH, Mohanty CS. De novo sequencing and comparative analysis of leaf transcriptomes of diverse condensed tannin-containing lines of underutilized Psophocarpus tetragonolobus (L.) DC. Scientific Reports. 2017;7:44733. PubMed PMID: 28322296. PMCID: PMC5359716. Epub 2017/03/23. eng

[31] Wong Q, Massawe F, Mayes S. Improving winged bean (Psophocarpus tetragonolobus) productivity: An analysis of the determinants of productivity. Acta Horticulturae. 2015;1102:83-88

[32] Vatanparast M, Shetty P, Chopra R, Doyle JJ, Sathyanarayana N, Egan AN. Transcriptome sequencing and marker development in winged bean (Psophocarpus tetragonolobus; Leguminosae). Scientific Reports. 2016;6:29070

[33] Andueza-Noh RH, MartinezCastillo J, Chacon-Sanchez MI. Domestication of small-seeded lima bean (Phaseolus lunatus L.) landraces in Mesoamerica: Evidence from microsatellite markers. Genetica. 2015;143(6):657-669. PubMed PMID: 26391600. Epub 2015/09/24. eng

[34] Sprent JI, Odee DW, Dakora FD. African legumes: A vital but under-utilized resource. Journal of
Experimental Botany. 2010;61(5):

1257-1265. PubMed PMID: 19939887.

Epub 2009/11/27. eng

[35] Ballhorn DJ, Kautz S, Heil M, Hegeman AD. Cyanogenesis of wild lima bean (Phaseolus lunatus L.) is an efficient direct defence in nature. PLoS One. 2009;4(5):e5450. PubMed PMID: 19424497. PMCID: PMC2675055. Epub 2009/05/09. eng

[36] Azeke MA, Elsanhoty RM, Egielewa SJ, Eigbogbo MU. The effect of germination on the phytase activity, phytate and total phosphorus contents of some Nigerian-grown grain legumes. Journal of the Science of Food and Agriculture. 2011;91(1):75-79. PubMed PMID: 20859988. Epub 2010/09/23. eng

[37] Morris JB. Morphological and reproductive characterization in hyacinth bean, Lablab purpureus (L.) sweet germplasm with clinically proven nutraceutical and pharmaceutical traits for use as a medicinal food. Journal of Dietary Supplements. 2009;6(3): 263-279. PubMed PMID: 22435478. Epub 2009/01/01. eng

[38] Vidigal P, Duarte B, Cavaco AR, Cacador I, Figueiredo A, Matos AR, et al. Preliminary diversity assessment of an undervalued tropical bean (Lablab purpureus (L.) Sweet) through fatty acid profiling. Plant Physiology and Biochemistry. 2018;132:508-514. PubMed PMID: 30308461. Epub 2018/10/12. eng

[39] Akpapunam M, Sefa-Dedeh S. Jack bean (Canavalia ensiformis): Nutrition related aspects and needed nutrition research. Plant Foods for Human Nutrition. 1997;50(2):93-99

[40] Sivaraj N, Sunil N, Pandravada S, Kamala V, Rao B, Prasad R, et al. Fatty acid composition in seeds of Jack-bean [Canavalia ensiformis (L.) DC.] and Sword-bean [Canavalia gladiata (Jacq.) DC.] Germplasm from South India: 
A DIVA-GIS analysis. Seed Technology. 2010;32(1):46-53

[41] Gan RY, Kong KW, Li HB, Wu K, Ge YY, Chan CL, et al. Separation, identification, and bioactivities of the main gallotannins of red sword bean (Canavalia gladiata) Coats. Frontiers in Chemistry. 2018;6:39. PubMed PMID: 29541634. PMCID: PMC5835520. Epub 2018/03/16. eng

[42] Ekanayake S, Jansz ER, Nair BM. Literature review of an underutilized legume: Canavalia gladiata L. Plant Foods for Human Nutrition (Dordrecht, Netherlands). 2000;55(4):305-321. PubMed PMID: 11086874. Epub 2000/11/22. eng

[43] Ekanayake S, Nair B, Jansz ER, Asp NG. Effect of processing on the protein nutritional value of Canavalia gladiata seeds. Die Nahrung. 2003;47(4):256260. PubMed PMID: 13678265. Epub 2003/09/19. eng

[44] Eknayake S, Jansz ER, Nair BM. Proximate composition, mineral and amino acid content of mature Canavalia gladiata seeds. Food Chemistry. 1999;66(1):115-119

[45] Ekanayake S, Skog K, Asp N-G. Canavanine content in sword beans (Canavalia gladiata): Analysis and effect of processing. Food and Chemical Toxicology. 2007;45(5):797-803

[46] Sharma KK, Sreelatha G, Dayal S. Pigeonpea (Cajanus cajan L. Millsp.). Methods in Molecular Biology (Clifton, NJ). 2006;343:359-367. PubMed PMID: 16988359. Epub 2006/09/22. eng

[47] Munoz N, Liu A, Kan L, Li MW, Lam HM. Potential uses of wild germplasms of grain legumes for crop improvement. International Journal of Molecular Sciences. 2017;18(2):1-28. PubMed PMID: 28165413. PMCID: PMC5343864. Epub 2017/02/07. eng
[48] Ajayi OB, Oyetayo FL. Potentials of Kerstingiella geocarpa as a health food. Journal of Medicinal Food. 2009;12(1):184-187. PubMed PMID: 19298213. Epub 2009/03/21. eng

[49] Obasi M, Agbatse A. Evaluation of nutritive value and some functional properties of Kersting's groundnut, (Kerstingiella geocarpa harms). Seeds for optimal utilization as food and feed source. The East African Agricultural Journal. 1994;54:66-74

[50] Obasi M, Ezedinma F. Floral biology of Kerstings groundnut (Kerstingiella geocarpa Harms). Ghana Journal of Agricultural Science. 1991;24-27:145-149

[51] Foyer CH, Lam HM, Nguyen HT, Siddique KH, Varshney RK, Colmer TD, et al. Neglecting legumes has compromised human health and sustainable food production. Nature Plants. 2016;2:16112. PubMed PMID: 28221372. Epub 2017/02/22. eng

[52] Foyer CH, Siddique KHM, Tai APK, Anders S, Fodor N, Wong FL, et al. Modelling predicts that soybean is poised to dominate crop production across Africa. Plant, Cell and Environment. 2019;42(1):373385. PubMed PMID: 30329164. Epub 2018/10/18. eng

[53] Acharjee S, Sarmah BK. Biotechnologically generating 'super chickpea' for food and nutritional security. Plant Science: An International Journal of Experimental Plant Biology. 2013;207:108-116. PubMed PMID: 23602105. Epub 2013/04/23. eng

[54] Nnamani CV, Ajayi SA, Oselebe HO, Atkinson CJ, Igboabuchi AN, Ezigbo EC. Sphenostylis stenocarpa (ex. A. Rich.) Harms., a fading genetic resource in a changing climate: Prerequisite for conservation and sustainability. Plants (Basel, Switzerland). 2017;6(3):1-16. 
PubMed PMID: 28704944. PMCID: PMC5620586. Epub 2017/07/15. eng

[55] Ogunsola KE, Ojuederie OB, Emmanuel B. In vitro morphogenic responses of African yam bean (Sphenostylis stenocarpa (Hochst ex. A. Rich.) Harms) accessions to plant growth regulators. Plant Cell, Tissue and Organ Culture (PCTOC). 2016;127(3):613-622

[56] Adewale B, Vroh-Bi I, Dumet D, Nnadi S, Kehinde O, Ojo D, et al. Genetic diversity in African yam bean accessions based on AFLP markers: Towards a platform for germplasm improvement and utilization. Plant Genetic Resources. 2015;13(2):111-118

[57] Adewale DB, Adegbite AE. Investigation of the breeding mechanism of African yam bean [Fabaceae] (Sphenostylis stenocarpa Hochst. Ex. A. Rich) Harms. Notulae Scientia Biologicae. 2018;10(2):199-204

[58] Odongo FO, Oyoo ME, Wasike V, Owuoche JO, Karanja L, Korir P. Genetic diversity of Bambara groundnut (Vigna subterranea (L.) verdc.) landraces in Kenya using microsatellite markers. The African Journal of Biotechnology. 2015;14(4):283-291

[59] Molosiwa OO, Aliyu S, Stadler F, Mayes K, Massawe F, Kilian A, et al. SSR marker development, genetic diversity and population structure analysis of Bambara groundnut [Vigna subterranea (L.) Verdc.] landraces. Genetic Resources and Crop Evolution. 2015;62(8):1225-1243

[60] Bharatkumar C. Genetic Improvement of Bambara Groundnut (Vigna subterranea (L.) Verdc) Through Mutation Breeding. Bengaluru: University of Agricultural Sciences, GKVK; 2015

[61] Shashidhar H, Savithramma D. Genetic enhancement of protein and methionine content in Bambara groundnut (Vigna subterranea (L.) Verdc.) through mutation breeding. International Journal. 2015;8

[62] Mubaiwa J, Fogliano V, Chidewe C, Linnemann AR. Bambara groundnut (Vigna subterranea (L.) Verdc.) flour: A functional ingredient to favour the use of an unexploited sustainable protein source. PLoS One. 2018;13(10):e0205776

[63] Bamba ASA. Beyond Landraces:

Framework for the Genetic Improvement of Bambara Groundnut [Vigna subterranea (L.) Verdc.] for Global Food Security. United Kingdom: University of Nottingham; 2017

[64] Wong Q, Massawe F, Mayes K, Blythe M, Mayes S, editors. Molecular genetic tools to support genetic improvement of winged bean (Psophocarpus tetragonolobus) for food and nutrition security. In: XXIX International Horticultural Congress on Horticulture: Sustaining Lives, Livelihoods and Landscapes (IHC2014); 2014;1110:2016

[65] Wong Q, Massawe F, Mayes S, editors. Improving winged bean (Psophocarpus tetragonolobus) productivity: An analysis of the determinants of productivity. In: XXIX International Horticultural Congress on Horticulture: Sustaining Lives, Livelihoods and Landscapes (IHC2014); 2014;1102

[66] Wong QN, Tanzi AS, Ho WK, Malla S, Blythe M, Karunaratne A, et al. Development of gene-based SSR markers in winged bean (Psophocarpus tetragonolobus (L.) DC.) for diversity assessment. Genes. 2017;8(3):100

[67] Li F, Cao D, Liu Y, Yang T, Wang G. Transcriptome sequencing of lima bean (Phaseolus lunatus) to identify putative positive selection in Phaseolus and legumes. International Journal of Molecular Sciences. 2015;16(7):15172-15187 
[68] Laxmi K. SSR Marker Assaybased Polymorphism among the Dolichos Bean (Lablab purpureus L.) Germplasm Accessions Differing in Photoperiod-induced Sensitivity to Flowering Time. Bengaluru: University of Agricultural Sciences, GKVK; 2015

\section{[69] Zhang G, Xu S, Mao W, Gong Y,} $\mathrm{Hu}$ Q. Development of EST-SSR markers to study genetic diversity in hyacinth bean (Lablab purpureus L.). Plant Omics. 2013;6(4):295

[70] Kumar H, Gowda M, Ramesh S. Identification of cross legume species/ genera SSR markers polymorphic to parents of recombinant inbreed lines derived from two bi-parental crosses in dolichos bean (Lablab purpureus $\mathrm{L}$. sweet). Mysore Journal of Agricultural Sciences. 2016;50(2):372-375

[71] Rai KK, Rai N, Rai SP. Recent advancement in modern genomic tools for adaptation of Lablab purpureus $\mathrm{L}$ to biotic and abiotic stresses: Present mechanisms and future adaptations. Acta Physiologiae Plantarum. 2018;40(9):164

[72] Yao LM, Wang B, Cheng LJ, Wu TL. Identification of key drought stressrelated genes in the hyacinth bean. PLoS One. 2013;8(3):e58108

[73] Oboh HA, Muzquiz M, Burbano C, Cuadrado C, Pedrosa MM, Ayet G, et al. Effect of soaking, cooking and germination on the oligosaccharide content of selected Nigerian legume seeds. Plant Foods for Human Nutrition (Dordrecht, Netherlands). 2000;55(2):97-110. PubMed PMID: 10898479. Epub 2000/07/18. eng

[74] Viera Diaz J. Genetic improvement of legumes. Archivos Latinoamericanos de Nutrición. 1996;44(4 Suppl 1):41s43s. PubMed PMID: 9221716. Epub 1996/12/01. Mejoramiento genetico de leguminosas. spa
[75] Bohra A, Jha R, Pandey G, Patil PG, Saxena RK, Singh IP, et al. New hypervariable SSR markers for diversity analysis, hybrid purity testing and trait mapping in Pigeonpea [Cajanus cajan (L.) Millspaugh]. Frontiers in Plant Science. 2017;8:377. PubMed PMID: 28408910. PMCID: PMC5374739. Epub 2017/04/15. eng

[76] Priyanka B, Sekhar K, Sunita T, Reddy VD, Rao KV. Characterization of expressed sequence tags (ESTs) of pigeonpea (Cajanus cajan L.) and functional validation of selected genes for abiotic stress tolerance in Arabidopsis thaliana. Molecular Genetics and Genomics : MGG. 2010;283(3): 273-287. PubMed PMID: 20131066. Epub 2010/02/05. eng

[77] Varshney RK, Chen W, Li Y, Bharti AK, Saxena RK, Schlueter JA, et al. Draft genome sequence of pigeonpea (Cajanus cajan), an orphan legume crop of resource-poor farmers. Nature Biotechnology. 2012;30(1):83

[78] Pontes Junior V, Melo P, Pereira H, Melo L. Genetic potential of common bean progenies obtained by different breeding methods evaluated in various environments. Embrapa Arroz e Feijão-Artigo em periódico indexado (ALICE). 2016;15(3):gmr15038622

[79] Rodríguez De Luque JJ, Creamer B. Principal constraints and trends for common bean production and commercialization; establishing priorities for future research. Agronomía Colombiana. 2014;32(3):423-431

[80] Blair M, Galeano C, Tovar E, Torres M, Velasco A, Beebe SE, et al. Development of a Mesoamerican intragenepool genetic map for QTL detection in a drought tolerant $\mathrm{x}$ susceptible common bean (Phaseolus vulgaris $\mathrm{L}$.) cross. 2012;29:71-88

[81] Baldermann S, Blagojević L, Frede K, Klopsch R, Neugart S, Neumann A, 
et al. Are neglected plants the food for the future? Critical Reviews in Plant Sciences. 2016;35(2):106-119

[82] Dansi A, Vodouhè R, Azokpota $\mathrm{P}$, Yedomonhan $\mathrm{H}$, Assogba $\mathrm{P}$, Adjatin A, et al. Diversity of the neglected and underutilized crop species of importance in Benin. The Scientific World Journal. 2012;2012:1-19

[83] Padulosi S, Amaya K, Jäger M, Gotor E, Rojas W, Valdivia R. A holistic approach to enhance the use of neglected and underutilized species: The case of Andean grains in Bolivia and Peru. Sustainability. 2014;6(3):1283-1312

[84] Fatokun C, Girma G, Abberton M, Gedil M, Unachukwu N, Oyatomi O, et al. Genetic diversity and population structure of a mini-core subset from the world cowpea (Vigna unguiculata (L.) Walp.) germplasm collection. Scientific Reports. 2018;8(1):16035

[85] Boukar O, Fatokun CA, Huynh BL, Roberts PA, Close TJ. Genomic tools in cowpea breeding programs: Status and perspectives. Frontiers in Plant Science. 2016;7:757. PubMed PMID: 27375632. PMCID: PMC4891349. Epub 2016/07/05. eng

[86] Saka J, Ajibade S, Adeniyan O, Olowoyo R, Ogunbodede B. Survey of underutilized grain legume production systems in the Southwest agricultural zone of Nigeria. Journal of Agricultural and Food Information. 2004;6(2-3):93-108

[87] Chapman MA. Transcriptome sequencing and marker development for four underutilized legumes. Applications in Plant Sciences. 2015;3(2):1-5. PubMed PMID: 25699221. PMCID: PMC4332146. Epub 2015/02/24. eng

[88] Cooper JW, Wilson MH, Derks MFL, Smit S, Kunert KJ, Cullis C, et al.
Enhancing faba bean (Vicia faba L.) genome resources. Journal of Experimental Botany. 2017;68(8):1941-1953. PubMed PMID: 28419381. PMCID: PMC5429004. Epub 2017/04/19. eng

[89] Obala J, Saxena RK, Singh VK, Kumar CVS, Saxena KB, Tongoona P, et al. Development of sequence-based markers for seed protein content in pigeonpea. Molecular Genetics and Genomics: MGG. 2019;294(1):5768. PubMed PMID: 30173295. Epub 2018/09/03. eng

[90] Kumawat G, Raje RS, Bhutani S, Pal JK, Mithra AS, Gaikwad K, et al. Molecular mapping of QTLs for plant type and earliness traits in pigeonpea (Cajanus cajan L. Millsp.). BMC Genetics. 2012;13:84. PubMed PMID: 23043321. PMCID: PMC3504571. Epub 2012/10/10. eng

[91] Wu GA, Prochnik S, Jenkins J, Salse J, Hellsten U, Murat F, et al. Sequencing of diverse mandarin, pummelo and orange genomes reveals complex history of admixture during citrus domestication. Nature Biotechnology. 2014;32(7):656-662. PubMed PMID: 24908277. PMCID: PMC4113729. Epub 2014/06/09. eng

[92] Borlaug NE. Contributions of conventional plant breeding to food production. Science (New York, N.Y.). 1983;219(4585):689-693. PubMed PMID: 17814030. Epub 1983/02/11. eng

[93] Zargar SM, Mahajan R, Nazir M, Nagar P, Kim ST, Rai V, et al. Common bean proteomics: Present status and future strategies. Journal of Proteomics. 2017;169:239-248. PubMed PMID: 28347863. Epub 2017/03/30. eng

[94] Jarquin D, Kocak K, Posadas L, Hyma K, Jedlicka J, Graef G, et al. Genotyping by sequencing for genomic prediction in a soybean breeding population. BMC Genomics. 2014;15:740. 
PubMed PMID: 25174348. PMCID: PMC4176594. Epub 2014/09/02. eng

[95] Takahashi Y, Somta P, Muto C, Iseki K, Naito K, Pandiyan M, et al. Novel genetic resources in the genus Vigna unveiled from gene bank accessions. PLoS One. 2016;11(1):e0147568

[96] Wojciechowski MF, Lavin M, Sanderson MJ. A phylogeny of legumes (Leguminosae) based on analysis of the plastid matK gene resolves many well-supported subclades within the family. American Journal of Botany. 2004;91(11):1846-1862

[97] Popoola J, Adebayo B, Adegbite A, Omonhinmin CA, Adewale B. Fruit morphometric and RAPD evaluation of intraspecific variability in some accessions of African yam bean (Sphenostylis stenocarpa Hochst. Ex. A. Rich. Harms). Annual Research and Review in Biology. 2017;14(4):1-10

[98] Morgante M, Olivieri A. PCRamplified microsatellites as markers in plant genetics. The Plant Journal. 1993;3(1):175-182

[99] Saxena RK, von Wettberg E, Upadhyaya HD, Sanchez V, Songok S, Saxena K, et al. Genetic diversity and demographic history of Cajanus spp. illustrated from genome-wide SNPs. PLoS One. 2014;9(2):e88568. PubMed PMID: 24533111 . PMCID: PMC3922937. Epub 2014/02/18. eng

[100] Mohanty CS, Verma S, Singh V, Khan S, Gaur P, Gupta P, et al. Characterization of winged bean (Psophocarpus tetragonolobus (L.) DC.) based on molecular, chemical and physiological parameters. American Journal of Molecular Biology. 2013;3(04):187

[101] Jackson SA, Iwata A, Lee SH, Schmutz J, Shoemaker R. Sequencing crop genomes: Approaches and applications. The New Phytologist. 2011;191(4):915-925

[102] Parisod C, Alix K, Just J, Petit M, Sarilar V, Mhiri C, et al. Impact of transposable elements on the organization and function of allopolyploid genomes. The New Phytologist. 2010;186(1):37-45

[103] Meyers BC, Tingey SV, Morgante M. Abundance, distribution, and transcriptional activity of repetitive elements in the maize genome. Genome Research. 2001;11(10):1660-1676

[104] Jiang N, Bao Z, Zhang X, Eddy SR, Wessler SR. Pack-MULE transposable elements mediate gene evolution in plants. Nature. 2004;431(7008):569

[105] Bennetzen JL. Transposable elements, gene creation and genome rearrangement in flowering plants. Current Opinion in Genetics and Development. 2005;15(6):621-627

[106] Du J, Grant D, Tian Z, Nelson RT, Zhu L, Shoemaker RC, et al. SoyTEdb: A comprehensive database of transposable elements in the soybean genome. BMC Genomics. 2010;11:113. PubMed PMID: 20163715. PMCID: PMC2830986. Epub 2010/02/19. eng

[107] Singh A, Sharma AK, Singh NK, Sharma TR. PpTFDB: A pigeonpea transcription factor database for exploring functional genomics in legumes. PLoS One. 2017;12(6):e0179736. PubMed PMID: 28651001. PMCID: PMC5484553. Epub 2017/06/27. eng

[108] Abdelrahman M, Jogaiah S, Burritt DJ, Tran LSP. Legume genetic resources and transcriptome dynamics under abiotic stress conditions. Plant, Cell and Environment. Sep 2018;41(9):1972-1983

[109] Bonthala VS, Mayes K, Moreton J, Blythe M, Wright V, May ST, 
et al. Identification of gene modules associated with low temperatures response in Bambara groundnut by network-based analysis. PLoS One. 2016;11(2):e0148771. PubMed PMID: 26859686. PMCID: PMC4747569. Epub 2016/02/10. eng

[110] Ribaut J, De Vicente M, Delannay X. Molecular breeding in developing countries: Challenges and perspectives. Current Opinion in Plant Biology. 2010;13(2):213-218

[111] Varshney RK, Glaszmann JC, Leung H, Ribaut JM. More genomic resources for less-studied crops. Trends in Biotechnology. 2010;28(9):452-460

[112] Tan H, Huang H, Tie M, Tang Y, Lai Y, Li H. Transcriptome profiling of two Asparagus bean (Vigna unguiculata subsp. sesquipedalis) cultivars differing in chilling tolerance under cold stress. PLoS One. 2016;11(3):e0151105.

PubMed PMID: 26954786. PMCID:

PMC4783050. Epub 2016/03/10. eng

[113] Ahmad NS, Redjeki ES, Ho WK, Aliyu S, Mayes K, Massawe F, et al. Construction of a genetic linkage map and QTL analysis in Bambara groundnut. Genome. 2016;59(7):459472. PubMed PMID: 27253730. Epub 2016/06/03. eng

[114] Janila P, Nigam SN, Pandey MK, Nagesh P, Varshney RK. Groundnut improvement: Use of genetic and genomic tools. Frontiers in Plant Science. 2013;4:23. PubMed PMID: 23443056. PMCID: PMC3580887. Epub 2013/02/28. eng

[115] Saxena RK, Rathore A, Bohra A, Yadav P, Das RR, Khan AW, et al. Development and application of highdensity Axiom Cajanus SNP array with 56K SNPs to understand the genome architecture of released cultivars and founder genotypes. The Plant Genome. 2018;11(3):1-10. PubMed PMID: 30512043. Epub 2018/12/05. eng 



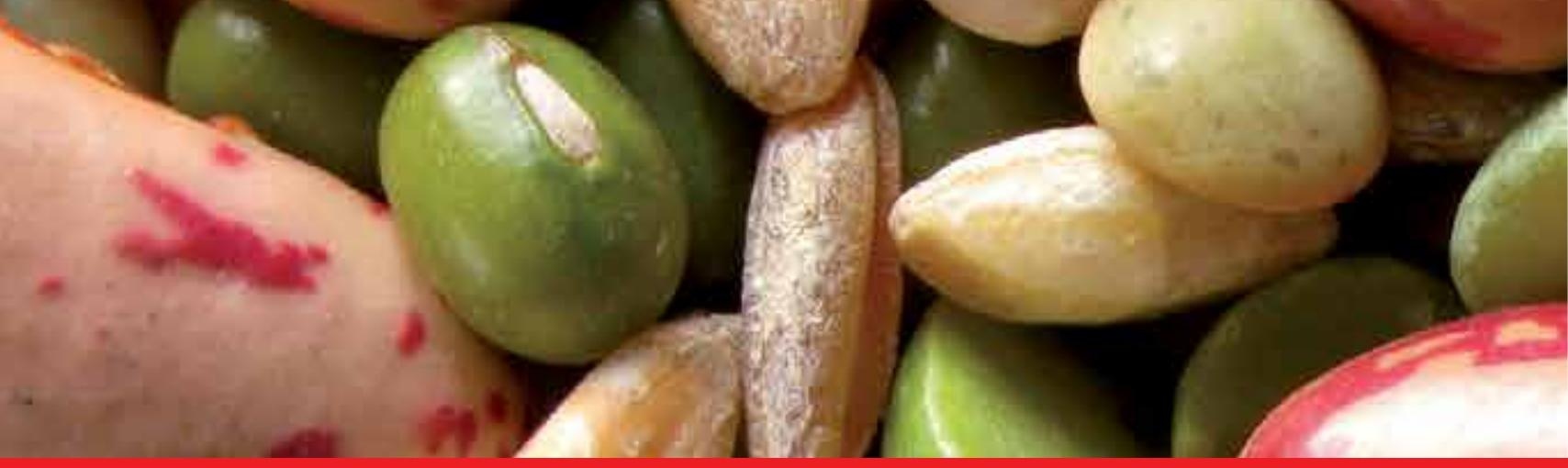

\section{Edited by Farooq Shah, Zafar Khan, Amjad Iqbal, Metin Turan and Murat Olgun}

Cultivation of grain crops has been rightly recognized as one of the main drivers in shaping human civilizations. Considering their key role in fulfilling a major portion of the global food needs, grain crops are the most widely grown crops around the world. Unfortunately, like many other agronomic crops, grain crops are quite vulnerable to climate change and this has posed multifaceted threats to agricultural sustainability. To add to the menace, the deteriorating quantity and quality of both land and water as primary factors of production are further aggravating the scenario. Confronting such challenges demands innovative adaptation strategies through intensification of grain crop production that can ensure grain self-sufficiency worldwide.

\section{IntechOpen}
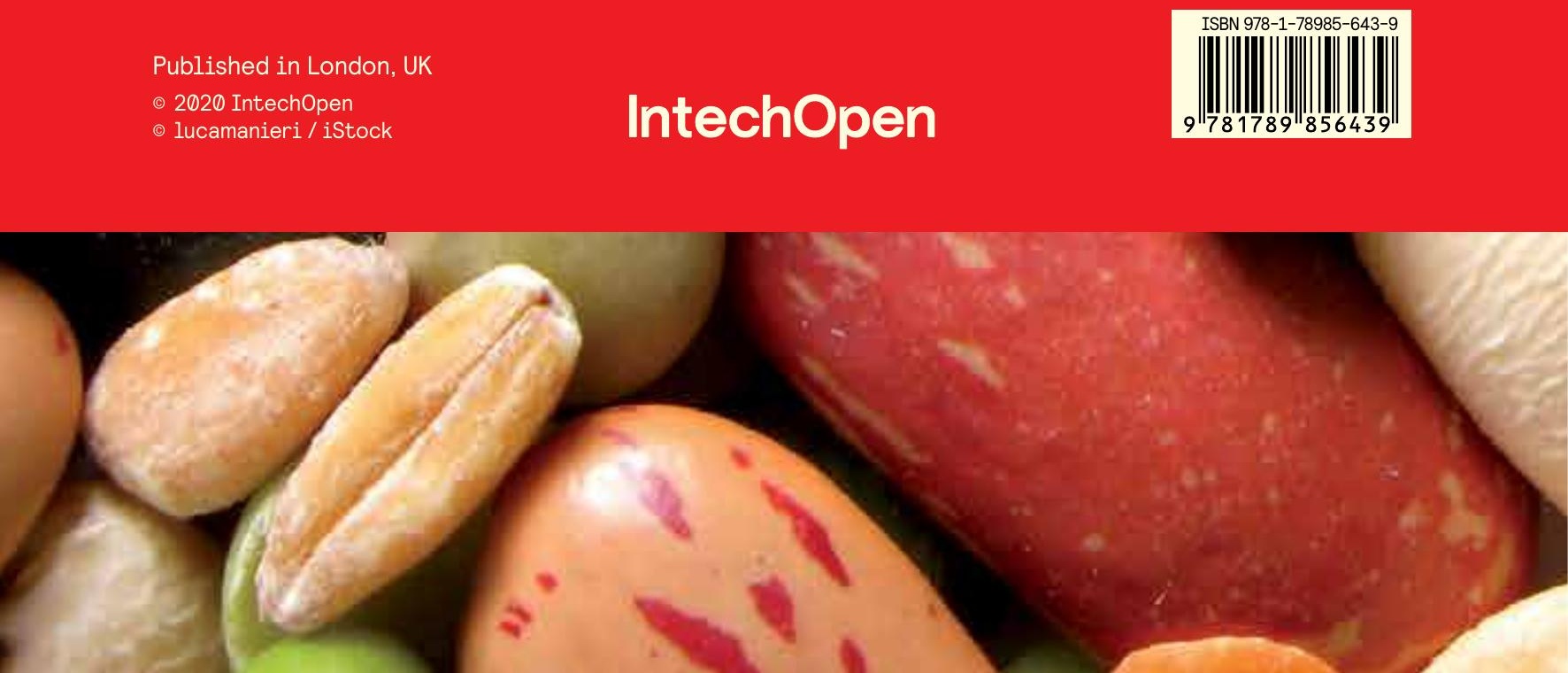